Florida International University FIU Digital Commons

$10-1-2013$

\title{
Clean Hydrogen Production and Carbon dioxide Capture Methods
}

Sushant Kumar

skuma002@fiu.edu

DOI: $10.25148 /$ etd.FI13120609

Follow this and additional works at: https://digitalcommons.fiu.edu/etd

Part of the Other Materials Science and Engineering Commons

\section{Recommended Citation}

Kumar, Sushant, "Clean Hydrogen Production and Carbon dioxide Capture Methods" (2013). FIU Electronic Theses and Dissertations. 1039.

https://digitalcommons.fiu.edu/etd/1039

This work is brought to you for free and open access by the University Graduate School at FIU Digital Commons. It has been accepted for inclusion in FIU Electronic Theses and Dissertations by an authorized administrator of FIU Digital Commons. For more information, please contact dcc@fiu.edu. 


\section{FLORIDA INTERNATIONAL UNIVERSITY}

Miami, Florida

\section{CLEAN HYDROGEN PRODUCTION AND CARBON DIOXIDE CAPTURE}

METHODS

A dissertation submitted in partial fulfillment of the

requirements for the degree of

DOCTOR OF PHILOSOPHY

in

MATERIALS SCIENCE AND ENGINEERING

by

Sushant Kumar

2013 


\section{To: Dean Amir Mirmiran}

College of Engineering and Computing

This dissertation, written by Sushant Kumar, and entitled Clean Hydrogen Production and Carbon dioxide Capture Methods, having been approved in respect to style and intellectual content, is referred to you for judgment.

We have read this dissertation and recommend that it be approved.

Arvind Agarwal

Chunlei Wang

Jiuhua Chen

Krish Jayachandran

Surendra K. Saxena, Major Professor

Date of Defense: October 1, 2013

The dissertation of Sushant Kumar is approved.

Dean Amir Mirmiran

College of Engineering and Computing

Dean Lakshmi N. Reddi

University Graduate School

Florida International University, 2013 


\section{DEDICATION}

In loving memory of my father

"I have a lot to learn and long way to go,

I may fall on the way,

But I won't give up,

As I know, you are with me" 


\section{ACKNOWLEDGMENTS}

I sincerely thank my adviser, Professor Surendra K. Saxena, for his invaluable guidance, encouragement and support, not only pertaining to research but to many other facets of life. His constructive criticism and critical review were absolute blessings for my research work. I greatly appreciate his long hours of discussion. Those experiences have pushed my boundaries of thinking and ingrained confidence in me.

I wish to extend my gratitude to committee members, Dr. Arvind Agarwal, Dr. Jiuhua Chen, Dr. Chunlei Wang and Dr. Krish Jayachandran for their continuous support and encouragement. I acknowledge Dr. Jiuhua Chen for his useful discussions on my research work. I wish to thank Dr. Wang and Dr. Jayachandran for always extending their help when I needed them. I can’t forget my first meeting with Dr. Arvind Agarwal. I would like to thank him for the words that he told me at that meeting. Those inspiring words will always keep me moving.

I offer my heartfelt thanks to Dr. Vadym Drozd. Without his suggestions and help, this work would not have resulted. Special thanks to Dr. Andriy Durygin for helping me in learning the instruments. Dr. Durygin has always motivated me to do better at work. I owe him big thanks.

I shall be grateful to University Graduate School, FIU for supporting me with through Dissertation Evidence Acquisition (DEA) and Dissertation Year Fellowship (DYF) awards. I highly appreciate Dr. Cesar Levy and Dr. Giri Narasimhan for their extensive help during my doctoral study. I am also thankful to Department of Mechanical and Materials Engineering for their substantial teaching assistantship. 
It gives me an immense pleasure to acknowledge my wonderful friends for helping me during challenging phases of my life. I would not have come so far without their unconditional support and wishes. I wish them, a great life full of happiness and success.

I fell short of words to express my wholehearted gratitude to my family for being my source of energy. Their blessings, selfless and unfeigned love and empathy always motivated me to be happy. Lastly, I would like to thank my mother for her eternal love and sacrifice for me. This dissertation is a gift for her. 


\section{ABSTRACT OF THE DISSERTATION \\ CLEAN HYDROGEN PRODUCTION AND CARBON DIOXIDE CAPTURE \\ METHODS \\ by}

Sushant Kumar

Florida International University, 2013

Miami, Florida

Professor Surendra K. Saxena, Major Professor

Fossil fuels constitute a significant fraction of the world's energy demand. The burning of fossil fuels emits huge amounts of carbon dioxide into the atmosphere. Therefore, the limited availability of fossil fuel resources and the environmental impact of their use require a change to alternative energy sources or carriers (such as hydrogen) in the foreseeable future. The development of methods to mitigate carbon dioxide emission into the atmosphere is equally important. Hence, extensive research has been carried out on the development of cost-effective technologies for carbon dioxide capture and techniques to establish hydrogen economy.

Hydrogen is a clean energy fuel with a very high specific energy content of about $120 \mathrm{MJ} / \mathrm{kg}$ and an energy density of $10 \mathrm{Wh} / \mathrm{kg}$. However, its potential is limited by the lack of environment-friendly production methods and a suitable storage medium. Conventional hydrogen production methods such as Steam-methane-reformation and Coal-gasification were modified by the inclusion of $\mathrm{NaOH}$. The modified methods are thermodynamically more favorable and can be regarded as near-zero emission production routes. Further, suitable catalysts were employed to accelerate the proposed $\mathrm{NaOH}-$ 
assisted reactions and a relation between reaction yield and catalyst size has been established. A 1:1:1 molar mixture of $\mathrm{LiAlH}_{4}, \mathrm{NaNH}_{2}$ and $\mathrm{MgH}_{2}$ were investigated as a potential hydrogen storage medium. The hydrogen desorption mechanism was explored using in-situ XRD and Raman Spectroscopy.

Mesoporous metal oxides were assessed for $\mathrm{CO}_{2}$ capture at both power and non-power sectors. A $96.96 \%$ of mesoporous $\mathrm{MgO}$ (325 mesh size, surface area $=95.08 \pm 1.5 \mathrm{~m}^{2} / \mathrm{g}$ ) was converted to $\mathrm{MgCO}_{3}$ at $350^{\circ} \mathrm{C}$ and 10 bars $\mathrm{CO}_{2}$. But the absorption capacity of $1 \mathrm{~h}$ ball milled zinc oxide was low, $0.198 \mathrm{gCO}_{2} / \mathrm{gZnO}$ at $75^{\circ} \mathrm{C}$ and 10 bars $\mathrm{CO}_{2}$. Interestingly, $57 \%$ mass conversion of $\mathrm{Fe}$ and $\mathrm{Fe}_{3} \mathrm{O}_{4}$ mixture to $\mathrm{FeCO}_{3}$ was observed at $200^{\circ} \mathrm{C}$ and 10 bars $\mathrm{CO}_{2} . \mathrm{MgO}, \mathrm{ZnO}$ and $\mathrm{Fe}_{3} \mathrm{O}_{4}$ could be completely regenerated at $550^{\circ} \mathrm{C}$, $250^{\circ} \mathrm{C}$ and $350^{\circ} \mathrm{C}$ respectively. Furthermore, the possible retrofit of $\mathrm{MgO}$ and a mixture of $\mathrm{Fe}$ and $\mathrm{Fe}_{3} \mathrm{O}_{4}$ to a $300 \mathrm{MWe}$ coal-fired power plant and iron making industry were also evaluated. 


\section{TABLE OF CONTENTS}

CHAPTER

PAGE

1. INTRODUCTION

$\begin{array}{lll}1.1 & \text { Overview and Challenges } & 2\end{array}$

1.2 Purpose of the dissertation 8

1.3 Structure of the dissertation 9

1.4 References 11

2. EXPERIMENTAL TECHNIQUES AND DETAILS

$\begin{array}{lll}2.1 & \text { Powder X-ray Diffraction } & 13\end{array}$

$\begin{array}{lll}2.2 & \text { Raman Spectroscopy } & 15\end{array}$

2.3 Experimental set-up for hydrogen producing reactions 17

2.4 Experimental set-up for $\mathrm{CO}_{2}$ capture reaction 19

$\begin{array}{ll}2.5 & 19\end{array}$

$\begin{array}{lll}2.6 & \text { Brunauer-Emmett-Teller analysis } & 21\end{array}$

$\begin{array}{ll}2.7 & \text { Thermo-gravimetric analysis } \\ 2.8 & 23\end{array}$

$2.8 \quad$ Fourier Transform Infra-red technique 23

$2.9 \quad$ PCT-Pro $2000 \quad 24$

2.10 Differential Scanning Calorimetry 25

$\begin{array}{lll}2.11 \text { References } & 27\end{array}$

3. CLEAN PRODUCTION OF HYDROGEN 28

3.1 LITERATURE REVIEW 28

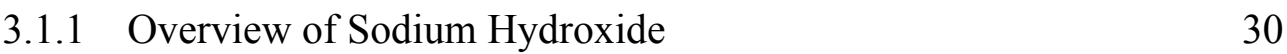

3.1.2 Sodium Hydroxide assisted hydrogen production schemes 32

3.1.2.1 Modified Industrial hydrogen production routes 32

3.1.2.2 Biomass 36

$\begin{array}{ll}\text { 3.1.2.3 Metals } & 37\end{array}$

3.1.2.4 Water-splitting thermochemical cycle $\quad 39$

3.1.2.5 Organic Compounds 41

$\begin{array}{lll}3.1 .3 & \text { Conclusion } & 44\end{array}$

3.1.4 References 45

3.2 MODIFIED STEAM -METHANE-REFORMATION REACTION $\quad 50$

$\begin{array}{ll}3.2 .1 \text { Introduction } & 50\end{array}$

3.2.2 Experimental Section $\quad 52$

3.2.3 Results and Discussion $\quad 53$

3.2.4 Economic Analysis $\quad 64$

3.2.5 References 67

3.3 A CATALYTIC STUDY OF THE MODIFIED COAL GASIFICATION

PROCESS TO PRODUCE CLEAN HYDROGEN GAS 69

3.3.1 Introduction $\quad 69$

$\begin{array}{ll}\text { 3.3.2 Materials and Methods } & 70\end{array}$

$\begin{array}{ll}\text { 3.3.2.1 Catalysts Preparation } & 70\end{array}$ 
3.3.2.2 Catalysts Characterization $\quad 71$

3.3.2.3 Reaction Study $\quad 71$

$\begin{array}{ll}\text { 3.3.3 Results and Discussion } & 72\end{array}$

3.3.3.1 Catalysts Crystallite Size $\quad 72$

3.3.3.2 Morphology and Particle Size analysis $\quad 74$

3.3.3.3 Reaction Results $\quad 76$

3.3.4 References 82

3.4 A CATALYTIC STUDY OF SODIUM HYDROXIDE AND CARBON MONOXIDE REACTION $\quad 84$

$\begin{array}{lll}3.4 .1 & \text { Introduction } & 84\end{array}$

3.4.2 Experimental Section $\quad 86$

3.4.2.1 Catalyst Preparation $\quad 86$

3.4.2.2 Particle Characterization $\quad 86$

3.4.2.3 Reaction Study $\quad 86$

$\begin{array}{lll}\text { 3.4.3 Results and Discussion } & 87\end{array}$

$\begin{array}{ll}\text { 3.4.3.1 Characterization of catalysts } & 87\end{array}$

3.4.3.2 Morphology and Particle Size $\quad 90$

3.4.3.3 Reaction Results 94

$\begin{array}{ll}3.4 .4 \text { References } & 101\end{array}$

4. HYDROGEN STORAGE USING METAL HYDRIDES 101

4.1 LITERATURE REVIEW 101

4.1.1 Potential hydrogen storage materials 103

4.1.2 Metal Hydrides 104

4.1.2.1 Reversible Storage Capacity 106

4.1.2.2 Gravimetric Storage Capacity 106

4.1.2.3 Volumetric Storage Capacity 107

4.1.3 Complex Hydrides 107

$\begin{array}{lll}\text { 4.1.4 Summary } & 109\end{array}$

4.1.5 References 111

4.2 In-Situ INVESTIGATION FOR THE DEHYDROGENATION

MECHANISM OF THE LiAlH $4-\mathrm{MgH}_{2}-\mathrm{NaNH}_{2}$ TERNARY SYSTEM 114

$\begin{array}{lll}\text { 4.2.1 Introduction } & 114\end{array}$

4.2.2 Experimental Section 116

4.2.3 Results and Discussion 117

4.2.3.1 Temperature-programmed Decomposition 117

4.2.3.2 Differential Scanning Calorimetry 119

4.2.3.3 Room Temperature Raman Spectrum 121

4.2.3.4 Temperature dependent in-situ Raman Spectrum 122

4.2.3.5 Room Temperature X-ray diffraction analysis 123

4.2.3.6 Temperature dependent in-situ X-ray diffraction analysis $\quad 125$

$\begin{array}{lll}4.2 .4 & \text { References } & 129\end{array}$ 
5. CARBON DIOXIDE CAPTURE USING METAL OXIDES 132

5.1 LITERATURE REVIEW 132

5.1.1 Selection criteria for metal oxides 134

$\begin{array}{ll}\text { 5.1.2 Metal oxides } & 137\end{array}$

5.1.2.1 Alkali metal based oxides $\quad 137$

5.1.2.2 Alkali earth metal oxides $\quad 140$

5.1.2.3 Transition metal oxides $\quad 143$

5.1.2.4 Miscellaneous $\quad 146$

$\begin{array}{lll}5.1 .3 & \text { Summary } & 147\end{array}$

5.1.4 References 148

5.2 AN EXPERIMENTAL INVESTIGATION OF MESOPOROUS MgO

AS A POTENTIAL PRE-COMBUSTION CO SORBENT $_{5}$

5.2.1 Introduction 153

5.2.2 Experimental Procedure 157

5.2.3 Results and Discussion 158

5.2.4 References 167

5.3 INTEGRATION OF MgO TO A 300 MWe COAL-FIRED POWER

PLANT $\quad 170$

$\begin{array}{lll}\text { 5.3.1 Introduction } & 170\end{array}$

$\begin{array}{ll}\text { 5.3.2 Post-combustion Process } & 170\end{array}$

5.3.2.1 Mass and Energy Analysis $\quad 173$

5.3.2.2 Economic Analysis of the carbonation process 178

5.3.3 Pre-combustion Process 186

$\begin{array}{ll}\text { 5.3.3.1 Mass Balance Calculation } & 187\end{array}$

5.3.3.2 Energy Balance Calculation 189

5.4 MITIGATING $\mathrm{CO}_{2}$ EMISSIONS IN THE IRON INDUSTRY USING

MIXTURE OF MAGNETITE AND IRON 191

5.4.1 Introduction 191

5.4.2 Experimental Procedure 194

5.4.3 Results and Discussion 196

5.4.4 References 199

5.5 PROCESS DESIGN FOR THE PROPOSED CARBON DIOXIDE
SORBENT FOR IRON MAKING INDUSTRY

$\begin{array}{ll}\text { 5.5.1 Retrofit in a blast furnace } & 200\end{array}$

5.5.2 Mass balance calculation 203

5.5.3 Energy balance calculation 206

5.5.4 Advantages of the proposed scheme 208

5.6 THE EFFECT OF ELEVATED PRESSURE, TEMPERATURE

AND PARTICLES MORPHOLOGY ON THE CARBON

DIOXIDE CAPTURE USING ZINC OXIDE 211

5.6.1 Introduction 211

5.6.2 Experimental Procedure 212

5.6.3 Thermodynamics and Structural Properties 215

5.6.4 Reaction Results 220

5.6.5 Discussion 223 
6. MISCELLANEOUS

6.1 HIGH PRESSURE AND HIGH TEMPERATURE STUDY FOR THE MIXTURE OF $\mathrm{MgH}_{2}$ AND Si USING MULTI ANVIL PRESS

6.1.1 Introduction

6.1.2 Experimental Section

234

6.1.3 Results and Discussions

234

6.1.4 References

238

7. SUMMARY

239

7.1 Conclusions

239

7.2 Recommendations of the Future Research

242

VITA

244 


\section{LIST OF TABLES}

TABLE

PAGE

Table $1.1 \quad$ Six basic hydrogen storage methods...............................

Table 1.2 Original and revised DOE targets for on-board hydrogen storage systems

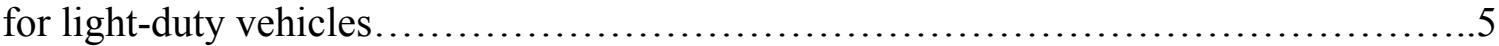

Table $1.3 \quad$ Materials for $\mathrm{CO}_{2}$ capture.....................................

Table $2.1 \quad$ Classification of pores according to their width....................... 23

Table 3.1.1 Comparison of the commercially available production methods for sodium hydroxide................................................................... 31

Table 3.2.1 Crystallite size for variously milled nickel catalysts.................. 56

Table 3.4.1 Crystallite size of variously ball milled catalysts....................89

Table 4.1.1 Summary of the complex hydrides................................109

Table 4.2.1 Hydrogen storage properties for the binary system composed of $\mathrm{LiAlH}_{4}$ -

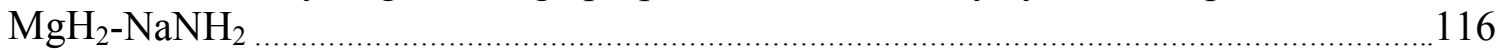

Table 4.2.2 Phases present at different temperatures for $\mathrm{LiAlH}_{4}+\mathrm{MgH}_{2}+\mathrm{NaNH}_{2}$

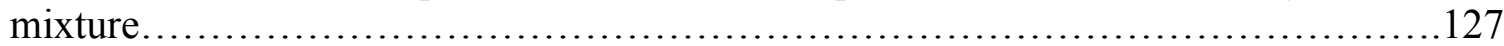

Table 5.2.1 $\quad \mathrm{CO}_{2}$ uptake capacity of $\mathrm{MgO}$ obtained from the literature.............156

Table 5.2.2 Surface Properties of $\mathrm{MgO}$ particles before and after carbonation reaction

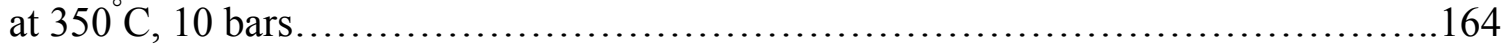

Table 5.3.1 Mass and molar flue gas composition...........................173

Table 5.3.2 Energy balance calculation for Post-combustion $\mathrm{CO}_{2}$ capture using $\mathrm{MgO}$

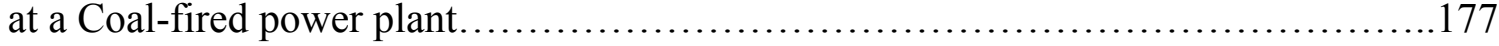

Table 5.3.3 Detailed economic analysis for Post-combustion $\mathrm{CO}_{2}$ capture using

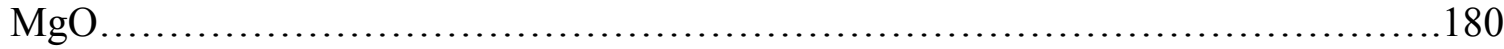

Table 5.3.4 Levelized Cost for Post-combustion $\mathrm{CO}_{2}$ capture using $\mathrm{MgO}$...........182

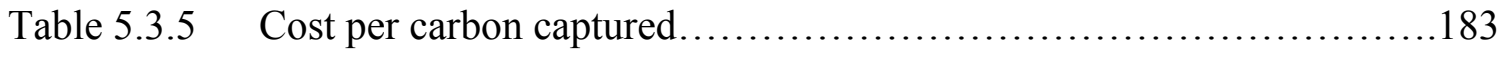

Table 5.3.6 Transportation cost........................................ 185

Table 5.3.7 Mass balance calculation for pre-combustion $\mathrm{CO}_{2}$ capture using $\mathrm{MgO}$ at a coal-fired power plant..................................................... 188 
Table 5.4.1 Experimental result for reaction [5.4.1] at different set of temperature,

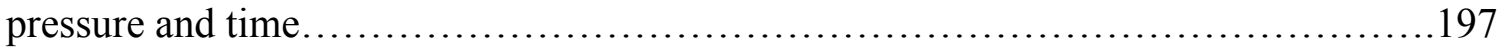

Table 5.5.1 Reactions involved in the proposed scheme for $\mathrm{CO}_{2}$ capture at iron

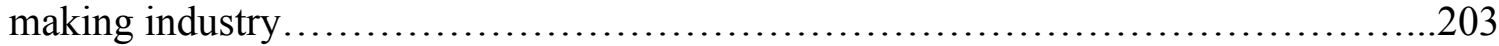

Table 5.5.2 Mass balance for the proposed scheme..............................205

Table 5.5.3 Energy consumed and released at different stages of the proposed

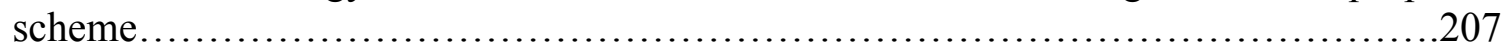

Table 5.6.1 Effect of ball milling on sorbent $(\mathrm{ZnO})$ properties..................218

Table 6.1 Literature survey for (de-) hydrogenation of $\mathrm{MgH}_{2} / \mathrm{Si}$ System.........233 


\section{LIST OF FIGURES}

FIGURE

PAGE

Figure 1.1.1 World leading energy resources demand in year 2010 and $2035 \ldots \ldots \ldots \ldots .2$

Figure 1.2.1 Flowchart of the research plan...................................... 11

Figure 2.1 Schematic for Raman Spectroscopy................................15

Figure 2.2 Raman experimental arrangement at CeSMEC..........................16

Figure 2.3 Experimental set up for study of hydrogen producing reactions.............18

Figure 2.4 Experimental arrangements for study of metal oxide-carbon dioxide reactions

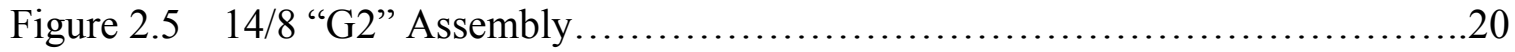

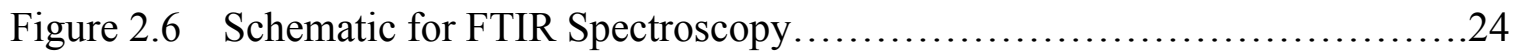

Figure 3.1.1 Simplified schematic of hydrogen production using SMR technique....... 29

Figure 3.1.2 Membrane cell process schematic for production of sodium hydroxide................................................................. 32

Figure 3.1.3 (a) Equilibrium in the system $2 \mathrm{NaOH}+\mathrm{C}+\mathrm{H}_{2} \mathrm{O}$ (b) Equilibrium composition in the system $2 \mathrm{NaOH}+\mathrm{CO}$ (c) Equilibrium in the system $4 \mathrm{NaOH}+\mathrm{C}+\mathrm{CO}_{2}$ (d) the gas-

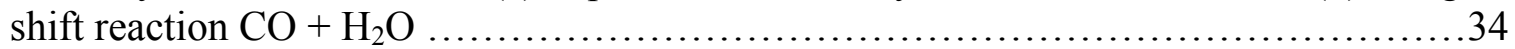

Figure 3.1.4 Schematic for Water Splitting Thermochemical Cycle $(\mathrm{MO}=$ metal

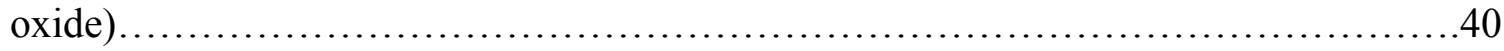

Figure 3.1.5 Electricity generation using alkaline hydroxide $(\mathrm{NaOH})$ for the electrolysis

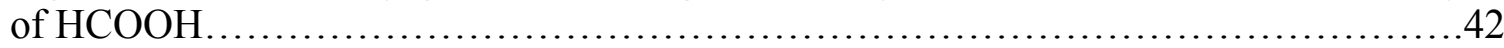

Figure 3.2.1 (a) equilibrium in the system methane-water and (b) when modified by addition of sodium hydroxide. .51

Figure 3.2.2 Results relating the formation of sodium carbonate as a function of the methane flow. In 30 minutes, the reaction in an open system is completed at any temperature above $600^{\circ} \mathrm{C}$. One data point at $700^{\circ} \mathrm{C}$ was not included in the fitting procedure. .53 
Figure 3.2.3 The data on $\%$ conversion of $\mathrm{NaOH}$ to $\mathrm{Na}_{2} \mathrm{CO}_{3}$ as a function of temperature and time for $25 \mathrm{ml} / \mathrm{min}$ methane flow rate. An estimate of error is provided by the repeated experiment at $500^{\circ} \mathrm{C}$. The curves are smoothed spline fit to show the trends. No

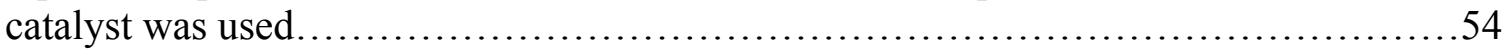

Figure 3.2.4 Nickel particle size distribution for (a) Raw (b) $2 \mathrm{~h}$ ball milled (c) $3 \mathrm{~h}$ ball milled (d) 4 h ball milled....................................................... 57

Figure 3.2.5 X-ray diffraction patterns for different time ball milled nickel catalysts.....58

Figure 3.2.6 Effect of using $2 \mathrm{~h}$ ball milled nickel catalyst. The arrows show the significant change in the conversion amount for a given time.

Figure 3.2.7 The experimental data on a sample with catalysis and without for 30 minutes between 300 to $600^{\circ} \mathrm{C}$

Figure 3.2.8 The effect of variously ball-milled catalyst on the carbonation reaction at $300^{\circ} \mathrm{C}$ 61

Figure 3.2.9 SEM images of nickel particles (a) without ball milling magnification 2000x (b) Ball milled for 2 hrs, magnification 2000x (c) Ball milled for 3 hrs, magnification 1000x; (d) Ball milled for 4 hrs, magnification 2000x.................. 62

Figure 3.2.10 The effect of different alkali hydroxide on the Carbonation reaction at $400^{\circ} \mathrm{C}$ 63

Figure 3.2.11 The price difference in soda and sodium hydroxide determines the price of hydrogen. In this example the price of hydrogen is fixed at $\$ 1000 /$ tonne. If the price of soda goes below the sodium hydroxide by $\$ 30 /$ tonne, the method may not be profitable. .64

Figure 3.3.1 X-ray diffraction pattern for variously ball milled Raney nickel............72

Figure 3.3.2 Back scattered SEM image of (i) without (ii) $1 \mathrm{~h}$ (iii) $2 \mathrm{~h}$ and (iv) $4 \mathrm{~h}$ ball milled. .74

Figure 3.3.3 SEM images of (i) variously ball milled Raney nickel each at 2000x magnification (ii) $2 \mathrm{~h}$ ball milled Raney nickel showing caves at $5000 \mathrm{x}$ magnification............................................................ 75

Figure 3.3.4 X-ray diffraction pattern confirms the product formation in the presence of nickel catalyst for reaction (1) at $600^{\circ} \mathrm{C}$. .77

Figure 3.3.5 \% Conversion of $\mathrm{NaOH}$ to $\mathrm{Na}_{2} \mathrm{CO}_{3}$ for different sized coal particles at

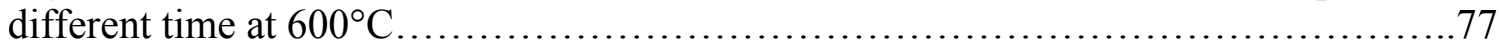


Figure 3.3.6 \% Conversion of $\mathrm{NaOH}$ to $\mathrm{Na}_{2} \mathrm{CO}_{3}$ for (i) different catalysts at $600^{\circ} \mathrm{C}$ and (ii) different sized Raney nickel at $500^{\circ} \mathrm{C}$. .78

Figure 3.4.1 X-ray diffraction patterns for variously ball milled (a) alumina mixed nickel (b) magnetite (c) Raney nickel. .88

Figure 3.4.2 SEM image of (a) alumina mixed nickel ball milled for (i) 1 hour (ii) 2 hours (iii) 4 hours at (b) magnetite ball milled for (i) 1 hour (ii) 2 hours (iii) without ball milling at 2000x each. .91

Figure 3.4.3 SEM image of Raney nickel (i) without (ii) $2 \mathrm{~h}$ (iii) $4 \mathrm{~h}$ ball milling at 2000x each and (iv) $2 \mathrm{~h}$ ball milled Raney nickel with pores (at 5000x) ..................... 92

Figure 3.4.4 Change of average particle size of catalysts with milling time. .93

Figure 3.4.5\% Conversion of $\mathrm{NaOH}$ to $\mathrm{Na}_{2} \mathrm{CO}_{3}$ for variously ball milled alumina mixed nickel $(2: 1)($ wt. $\%)$ at $300^{\circ} \mathrm{C}$ .95

Figure 3.4.6\% Conversion of $\mathrm{NaOH}$ to $\mathrm{Na}_{2} \mathrm{CO}_{3}$ for variously ball milled magnetite at $300^{\circ}$ C. 1 and $2 \mathrm{~h}$ ball milling time has exhibited a comparable result. .96

Figure 3.4.7 \% Conversion of $\mathrm{NaOH}$ to $\mathrm{Na}_{2} \mathrm{CO}_{3}$ for variously ball milled Raney nickel at $300^{\circ}$ C. $2 \mathrm{~h}$ ball milling time has exhibited the best result...........................97

Figure 4.1.1 Primitive phase diagram of hydrogen.............................. 101

Figure 4.1.2 Chart for the potential reversible hydrogen system.................... 103

Figure 4.1.3 Schematic of hydrogen interaction with metal. The solid solution $\alpha$-phase and the hydride $\beta$-phase. .104

Figure 4.2.1 Temperature programmed decomposition of the $\mathrm{LiAlH}_{4}-\mathrm{MgH}_{2}-\mathrm{NaNH}_{2}$ $(1: 1: 1)$ mixture. 118

Figure 4.2.2 Differential scanning calorimetry (DSC) traces for $\mathrm{LiAlH}_{4}-\mathrm{MgH}_{2}-\mathrm{NaNH}_{2}$ samples, with a heating rate of $5^{\circ} \mathrm{C} / \mathrm{min}$.

Figure 4.2.3 DSC traces of the $\mathrm{LiAlH}_{4}-\mathrm{MgH}_{2}-\mathrm{NaNH}_{2}$ at different heating rates. The inset plot is the Kissinger's analysis for the hydrogen desorption reaction of the ternary hydrides

Figure 4.2.4 Room Temperature Raman Spectra for unmillled and 0.5h mechanically milled $\mathrm{LiAlH}_{4}-\mathrm{MgH}_{2}-\mathrm{NaNH}_{2}$ mixture.

Figure 4.2.5 Temperature dependent Raman Spectra for unmilled $\mathrm{LiAlH}_{4}-\mathrm{MgH}_{2}-$ $\mathrm{NaNH}_{2}$ 
Figure 4.2.6 Temperature dependent Raman Spectra for mechanically milled $\mathrm{LiAlH}_{4}-$

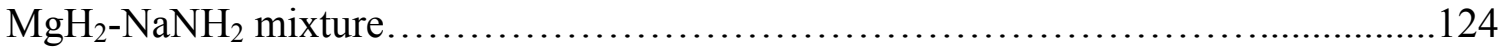

Figure 4.2.7 X-ray diffraction pattern for milled and unmilled $\mathrm{LiAlH}_{4}-\mathrm{MgH}_{2}-\mathrm{NaNH}_{2}$ mixture. 125

Figure 4.2.8 Temperature dependent X-ray diffraction pattern for unmilled $\mathrm{LiAlH}_{4}-$

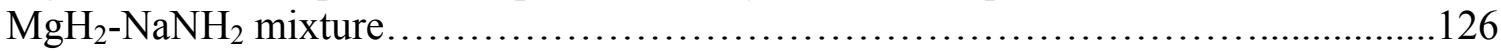

Figure 5.1.1 A Cyclic $\mathrm{CO}_{2}$ capture process for metal oxides (MO) and metal carbonates

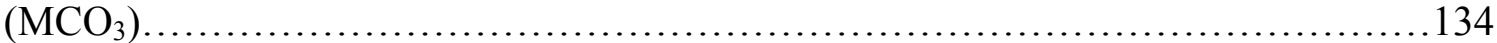

Figure 5.1.2 Thermodynamic properties and $\mathrm{CO}_{2}$ wt. \% for metal oxides $\mathrm{MO}(\mathrm{s})+\mathrm{CO}_{2}$ $(\mathrm{g})=\mathrm{MCO}_{3}(\mathrm{~s})$ at $300 \mathrm{~K}$ 135

Figure 5.2.1 X-ray diffraction patterns for $\mathrm{MgCO}_{3}$ formation after reaction at various temperatures and $\mathrm{CO}_{2}$ pressure of (a) 10 bars and (b) 50 bars 159

Figure 5.2.2 Adsorption/absorption model for $\mathrm{MgO}-\mathrm{CO}_{2}-\mathrm{H}_{2} \mathrm{O}$ reaction..............160

Figure 5.2.3 DTG plots for product at (a) $300^{\circ} \mathrm{C}$ and 10 bars and (b) $350^{\circ} \mathrm{C}$ and 10 bars. 161

Figure 5.3.1 Process design for post-combustion $\mathrm{CO}_{2}$ capture using $\mathrm{MgO} \ldots \ldots \ldots \ldots . . .174$

Figure 5.3.2 Process design for pre-combustion $\mathrm{CO}_{2}$ capture using $\mathrm{MgO}$.............187

Figure 5.4.1 Equilibrium composition in the system $\mathrm{Fe}_{3} \mathrm{O}_{4}+\mathrm{Fe}+4 \mathrm{CO}_{2}$ at 10 and 50 bars pressure. 193

Figure 5.4 .2 (i) $\mathrm{X}$-ray diffraction pattern confirm the siderite formation for reaction [5.4.1] performed at $100^{\circ} \mathrm{C}, 50$ bars and $3 \mathrm{~h}$ (ii) X-ray diffraction pattern of the products for different molar composition of magnetite and iron mixture at $200^{\circ} \mathrm{C}, 10$ bars and $1 \mathrm{~h}$ (iii) DTG plot for product obtained as a result of reaction [5.4.1] performed at $200^{\circ} \mathrm{C}, 10$

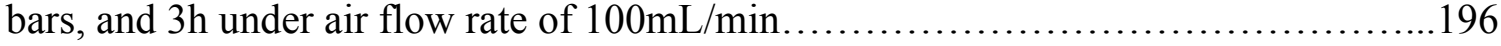

Figure 5.5.1 Flow sheet for carbonation process integrated to a blast furnace..........200

Figure 5.5.2 Process scheme for post-combustion $\mathrm{CO}_{2}$ capture using magnetite and iron mixture at iron making industry. .202

Figure 5.6.1 Equilibrium temperature for $\mathrm{ZnO}+\mathrm{CO}_{2} \rightarrow \mathrm{ZnCO}_{3}$ reaction at different $\mathrm{P}_{\mathrm{CO} 2}$ (0.1-100 bars) in the presence and absence of water. 215

Figure 5.6.2 SEM image of (i) as received $\mathrm{ZnO}$ (ii) $1 \mathrm{~h}$ ball milled (iii) $2 \mathrm{~h}$ ball milled and (iv) $\mathrm{AR}$ (after reaction) $\mathrm{ZnO}$ at a magnification of 20, 000x each. 217 
Figure 5.6.3 Particle size distribution plots for variously milled $\mathrm{ZnO}$....

Figure 5.6.4 X-ray Diffraction patterns confirm the (i) product formation (JCPDS \# 110287) (ii) regeneration of $\mathrm{ZnO}$ (JCPDS \#89-1397) (iii) FTIR -spectra of the product in

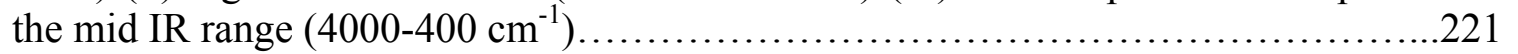

Figure 5.6.5 TG-DTG plot of thermal decomposition reaction of product; sample mass $10.0 \mathrm{mg}$, heating rate $10^{\circ} \mathrm{C} / \mathrm{min}$, and argon atmosphere.

Figure 5.6.6 (i) Plot for capture capacity of $\mathrm{ZnO}$ at various pressure and time keeping constant temperature of $75^{\circ} \mathrm{C}$. .224

Figure 5.6.6 (ii) $\mathrm{CO}_{2}$ capture capacity variation with temperature at pressure of 10

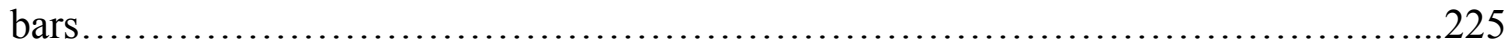

Figure 5.6.6 (iii) Effect of particle size on capture capacity of $\mathrm{ZnO} \ldots \ldots \ldots \ldots \ldots \ldots . .226$

Figure 6.1 (i) X-ray diffraction of the product after compression to $4 \mathrm{GPa}$ at $500^{\circ} \mathrm{C}$ for $2 \mathrm{~h}$ and $150^{\circ} \mathrm{C}$ for $12 \mathrm{~h}$ (ii) X-ray diffraction of $\mathrm{MgH}_{2}$ used and product obtained after the experiment and (iii) Raman Spectra of the product.............................. 235

Figure 6.2 X-ray diffraction of the product after compression to $4 \mathrm{GPa}$ at $900^{\circ} \mathrm{C}$ for $2 \mathrm{~h}$

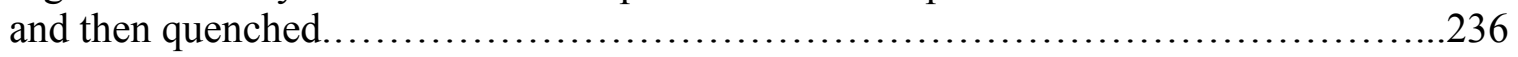

Figure 6.3 shows the X-ray diffraction of the product obtained after ball milling under $\mathrm{H}_{2}$ atmosphere. 


\section{INTRODUCTION}

The aim of this study is to investigate the material and process that can deal with the issues related to global warming and use of fossil fuels. In line with these objectives, this study emphasizes: (1) clean hydrogen production methods, (2) storage of hydrogen using solid metal hydrides, and (3) metal oxides for carbon dioxide capture at power and nonpower sectors.

The first section of the dissertation (Chapter 3) deals with the study of clean hydrogen production method. In the past two decades, lot of attention has been focused on the mitigation of carbon dioxide emissions during hydrogen production. This work examines the inclusion of sodium hydroxide to the existing major hydrogen production technologies. Using the proposed techniques, sodium hydroxide not only facilitates hydrogen generation but also locks carbon dioxide in the form of sodium carbonate. The work also identifies suitable catalysts to accelerate the reactions.

The second section of the dissertation (Chapter 4) is aimed to investigate materials that can store hydrogen. This part of the dissertation examines the dehydrogenation kinetics and mechanism of multinary complex metal hydrides. A part of this section (Chapter 6) also describes the behavior of magnesium hydride and silicon under extreme pressure and temperature condition.

The last section of the dissertation (Chapter 5) focuses on the capture of carbon dioxide using metal oxides. The growing use of fossil fuels to meet the energy demands has led to a rapid increase in carbon dioxide levels in the atmosphere. This part deals with the 
investigation of potential use of metal oxide as a carbon dioxide sorbent. In the latter part, an energy and economic analysis is performed to evaluate the integration of metal oxides to the existing power and non-power sectors for the capture of carbon dioxide.

\subsection{Overview and Challenges}

Fossil fuels (coal, oil and natural gas) continue to be the primary energy source for electricity, transportation and residential services. International Energy Agency (IEA) reports the energy demand by fuel for 2010 and 2035 [Fig. 1.1.1]. The trend clearly shows the continued significance of fossil fuel for energy demand [1].

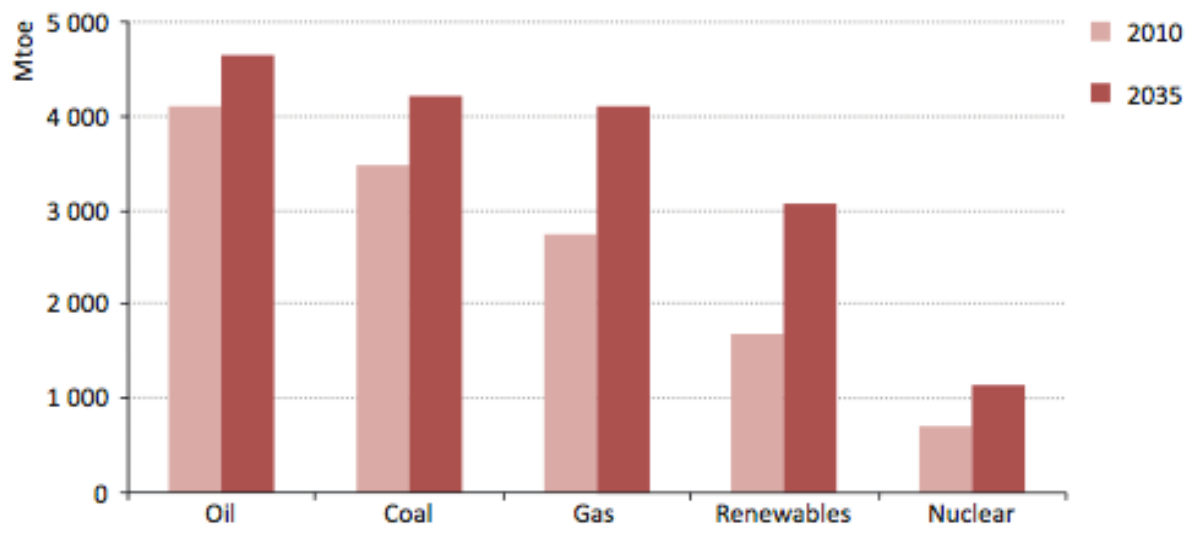

Figure 1.1.1 World leading energy resources demand in year 2010 and 2035.

Fossil fuels are relatively less expensive than renewable sources (such as solar, wind, geothermal and biomass) for large-scale applications. The vast depletion of fossil fuels, the increase in carbon dioxide levels in the atmosphere, and the related environmental hazards are growing concerns for mankind. Moreover, the energy demand is projected to 
increase over $60 \%$ in 2030 , developing an alternative energy source as well as mitigating carbon dioxide emission is becoming ever more pressing.

Hydrogen is a clean energy fuel with a very high specific energy content of about 120 $\mathrm{MJ} / \mathrm{kg}$ and an energy density of $10 \mathrm{Wh} / \mathrm{kg}$. Hydrogen is environmentally friendly and can be used without concerns over the greenhouse gas emissions at the point of use. Hydrogen is produced using both renewable and non-renewable resources. The available technologies for hydrogen production are the reforming of natural gas; gasification of coal and biomass; and the splitting of water by water-electrolysis, photo-electrolysis, photo-biological production, water splitting thermochemical cycle and high temperature decomposition [2].

Currently, Steam Methane Reformation (SMR) is the most common and least expensive method to produce hydrogen [3]. It is a two-step process. At first step, methane reacts with steam at temperature (700-1100) ${ }^{\circ} \mathrm{C}$ to form Syn gas (mixture of carbon monoxide and hydrogen) and then carbon monoxide reacts with steam to produce additional hydrogen. A simple calculation shows that while producing 1 gram of hydrogen via SMR technique, 10.5 grams of carbon dioxide is emitted. Such an undesired vast emission of carbon dioxide downgrades the use of the conventional SMR technique to produce hydrogen. Thus, it is essential to develop a method that can produce hydrogen without or reduced carbon dioxide emissions. Several methods have been proposed to mitigate carbon emission but most of them are either expensive compared to those using fossil fuels, or are in the very early stages of development. Thus, the dependence on fossil fuel for the production of hydrogen seems to be certain in the foreseeable future. 
Another major challenge to the use of hydrogen as an energy carrier is to develop a safe and economical hydrogen storage system. A large quantity of hydrogen is consumed mostly in refineries and chemical plants where it is produced. For such use, storage is not an issue. However, for use of hydrogen in automobiles, storage is still a big challenge [4]. Hydrogen has a low density and even when it is stored as liquid in a cryogenic tank or as gas in a compressed tank, the amount of energy that can be stored within the available space is limited. The aim is to reach the highest volumetric capacity by using less external material. The other vital criterion for hydrogen storage is the reversibility of uptake and release. At present, six reversible hydrogen storage methods are identified with high gravimetric and volumetric density which is listed in Table 1.1.

\begin{tabular}{|c|c|c|c|c|}
\hline Storage method & $\rho_{\mathrm{m}}(\mathrm{mass} \%)$ & $\rho_{\mathrm{v}}\left(\mathrm{kgH}_{2} \mathrm{~m}^{-3}\right)$ & $\mathrm{T}\left({ }^{\circ} \mathrm{C}\right)$ & $\mathrm{P}(\mathrm{bar})$ \\
\hline High pressure gas cylinders & 13 & $<40$ & 25 & 800 \\
\hline $\begin{array}{c}\text { Liquid hydrogen in cryogenic } \\
\text { tanks }\end{array}$ & Size dependent & 70.8 & -252 & 1 \\
\hline $\begin{array}{c}\text { Adsorbed hydrogen } \\
\text { Absorbed on interstitial sites in } \\
\text { a host metal }\end{array}$ & $\sim 2$ & 20 & -80 & 100 \\
\hline $\begin{array}{c}\text { Complex compounds } \\
\text { Abith water }\end{array}$ & $<2$ & 150 & 25 & 1 \\
\hline $\begin{array}{c}\text { Metal and complexes together } \\
\text { with }\end{array}$ & $<40$ & $>150$ & 25 & 1 \\
\hline
\end{tabular}

Table 1.1 Six basic hydrogen storage methods [5] 
High pressure cylinders and liquid hydrogen storage methods are well-established for laboratory and space applications, respectively. However, hydrogen stored in solid metal hydrides is safer alternative to liquid or pressurized forms. Table 1.2 summarizes the detailed requirements of metal hydrides for automobile applications.

\begin{tabular}{|c|c|c|c|c|}
\hline Storage System Parameter & $\begin{array}{c}\text { Original } \\
2010 \text { target }\end{array}$ & $\begin{array}{c}\text { New } \\
2010 \text { target }\end{array}$ & $\begin{array}{l}2017 \\
\text { target }\end{array}$ & $\begin{array}{c}\text { Ultimate } \\
\text { target }\end{array}$ \\
\hline $\begin{array}{l}\text { Gravimetric Capacity } \\
\left(\mathrm{kgH}_{2} / \mathrm{kg} \text { system }\right)\end{array}$ & $6 \%$ & $4.5 \%$ & $5.5 \%$ & $7.5 \%$ \\
\hline $\begin{array}{c}\text { Volumetric Capacity } \\
\left(\mathrm{gH}_{2} / \mathrm{L} \text { system }\right)\end{array}$ & 45 & 28 & 40 & 70 \\
\hline Operational cycle life & 1000 & 1000 & 1500 & 1500 \\
\hline Fill time (min., for $5 \mathrm{~kg}$ ) & 3 & 4.2 & 3.3 & 2.5 \\
\hline $\begin{array}{l}\text { Minimum full flow } \\
\text { rate }\left(\mathrm{gH}_{2} / \mathrm{s} / \mathrm{kW}\right)\end{array}$ & 0.02 & 0.02 & 0.02 & 0.02 \\
\hline $\begin{array}{l}\text { Min. delivery pressure } \\
\text { (a) } 85^{\circ} \mathrm{C} \text { PEMFC, (atm) }\end{array}$ & 8 & 5 & 4 & 3 \\
\hline Fuel Purity & $99.99 \%$ & $99.97 \%$ & $99.97 \%$ & $99.97 \%$ \\
\hline
\end{tabular}

Table 1.2 Original and revised DOE targets for on-board hydrogen storage systems for light-duty vehicles [6]

Besides developing alternative energy resource, mitigation of carbon dioxide emission is equally desired. Natural greenhouse gases $\left(\mathrm{CO}_{2}, \mathrm{CH}_{4}, \mathrm{~N}_{2} \mathrm{O}, \mathrm{CFCs}, \mathrm{HFCs}, \mathrm{PFCs}, \mathrm{SF}_{6}\right.$ and 
$\mathrm{H}_{2} \mathrm{O}$ ) are responsible for raising the temperature of the earth to $33^{\circ} \mathrm{C}$, making it habitable [7]. However, concentration of greenhouse gases in the atmosphere has increased significantly since the Industrial Revolution. One major concern is over the increase in the concentration of greenhouse gases, which may warm the planet.

The combustion of fossil fuels emits carbon dioxide into the atmosphere. Carbon dioxide is the most significant greenhouse gas and largely responsible for the increase in greenhouse effect. Therefore, it is essential to capture carbon dioxide from the industrial flue gas stream, one of the leading contributors of the anthropogenic gases [8]. The development of Carbon Capture and Sequestration (CCS) technology can be seen as a viable solution to mitigate the vast carbon emission. CCS constitutes the process (1) of separation of carbon dioxide from industrial flue gas stream; (2) liquefaction of pure carbon dioxide; (3) transportation of liquefied carbon dioxide using pipelines to a geological storage site; and (4) eventually underground storage of liquefied carbon dioxide. CCS could be applied using available technologies, as many of the components in these systems are already in use. However, there is a large scope for improvements in energy efficiency and reduction in carbon capture cost for the existing carbon dioxide mitigation technologies.

Currently, various carbon dioxide capture technologies exist including physical absorption [9-10], chemical absorption [11-12], adsorption [13] and membranes [14]. Table 1.3 summarizes the materials used for $\mathrm{CO}_{2}$ capture in the context of Post-, Pre- and Oxy- Combustion Processes [15]. However, they are still far from being considered as a technologically viable solution. The obvious bottlenecks are the huge amount of flue gas, 
which needs to be treated as well as the low mass transfer rate that occurs during the processes. Among all the proposed techniques, chemical absorption using aqueous alkanolamine solutions is the most conventional way for carbon dioxide capture.

\begin{tabular}{|c|c|c|c|}
\hline Separation Techniques & $\begin{array}{c}\text { Post- } \\
\text { combustion }\end{array}$ & $\begin{array}{c}\text { Pre- } \\
\text { combustion }\end{array}$ & Oxy- \\
combustion
\end{tabular}

Table 1.3 Materials for $\mathrm{CO}_{2}$ capture

However, these amine based solutions suffer severe drawbacks such as high energy consumption in regeneration process, high corrosive rate of equipment, essential pretreatment steps, large absorber volume and high sorbent cost. Because of these limitations of the chemical absorption techniques, an alternative way for post, oxy or precombustion carbon dioxide capture at fossil fuel burning power plants, mainly a solid adsorption/absorption method, can be proposed. 


\subsection{Purpose of the Dissertation}

The limitations to realize hydrogen-based economy need to be overcome in the near future. Similarly, it is necessary to reduce carbon dioxide emissions at various industrial sectors. Such challenges are the motivation for this dissertation.

The focus is to use fossil fuel (such as coal and methane) and toxic gas (carbon monoxide) for the production of hydrogen in such a way that there is a relatively less carbon dioxide gas emission at a point source as compared with the existing technologies. Sodium hydroxide, a byproduct of the chlor-alkali process, can simultaneously be used to produce hydrogen and capture carbon dioxide. Moreover, different catalysts such as nickel, Raney nickel, magnetite, and alumina mixed nickel are chosen to accelerate such sodium hydroxide assisted hydrogen producing reactions. The effects of ball milling on catalysts are investigated and thus correlation between the reaction yield and catalysts size has also been established.

Solid metal hydrides with high volumetric and gravimetric storage capacities are selected for hydrogen storage. A part of this dissertation investigates the dehydrogenation kinetics and mechanism for multinary complex metal hydride, Li-Mg-Na-Al-N-H. The dehydrogenation rate is also examined for the variously milled samples. Another focus is to examine the interaction between light metal hydrides, such as magnesium hydride and silicon, under extreme pressure and temperature conditions. A large volume multi anvil apparatus is employed to pressurize and heat the mixture of magnesium hydride and silicon to a desired set of pressure and temperature for the specified duration. 
The final section of this dissertation investigates magnesium oxide, iron based compounds and zinc oxide as potential carbon dioxide sorbent for power and non-power sectors. The criterion for the selection of the sorbents is mainly based on the accessibility, thermodynamics, absorption capacity and economics. The role of water and partial pressure of carbon dioxide is also examined for the sorbent absorption capacity. Moreover, other structural parameters such as particle size, pore volume, pore size and surface area of the sorbent are also explored. Based on the experimental findings, mass and energy balance calculations are performed for the pre- and post-combustion capture at a coal-fired power plant (300 MWe) and iron making industry.

\subsection{Structure of the dissertation}

The dissertation has been arranged in various chapters, sections and subsections to describe: the current status of the issues and the state-of-the-art, the experimental methods used in this study, analysis of the experimental outcomes and the future scope and recommendations. Chapter 2 explains the employed characterization techniques and experimental set-up for carrying out the proposed reactions. Chapter 3 describes the proposed clean production routes of hydrogen. This chapter first provides the comprehensive literature review, and then experimental results for modified hydrogen producing routes are explained in the following subsections. Chapter 4 provides the experimental findings for the storage of hydrogen using different metal hydrides.

Chapter 5 focuses on the capture of carbon dioxide using metal oxides. The beginning section reviews the current state-of-the-art and further different metal oxides are tested 
for $\mathrm{CO}_{2}$ capture at different sets of conditions. Chapter 6 presents summary of the dissertation and recommendations for future research. 


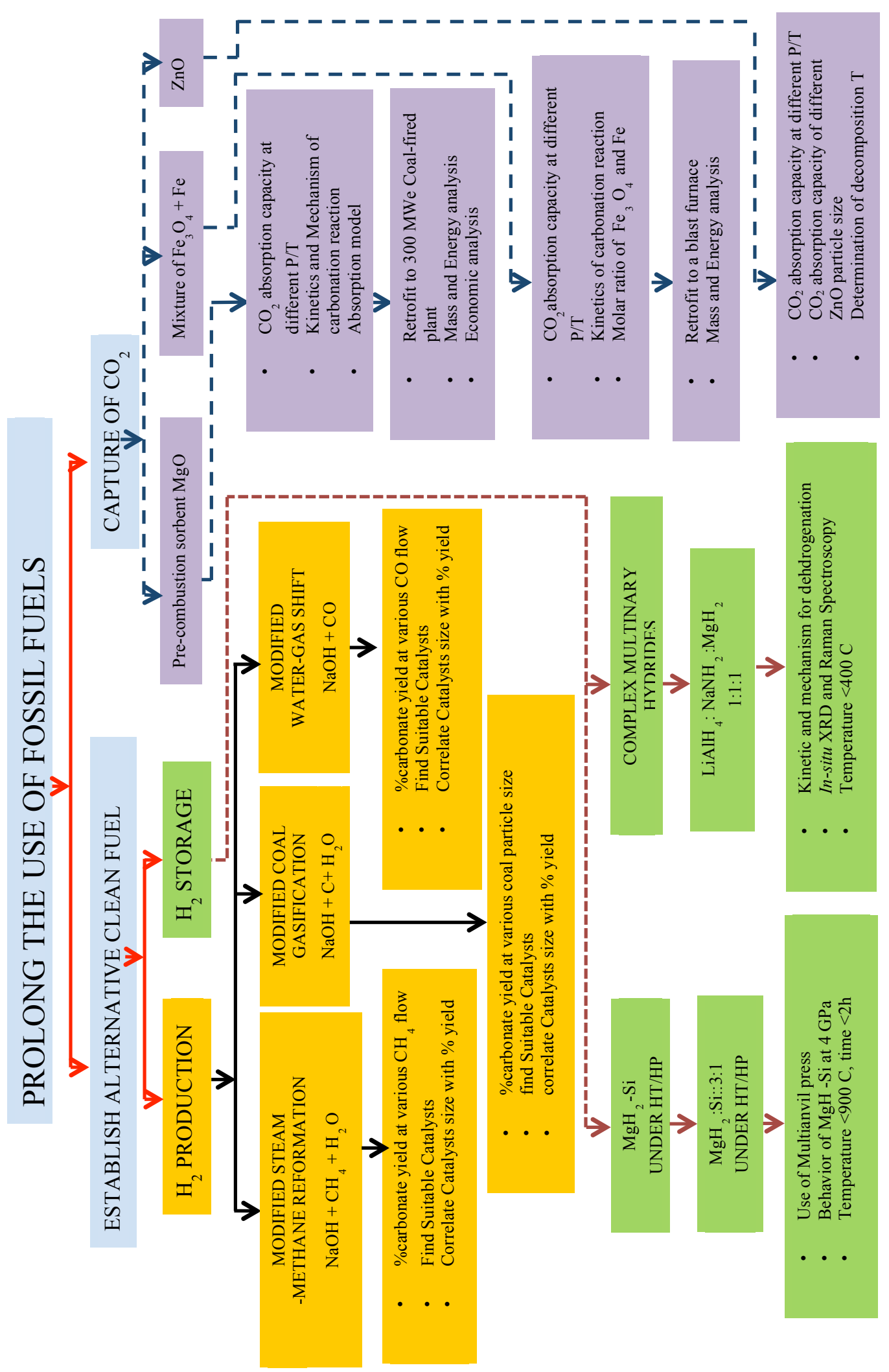

Figure 1.2.1 Flow chart of the research plan 


\subsection{References}

[1]International energy agency,world energy $\quad$ outlook 2012. www.worldenergyoutlook.com

[2] S. Kumar, S. K. Saxena, Materials and processes for energy: communicating current research and technological developments, Ed. A. Mendez-Vilas, Formatex Research Center (Badajoz, Spain), 2013, In Press.

[3] R.F. Probstein, R.E. Hicks, Synthetic fuels, 3rd ed. New York, Dover Publications, 2006.

[4] D. P. Broom, Hydrogen storage materials: the characterization of their storage properties, London, Springer, 2011. DOI: 10.1007/978-0-85729-221-6_1

[5] A. Zuttel, Materials Today, 2003, 6, 24-33.

[6] L.E. Klebanoff, J.O. Keller, International Journal of Hydrogen Energy, 2013, 38, 4533-4576.

[7] M.V. Iyer, High Temperature Reactive Separation Process for Combined Carbon dioxide and sulfur dioxide from Flue gas and Enhanced Hydrogen Production with in-situ Carbon dioxide Capture using High Reactivity Calcium and Biomineral sorbents, Ohio State University, 2006.

[8] T.C. Merkel, H. Lin, X. Wei, R. Baker, Journal of Membrane Science, 2010, 359, $126-139$.

[9] R.J. Littel, G.F. Versteeg, W.P.M. Van Swaaij, Chemical Engineering Science, 1991, 46, 3308-3313.

[10] P. Chiesa, S.P. Consonni, Journal of Engineering for Gas Turbines and Power, 1999, 121, 295-305.

[11] S. Bishnoi, G.T. Rochelle, Chemical Engineering Science, 2000, 55, 5531-5543.

[12] G.T. Rochelle, Science, 2009, 325, 1652-1654.

[13] P.J.E. Harlick, F.H. Tezel, Microporous and Mesoporous Materials, 2004, 76, 7177.

[14] C.E. Powell, G.G. Qiao, Journal of Membrane Science, 2006, 279, 1-49.

[15] D.M. D. Alessandro, B. Smit, J. R. Long, Angewandte Chemie International Edition, 2010, 49, 6058-6082. 


\section{EXPERIMENTAL TECHNIQUES AND DETAILS}

\subsection{Powder X-ray diffraction}

The X-ray powder diffraction method dates back to Debye and Scherrer who were first to observe LiF powder diffraction pattern and thus solving its crystal structure. Powder Xray diffraction is a non-destructive technique which identifies the chemical composition and determines the crystal structure of the material [1]. X-rays are generated using two different methods. The first is a device, an X-ray tube, where electromagnetic waves are produced from impact of high-energy electrons with a metal target. Another is advance source of X-ray radiation- the synchrotron, where high energy electrons are confined in a storage ring. These high energy electrons move in a circular orbit and emit electromagnetic radiation. Conventional X-ray sources generally have a low-efficiency, and their brightness is limited by the thermal properties of the target material. At CeSMEC, Mo is used as the target; however others including $\mathrm{Cu}, \mathrm{Co}, \mathrm{Fe}$ and $\mathrm{Cr}$ can also be employed. Conventional X-ray sources must be continuously cooled because almost all the kinetic energy of the accelerated electrons is converted into heat. However, synchrotron sources do not need to be cooled as they are extremely bright and their brightness is only limited by the flux of electrons in the high energy beam.

Although powder diffraction lacks the three-dimensionality of a diffraction pattern, the basic nature of the method is appreciated from the fact that each pattern represents onedimensional projection of the three-dimensional reciprocal lattice of the crystal. However, the quality of powder diffraction pattern is limited by the factors such as the physical and chemical compositions of the specimen, nature and energy of the available 
radiation and the resolution of the instrument. The scattered intensity is measured as a function of a single independent variable- the Bragg angle.

The powder diffraction experiment is powerful as the different structural features of a material have different effects on various parameters of its diffraction pattern. A change in the atomic parameters such as the coordinates of atoms in the unit cell or populations of different sites in the lattice of the crystalline phases is reflected in the relative intensities and/or positions of the Bragg peaks. The microscopic changes such as deformation or reduction in grain size of the material affects the shapes, intensities and positions of the Bragg peaks. Hence, a lot of the structural information about the material is embedded into its powder-diffraction pattern.

In powder diffraction, it is crucial to have a plain surface. In general, to obtain better diffraction pattern, samples are ground to micron sizes and placed inside a sample holder such as quartz capillary. A large area of the Debye ring can be measured with 2D diffraction detection in transmission geometry and can be evaluated for structural and chemical properties of the material.

X-ray diffraction studies are conducted using Bruker-GADDS/D8 X-ray system with MacSci rotating anode of Molybdenum $(\lambda=0.71073 \AA)$ and Apex Smart CCD detector. The dehydrogenation study of multinary complex hydrides are carried out using homemade heater coupled with thermo controller to heat the sample for in situ XRD experiments up to $500^{\circ} \mathrm{C}$. The sample position is calibrated using the standard, $\mathrm{LaB}_{6}$ (Lanthanum Hexaboride). 


\subsection{Raman Spectroscopy}

In Raman spectroscopy, the sample is irradiated by intense laser beams in the UV-visible region $\left(v_{0}\right)$, and the scattered light is generally observed in the direction perpendicular to the incident beam [2].
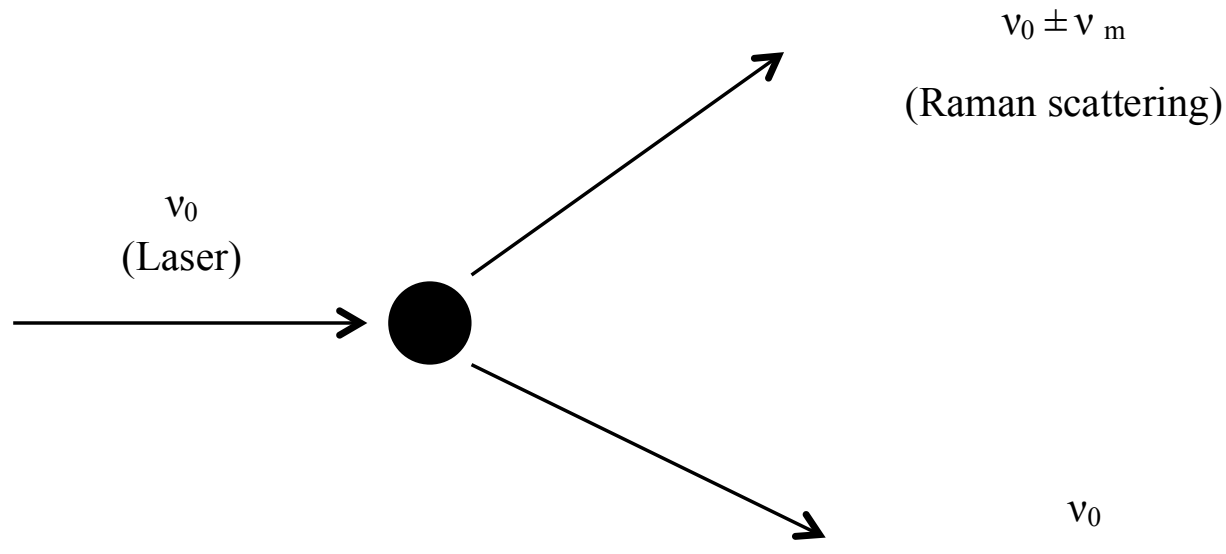

(Rayleigh scattering)

Figure 2.1 Schematic for Raman Spectroscopy

One of the scattered lights is strong and has the exact frequency as the incident beam, called Rayleigh scattering and other is very weak $\left(\sim 10^{-5}\right.$ of the incident beam) and has frequencies $v_{0} \pm v_{\mathrm{m}}$, where $v_{\mathrm{m}}$ is vibrational frequency of a molecule [Fig. 2.1]. The $v_{0}-v$ $\mathrm{m}$ and $v_{0}+v_{\mathrm{m}}$ lines are known as the Stokes and anti-stokes lines, respectively. The Raman shift represents the change in the frequency of the scattered light from the laser frequency which suggests the energy in the form of phonons is deposited in the sample. 


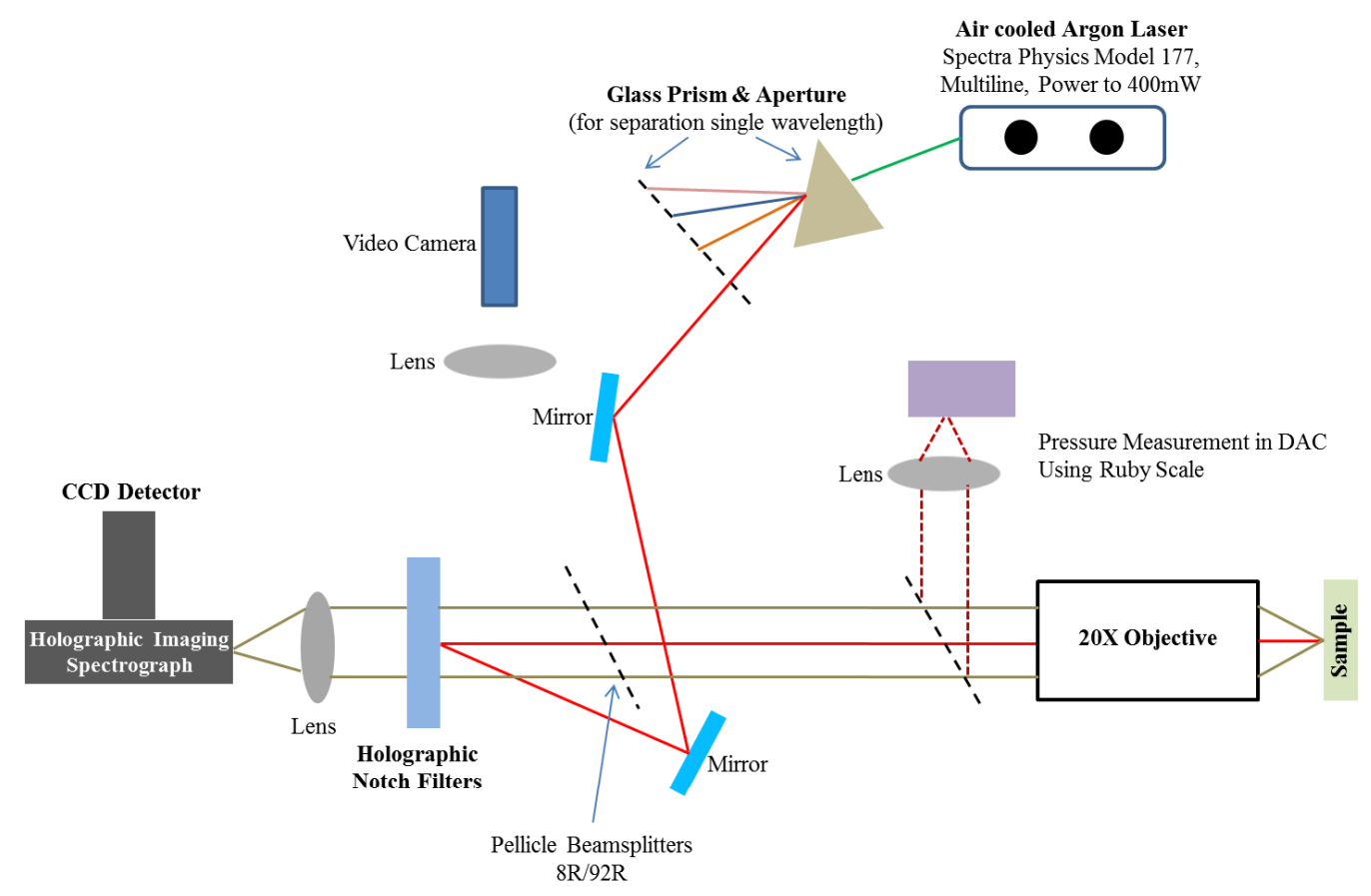

Figure 2.2 illustrates the Raman experimental arrangement at CeSMEC

The laser beam from the argon ion laser is filtered to achieve a monochromatic beam, which is further directed by a system of mirrors to a focusing/collecting lens and focused on the sample. The backscattered beam is then directed to the spectrometer through filters and gratings. The holographic notch filters permit absorption of Raman scattered light closer to the Rayleigh line with fewer ripples. The holographic transmission gratings allow acquiring entire Raman spectrum. The system detector, a multichannel CCD array, reads signal as a function of position. Computer equipped with Andor software converts the wavelength-intensity information to frequency-shift versus intensity plots. The extent to which the image may move along the face of the CCD array is determined by the slitwidth. The final slit-width should be smaller than peak width for the better resolution of a Raman peak. The dark current of CCD array depends on the detector temperature and thus needs to be cooled. Joule Thomson effect is used to cool CCD set up. The intensity 
of Raman spectrum is dependent on the applied laser power, slit width and the sample properties (intrinsic strength of the Raman modes, absorptive or reflective power of the sample).

Raman spectroscopy experiments are performed using an argon ion $\left(\mathrm{Ar}^{+}\right)$laser system (Spectra Physics, model 177G02) of $\lambda=514.5 \mathrm{~nm}$. Backscattered Raman spectra are captured by high throughput holographic imaging spectrograph (Kaiser Optical Systems, model HoloSpec $f / 1.8 \mathrm{i}$ ) with volume transmission grating, holographic notch filter and thermoelectrically cooled CCD detector (Andor Technology). The average spot size of the laser beam used is approximately $5 \mu \mathrm{m}$. The Raman spectrometer system has a spectral resolution of $4 \mathrm{~cm}^{-1}$ and the spectra are collected at an exposure of $600 \mathrm{~s}$.

\subsection{Experimental set up for hydrogen producing reactions}

Fig. 2.3 illustrates the experimental set up for hydrogen producing reactions. It is a homemade furnace ( $1 \mathrm{ftx} 1 \mathrm{ftx} 1 \mathrm{ft})$ which facilitates the study for effect of gases over a bed of solid/liquid at various temperatures. Solid samples are put in an alumina boat and placed at the hot spot position in an alumina tubular furnace (18.5" long and 0.7 " in diameter). Before reaction, nitrogen gas is used to create an inert atmosphere. Once the required temperature is attained, the flow of nitrogen gas is ceased to zero and the desired gas $\left(\mathrm{CH}_{4}\right.$ or $\left.\mathrm{CO}\right)$ is fed to the furnace. As required, steam is also delivered to the furnace as shown in Fig. 2.3. However, steam flow rates are not controlled. 


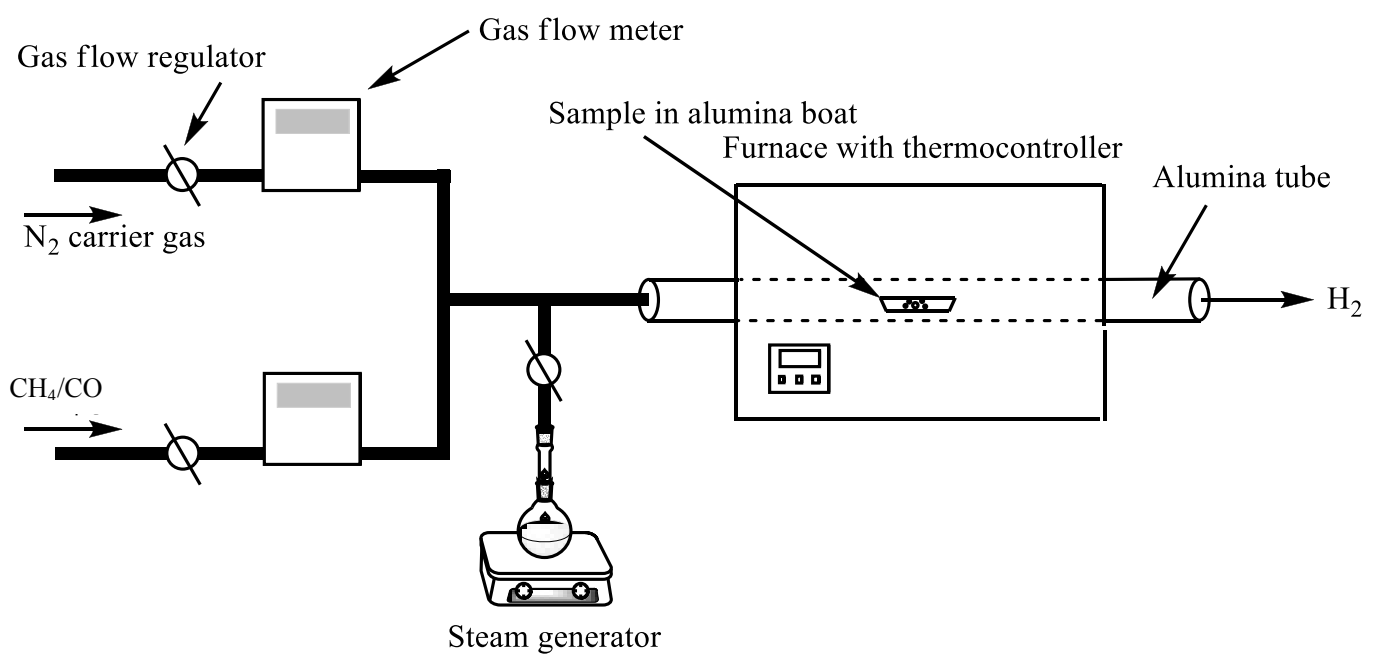

Figure 2.3 Experimental set up for study of hydrogen producing reactions

The extent of proposed hydrogen producing reaction is analyzed by calculating the amount of sodium carbonate. The mixture of product $\left(\mathrm{Na}_{2} \mathrm{CO}_{3}\right)$ and un-reacted reactant $(\mathrm{NaOH})$ is titrated against $0.1009 \mathrm{~N}$ volumetric standard solution of nitric acid (Aldrich). The equivalent points are detected by using acid-base indicators (Phenolphthalein and Methyl Orange). The equivalents can be detected by using acid-base indicators; here phenolphthalein and methyl orange are the indicators. $\mathrm{NaHCO}_{3}$ does not form in the reaction but it does during titration:

$$
\mathrm{Na}_{2} \mathrm{CO}_{3}+\mathrm{HNO}_{3} \rightarrow \mathrm{NaHCO}_{3}+\mathrm{HNO}_{3}
$$

and then

$$
\mathrm{NaHCO}_{3}+\mathrm{HNO}_{3} \rightarrow \mathrm{NaNO}_{3}+\mathrm{CO}_{2}+\mathrm{H}_{2} \mathrm{O}
$$




\subsection{Experimental set up for study of carbon dioxide capture reaction}

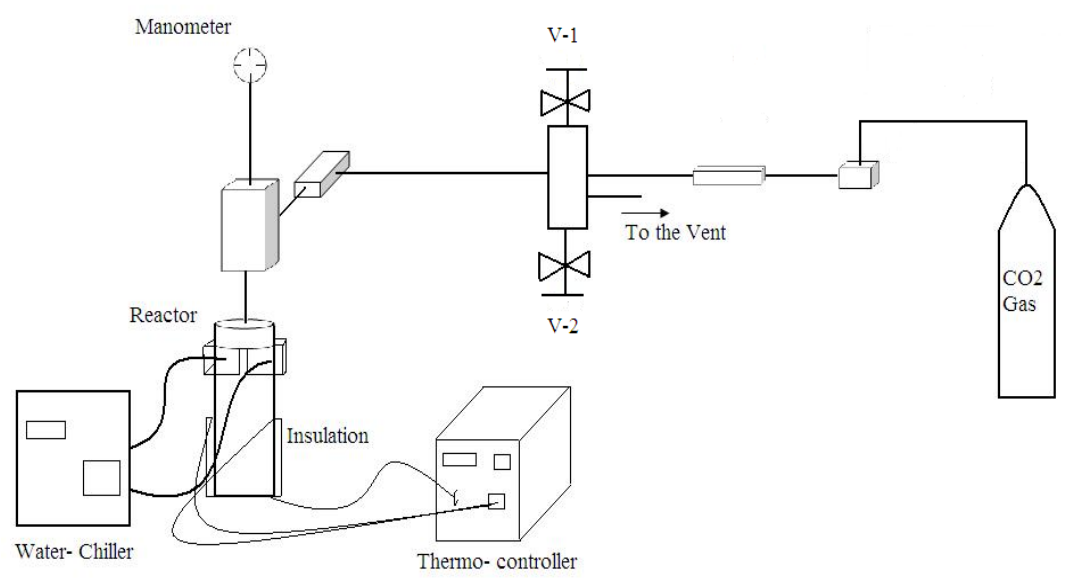

Figure 2.4 Experimental arrangements for study of metal oxide-carbon dioxide reactions.

Few grams of oxide are put inside a closed cylindrical vessel (1.25" long and 0.35 " internal diameter) with specific amount of water is also sprinkled on the reactor walls as shown in Fig. 2.4. Chemically pure and pressurized carbon dioxide gas (Airgas) is passed into this system. Before experiments, carbon dioxide gas is flushed three times to ensure a pure carbon dioxide atmosphere inside the reactor. The reactions are performed for desired set of time, temperature and pressure conditions.

\subsection{Multi anvil press}

Multi anvil press is a two-stage type apparatus able to reach pressure maximum of $25 \mathrm{GPa}$ and temperature maximum of $2400^{\circ} \mathrm{C}$ [3]. The first stage consists of six stainless steel wedges which enclose the second stage in a cubic cavity. The force is applied to the wedges by single ram. The second stage of anvils consists in eight tungsten carbide cubes 
with truncated corners. These cubes are hold together using epoxy-impregnated fiberglass laminate sheets which also insure electrical insulation with the wedges. The pressure cell is a sintered $\mathrm{MgO}$ octahedron. The pressure cell is compressed in the octahedral cavity formed by the truncated cubes.

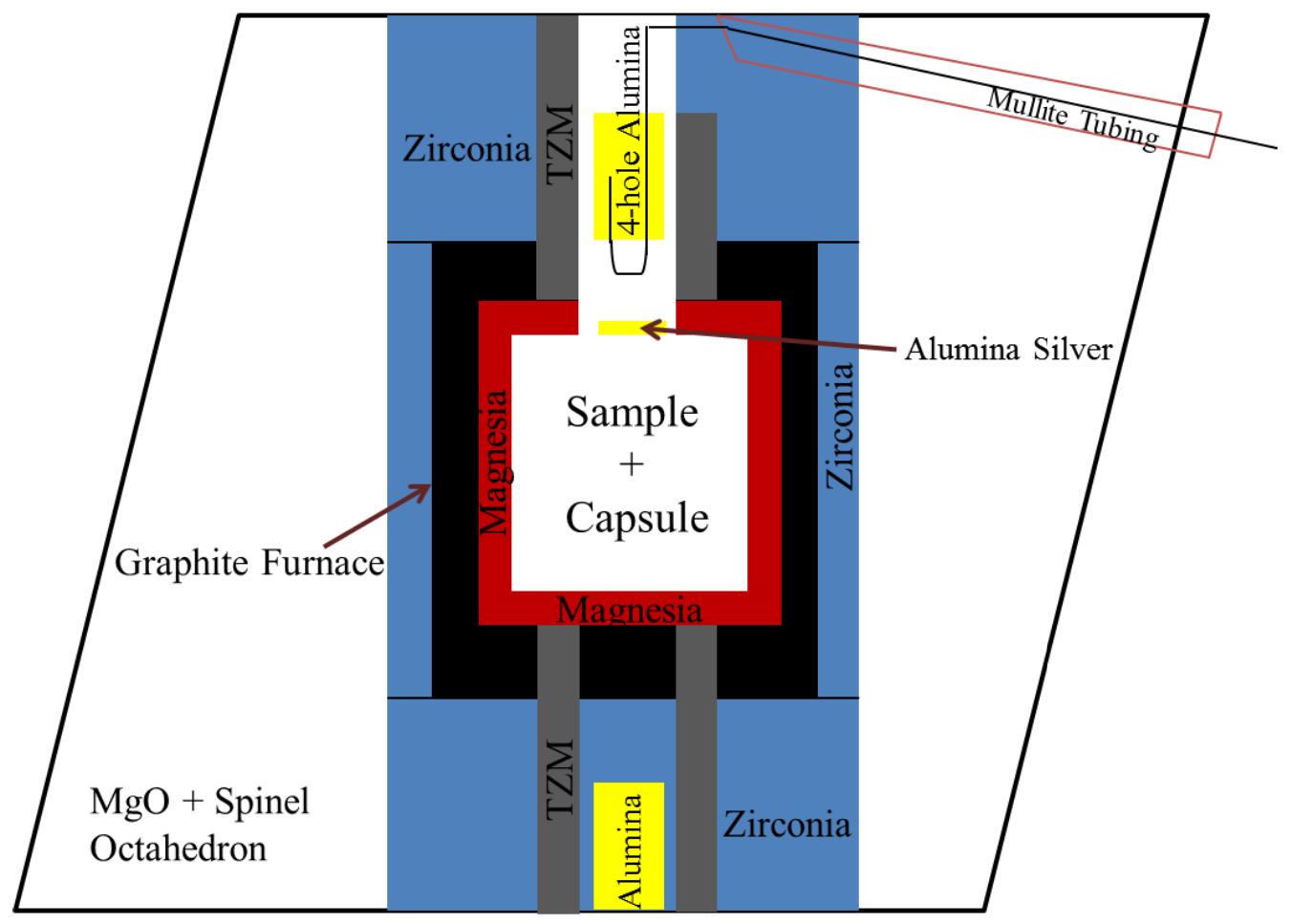

Figure 2.5 14/8 “G2” Assembly

The sample loaded in the octahedron shown in Fig. 2.5 is heated by a Rhenium Furnace. $\mathrm{A} \mathrm{LaCrO}_{3}$ sleeve is inserted around the heater for thermal insulation. The sample is encapsulated in a Rhenium capsule and placed in $\mathrm{MgO}$ sleeve to insure quasi-hydrostatic conditions. The temperature is measured close to the sample using a thermocouple (W5\%Re-W26\%Re) in an $\mathrm{Al}_{2} \mathrm{O}_{3}$ sleeve. 
Tungsten carbide anvils are used to generate high pressure. Pyrophyllite gasket and extruding pressure medium support the large stress gradients generated in the anvils. The pressure is driven by a hydraulic system. The pressure generated in the cell depends on the truncation edge- length (TEL) of the tungsten carbide cube and on the octahedral edge-length (OEL) if the octahedron as well as on materials used and on the crosssectional dimensions of the gaskets. Different assemblies are named after the ratio of these two lengths; OEL/TEL in mm. increasing the OEL/ TEL ratio results in a decrease of the sample size and in an increase of the pressure range.

The press can be used to perform different types of experiments such as

(1) Synthesis and sintering under high temperature and/or high pressure

(2) Study of phase diagram

(3) Electrical conductivity

(4) Ultra-sonic measurements

\subsection{Brunauer-Emmett-Teller analysis}

When a solid is exposed in a closed environment to a gas or vapor at a definite pressure, the solid begins to adsorb the gas [4]. As a consequence, increase in weight of the solid and decrease in the pressure of the gas can be observed. However, after a time the pressure becomes constant and correspondingly the weight ceases to increase any further. The amount of the adsorbed gas can either be calculated from the drop in pressure by use of gas laws or can be determined directly as the increase in weight of the solid. The quantity of the gas adsorbed by a sample is proportional to the mass $m$ of the sample. Assuming $n$ is the quantity of adsorbed gas in moles per gram of solid, 


$$
n=f(p, T, g a s, \text { solid })
$$

The adsorption of a gas by solid can yield valuable information about surface area and pore structure of the solid. As the range of suitable adsorptives is quite narrow, by far the most frequently used one being nitrogen at its boiling point, $77 \mathrm{~K}$. The concept of BET theory is an extension of Langmuir theory with the hypothesis: (a) gas molecules adsorb on solids in layers; (b) no chemical or physical interaction is assumed between two adsorption layers; and (c) each layer abides the Langmuir theory.

The surface area of a solid is inversely proportional to the size of the constituent particles $(A \propto 1 / l)$. However, in practice, constituent particles are of different sizes and irregular shapes and thus the relationship is more complicated. The particles of fine powder (primary particles) sticks together more or less firmly under the action of surface forces to form secondary particles. A pore system constitutes the space between the primary particles within a secondary particle, together with those between a secondary particle and its neighbors. The size and shape of individual pores vary within a given solid. Below is the classification of pores according to their average width originally proposed by Dubinin and then officially accepted by International Union of Pure and Applied Chemistry. 


\begin{tabular}{|c|c|}
\hline & Pore width \\
\hline Micropores & $<\sim 20 \AA$ \\
\hline Mesopores & $\sim 20 \AA<<\sim 500 \AA$ \\
\hline Macropores & $>\sim 500 \AA$ \\
\hline
\end{tabular}

Table 2.1 Classification of pores according to their width

\subsection{Thermo gravimetric analysis}

Thermo gravimetric analysis (TGA) is a technique to precisely measure the rate of change in mass of a sample as function of temperature under controlled atmosphere [5]. The technique can characterize materials that exhibit mass change due to decomposition, oxidation, or dehydration. The efficiency of TGA is dependent on the accurate measurement of sample weight, temperature and change in temperature. Mass calibration experiments needs to be conducted at regular intervals to understand the buoyancy effect by air, temperature gradients and convection currents within the furnace tube.

In this dissertation, the decomposition temperature of carbonates is determined using Perkin Elmer TGA instrument. Samples in milligram quantity are heated up to $500^{\circ} \mathrm{C}$ under different flow rate of inert gas (mainly argon). Moreover, TGA results are also used to evaluate the percentage conversion of oxide to carbonate.

\subsection{Fourier Transform Infrared Spectroscopy (FTIR)}

FTIR is a chemically-specific analysis technique [6]. It is employed to identify chemical compounds, and substituent groups. An infrared is an absorption technique, infrared passes through the sample, and is then detected. Fig. 2.6 shows the configuration of FTIR 
spectrometers based on Michelson Interferometer. At the interferometer, light strikes the beam splitter and splits in half. First half is directed to moving mirror (to and fro movement) and other half to the fixed mirror. After reflections from these mirrors, the beam splitter recombines the light which is further guided towards the sample. This light is absorbed by the sample and recorded by the detector.

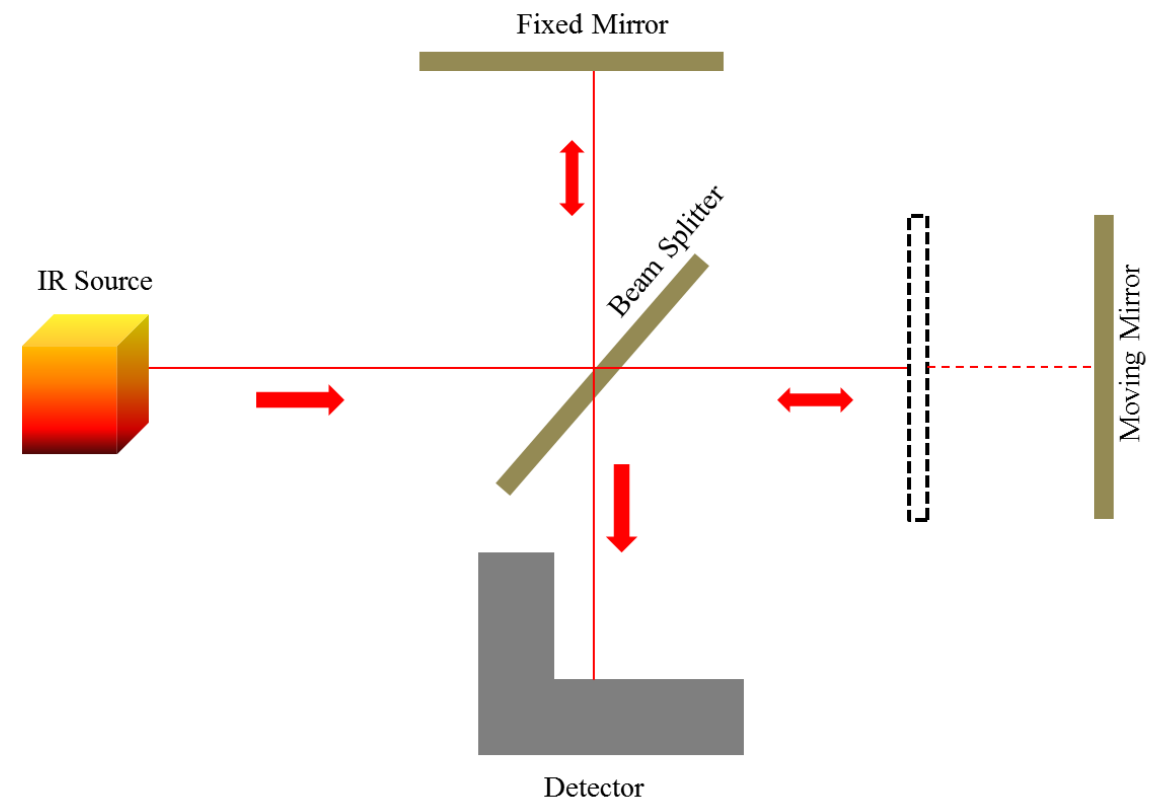

Figure 2.6 Schematic for FTIR Spectroscopy

\subsection{Sieverts-type apparatus HyEnergy PCTPro-2000}

PCTPro-2000 is fully automated Sievert's apparatus for measuring gas sorption properties of the materials. It can precisely measure the PCT (Pressure Composition Isotherms), Gas Sorption Kinetics, Heat-of-Formation, Volume Calibration and Packing Density measurements. This instrument is designed for accurate measurements over 
broad range of temperature, pressure and size. It can measure sample quantities down to milligrams and the temperature can be raised up to $400^{\circ} \mathrm{C}$.

The amount of gas absorbed or desorbed by the material is pressure and temperature dependent and thus needs to be precisely evaluated. A large number of hydrides desorb hydrogen via multi-step reactions and HyEnergy PCTPro-2000 can be used to obtain the hydrogen desorption rate. Here, standard start-up procedures, namely, leak check, purge gas and volume calibration at $50^{\circ} \mathrm{C}$ is used. The de-hydrogenation experiments for multinary complex hydrides are performed in a static vacuum $(\sim 0.01-0.05$ bar). The temperature programmed desorption measurements are performed between $50-380^{\circ} \mathrm{C}$ with a heating ratio of $5^{\circ} \mathrm{C} / \mathrm{min}$. After $7 \mathrm{~h}$ the vacuum is adjusted to the original level because of pressure increase in the experimental set-up and reservoir caused by hydrogen evolution from the sample and temperature change since temperature programmed desorption is applied. The blank tests performed under temperature programmed desorption conditions to estimate the approximate error of the whole measurement in the vacuum and up to $\sim 1$ bar resulted in negligible wt.\% changes (up to $\sim 0.1$ wt.\%). The error of the measured temperature can be estimated to be at $\pm 2-3^{\circ} \mathrm{C}$.

\subsection{Differential Scanning Calorimetry (DSC)}

DSC is a thermoanalytical technique used to determine the work done on a given sample for phase transformation and decomposition [7]. The sample and reference materials are maintained at nearly equal temperature. When sample undergoes an exothermic process (such as crystallization), less heat is required to raise the sample temperature. The difference of heat flow is accounted as a function of temperature. Therefore, DSC plot 
determines the value of heat absorbed or released during any phase transition. DSC can be used to observe fusion, crystallization, glass transition, oxidation and other chemical reaction. 


\subsection{References}

[1] V.K. Pecharsky, P.Y.Zavalij, Fundamentals of Powder Diffraction and Structural Characterization of Materials, Springer, New York, $2^{\text {nd }}$ ed., 2009

[2] J.R. Ferraro, K. Nakamoto, Introductory Raman Spectroscopy, Academic Press, London, 1994.

[3] G.Y. Bussod, T. Katsura, D.C. Rubie, Pure and applied geophysics, 1993, 141, 579599.

[4] S.J. Gregg, K.S.W. Sing, Adsorption, Surface Area and Porosity, Academic Press, London, $2^{\text {nd }}$ ed., 1982.

[5] D. Clement, Inorganic Thermogravimetric Analysis, Elsevier, New York, $2^{\text {nd }}$ ed., 1963.

[6] D.A. Burns, E.W. Ciurczak, Handbook of near Infra-red Analysis, CRC Press, Boca Raton, $3^{\text {rd }}$ ed., 2008.

[7] G.W.H. Hohne, W.F. Hemminger, H.J. Flammersheim, Differential Scanning Calorimetry, Springer, New York, $2^{\text {nd }}$ ed., 2003. 


\section{CLEAN PRODUCTION ROUTES OF HYDROGEN}

\subsection{LITERATURE REVIEW}

Hydrogen is the lightest and most abundant element on the earth. However, unlike oxygen, hydrogen is not found as free in the nature at any significant concentration. Hydrogen is an important starting ingredient for chemical, metallurgical, pharmaceutical, food and electronic industries. Ammonia synthesis and oil refineries together consumes about three-fourth of the total hydrogen produced in United States.

The principal methods for the production of hydrogen include water-electrolysis and natural gas reforming processes [1]. However, photo-electrolysis, photo-biological production and high temperature decomposition are in the developing stage. Thus, extensive research and development is needed to mature these technologies for any future commercial applications.

Steam methane reforming (SMR) is a hydrocarbon-based oxidative process and by far the most common and widely used industrial method for hydrogen production. The technology supplies about $40 \%$ of the total world production. Fig. 3.1.1 depicts the simplified schematic of SMR technique. 


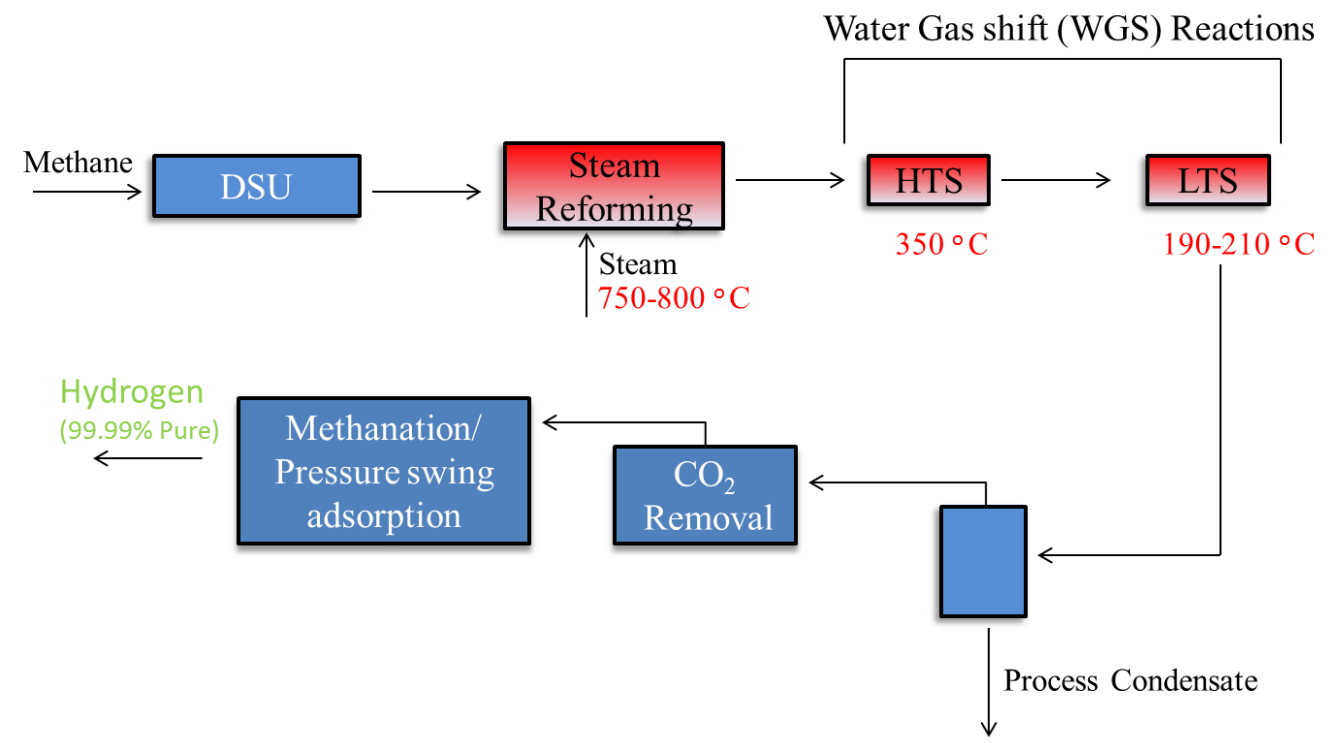

Figure 3.1.1 Simplified schematic of hydrogen production using SMR technique

The operating units of an SMR plant consists of methane gas desulphurization unit, steam reforming, water-gas shift reactors, hydrogen gas separation and carbon dioxide removal unit. WGS catalysts are prone to sulfur poisoning and thus a high degree desulphurization is required. Sulfur-organic compounds such as thiols are first transformed into hydrogen sulfide by catalytic hydrogenation reaction (Co-Mo catalysts, $290-370^{\circ} \mathrm{C}$ ). Hydrogen sulfide is further scrubbed using $\mathrm{ZnO}\left(340-390^{\circ} \mathrm{C}\right)$ and forms $\mathrm{ZnS}$. In the reforming reactor, the preheated mixture of methane $\left(500^{\circ} \mathrm{C}\right)$ and steam $\left(2.6 \mathrm{MPa}, 500^{\circ} \mathrm{C}\right)$ is passed through externally heated reformer tubes filled with nickel catalyst, where the following reaction occurs:

$$
\mathrm{CH}_{4}(\mathrm{~g})+\mathrm{H}_{2} \mathrm{O}(\mathrm{g}) \rightarrow \mathrm{CO}(\mathrm{g})+3 \mathrm{H}_{2}(\mathrm{~g})
$$

The gaseous mixture of carbon monoxide, steam and hydrogen leaves the reforming reactor at around $800-900^{\circ} \mathrm{C}$. The mixture is cooled instantaneously to $350{ }^{\circ} \mathrm{C}$ (steam generation step) and is fed to WGS reactors. Carbon monoxide reacts with steam to form carbon dioxide and generates additional hydrogen. The combination of high and low temperature WGS reactors consumes $92 \%$ of the carbon monoxide in the reformate gas. 
There are two ways to separate hydrogen from carbon dioxide: (a) solvent (monoethanolamine, water, ammonia solutions, methanol and potassium carbonate solution) and (b) pressure swing adsorption (PSA) system. The PSA unit operates at 20 atm and comprises multiple adsorption beds, generally filled with molecular sieves of definite pore size.

However, carbon dioxide emission from a typical SMR plant is about $0.44 \mathrm{Nm}^{3} \mathrm{CO}_{2} / \mathrm{m}^{3}$ $\mathrm{H}_{2}$. Thus, an SMR hydrogen plant with the capacity of 2.5 million $\mathrm{m}^{3}$ of hydrogen per day vents about 1 million $\mathrm{m}^{3}$ of carbon dioxide per day into the atmosphere. As a consequence, four different mitigation techniques have been proposed to curb the vast carbon dioxide emissions:

(1) Use of nuclear reactors;

(2) Modify SMR technique;

(3) Sequesters carbon dioxide produced at SMR hydrogen plant;

(4) Thermally dissociates hydrocarbon into hydrogen and carbon.

Interestingly, a large number of these methods include sodium hydroxide as an essential ingredient. The use of sodium hydroxide for production of hydrogen is not new and was in application even during $19^{\text {th }}$ century. In the following sections, the significance of sodium hydroxide for the hydrogen production process will be discussed in details.

\subsubsection{Overview of Sodium hydroxide (NaOH)}

Previous technology for sodium hydroxide production included mixing of calcium hydroxide with sodium carbonate. This process was named as "causticizing".

$$
\mathrm{Ca}(\mathrm{OH})_{2}(\mathrm{aq})+\mathrm{Na}_{2} \mathrm{CO}_{3}(\mathrm{~s})=\mathrm{CaCO}_{3} \downarrow+2 \mathrm{NaOH}(\mathrm{aq})
$$

Currently, sodium hydroxide is produced by the electrolysis of brine $(\mathrm{NaCl})$ : 


$$
2 \mathrm{NaCl}+2 \mathrm{H}_{2} \mathrm{O}=2 \mathrm{NaOH}+\mathrm{Cl}_{2} \uparrow+\mathrm{H}_{2} \uparrow
$$

Besides hydrogen evolution, reaction (3.1.3) produces chlorine (a toxic gas) and sodium hydroxide. Moreover, the electrolysis of brine is also a high energy consuming process. Thus, the combined effect of high energy requirement and emission of chlorine gas makes the production of sodium hydroxide using electrolysis of brine, an environmentally unsafe process.

Table 3.1.1 compares the three commercially available production methods for sodium hydroxide. It can be observed that diaphragm cell process produces the lowest quality electrochemical caustic soda solutions (only $12 \mathrm{wt} . \%$ ). Therefore, evaporation is required to raise the concentration up to $50 \mathrm{wt}$ \% solution as in mercury-cell process. Hence, the amount of steam consumption varies according to the strength of the produced electrochemical caustic soda solutions.

\begin{tabular}{|c|c|c|c|}
\hline Factors & Diaphragm & Mercury & Membrane \\
\hline Use of mercury & No & Yes & No \\
\hline $\mathrm{Cl}_{2}$ as a byproduct & Yes & No & Yes \\
\hline Operating current density $\left(\mathrm{kA} / \mathrm{m}^{2}\right)$ & $0.9-2.6$ & $8-13$ & $3-5$ \\
\hline Cell voltage (V) & $2.9-3.5$ & $3.9-4.2$ & $3.0-3.6$ \\
\hline $\mathrm{NaOH}$ strength (wt. \%) & 12 & 50 & $33-35$ \\
\hline $\begin{array}{c}\text { Energy consumption }\left(\mathrm{kWh} / \mathrm{MTCl}_{2}\right) \\
\text { at a current density }\left(\mathrm{kA} / \mathrm{m}^{2}\right)\end{array}$ & $2720(1.7)$ & $3360(10)$ & $2650(5)$ \\
\hline $\begin{array}{c}\text { Steam consumption }\left(\mathrm{kWh} / \mathrm{MT} \mathrm{Cl}_{2}\right) \\
\text { for concentration to } 50 \% \mathrm{NaOH}\end{array}$ & 610 & 0 & 180 \\
\hline$\% \mathrm{NaOH}$ produced in $\mathrm{USA}$ & 62 & 10 & 24 \\
\hline
\end{tabular}

Table 3.1.1 Comparison of the commercially available production methods for sodium hydroxide 
Figure 3.1.2 illustrates the membrane cell used for the electrolysis of brine.

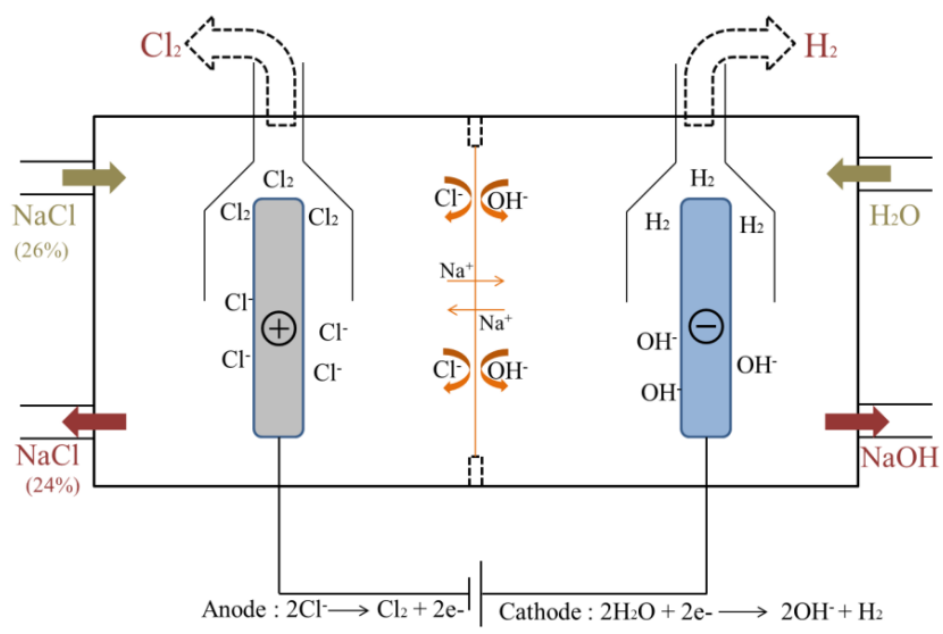

Figure 3.1.2 Membrane cell process schematic for production of sodium hydroxide.

\subsubsection{NaOH assisted Hydrogen Production Schemes}

\subsubsection{Modified Industrial Hydrogen Production}

Reaction between $\mathrm{NaOH}$ and $\mathrm{CO}$ yielding sodium formate ( $\mathrm{HCOONa}$ ) was described by Berthelot in 1856 . When heated above $250^{\circ} \mathrm{C}$, HCOONa transforms into oxalate with release of hydrogen:

$$
\begin{aligned}
& \mathrm{NaOH}(\mathrm{s})+\mathrm{CO}(\mathrm{g})=\mathrm{HCOONa}(\mathrm{s}) \\
& 2 \mathrm{HCOONa}(\mathrm{s})=\mathrm{Na}_{2} \mathrm{C}_{2} \mathrm{O}_{4}(\mathrm{~s})+\mathrm{H}_{2}(\mathrm{~g})
\end{aligned}
$$

In 1918 Boswell and Dickson demonstrated that when carbon monoxide is heated with excess of sodium hydroxide at temperatures at which formate is transformed into oxalate, oxidation almost quantitatively to carbon dioxide occurs with the evolution of an equivalent amount of hydrogen [2]:

$$
2 \mathrm{NaOH}(\mathrm{s})+\mathrm{CO}(\mathrm{g})=\mathrm{Na}_{2} \mathrm{CO}_{3}(\mathrm{~s})+\mathrm{H}_{2}(\mathrm{~g})
$$


Large scale hydrogen producing methods such as coal-gasification and WGS reaction needs to be modified. Coal-gasification process requires coal as a raw material and is a very energy intensive process. However, the WGS method is an exothermic reaction and operates at a high to low temperature. WGS reaction is an integral step for SMR technique as it produces additional hydrogen. Therefore, any modifications to these conventional techniques that can significantly reduce carbon dioxide emission are highly desired. 

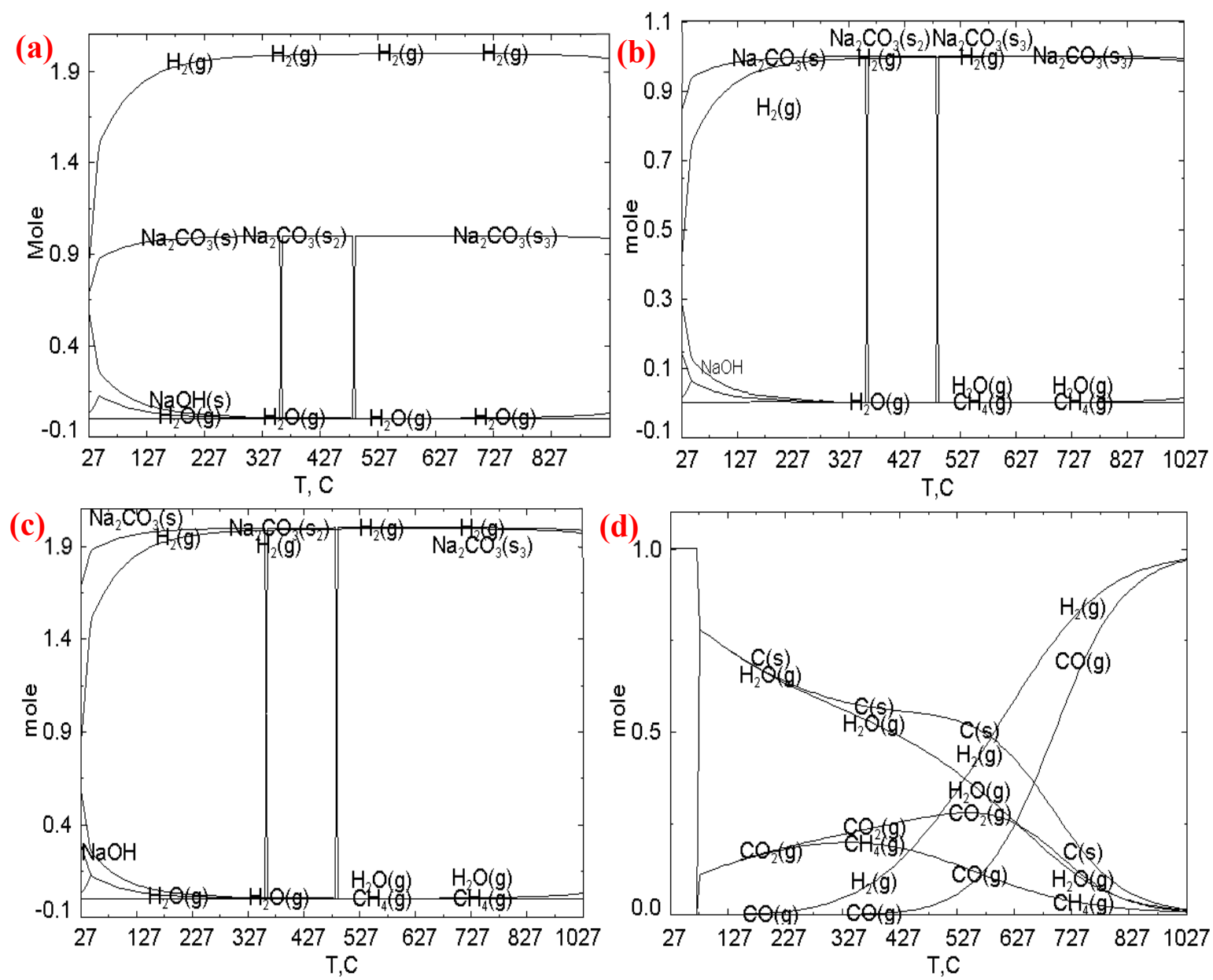

Figure 3.1.3 (a) equilibrium in the system $2 \mathrm{NaOH}+\mathrm{C}+\mathrm{H}_{2} \mathrm{O}$ (b) equilibrium composition in the system $2 \mathrm{NaOH}+\mathrm{CO}$ (c) equilibrium in the system $4 \mathrm{NaOH}+\mathrm{C}+\mathrm{CO}_{2}$ (d) the gasshift reaction $\mathrm{CO}+\mathrm{H}_{2} \mathrm{O}$

Saxena proposed reaction (3.1.7) and performed the thermodynamic calculation using the software FACTSAGE and the databases therein [3]. Although reaction (3.1.7) is endothermic, it can mitigate carbon dioxide emission by forming $\mathrm{Na}_{2} \mathrm{CO}_{3} . \mathrm{Na}_{2} \mathrm{CO}_{3}$ and $\mathrm{H}_{2}$ are generated over a wide range of temperature $\left(100-800^{\circ} \mathrm{C}\right)$.

$2 \mathrm{NaOH}(\mathrm{s})+\mathrm{C}(\mathrm{s})+\mathrm{H}_{2} \mathrm{O}(\mathrm{g}) \rightarrow \mathrm{Na}_{2} \mathrm{CO}_{3}(\mathrm{~s})+2 \mathrm{H}_{2}(\mathrm{~g}) \Delta \mathrm{H}=645.8 \mathrm{~kJ}\left(600^{\circ} \mathrm{C}\right)$ 
Reaction (3.1.8) can be considered as a combination of the Boudouard reaction $\left(\mathrm{C}+\mathrm{CO}_{2}\right.$ $\rightarrow \mathrm{CO})$ and Reaction 3.1.6 $\left(2 \mathrm{NaOH}+\mathrm{CO} \rightarrow \mathrm{Na}_{2} \mathrm{CO}_{3}+\mathrm{H}_{2}\right)$ :

$$
4 \mathrm{NaOH}(\mathrm{s})+\mathrm{C}(\mathrm{s})+\mathrm{CO}_{2}(\mathrm{~g}) \rightarrow 2 \mathrm{Na}_{2} \mathrm{CO}_{3}(\mathrm{~s})+2 \mathrm{H}_{2}(\mathrm{~g}) \Delta \mathrm{H}=-662 \mathrm{~kJ}\left(600^{\circ} \mathrm{C}\right)
$$

Sodium in the above reactions may be replaced by potassium.

In the subsequent sections of this chapter, thermodynamic calculation shows that the addition of sodium hydroxide to methane, coal and carbon monoxide lowers the operating temperature and can significantly reduce the carbon dioxide emission.

A similar concept of including sodium hydroxide as a reactant for hydrogen production is already in use at industrial scale. For instance, the black liquor gasification process utilizes alkali hydroxide to serve the dual purpose of hydrogen production and carbon sequestration. In a typical pulping process for paper production, approximately one-half of the raw materials are converted to pulp and other half is dissolved in the black liquor. The black liquor solution consists of well- dispersed carbonaceous material, steam and alkali metal which are burned to provide part of energy for the plant. Due to the presence of carbonaceous material and water in the liquor, following carbon-water reaction predominates:

$$
\begin{gathered}
\mathrm{C}(\mathrm{s})+\mathrm{H}_{2} \mathrm{O}(\mathrm{g})=\mathrm{CO}(\mathrm{g})+\mathrm{H}_{2}(\mathrm{~g}) \\
\mathrm{CO}(\mathrm{g})+\mathrm{H}_{2} \mathrm{O}(\mathrm{g})=\mathrm{CO}_{2}(\mathrm{~g})+\mathrm{H}_{2}(\mathrm{~g})
\end{gathered}
$$

However, due to the thermodynamic limitations, reaction (3.1.10) never proceeds towards completion; therefore hydrogen concentration does not exceed a certain limit. However, in the presence of sodium hydroxide, carbon dioxide capture medium, the equilibrium 
can be shifted to drive reaction (3.1.10) towards completion and therefore maximize hydrogen concentration. Consequently, carbon monoxide and carbon dioxide concentration reduces significantly in the product gases.

\subsubsection{Biomass}

Biomass is a renewable energy resource obtained from solar energy, carbon dioxide and water. Biomass does not increase carbon dioxide level in the atmosphere as it uptakes the same amount of carbon while growing as releases when burnt as a fuel.

Biomass + heat + steam $\rightarrow \mathrm{H}_{2}+\mathrm{CO}+\mathrm{CO}_{2}+\mathrm{CH}_{4}+$ Light/ Heavy hydrocarbons + Char (3.1.11)

One of the major issues other than high carbon emission in biomass gasification is to deal with tar formation that occurs during the gasification process. The undesirable tar may cause the formation of tar aerosol and a more complex polymer structure, which are unfavorable for hydrogen production through steam reforming. The existing methods to

minimize tar formation are: (a) proper designing of gasifier (b) proper control and operation and (c) use of additives or catalysts.

Sodium hydroxide-promoted biomass gasification to generate hydrogen without carbon monoxide and carbon dioxide formation generates hydrogen and capture carbon [4]. Cellulose $\left[\mathrm{C}_{6} \mathrm{H}_{10} \mathrm{O}_{5}\right]$, D-glucose $\left[\mathrm{C}_{6} \mathrm{H}_{12} \mathrm{O}_{6}\right]$ and sucrose $\left[\mathrm{C}_{12} \mathrm{H}_{22} \mathrm{O}_{11}\right]$ reacts with water vapor in the presence of sodium hydroxide to form sodium carbonate and hydrogen. However, the product consists of hydrocarbons such as methane and thus lowers the $\%$ hydrogen yield. Nickel catalysts supported on alumina can reduce the formation of methane and increase the hydrogen yield to roughly $100 \%$ [5-9]. The mechanism of 
alkali promoted steam gasification of biomass indicates that the dehydrogenation of cellulose in presence of $\mathrm{Na}^{+}$and $\mathrm{OH}^{-}$ions yields hydrogen. The concentration of $\mathrm{Na}^{+}$and $\mathrm{OH}^{-}$ions strongly influences the dehydrogenation of cellulose [10-11].

Despite that the sodium hydroxide-promoted reaction provides many advantages; the alkali metal costs and their recycling are major concerns [12] Su et al used a new catalyst derived from sodium aluminum oxide $\left(\mathrm{Al}_{2} \mathrm{O}_{3} \cdot \mathrm{Na}_{2} \mathrm{O}\right), \mathrm{Al}_{2} \mathrm{O}_{3} \cdot \mathrm{Na}_{2} \mathrm{O} \cdot \mathrm{xH}_{2} \mathrm{O} / \mathrm{NaOH} / \mathrm{Al}(\mathrm{OH})_{3}$, to increase the hydrogen content in the product after steam gasification of cellulose. The gasification temperature was kept below $500^{\circ} \mathrm{C}$ to prevent any tar formation [13-14]. Moreover, sodium hydroxide can also significantly decrease the pyrolysis temperature of biomass species [15]. Sodium ion, being small, can penetrate into the biomass texture and break the hydrogen bridges. Consequently, devolatilization occurs rapidly. Thus, it can be seen that sodium hydroxide does play a significant role in biomass gasification.

\subsubsection{Metals}

Metals can react in the presence or absence of water and sodium hydroxide to produce hydrogen. Transition metals form metal oxides and hydrogen during the reaction with sodium hydroxide [16]. Moreover, ferrosilicon when reacts with sodium hydroxide produces sodium silicate and hydrogen [17]. Here, we focus on the Al-NaOH- $\mathrm{H}_{2} \mathrm{O}$ system.

Hydrogen gas is generated from the chemical reaction between $\mathrm{Al}$ and water $\left(3.7 \mathrm{wt} \% \mathrm{H}_{2}\right.$, theoretical yield) [18]. $\mathrm{Al} / \mathrm{H}_{2} \mathrm{O}$ system is indeed a safe method to generate hydrogen. But the system has kinetic limitations as the metal surface passivation in neutral water occurs 
more easily and the metal activity with water is extremely low. Thus, improving the aluminum activity in water is an important task. To solve the problem of surface passivation of aluminum, various solutions have been suggested so far. The solutions either include the addition of hydroxides [19-20] metal oxides [21-22] selected salts [2324] or alloying aluminum with low melting point metal [25-28]. Alkali-promoted $\mathrm{Al} / \mathrm{H}_{2} \mathrm{O}$ system is favored over other metal systems because of high hydrogen generation rate. When the reaction between aluminum and water is assisted by alkali, $\mathrm{OH}^{-}$ions are able to destroy the protective oxide layer on the aluminum surface forming aluminate ions, $\mathrm{AlO}_{2}{ }^{-}$

The reaction between aluminum and water with sodium hydroxide solution produces hydrogen, which can be expressed as follows [3.1.12]

$$
\begin{gathered}
2 \mathrm{Al}+6 \mathrm{H}_{2} \mathrm{O}+\mathrm{NaOH} \rightarrow 2 \mathrm{NaAl}(\mathrm{OH})_{4} \downarrow+3 \mathrm{H}_{2} \uparrow \\
\mathrm{NaAl}(\mathrm{OH})_{4} \rightarrow \mathrm{NaOH}+\mathrm{Al}(\mathrm{OH})_{3} \downarrow
\end{gathered}
$$

Sodium hydroxide consumed for the hydrogen generation in exothermic reaction (3.1.12) will be regenerated through the decomposition of $\mathrm{NaAl}(\mathrm{OH})_{4}$ via reaction (3.1.13). Reaction (3.1.13) also produces a crystalline precipitate of aluminum hydroxide. The combination of above two reactions completes the cycle and shows that only water will be consumed in the whole process if the process is properly monitored. Previous works reported kinetics of the reaction between aluminum and water with sodium hydroxide solution and calculated the activation energy in the range of 42.5-68.4 kJ/mol [29, 30]. 
Several researchers examined the effects of other crucial parameters which control the hydrogen generation behavior for alkali assisted $\mathrm{Al} / \mathrm{H}_{2} \mathrm{O}$ system. The parameters include temperature, alkali concentration, morphology, initial amount of $\mathrm{Al}$; and concentration of aluminate ions [31, 32]. Moreover, Soler et al. compared the hydrogen generation performance of three different hydroxides: $\mathrm{NaOH}, \mathrm{KOH}$ and $\mathrm{Ca}(\mathrm{OH})_{2}$ and found that $\mathrm{NaOH}$ solution consumes aluminum faster compared with other two hydroxides [33]. Interestingly, S.S. Martinez et al. treated Al-can wastes with sodium hydroxide solution at room temperature to generate highly pure hydrogen. The byproduct $\left(\mathrm{NaAl}(\mathrm{OH})_{4}\right)$ was used to prepare a gel of $\mathrm{Al}(\mathrm{OH})_{3}$ to treat drinking water contaminated with arsenic [34]. On the basis of the above mentioned reactions, several patents have been filed in last decade [35-41].

\subsubsection{Water Splitting Thermochemical Cycle}

Solar energy is used to produce hydrogen via 2 or 3 steps water splitting process. It should be noted that water is not directly split in hydrogen and oxygen using this technology solution. But there is a series of chemical reactions which utilizes oxides and thermal energy from renewable sources (such as solar energy) that can convert water into stoichiometric amounts of hydrogen and oxygen [42-43]. The water splitting thermochemical cycle is demonstrated in Figure 3.1.4. The figure demonstrates a 3 step water splitting process $-(1)$ reduction of oxides (energy intensive process, $800-1000^{\circ} \mathrm{C}$ ) (2) reaction of reduced oxide with sodium hydroxide (hydrogen generation step) and (3) hydrolysis reaction (sodium hydroxide recovery step). 
Any thermodynamically favorable oxide can be selected and use to generate hydrogen. Thus, so far, a large number of oxides have been considered. The water splitting thermochemical cycle reactions can be mainly classified as (1) 2- step water splitting [4448] (2) iodine-sulfur process [49-51] and (3) calcium-bromine process [52-54].

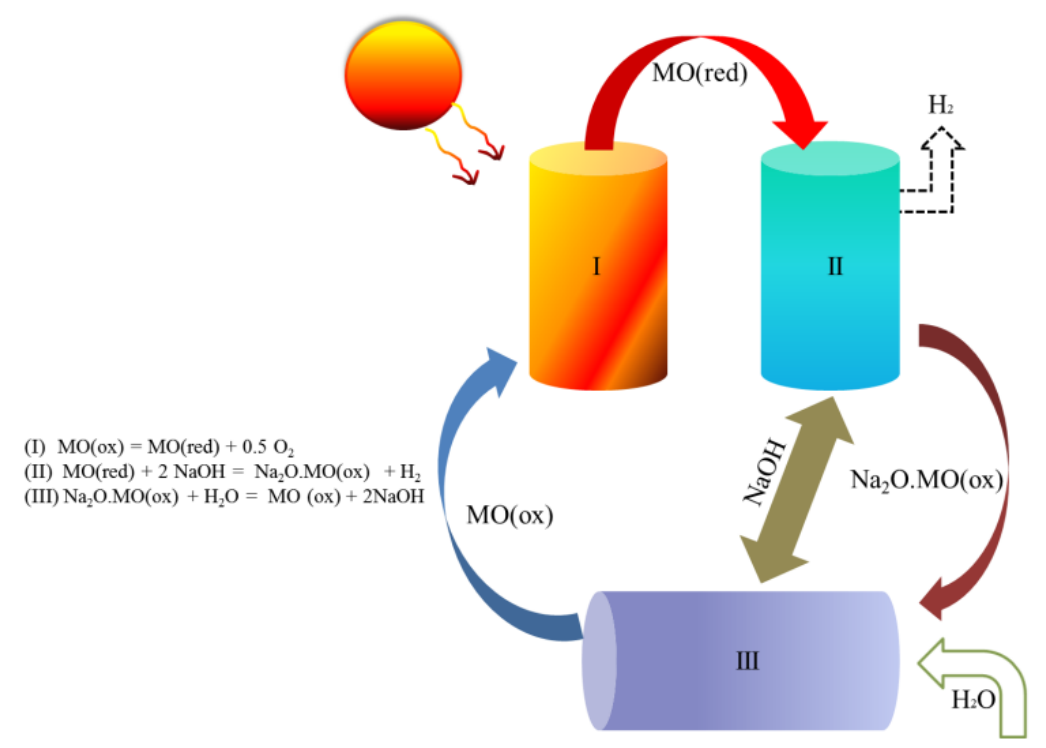

Figure 3.1.4 Schematic for Water Splitting Thermochemical Cycle $(\mathrm{MO}=$ metal oxide $)$

Here, we focus only on alkali metal assisted water splitting thermochemical cycles and summary of the previous experimental results can be found elsewhere [55]. The presence of sodium hydroxide is able to reduce the hydrogen generation reaction temperature. Recently, Miyoka et al considered sodium redox reaction and conducted several experiments in a non-equilibrium condition but could not achieve a $100 \%$ conversion [56]. It was attributed to the slow kinetics of both the hydrogen generation reaction and sodium recovery. Moreover, sodium hydroxide facilitates oxidation in the water splitting step. But the volatility of sodium hydroxide at temperature higher than $800^{\circ} \mathrm{C}$ and incomplete $\mathrm{Na}^{+}$extraction by water to recover sodium hydroxide limits its application. 
Several research groups concluded that even though sodium or sodium hydroxide assisted reaction has major advantages; their recovery could be a big challenge. Interestingly, Weimer et al recommends membrane separation to recover sodium hydroxide [57]. Few researcher groups also pointed out the possibility of using sodium carbonate rather than sodium hydroxide $[58,60]$.

Besides sodium hydroxide recovery, there are other limitations too. For instance, the reduction of oxides requires a very high temperature. If such a high temperature will be provided by the solar energy, a large scale solar heat plant is needed. Thus at present, the construction of thermochemical hydrogen production plants is restricted by the location, cost and safety issues. Therefore, the major challenge is to lower the operating temperature of water splitting process. A low temperature water splitting process will allow the utilization of small-scale solar heat systems or even exhaust heat from industries. As sodium hydroxide can significantly reduce the operating temperature of the water splitting process, hence sodium hydroxide has a major role to play.

\subsubsection{Organic Compounds}

\section{(a) Formic acid ( $\mathrm{HCOOH})$}

Formic acid and its solution are industrial hazards. Any use of such chemical waste will be of a great advantage. Formic acid is considered for both hydrogen production and storage. Basically, formic acid can produce hydrogen using two methods: (1) Thermo catalytic decomposition and (2) Electrolysis in presence of sodium hydroxide. 
Formic acid thermally decomposes to produce hydrogen and carbon dioxide $\left(\Delta \mathrm{G}^{\circ}=-32.9\right.$ $\mathrm{kJ} / \mathrm{mol}, \Delta \mathrm{H}^{\circ}=31.2 \mathrm{~kJ} / \mathrm{mol}$ ), which is actually the reversible reaction of carbon dioxide hydrogenation [61-69]. Electrolysis of formic acid solutions in the presence of sodium hydroxide requires theoretically much lower energy than water [70]. Hence, use of formic acid solution to generate hydrogen will have double benefits of tackling pollution and generating clean energy. The electrochemical reaction for the electrolysis of formic acid solutions is as follows [71]:

$$
\begin{aligned}
& \text { Anode: } \mathrm{HCOOH}+\mathrm{OH}^{-} \rightarrow \mathrm{CO}_{2}+\mathrm{H}_{2} \mathrm{O}+2 \mathrm{e}^{-} \\
& \text {Cathode: } 2 \mathrm{H}_{2} \mathrm{O} \quad+2 \mathrm{e}^{-} \rightarrow \mathrm{H}_{2}+2 \mathrm{OH}^{-} \\
& \text {Overall reaction: } \mathrm{HCOOH} \quad \rightarrow \quad \mathrm{H}_{2}+\mathrm{CO}_{2}
\end{aligned}
$$

Figure 3.1.5 demonstrates the scheme of electricity generation via the combined use of alkaline hydroxide (sodium hydroxide) for the electrolysis of formic acid ( $\mathrm{HCOOH})$ and fuel cell. The separation of hydrogen and carbon dioxide is desired prior to injection in the fuel cell.

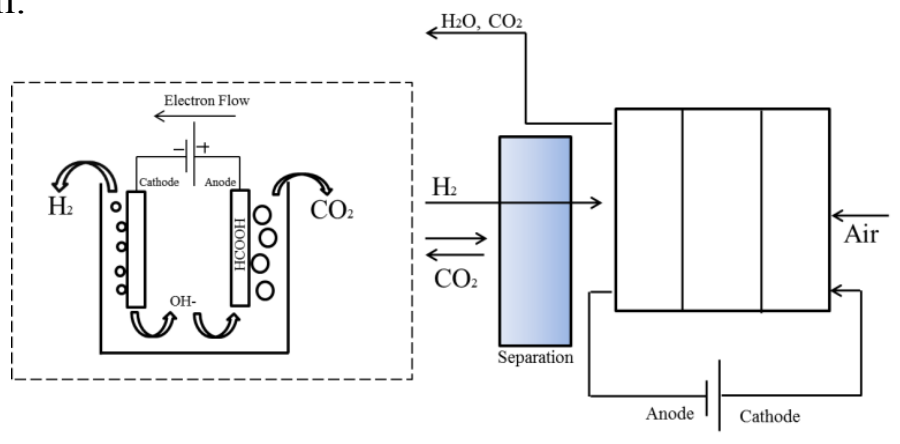

Fuel Cell

Figure 3.1.5 Electricity generation using alkaline hydroxide $(\mathrm{NaOH})$ for the electrolysis of $\mathrm{HCOOH}$ 


\section{(b) Formaldehyde (HCHO)}

An aqueous solution of formaldehyde when mixed with sodium hydroxide produces very small amount of hydrogen [72]. Thus, it is obvious that hydrogen evolution competes with the disproportionation of formaldehyde to corresponding alcohol and acid [73, 74]. Further, Ashby et al proposed a mechanistic explanation of hydrogen evolution from formaldehyde in the presence of sodium hydroxide [75].The mechanism indicates that one hydrogen atom originates from the water and the other from the organic moiety. The experimental study exhibits that when a dilute solution of formaldehyde $\left(4 \times 10^{-4} \mathrm{M}\right)$ reacts with concentrated sodium hydroxide (19M) at room temperature, hydrogen is produced in a significant amount. However, concentrated solution of formaldehyde when interacts with dilute sodium hydroxide solution produces only a trace amount of hydrogen.

When solution of hydrogen peroxide is mixed with formaldehyde in presence of sodium hydroxide, hydrogen is generated [76]. Hydrogen peroxide oxidizes formaldehyde to formic acid and sodium hydroxide further neutralizes the acid.

$$
\mathrm{H}_{2} \mathrm{O}_{2}+2 \mathrm{HCHO}+2 \mathrm{NaOH}=2 \mathrm{HCOONa}+\mathrm{H}_{2}+2 \mathrm{H}_{2} \mathrm{O}
$$

However, no trace of hydrogen is observed in the absence of sodium hydroxide [77-79]. The reaction (3.1.15) is limited by slow kinetics and requires a large excess of alkali hydroxide. When hydrogen peroxide is replaced by cuprous oxide, hydrogen is generated in a quantitative amount. 


\subsubsection{Conclusion}

The use of sodium hydroxide for hydrogen production is justified by the high reaction rate, lower operating temperature and overall reduction in carbon dioxide emission. Depending on the reaction and its conditions, sodium can produce or store hydrogen. Moreover, several situations illustrate how sodium hydroxide binds with carbon dioxide and forms valuable chemical compound, $\mathrm{Na}_{2} \mathrm{CO}_{3}$.

However, a major limitation for the inclusion of sodium hydroxide as one of the primary ingredients for generating hydrogen is the production route of sodium hydroxide itself. At present, energy intensive process (electrolysis of brine) is the prime method to produce sodium hydroxide.

In the following sections, sodium hydroxide is included as a reactant in major fossil fuels based hydrogen producing technologies is explained. 


\subsubsection{References}

[1] R.F. Probstein, R.E. Hicks, Synthetic fuels, 3rd ed. New York: Dover Publications, 2006.

[2] M.C. Boswell, J.V. Dickson, Journal of the American Chemical Society, 1918, 40, $1779-1786$.

[3] S. K. Saxena, V. Drozd, A. Durygin, International Journal of Hydrogen Energy, 2008, 33, 3625-3631.

[4] M. Ishida, S. Takenaka, I. Yamanaka, K. Otsuka, Energy \& Fuels, 2006, 20, 748-753.

[5] T. Minowa, Z. Fang, Journal of Chemical Engineering of Japan, 1998, 31,488-491.

[6] T. Minowa, Z. Fang, T. Ogi, G. Varhegyi, Journal of Chemical Engineering of Japan, 1998, 31,131-134.

[7] R. Muangrat, J.A. Onwudili, P.T. Williams, International Journal of Hydrogen Energy, 2010, 35, 7405-7415.

[8] J.A. Onwudili, P.T. Williams, International Journal of Hydrogen Energy, 2009, 34, 5645-5656.

[9] S. Su, W. Li, Z. Bai, H. Xiang, J. Bai, International Journal of Hydrogen Energy, 2010, 35, 4459-4465.

[10] R. Muangrat, J.A. Onwudili, P.T. Williams, Applied Catalysis B: Environmental. 2010, 100, 440-449

[11] M. Ishida, K. Otsuka, S. Takenaka, I. Yamanaka, Journal of Chemical Technology and Biotechnology, 2005, 80, 281-284.

[12] S. Su, W. Li, Z. Bai, H. Xiang, International Journal of Hydrogen Energy, 2008, 33, 6947-6952.

[13] S. Su, W. Li, Z. Bai, H. Xiang, J. Bai, Journal of Fuel Chemistry \& Technology, 2010, 38, 270-274.

[14] J. Wang, M. Zhang, M. Chen, F. Min, S. Zhang, Z. Ren, Y. Yan, Thermochimica Acta, 2006, 444, 110-114.

[15] D. D. Williams, J.A. Grand, R.R. Miller, Journal of the American Chemical Society, 1956, 78, 5150-5155.

[16] Annual Report National Advisory Committee for aeronautics.Washigton,DC:1934. 
[17] H.Z. Wang, D.Y.C. Leung, M.K.H. Leung, M. Ni, Renewable and Sustainable Energy Reviews, 2009, 13, 845-853.

[18] D. Belitskus, Journal of the Electrochemical Society, 1970, 117, 1097-1099.

[19] C.R. Jung, A. Kundu, B. Ku, J.H. Gil, H.R. Lee, J.H. Jang, Journal of Power Sources, 2008, 175, 490-494.

[20] Z.Y. Deng, Y.B. Tang, L.L. Zhu, Y. Sakka, J. Ye, International Journal of Hydrogen Energy, 2010, 35, 9561-9568.

[21] P. Dupiano, D. Stamatis, E.L. Dreizin, International Journal of Hydrogen Energy, 2011, 36, 4781-4791.

[22] J. Skrovan, A. Alfantazi, T. Troczynski, Journal of Applied Electrochemistry, 2009, $39,1695-1702$.

[23] L. Soler, J. Macana's, M. Muñz, J. Casado, Proceedings of International Hydrogen Energy. Congress and Exhibition IHEC, Istanbul, Turkey, 2005

[24] W. Wang, D.M. Chen,K. Yang, International Journal of Hydrogen Energy, 2010, $35,12011-12019$.

[25] J.T. Ziebarth , J.M. Woodall, R.A. Kramer, G. Choi, International Journal of Hydrogen Energy, 2011, 36,5271-5279.

[26] M.Q. Fan, F. Xu, L.X. Sun, Energy \& Fuels, 2007, 21, 2294-2298.

[27] A.V. Ilyukhina, O.V. Kravchenk, B.M. Bulychev, E.I. Shkolnikov, International Journal of Hydrogen Energy, 2010, 35,1905-1910.

[28] Y.A. Aleksandrov, E.I. Tsyganova, A.L. Pisarev Russian Journal of General Chemistry, 2003, 73, 689-694.

[29] A.Z. Zhuk, A.E. Sheindlin, B.V. Kleymenov, Journal of Power Sources, 2006, 157, 921-926.

[30] D. Stockburger, J.H. Stannard, B.M.L. Rao, W. Kobasz, C.D. Tuck, Proceedings \& Symposium on the Hydrogen Storage Materials, Batteries \& Electrochemistry, 1992, $92,431-444$

[31] L. Soler, J. Macana's, M. Muño, J. Casado, Journal of Power Sources, 2007, $169,144-149$.

[32] S.S. Martı'nez, W.L. Benı'tesa, A. Gallegosa, P.J. Sebastia'n, Solar Energy Materials \& Solar Cells, 2005, 88, 237-243. 
[33] G.F. Brindley, US Patent 909536, 1909.

[34] G.F. Brindley, M. Bennie, US Patent 934036, 1909.

[35] G.C. Gill, US Patent 2721789, 1955.

[36] J.H. Checketts, US Patent 5728464, 1998.

[37] J.H. Checkettes , US Patent 5817157, 1998.

[38] E.R. Andersen, E.J. Andersen, US Patent 6506360, 2003

[39] E.R. Andersen, E.J. Andersen, US Patent 2003/0118505 A1, 2003.

[40] E.R. Andersen, US Patent 2004/0115125 A1, 2004.

[41] S.A. Yalc, International Journal of Hydrogen Energy, 1989, 14, 551-561.

[42] S. Abanades, P. Charvin, G. Flamant, P. Neveu, Energy, 2006, 31, 2805-2822.

[43] J.D. Holladay, J. Hu, D.L. King, Y. Wang, Catalysis Today, 2009, 139,244-260.

[44] T. Nakamura, Solar Energy, 1977, 19, 467-475.

[45] F. Sibieude, M. Ducarroir, A. Tofighi, J. Ambriz, International Journal of Hydrogen Energy, 1982, 7, 79-88.

[46] J.J. Ambriz, M. Ducarroir, F. Sibieude, International Journal of Hydrogen Energy, 1982, 7,143-153

[47] A. Weidenkaff, A. Steinfeld, A. Wokaun, P.O. Auer, B. Eichler, A. Reller, Solar Energy, 1999, 65,59-69.

[48] M. Lundberg, International Journal of Hydrogen Energy, 1993, 18,369-376.

[49] D. O’Keefe, C. Allen, G. Besenbruch, L. Brown, J. Norman, R. Sharp, International Journal of Hydrogen Energy, 1982, 7,381-392

[50] M. Sakurai, H. Nakajima, R. Amir, K. Onuki, S. Shimizu, International Journal of Hydrogen Energy, 2000, 25,613-619.

[51] S. Kubo, H. Nakajima, S. Kasahara, S. Higashi, T. Masaki, H.A. Abe, Nuclear Engineering \& Design, 2004, 233, 347-354.

[52] H. Kameyama, K. Yoshida, International Journal of Hydrogen Energy, 1981, 6, $567-575$. 
[53] H. Kameyama, Y. Tomino, T. Sato, R. Amir, A. Orihara, M. Aihara, International Journal of Hydrogen Energy, 1989, 14, 323-330

[54] M. Sakurai, E. Bilgen, A. Tsutsumi, K. Yoshida, International Journal of Hydrogen Energy, 1996, 21, 865-70.

[55] S. Kumar, S. K. Saxena, Materials and processes for energy: communicating current research and technological developments, Ed. A. Mendez-Vilas, Formatex Research Center (Badajoz, Spain), 2013, In Press.

[56] H. Miyoka, T. Ichikawa, N. Nakamura, Y. Kojima, International Journal of Hydrogen Energy, 2012, 37, 17709-17714.

[57] A. Weimer, H2A analysis for Manganese oxide based solar thermal water splitting cycle. University of Colorado, STCH, 2008.

[58] Y. Tamura, A. Steinfeld, P. Kuhn, K. Ehrensberger, Energy, 1995, 20,325-330.

[59] M. Sturzenegger, J. Ganz, P. Nüesch, T. Schelling, Journal de Physique archives, 1999, 09, Pr3-331-Pr3-335

[60] B. Xu, Y. Bhawe, M.E. Davis, Proceedings of the National Academy of Sciences, 2012, 109, 9260-9264.

[61] P.B. Kreider, H.H. Funke, K. Cuche, M. Schmidt, A. Steinfeld , A.W. Weimer, International Journal of Hydrogen Energy, 2011, 36, 7028-7037

[62] P. Charvin, S. Abanades, E. Beche, F. Lemont, G. Flamant, Solid State Ionics, 2009, $180,1003-1010$.

[63] W. Leitner, E. Dinjus, F. Gaßner, Journal of Organometallic Chemistry, 1994, 475, $257-266$.

[64] R.S. Coffey, Chemical Communications, 1967, 18: 923b-924.

[65] T. Yoshida, Y. Ueda, S. Otsuka, Journal of the American Chemical Society, 1978, $100,3941-3942$.

[66] R.S. Paonessa, W.C. Trogler, Journal of the American Chemical Society, 1982, 104, $3529-3530$.

[67] I. Joszai, F. Joo, Journal of Molecular Catalysis A: Chemical, 2004, 224: 87-91.

[68] Y. Gao, J.K. Kuncheria, G.P.A. Yap, R.J. Puddephatt, Chemical Communications, 1998, 21,2365 - 2366. 
[69] J.H. Shin, D.G. Churchill, G. Parkin, Journal of Organometallic Chemistry, 2002, $642,9-15$.

[70] B. Loges, A. Boddien, F. Gartner, H. Junge, M. Beller, Topics in Catalysis, 2010, $53,902-914$.

[71] S. Fukuzumi, T. Suenobu, S. Ogo, US Patent application no US2010/ 0034733 A1

[72] W.L. Guo, L. Li, L.L. Li, S. Tian, S.L. Liu,Y.P. Wu, International Journal of Hydrogen Energy, 2011, 36, 9415-9419

[73] A. Majewski, D.J. Morris, K. Kendall, M.A. Wills, ChemSusChem, 2010, 3, 431434.

[74] O. Loew, Berichte der deutschen chemischen Gesellscha, 1887, 20, 144-145.

[75] E.C. Ashby, F. Doctorovich, C.L. Liotta, H.M. Neumann, E.K. Barefield, A. Konda , K. Zhang, J. Hurley, D.D. Siemer, Journal of the American Chemical Society, 1993, 115, 1171-1173.

[76] M.F. Ansell, S. Coffey, E.H. Rodd, Rodd's Chemistry of Carbon Compounds.2nd ed. Amesterdam, Elsiever, 1965.

[77] S. Kapoor, S. Naumov, Chemical Physics Letters, 2004, 387, 322-326.

[78] A. Harden, Journal of the Society of Chemical Indusry, 1899, 15, 158-159.

[79] C.N. Satterfield, R.E. Wilson, R.M. LeClair, R.C. Reid, Analytical Chemistry, 1954, 26, $1792-1797$. 


\subsection{MODIFIED STEAM-METHANE-REFORMATION (MSMR)}

\subsubsection{Introduction}

A major problem in using hydrogen for transportation is the use of the SMR technique [1] for hydrogen production. This technique causes a large carbon emission and requires metal-based catalysis. There are several proposed methods being currently under study to solve this problem [2-6]. In this chapter, steam-methane-reformation is modified using sodium hydroxide, producing hydrogen with zero carbon emission. The purpose of this chapter is to show that production of hydrogen with zero emission could be a very profitable business. Once this problem is solved, the technology already exists which can use hydrogen as a fuel-carrier in many applications.

\section{The Steam-methane reformation}

The cheapest and most common method of producing commercial bulk hydrogen as well as the hydrogen used in the industrial synthesis of ammonia is considered to be the one involving the reactions at high temperatures $\left(700-1100^{\circ} \mathrm{C}\right)$ and in the presence of a metal-based catalyst (nickel). Steam reacts with methane to yield carbon monoxide and hydrogen:

$$
\mathrm{CH}_{4}+\mathrm{H}_{2} \mathrm{O} \rightarrow \mathrm{CO}+3 \mathrm{H}_{2} \text { (endothermic, requires heat) }
$$

Additional hydrogen can be recovered by a lower-temperature gas-shift reaction with the carbon monoxide produced. The reaction is:

$$
\mathrm{CO}+\mathrm{H}_{2} \mathrm{O} \rightarrow \mathrm{CO}_{2}+\mathrm{H}_{2} \text { (exothermic, produces heat) }
$$


The United States produces nine million tons of hydrogen per year, mostly with steam reforming of natural gas.

\section{The modified reaction}

The modified reaction is as follows:

$$
\mathrm{CH}_{4}+2 \mathrm{NaOH}+\mathrm{H}_{2} \mathrm{O}=\mathrm{Na}_{2} \mathrm{CO}_{3}+4 \mathrm{H}_{2}
$$

A comparison of the standard SMR reaction and the modified reaction is shown in Fig.3.2.1a and 3.2.1b. These thermodynamic calculations as well as the experiments conducted [7] show clearly that a) the modified reaction proceeds at lower temperatures and b) the metal-based catalysis is not required. The total energy requirement for the combined SMR and gas-shift reactions for the complete reaction (maximum hydrogen production) is $430 \mathrm{~kJ} / \mathrm{mol}$ of methane (at $1200 \mathrm{~K}$ ) versus $244 \mathrm{~kJ}$ (at $700 \mathrm{~K}$ ) for the modified reaction.

(a)

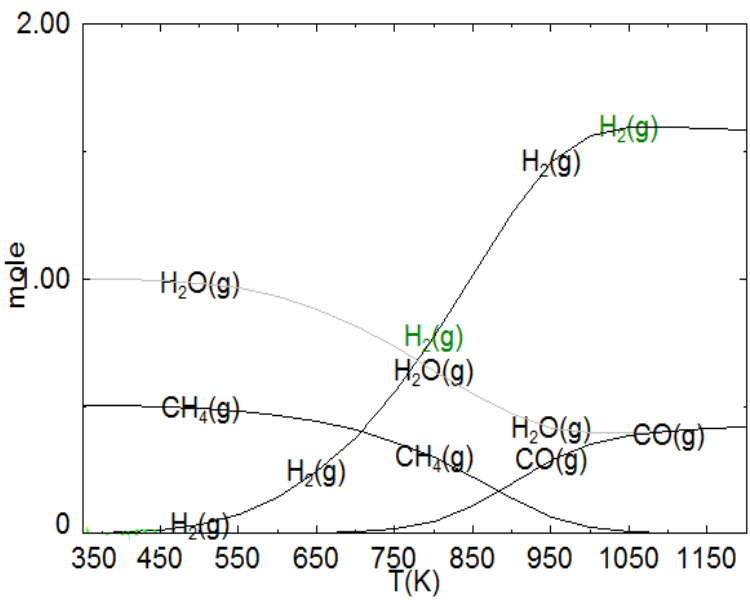

(b) $.5 \mathrm{CH} 4+.5 \mathrm{H} 2 \mathrm{O}+\mathrm{NaOH}$

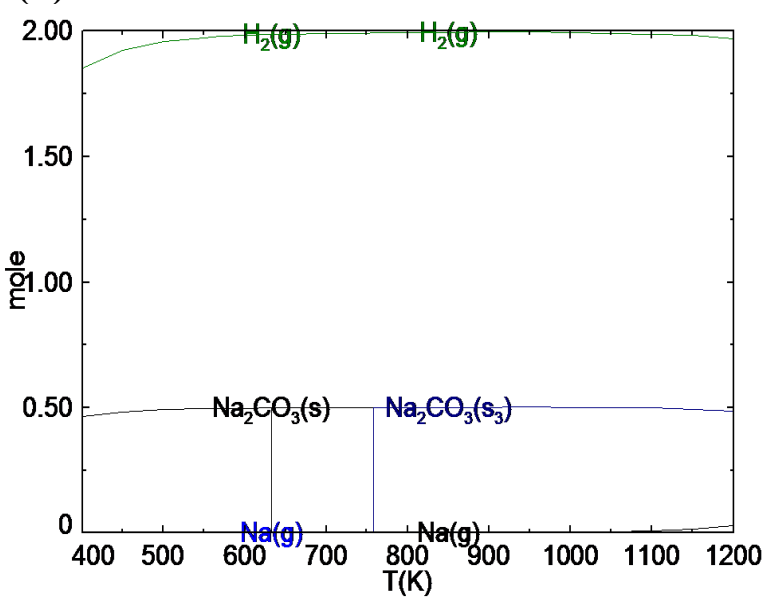

Figure 3.2.1 (a) equilibrium in the system methane-water and (b) when modified by addition of sodium hydroxide 
The result of modifying the SMR reaction by introducing sodium hydroxide is presented. Further, the possibility of reducing the temperature by catalysis is checked. Variously sized nickel powder is used to demonstrate the effect on temperature.

\subsubsection{Experimental Section}

The reaction:

$$
2 \mathrm{NaOH}(\mathrm{s})+\mathrm{CH}_{4}(\mathrm{~g})+\mathrm{H}_{2} \mathrm{O}(\mathrm{g}) \rightarrow \mathrm{Na}_{2} \mathrm{CO}_{3}(\mathrm{~s})+4 \mathrm{H}_{2}(\mathrm{~g})
$$

was studied experimentally. Anhydrous Sodium hydroxide was supplied by SigmaAldrich with a purity of $98 \%$. About 0.1 gm of sodium hydroxide was dissolved using a minimal amount of distilled water in an alumina boat and then this crucible was put in a tubular furnace with an alumina tube. Once the required temperature was attained, the flow rate of nitrogen gas was decreased from $50 \mathrm{ml} / \mathrm{min}$ to zero and the methane gas was fed at a few different rates.

Initially, the formation of carbonate was studied at 600,700 and $800^{\circ} \mathrm{C}$. At each temperature the reaction was carried out for 30 minutes fixed time with the methane flow varying between 10 to $25 \mathrm{ml} / \mathrm{min}$. Further, the effect of catalysts was determined keeping constant flow rate of methane $(25 \mathrm{ml} / \mathrm{min})$. Nickel Powder $(2-5 \mu \mathrm{m})$ with a purity of 99.99\% was delivered by Aldrich and used as a catalyst for this reaction. This catalytic behavior was also studied for different sizes of nickel powder produced by ball milling. Nickel is of a low cost, high activity and widely employed catalyst for the industrial application [8]. Various studies have been done so far which use nickel and support it as a catalyst which resulted in a better performance of SMR reaction [9-12]. Methane 
dissociates at nickel surface and enhances \% efficiency. The nickel powder is homogenously mixed with $\mathrm{NaOH}$ which is spread in a thin layer. On melting, the powder will spread with nickel distributed evenly.

The determination of the amount of soda formed during the reaction was performed by titrating the product against $0.1009 \mathrm{~N}$ volumetric standard solution of Nitric acid (Aldrich). The products of reaction were analyzed by powder X-ray diffraction using Bruker GADDS/D8 X-ray system with Apex Smart CCD Detector and Mo Ka-radiation. Ball milling of a catalyst was performed using planetary Retsch PM100 ball mill.

\subsubsection{Results and Discussion}

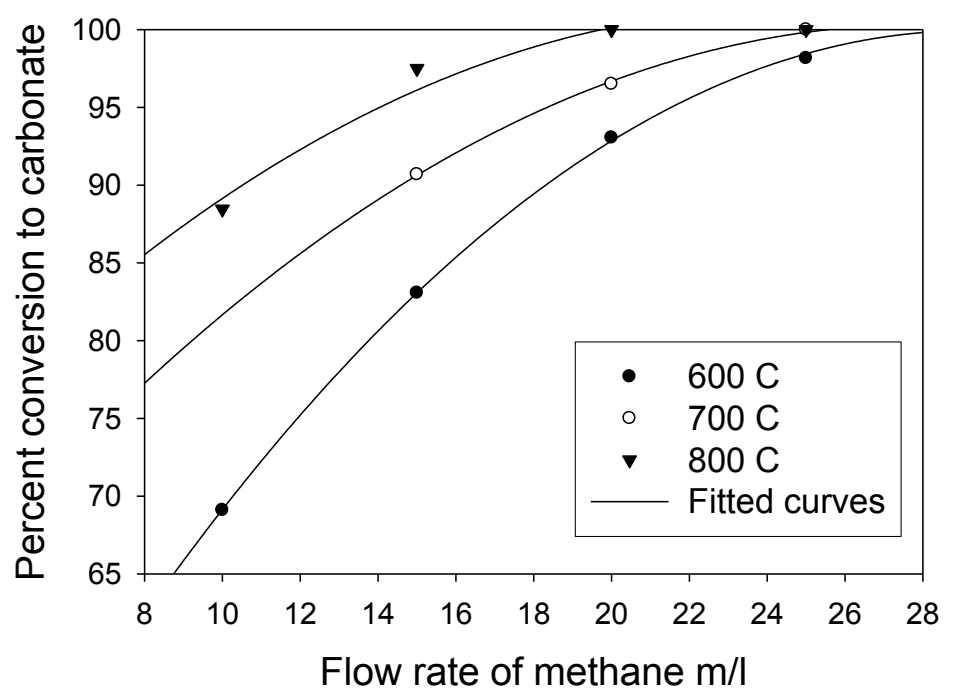

Figure 3.2.2 Results relating the formation of sodium carbonate as a function of the methane flow. In 30 minutes, the reaction in an open system is completed at any temperature above $600^{\circ} \mathrm{C}$. One data point at $700^{\circ} \mathrm{C}$ was not included in the fitting procedure. 
The results are shown in Fig.3.2.2. There is one anomalous point at $700^{\circ} \mathrm{C}$ which was not included in the regression analysis which gives us the following equation

$\%$ yield $=28.772+4.868 b-0.083 b^{2}\left(r^{2}=0.9997\right)$

The good fit shows the internal consistency of the results.

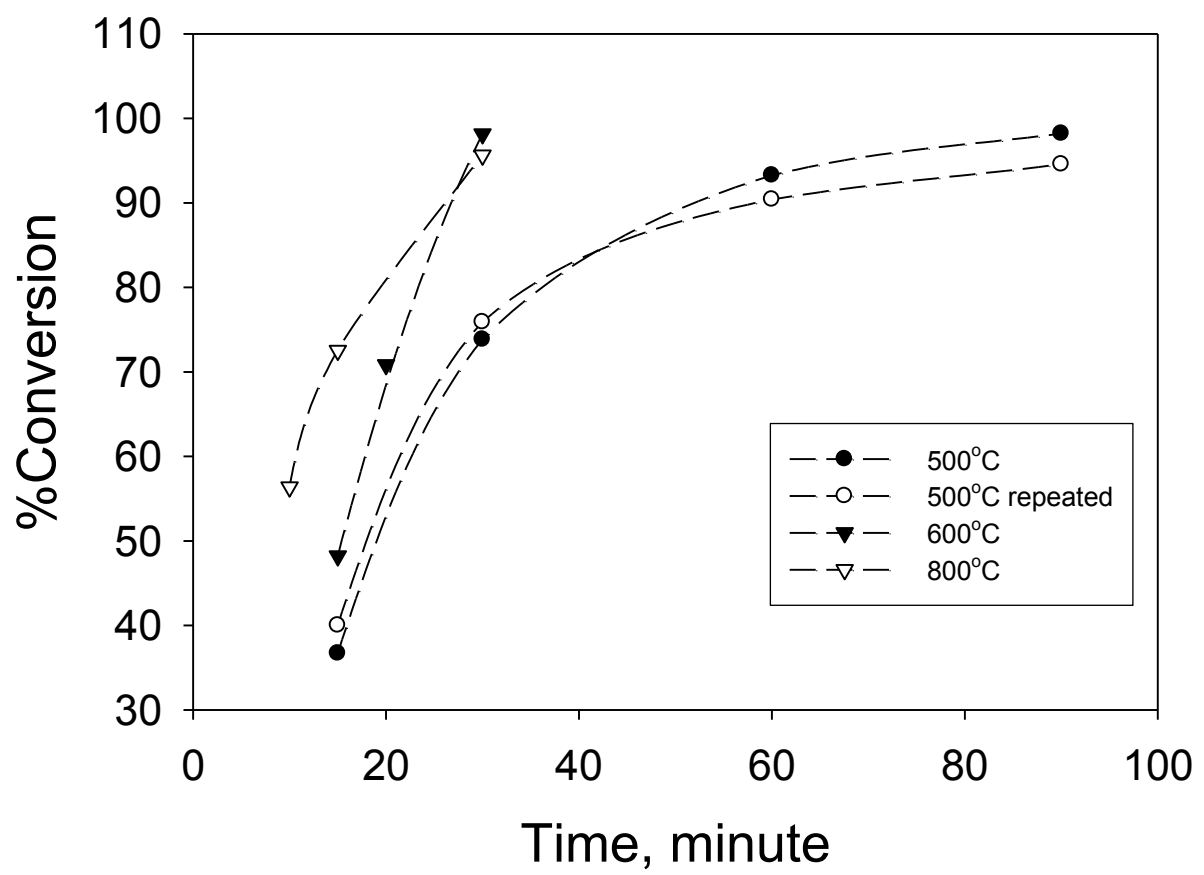

Figure 3.2.3. The data on $\%$ conversion of $\mathrm{NaOH}$ to $\mathrm{Na}_{2} \mathrm{CO}_{3}$ as a function of temperature and time for $25 \mathrm{ml} / \mathrm{min}$ methane flow rate. An estimate of error is provided by the repeated experiment at $500^{\circ} \mathrm{C}$. The curves are smoothed spline fit to show the trends. No catalyst was used.

Fig.3.2.3 shows the $\%$ amount of soda formed from the initial sodium hydroxide at temperatures of 500,600 and $800^{\circ} \mathrm{C}$. The estimated error is around $5 \%$ as may be judged from the repeated results at $500^{\circ} \mathrm{C}$. In 30 minutes, the reaction is essentially complete at 
$600^{\circ} \mathrm{C}$ without using any metal catalyst. According to X-ray diffraction study, the product of complete reaction is decahydrate of sodium carbonate, $\mathrm{Na}_{2} \mathrm{CO}_{3} \cdot 10 \mathrm{H}_{2} \mathrm{O}$.

In 1918, P. Sherrer explained that when parallel monochromatic radiation falls on a random oriented mass of crystals, the diffracted beam is broadened when the particle size is small. The two major informations that can be obtained from peak width analysis are crystallite size and lattice strain. Here, crystallite size of the catalysts is determined. Crystallite size represents the size of coherently diffracting domain. Due to the presence of polycrystalline aggregates, crystallite size is generally not the same as of particle size.

The diffraction patterns from the different ball milled catalysts have been observed based on Bragg's law $n \lambda=2 \mathrm{~d} \sin \theta$, where $\mathrm{n}$ is an integer, $\lambda$ is the wavelength of Mo $\mathrm{K}_{\alpha 1}$ radiation, $\mathrm{d}$ is inter planar spacing and $\theta$ is the diffraction angle. The output from the $\mathrm{X}$ ray analysis of these catalysts yields various plots of intensity versus angle of diffraction.

The evaluation of XRD peak broadening inherently adds error due to the instrument interference. Therefore, it is necessary to eliminate this problem. To do so, it is customary to collect a diffraction pattern from the line broadening of a standard material such as $\mathrm{LaB}_{6}$ to determine the instrumental broadening.

The Scherrer equation explains the relationship between mean crystallite size and diffraction line breadth. The equation that was employed here is

$$
D=0.9 \lambda /(\beta-\beta 0) \operatorname{Cos} \theta
$$

Where, $\lambda=$ wavelength of X-ray (Mo K $\alpha=0.71073 \AA$ ) 


$$
\begin{aligned}
& \beta=\text { breadth at half maximum intensity of a peak } \\
& \beta_{0}=\text { breadth at half maximum intensity of highly crystalline material }\left(\mathrm{LaB}_{6}\right) \\
& \theta=\text { Bragg angle, half of the spectrometer angle }
\end{aligned}
$$

The calculated crystallite size of different catalysts is reported in Table 3.2.1.

\begin{tabular}{|c|c|c|c|c|}
\hline Crystallite Size & Raw & $2 \mathrm{~h}$ & $3 \mathrm{~h}$ & $4 \mathrm{~h}$ \\
\hline$(\AA)$ & 304.8 & 265.7 & 239.9 & 184.7 \\
\hline
\end{tabular}

Table 3.2.1 Crystallite size for variously milled nickel catalysts

The result shows that prolonged ball milling time has generated much lower crystallite size and thus increased specific surface area for the catalysts. $4 \mathrm{~h}$ ball milled nickel has the minimum crystallite size and therefore maximum specific surface area. However, its catalytic activity is the lowest. The reason could be the agglomeration of particles that happened at prolonged ball milling. This causes the reduction in the effective surface area exposed for gas adsorption onto the catalytic material.

Fig.3.2.4 shows the distribution of particle size for different catalysts. The Gaussian fitted graph to the chart clarifies that the average particle size increases from 3-4 micron (for raw nickel) to 33-38 micron (for $4 \mathrm{~h}$ ball milled nickel). Referring to SEM image of the catalysts (Fig.3.2.9), it clearly shows that the platelets at $2 \mathrm{~h}$ ball milling time grew larger as the ball milling time progressed. 
(a)

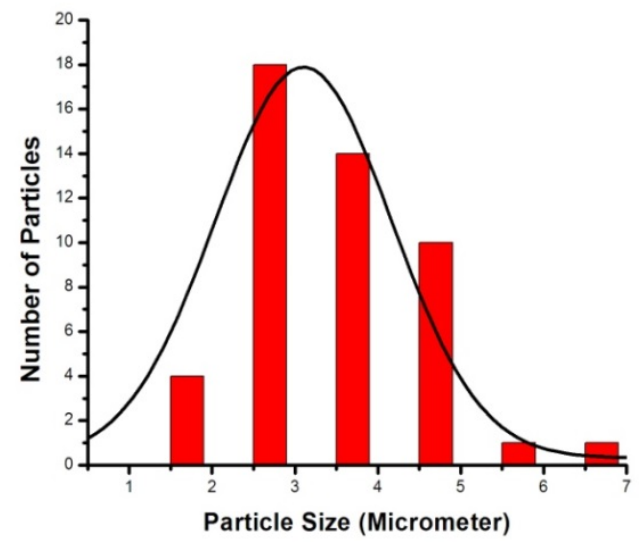

(c)

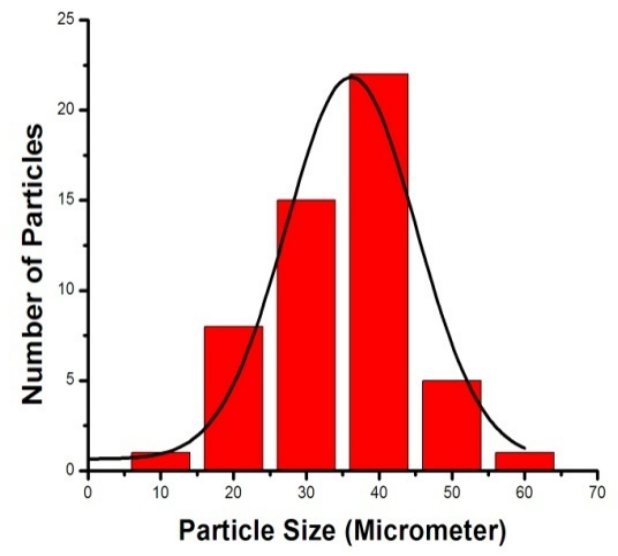

(b)

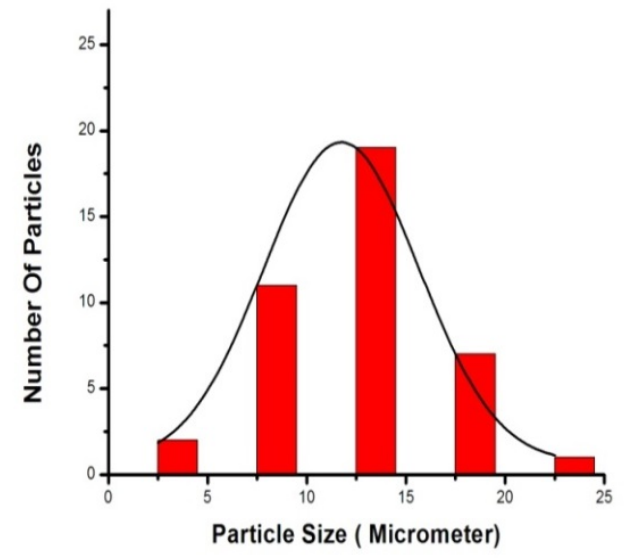

(d)

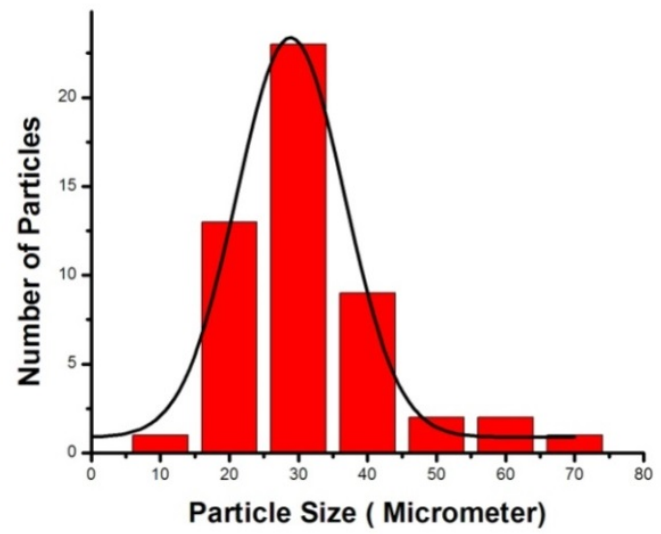

Figure 3.2.4 Nickel particle size distribution for (a) Raw (b) $2 \mathrm{~h}$ ball milled (c) $3 \mathrm{~h}$ ball milled (d) $4 \mathrm{~h}$ ball milled 
X-ray diffraction study of the different sized nickel revealed the absence of any oxide peaks of nickel. Nickel was observed un-oxidized for any ball milling duration. In Fig.3.2.5, the peak width broadened as time of milling was increased. So, the observation of smaller crystallite size at higher ball milling time seemed to be in congruency with the X-ray results.

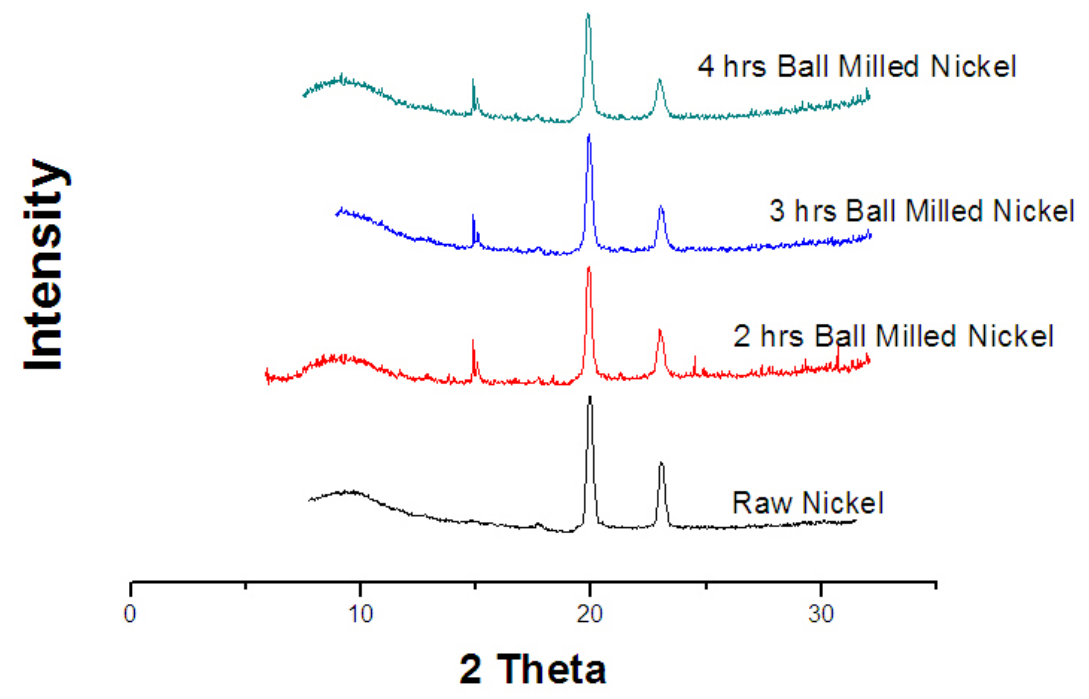

Figure 3.2.5 X-ray diffraction patterns for different time ball milled nickel catalysts

While the result in Fig.3.2.6 shows substantial improvement over the unmodified SMR reaction, we decided to study the effect of catalysis on the reaction using variously ball milled nickel catalyst. Nickel was used as 3 wt. \% of the initial amount of sodium hydroxide. Different size of nickel was considered. 


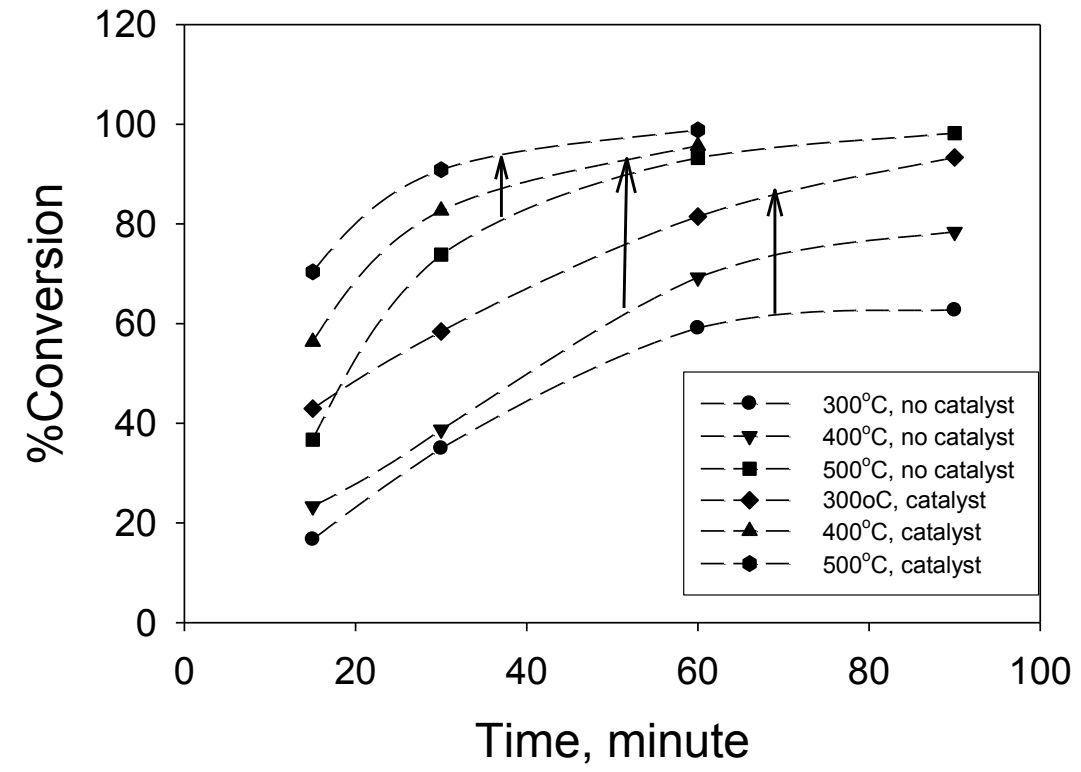

Figure 3.2.6 Effect of using $2 \mathrm{~h}$ ball milled nickel catalyst. The arrows show the significant change in the conversion amount for a given time

Fig.3.2.6 shows a comparison of the ball milled results with the data when no catalyst was used. As can be seen from the figure that there is a substantial effect of the ball milled catalyst on the carbonation reaction. This effect is most pronounced at lower temperature, where the conversion increases by close to $30 \%$ (Fig.3.2.7). But the effect decreases with temperature such that the conversion in 30 minutes is $100 \%$ complete between 500 to $550^{\circ} \mathrm{C}$ for the catalyzed sample whereas it takes only $600^{\circ} \mathrm{C}$ for the sample without catalysis (Fig.3.2.7). 


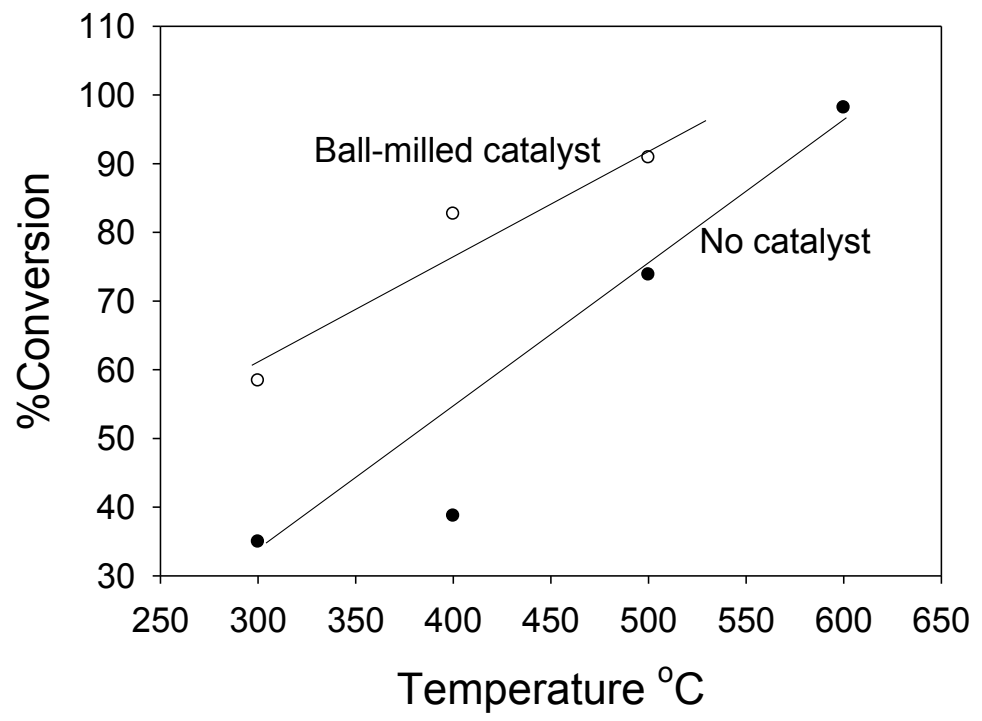

Figure 3.2.7. The experimental data on a sample with catalysis and without for 30 minutes between 300 to $600^{\circ} \mathrm{C}$

In the experiments as described above, ball milled nickel for $2 \mathrm{~h}$ was used. The effect of the duration of ball milling on the catalyst and resulting conversion is shown in Fig. 3.2.8. Four cases are compared, one with no catalyst, second with un-ball-milled catalyst, third and fourth with the catalyst ball-milled for 2 and $4 \mathrm{~h}$ respectively. It appears that ball-milling beyond $2 \mathrm{~h}$ leads to a decatalytic effect as may be noted from the data on the sample with $4 \mathrm{~h}$ ball milled nickel. 


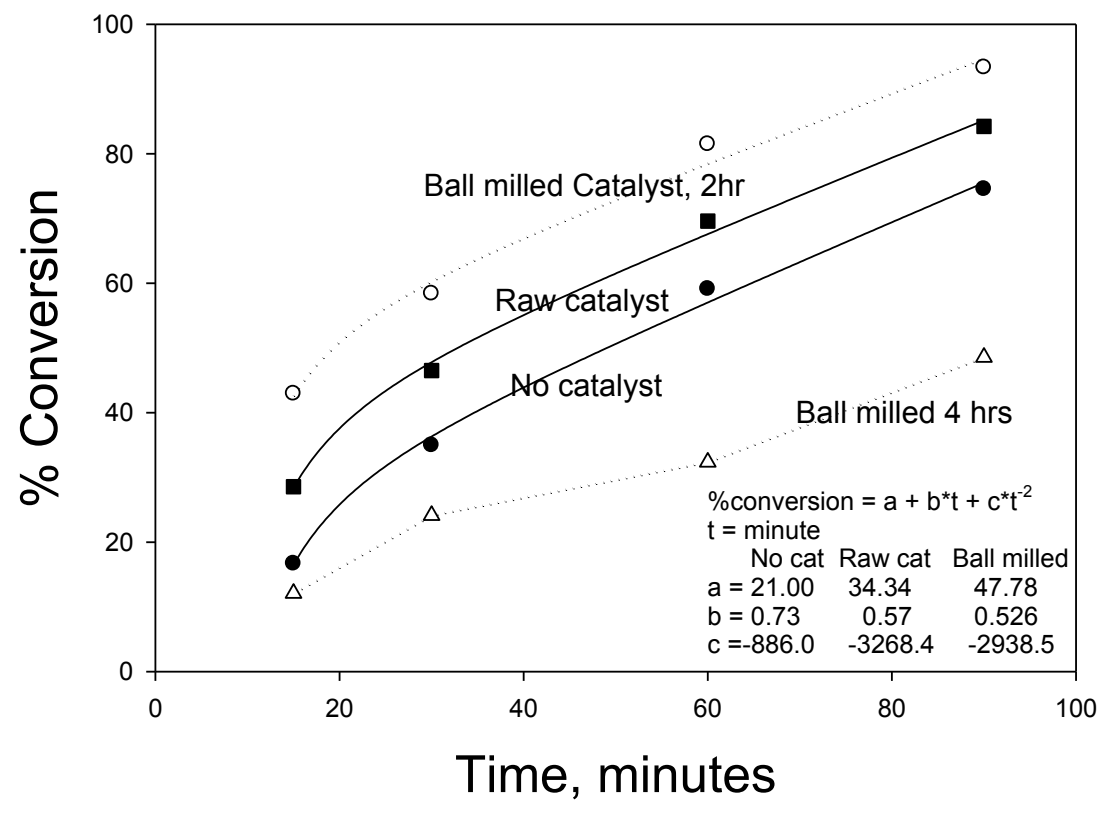

Figure 3.2.8 The effect of variously ball-milled catalyst on the carbonation reaction at $300^{\circ} \mathrm{C}$

To understand this phenomenon, we studied the ball milled samples with SEM. Fig. 3.2.9 shows the results. 


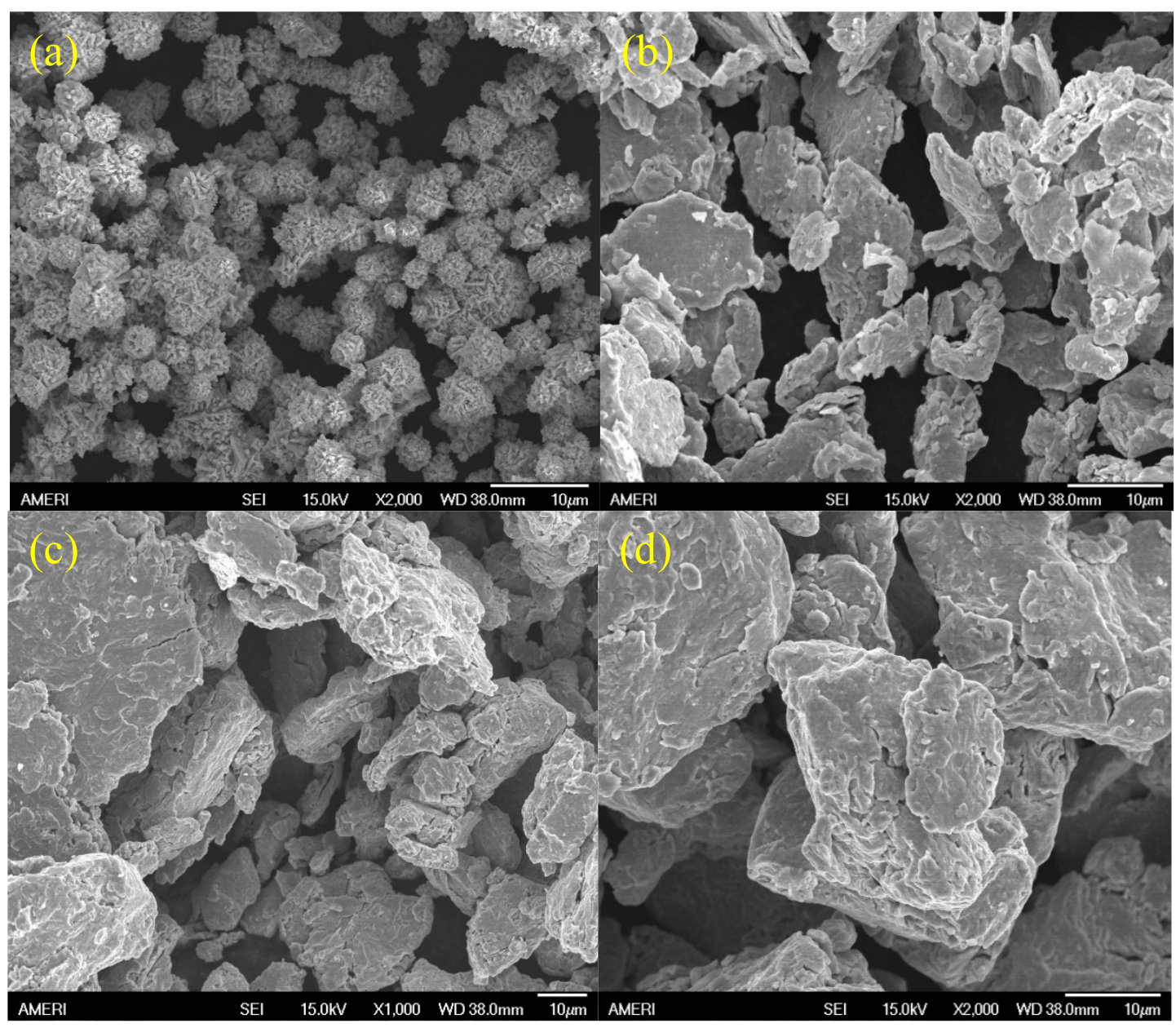

Figure 3.2.9 SEM images of nickel particles (a) without ball milling magnification 2000x

(b) Ball milled for 2 hrs, magnification 2000x (c) Ball milled for 3 hrs, magnification

1000x; (d) Ball milled for 4 hrs, magnification 2000x.

The morphology of as-received nickel particles is uneven and particle sizes are ranging from $2-5 \mu \mathrm{m}$. Ball milled for $2 \mathrm{~h}$ nickel has a platelet like structure with small thickness and therefore has the highest ratio of surface area to volume. However, this ratio drastically decreases as prolonged ball milling was performed. The globular particles of the catalyst (Fig.3.2.9a) become platelets after milling for $2 \mathrm{~h}$ (Fig.3.2.9b). After a continued grinding for $4 \mathrm{~h}$, the platelets instead of decreasing in size become larger 
(Fig.3.2.9d). The increased size would cause a decrease in the surface area leading to the reverse effect. Such decrease in a surface area of nickel powder with increasing ball milling time might be related to the absence of any milling media or dispersant.

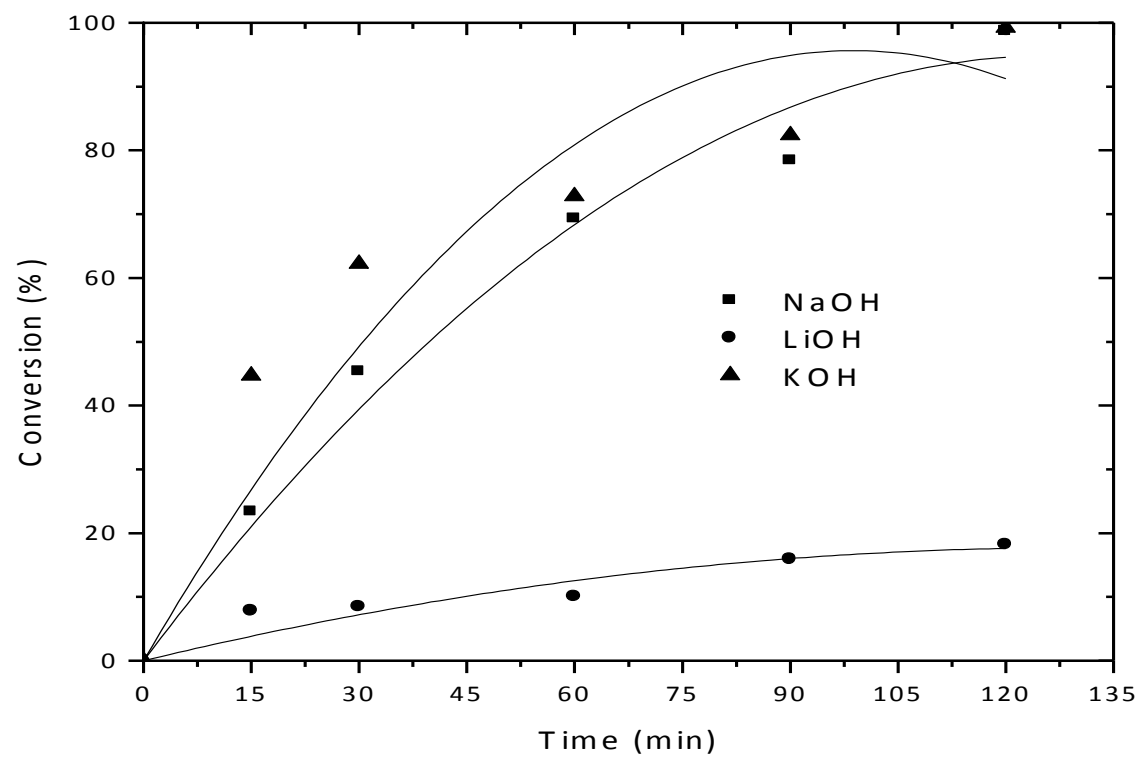

Figure 3.2.10 The effect of different alkali hydroxide on the Carbonation reaction at $400^{\circ} \mathrm{C}$.

In Fig. 3.2.10 effect of alkali hydroxide on the methane transformation rate at $400^{\circ} \mathrm{C}$ is shown for three alkali hydroxides. The carbonate formation rate becomes higher in the following order: $\mathrm{KOH} \approx \mathrm{NaOH}>\mathrm{LiOH}$. The similar observation of hydroxide reactivity is reported by Ishida et al. for the coal - alkali hydroxide - steam reaction [13] and by Kamo et al. for PVC or activated carbon steam gasification reaction [14]. The authors [M. Ishida] correlated such a change in hydroxide reactivity with their melting points. In our case, the reaction occurs with high rate well below the melting point of the hydroxides. Thus, change in reactivity of alkali hydroxides can be related with their alkalinity rather than with melting point differences. 


\subsubsection{Economic Analysis}

A method can be only useful to industry if it is economically viable. The economics of this process is as follows. For 40 tonnes of $\mathrm{NaOH}$ per hour+ 8 tonnes of methane feed, we produce 4 tonnes $\mathrm{H}_{2}$ and 53 tonnes of soda. The price variation of soda and of the hydroxide [15] would determine the price of hydrogen. A simple calculation, not taking account of the efficiency of the process, capital, operational and other costs, would show that for a fixed price of hydrogen of $\$ 1000 /$ tonne, the business would be profitable for a variety of market situations. The method of calculations is illustrated in Fig. 3.2.11. It shows if the price of the product soda and the reactant hydroxide is balanced, a plant owner with access to the hydroxide would earn a substantial profit. Losses would result if the demand for soda and hydrogen decreases and that of sodium hydroxide increases. More likely, if the proposed method is adopted the price of soda may increase due to the demand on hydrogen.

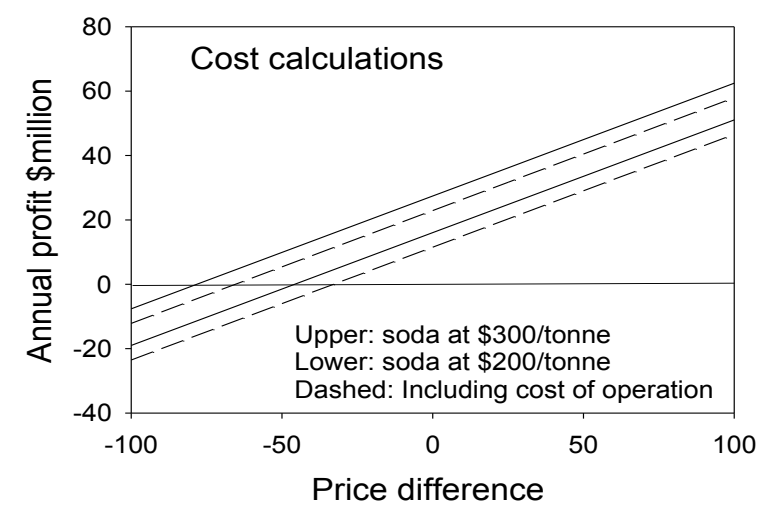

Figure 3.2.11 The price difference in soda and sodium hydroxide determines the price of hydrogen. In this example the price of hydrogen is fixed at $\$ 1000 /$ tonne. If the price of soda goes below the sodium hydroxide by $\$ 30 /$ tonne, the method may not be profitable. 
Note that sodium hydroxide is produced by the overall reaction for the electrolysis of brine as:

$$
2 \mathrm{NaCl}+2 \mathrm{H}_{2} \mathrm{O} \rightarrow \mathrm{Cl}_{2}+\mathrm{H}_{2}+2 \mathrm{NaOH}
$$

The reaction produces chlorine and sodium hydroxide in approximately equal amounts. Depending on which demand is dominant, either chlorine or $\mathrm{NaOH}$ can be regarded as a by-product and the price varies accordingly. Price fluctuations can be extreme: in the spot market in cases of oversupply, caustic soda prices can be as low as $\$ 20-30$ per tonne whereas, in short supply, prices can be $\$ 300$ and higher per tonne [16]. One may offset the vagary of the price fluctuation by converting the caustic soda to soda [17] because caustic soda can be substituted for soda ash in many uses, particularly in the pulp and paper, water treatment, and certain chemical sectors.

Unfortunately the chlor-alkali plants produce several more tons of carbon dioxide than we can sequester but as long as these plants exist and even grow in number all over the developing countries, we have no control on their carbon emission. This method reduces that emission that these plants produce and it does so with great profit to the plant owners. Furthermore, the use of hydrogen produced with zero carbon emission will add to the health of the environment. The following calculations show the environmental impact of this process:

There are close to 50 plants in the US which could use the modified SMR technique and each of the plants would produce 35040 tons of hydrogen annually. If we now accept that a hydrogen car using an internal combustion engine would run 300 miles on a full tank of hydrogen (8 kilograms) [18], we can run (35040000x300/8) 1,314,000,000 miles with 
hydrogen produced from one plant. If each car drives on the average 10,000 miles, we can run 131,400 cars on hydrogen produced from one plant or about 7 million cars from all the 50 plants. This number is close to about $10 \%$ cars in the US. The number will double if fuel-cell powered engines are used.

In summary, there is a way to produce hydrogen with zero emission by using the sodium hydroxide from existing chlor-alkali plants. This modified SMR process removes a major impediment in the use of hydrogen for vehicular transportation in a commercially viable way. 


\subsubsection{References}

1. R.F. Probstein, R.E. Hicks. Synthetic fuels. New York, Dover, 2006.

2. H.Z. Wang, D.Y.C. Leung, M.K.H. Leung, M. Ni, Renewable \& Sustainable Energy Reviews, 2009, 13, 845-53.

3. A. Shakeel, A. Abdullah, R. Faizur, A. Al-Dawood, A.M. Fahad, Appl. Catal. A: Gen., 2009, 359, 1-24.

4. M. Nazim, International Journal of Hydrogen Energy, 2001, 26, 1165-1175.

5. V. Drozd, S. Saxena, S.V. Garimella, A. Durygin, International Journal of Hydrogen Energy, 2007, 32, 3370-3375.

6. Y. Kalinci, A. Hepbasli, I. Dincer, International Journal of Hydrogen Energy, 2009, 34, 8799-8817.

7. S. K. Saxena, V. Drozd, A. Durygin, International Journal of Hydrogen Energy, 2008, 33, 3625-3631.

8. C. Pistonesi, A. Juan, B. Irigoyen, N. Amadeo, Applied Surface Science, 2007, 253, 4427-4437.

9. Y. Matsumura, T. Nakamori, Applied Catalysis A: Gen., 2004, 258, 107-114.

10. K. Hou, R. Hughes, Chemical Engineering Journal, 2001, 82, 311-328.

11. T. Numaguchi, K. Shoji, S. Yoshida, Applied Catalysis A: Gen., 1995, 133, 241262.

12. T. Nozaki, N. Muto, S. Kado, K. Okazaki, Catalysis Today, 2004, 89, 57-65.

13. M. Ishida, M. Toida, T. Shimizu, S. Takenaka, K. Otsuka, Industrial \& Engineering Chemistry Research, 2004, 43, 7204-7206.

14. T. Kamo, K. Takaoka, J. Otomo, H. Takahashi, J. Mater, Cycles Waste Management, 2006, 8,109-115.

15. Eurochlor report 1997. http://www.eurochlor.org/

16. http://www.icis.com/Articles/2009/12/30/9321358/OUTLOOK-10-US-chloralkali-on-a-tightrope.html 
17. S. Dennis, D. Kostick, Soda Ash. U.S. Geological Survey, Mineral Commodity Summaries, http://minerals.usgs.gov/minerals/pubs/commodity/soda_ash/610398.pdf

18. The hydrogen tank in BMW Hydrogen 7 takes up approximately 8 kilos (about 170 litres or $45 \mathrm{Imp}$ gals) of liquid hydrogen, the conventional gasoline tank has a volume of 74 litres or 16.3 Imp gals. http://www.worldcarfans.com/10611145727/bmw-hydrogen-7-in-depth 


\subsection{CATALYTIC STUDY OF THE MODIFIED COAL GASIFICATION PROCESS TO PRODUCE CLEAN HYDROGEN GAS}

\subsubsection{Introduction}

One of the major industrial methods of hydrogen production, coal-gasification, requires emission of several tonnes of carbon dioxide for each tonne of hydrogen and therefore, is not helpful to the environment. The solution to this problem is still under research. Here, the inclusion of sodium hydroxide in the coal gasification reaction lowers the reaction temperature and produces a carbonate $[1,2]$.

$$
\begin{aligned}
& 2 \mathrm{NaOH}(\mathrm{s})+\mathrm{C}(\mathrm{s})+\mathrm{H}_{2} \mathrm{O}(\mathrm{g})=\mathrm{Na}_{2} \mathrm{CO}_{3}(\mathrm{~s})+2 \mathrm{H}_{2}(\mathrm{~g}) \quad \Delta \mathrm{H}=64.58 \mathrm{~kJ}(600 \mathrm{~K}) \\
& \mathrm{C}(\mathrm{s})+2 \mathrm{H}_{2} \mathrm{O}(\mathrm{g})=\mathrm{CO}_{2}(\mathrm{~g})+2 \mathrm{H}_{2}(\mathrm{~g}) \quad \Delta \mathrm{H}=95.73 \mathrm{~kJ}(600 \mathrm{~K})
\end{aligned}
$$

Reaction (3.3.2) is a well-established coal gasification process. This process is operated between 500 and $1200^{\circ} \mathrm{C}$ in gasifiers. Gasifiers use steam, oxygen and/or air and produce a mixture of $\mathrm{CO}_{2}, \mathrm{CO}, \mathrm{H}_{2}, \mathrm{CH}_{4}$ and $\mathrm{H}_{2} \mathrm{O}$. Carbon monoxide gas is further processed by the shift-gas reaction to produce hydrogen with evolution of carbon dioxide. However, modified coal gasification reaction (here, reaction (3.3.1)) uses sodium hydroxide as a reactant which not only reduces the amount of required heat but also sequesters carbon dioxide gas.

Sodium hydroxide has been employed as a reactant to facilitate various reactions which are involved in the hydrogen gas production. Reichman et al. [3] suggested a process called Ovonic renewable hydrogen $(\mathrm{ORH})$. This method involves sodium hydroxide for the reformation of organic matter to produce hydrogen gas. While, William et al. [4] used sodium hydroxide as a promoter to produce hydrogen gas via hydrothermal gasification 
of glucose and other biomass sample. Kamo et al. [5] pyrolyzed dehydrochlorinated polyvinyl chloride (PVC) and activated carbon with sodium hydroxide and steam to generate hydrogen gas and sodium carbonate with methane, ethane and carbon dioxide as byproducts.

Nickel and Raney nickel are highly active and widely employed as catalysts for various industrial processes [6-10]. Numerous studies have confirmed the significant role of catalysts geometric factor, electronic factor and surface imperfections in determining their catalytic activity [11-17]. Therefore, it is always reasonable to explore the possible relation between the catalyst grain size and the reaction rate.

Here, different sized coal and catalysts particles are obtained using mechanical milling. Mechanical milling is regarded as one of the simple and common methods to obtain uniform distribution of composition. During mechanical process, powder particles undergo severe deformation which leads to various crystal defects such as lattice strains, dislocations, vacancies and morphological changes [18-20]. In this work, our focus is to study the catalytic behaviour of different sized and shaped catalysts and also to learn about the effect of using variously ball milled coal with this reaction.

\subsubsection{Materials and Methods:}

\subsubsection{Catalysts preparation}

The catalysts used for reaction (3.3.1) are nickel and Raney nickel. Nickel Powder (-100 mesh), Raney nickel (-325 mesh) were delivered by Sigma Aldrich and Acros Organics respectively. A planetary Retsch PM100 ball milling machine has been used to reduce the particle sizes of these catalysts. The cylindrical ball milling container has an internal 
diameter and length of 1.6 " each. The powder to ball weight ratio was $1 / 54$. Milling time varied from 1 to $4 \mathrm{~h}$ but the revolution speed $(250 \mathrm{rpm})$ remained the same.

\subsubsection{Catalyst Characterization}

X-ray diffraction patterns for different catalysts were obtained using Bruker GADDS/D8 X-ray system with Apex Smart CCD Detector and Mo direct-drive rotating anode (50 $\mathrm{kV} ; 20 \mathrm{~mA}$ ). JSM-5910-LV and JSM-6330F scanning electron microscope were used to study the surface morphology of the catalysts.

Image $\mathrm{J}$ software was used to determine the average particle sizes of both coal and Raney nickel catalysts. A total of nearly 50 particles were taken into consideration from 3-4 different SEM images to ensure a precise estimation of the average particle sizes.

\subsubsection{Reaction Study}

About $0.1 \mathrm{gm}$ of anhydrous sodium hydroxide (Sigma Aldrich (98\% purity)) was homogeneously mixed with a stoichiometric amount of anthracite coal in an alumina boat (reaction 1). Once the required temperature was attained, steam was allowed to pass through the alumina tube. The catalysts were added in an amount of 3 wt. \% of initial weight of sodium hydroxide. 


\subsubsection{Results and Discussion:}

\subsubsection{Catalysts Crystallite Size}

The crystallite size of these particles was calculated using Scherrer's formula [21]. The Scherrer equation describes the relationship between mean crystallite size and diffraction line width. The equation used here is

$$
D=\frac{0.9 \lambda}{\left(\beta-\beta_{0}\right) \operatorname{Cos} \theta}
$$

Where, $\lambda$ is the wavelength of X-ray radiation (Mo K $\left.\alpha_{1}=0.7093171 \dot{A}\right), \beta$ the width at half maximum intensity of a peak, $\beta_{0}$ the width at half maximum of highly crystalline material $\mathrm{LaB}_{6}$ and $\theta$ the Bragg angle, half of the diffractometer angle. The crystallite size signifies the size of coherently diffracting domain and it cannot be always regarded as particle size due to the presence of polycrystalline aggregates.

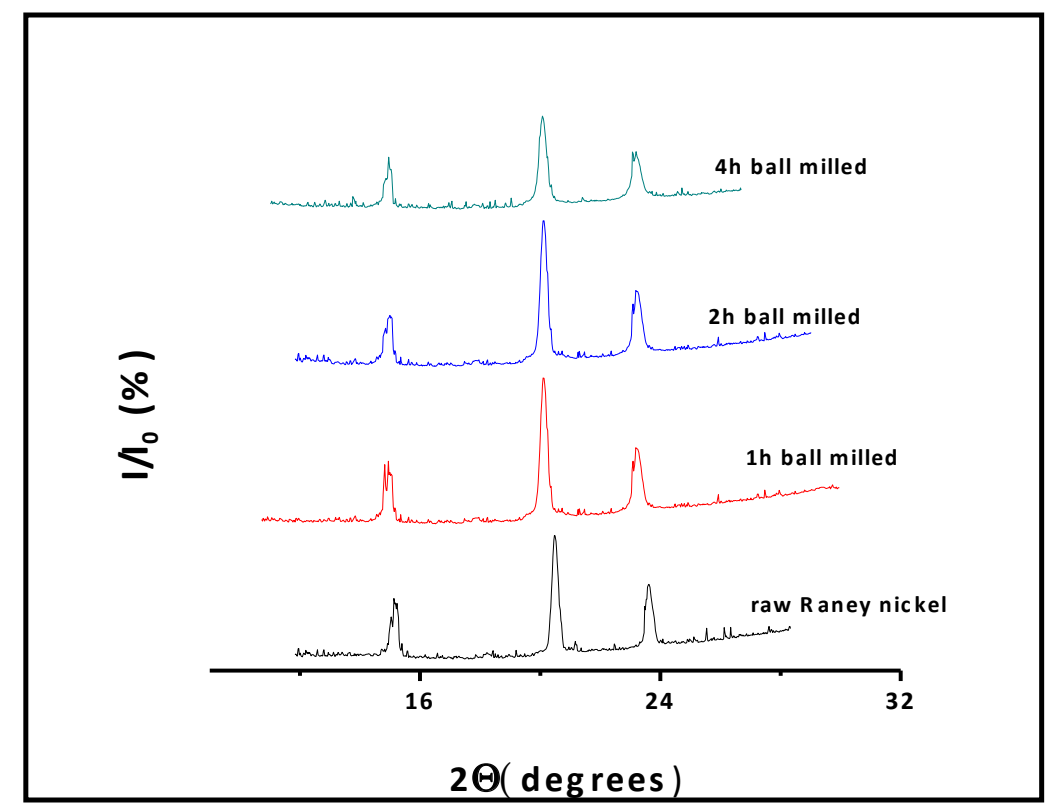


Figure 3.3.1 X-ray diffraction pattern for variously ball milled Raney nickel

Fig.3.3.1 illustrates the x-ray diffraction pattern for variously ball milled Raney nickel catalysts. The crystallite sizes for raw, 1, 2 or 4 h ball milled Raney nickel are 413, 347, 209 and $190 \AA$ respectively. It can be seen that as the crystallite sizes decreased due to ball milling, diffraction peaks shift towards the low angle direction and peak widths increase. During the prolonged ball milling time, the energy produced by ball milling drastically increases the strain rate and causes several modifications like vacancies, atomic site interchanges and dislocations [12,22-23]. However, Raney nickel nullifies the chance of any atomic site interchange but the possibility of formation and movement of dislocations can not be denied. According to Fetch, the generation and movement of dislocations could decrease grain size [24]. Here, it can be observed that for $2 \mathrm{~h}$ ball milled Raney nickel, there is relatively high \% reduction in the crystallite sizes. This suggests that the mechanical milling caused an intensive deformation for $2 \mathrm{~h}$ ball milled Raney nickel catalysts powders. 


\subsubsection{Morphology and particle size analysis}

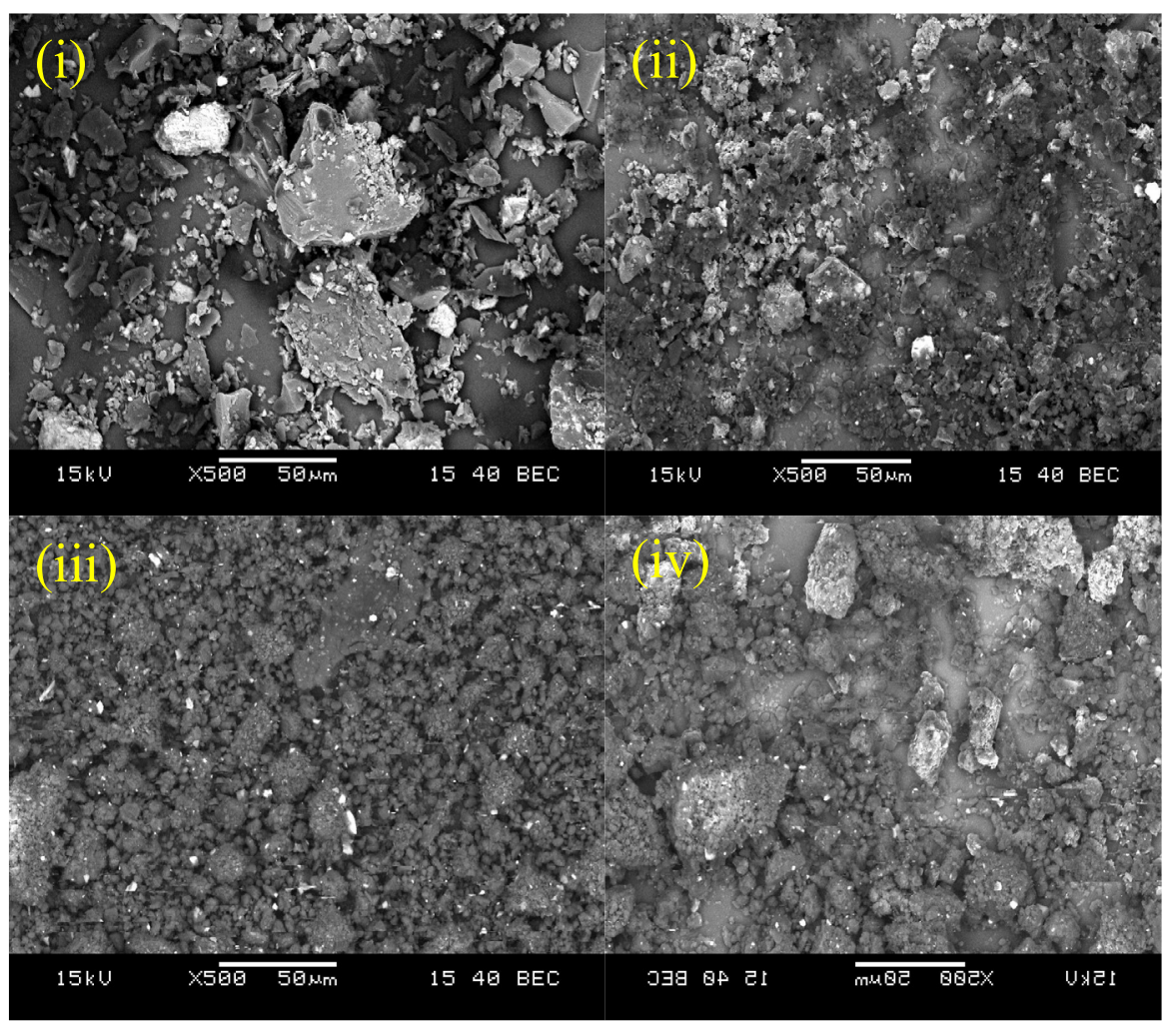

Figure 3.3.2 Back scattered SEM image of (i) without (ii) $1 \mathrm{~h}$ (iii) $2 \mathrm{~h}$ and (iv) $4 \mathrm{~h}$ ball milled coal

Figure 3.3.2 illustrates the back scattered scanning electron microscope images of variously milled coal particles. The mean particle size for raw, 1,2 or $4 \mathrm{~h}$ ball milled coal is $15.07,9.29,6.27$ and $13.97 \mu \mathrm{m}$ respectively. The smallest coal particle size of $6.27 \mu \mathrm{m}$ was obtained by ball milling for $2 \mathrm{~h}$. But if the time of ball milling was extended to $4 \mathrm{~h}$, the particles agglomerated resulting in larger particle sizes. 
(i)
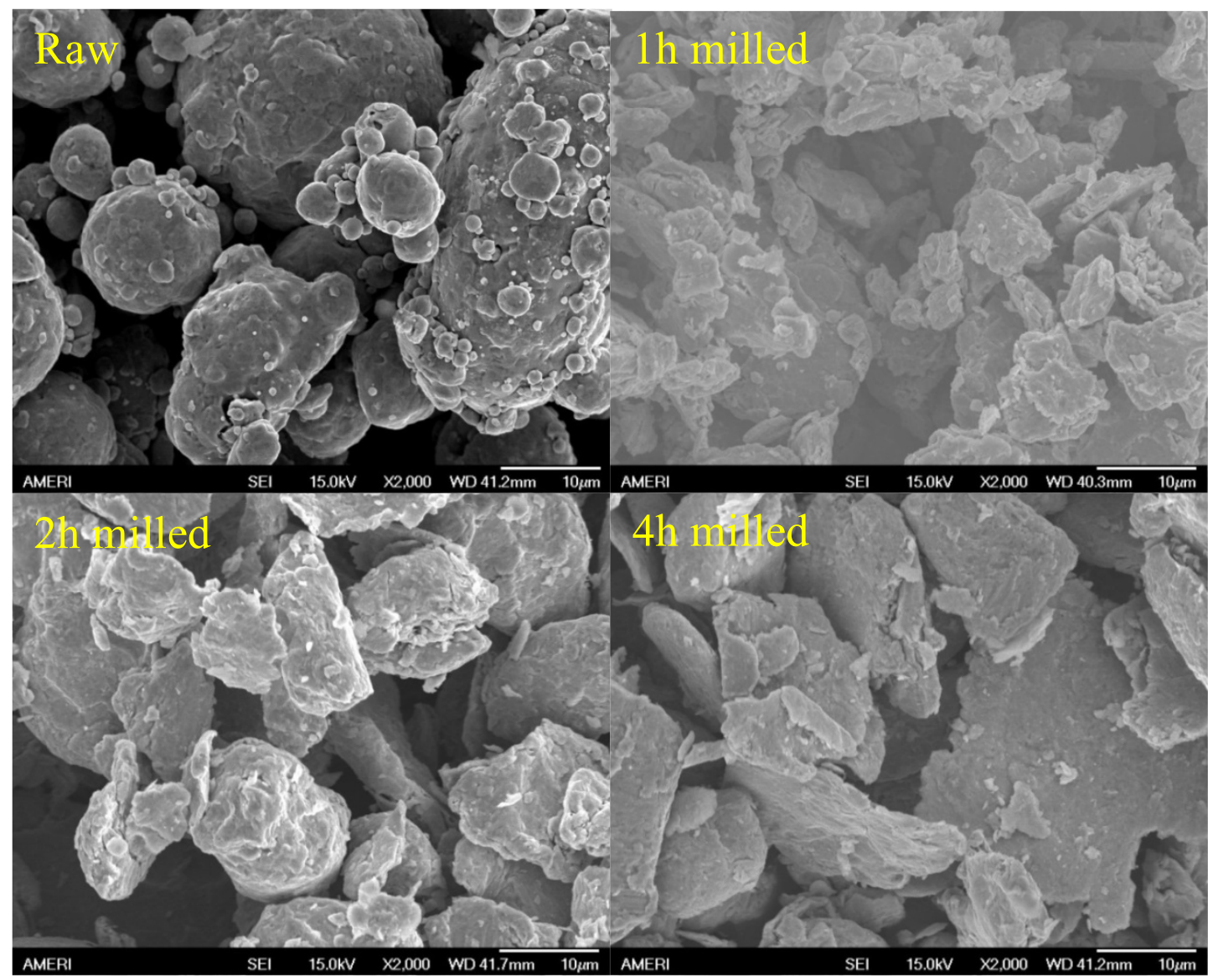

(ii)

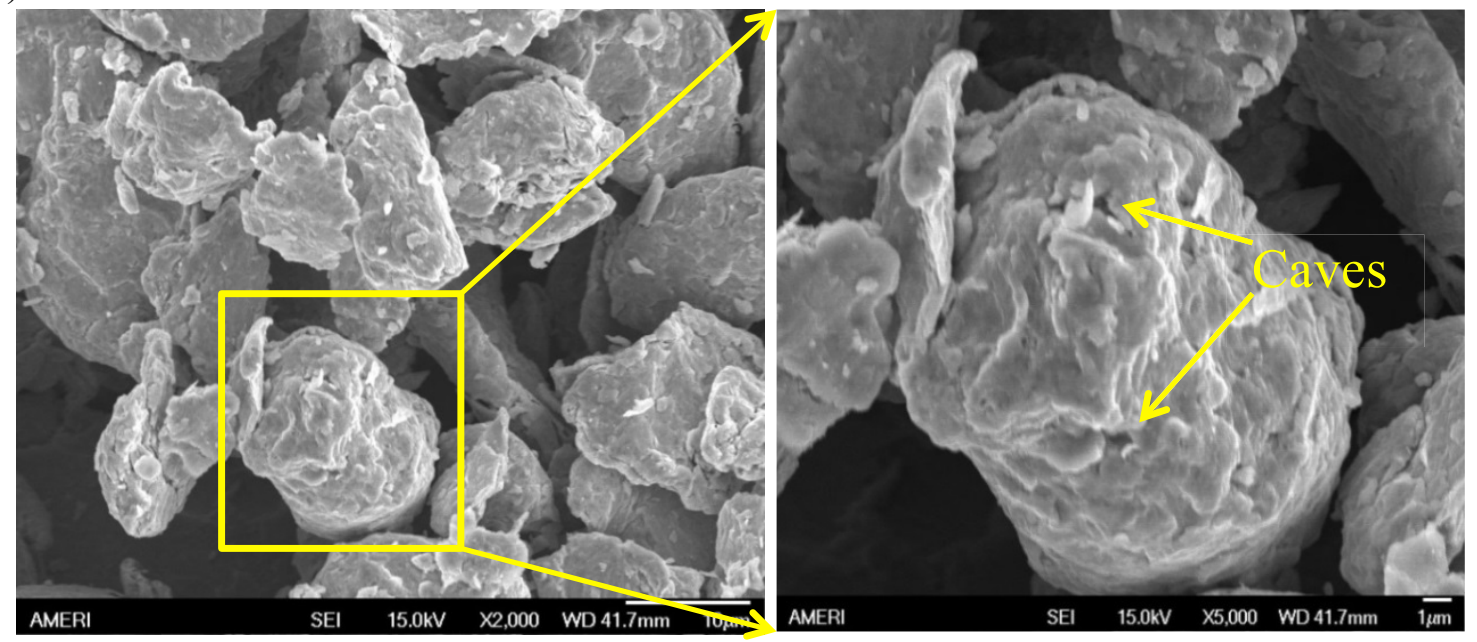

Figure 3.3.3 SEM images of (i) variously ball milled Raney nickel each at 2000X magnification (ii) $2 \mathrm{~h}$ ball milled Raney nickel showing caves at 5000x magnification. 
The particle size measurement of Raney nickel catalysts followed the same procedure as for the coal particles. The average particle sizes of raw, 1, 2 and 4 h Raney nickel catalysts lie in the range of $10-20 \mu \mathrm{m}$. However, it can be observed that the surface morphology of these particles varied drastically over different ball milling periods. Initially, raw Raney nickel particles are almost spherical in shape and have a very wide distribution of the particle sizes. When this was milled for $1 \mathrm{~h}$, their spherical shape has been transformed into a flaky disk shape. Its formation could be due to the impact actions

of the milling balls. However, when Raney nickel catalyst was ball milled for $2 \mathrm{~h}$ some of its flaky disk shaped particles transformed back to globular shape. These globular particles are formed by the agglomeration of the disk-shaped particles by folding, enclosure, unfolding and pile-up [25]. Prolonged ball milling time caused severe attrition of these globular particles and retransformed them into disk shaped particles [Figure 3.3.3 (i)].

\subsubsection{Reaction Results}

Figure 3.3.4 shows x-ray diffraction patterns for the product which confirms the formation of sodium carbonate by reaction (1) in the presence of nickel catalysts at 600 C. Peak locations for $\mathrm{Ni}, \mathrm{Na}_{2} \mathrm{CO}_{3}$ were obtained from JCPDS \#70-0989 and 37-0451 respectively. 


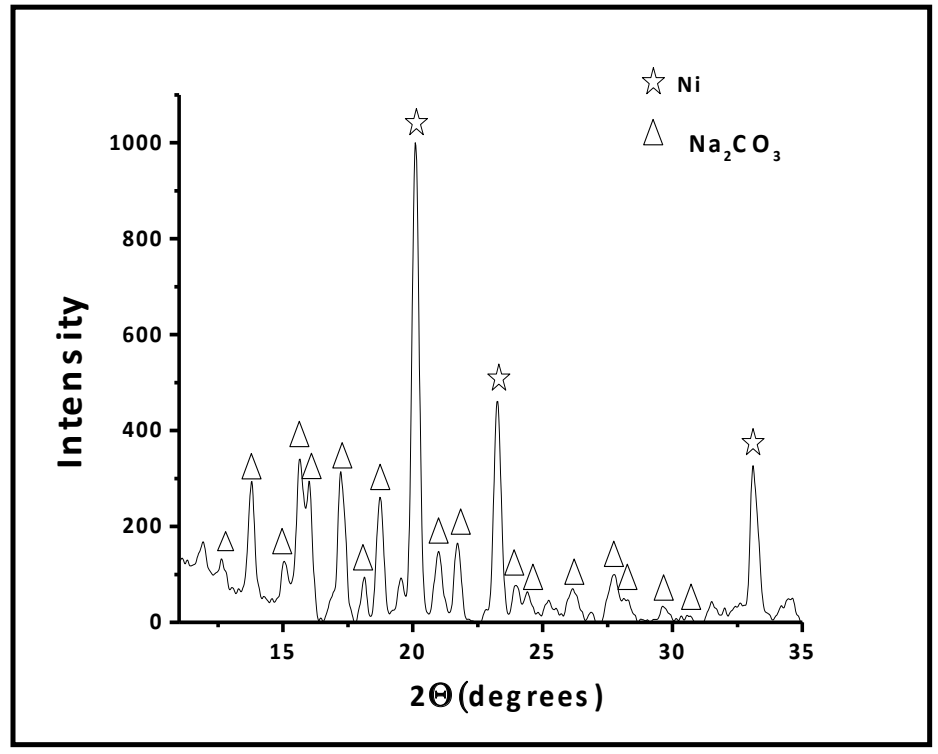

Figure 3.3.4 X-ray diffraction pattern confirms the product formation in the presence of nickel catalyst for reaction (1) at $600^{\circ} \mathrm{C}$

The experimental study of reaction (3.3.1) has been carried out at two different temperatures i.e. 500 and $600^{\circ} \mathrm{C}$. Figure 3.3 .5 demonstrates the reaction rate at $600^{\circ} \mathrm{C}$ for various coal particle sizes.

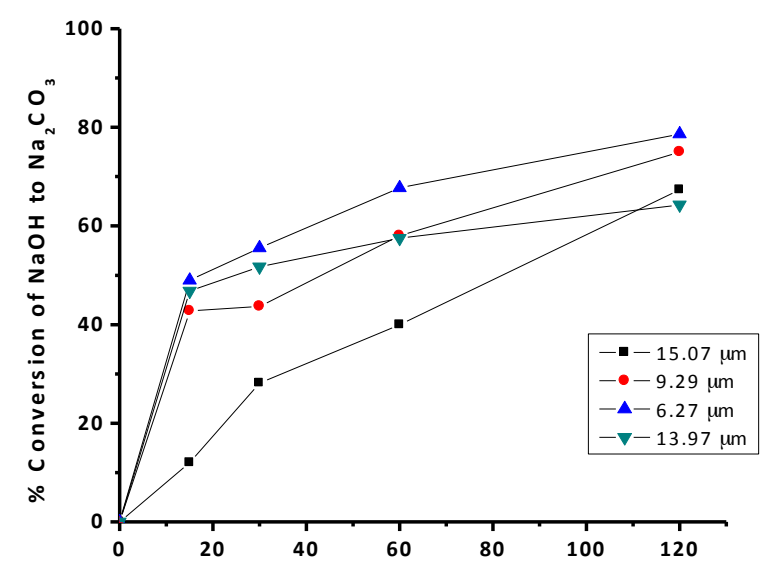

Time (mins)

Figure 3.3.5 \% Conversion of $\mathrm{NaOH}$ to $\mathrm{Na}_{2} \mathrm{CO}_{3}$ for different sized coal particles at different time at $600^{\circ} \mathrm{C}$ 
The graphs suggest that as the reaction time increased, formation of sodium carbonate also increased accordingly. However, the plot for $4 \mathrm{~h}$ ball milled coal shows a minute variation in the reaction yield at higher reaction times. The reason for this phenomenon lies in the surface morphology of coal particles. We note that as coal particle size increased, the reaction rate decreased accordingly.

The selectivity and activity of catalysts are often found to be largely dependent on the surface structure, particle morphology and size. In particular, the particle size is a critical issue as it determines the density of active sites. The catalytic study of $2 \mathrm{~h}$ ball milled coal (mean size of $6.27 \mu \mathrm{m})$ was performed using nickel metal powder (-100 mesh) and Raney nickel $\left(-325\right.$ mesh) at $600^{\circ} \mathrm{C}$. In the presence of highly active Raney nickel catalysts, reaction has a faster rate [Figure 3.3.6 (i)]. Raney nickel possesses highly porous microstructure and thus has high surface area.

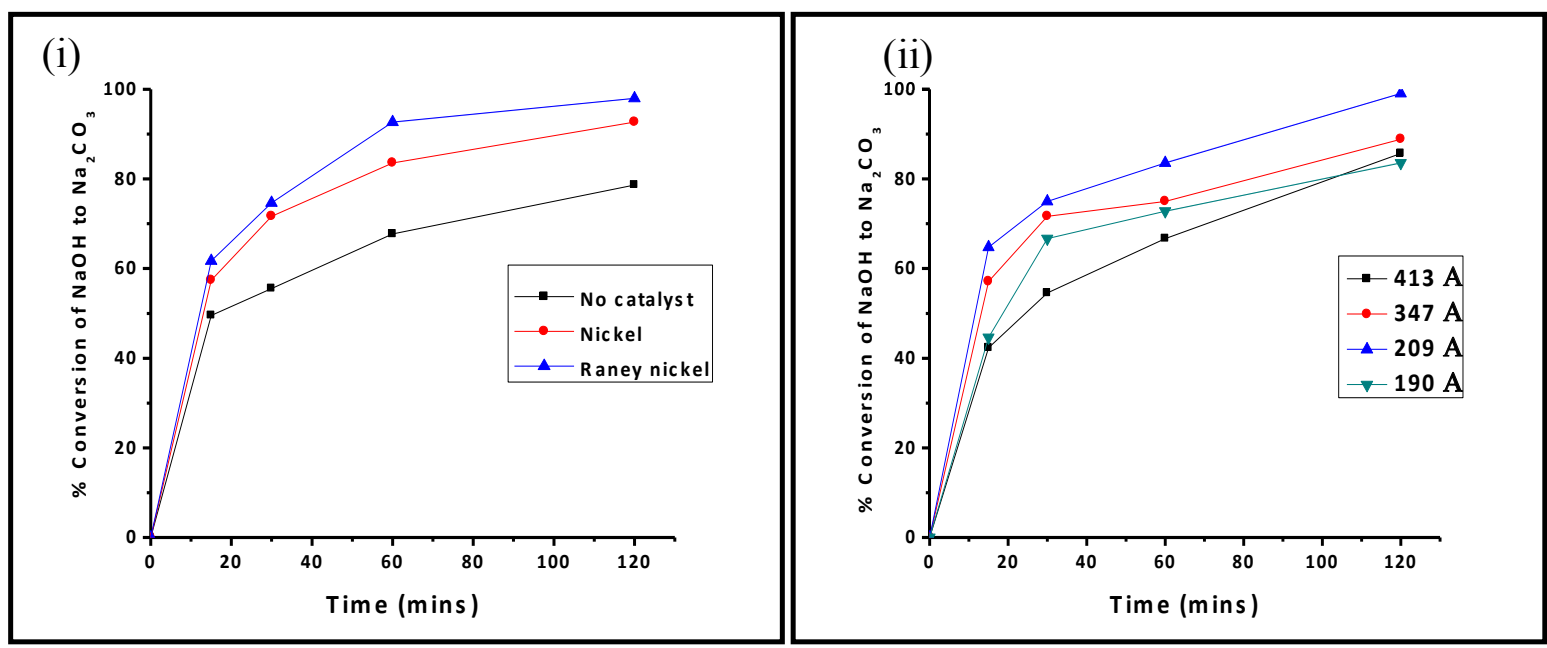

Figure 3.3.6 \% Conversion of $\mathrm{NaOH}$ to $\mathrm{Na}_{2} \mathrm{CO}_{3}$ for (i) different catalysts at $600^{\circ} \mathrm{C}$ and (ii) different sized Raney nickel at $500^{\circ} \mathrm{C}$ 
However, nickel can also act as a catalyst for reaction (1) but its observed activity is relatively lower than that of Raney nickel. Here, the purpose was to explore the effect of different sized Raney nickel catalysts. Therefore, raw Raney nickel catalysts were ball milled for different times.

Hydrogen generation curves for different sized Raney nickel at $500^{\circ} \mathrm{C}$ are plotted in Figure 3.3.6(ii). Results show that $2 \mathrm{~h}$ ball milled catalysts have the best effect compared to others. The reason for high catalytic activity of $2 \mathrm{~h}$ ball milled Raney nickel catalysts lie in the morphological as well as geometrical factors. SEM images in figure 3.3.3 show the surface morphology of variously ball milled Raney nickel. Fig.3.3.3 (ii) demonstrates the presence of a large number of open caves for $2 \mathrm{~h}$ ball milled Raney nickel which could be the reason for its high efficiency. In summary, globular catalyst particles exhibit high catalytic activity compared to that of flaky disk shaped catalyst. The deactivation of $4 \mathrm{~h}$ ball milled Raney nickel can be due to either a high mechanical abrasion of the catalysts surface or thermally induced deactivation. Since high temperature existed during prolonged milling, most likely it caused the loss of catalytic surface area because of the growth of the crystallites of the catalytic phase. A poor catalytic activity of the disk shaped $1 \mathrm{~h}$ ball milled Raney nickel can be explained in a similar fashion. Here, shape of the catalysts has been transformed into globular to flaky disk. This could have led to closing of the open caves. However, during $2 \mathrm{~h}$ of ball milling, flaky disk shaped particles agglomerate and leave a large number of open pores. In addition to the morphological aspect of the catalysts, there is also a geometric factor which is contributing to the catalytic activity. The maximum \% reduction in the crystallite size was observed for $2 \mathrm{~h}$ 
milling time of Raney nickel catalysts. Thus, a large number of formations and movement of dislocations or vacancies have occurred which led to an increased activity for $2 \mathrm{~h}$ ball milled Raney nickel catalysts.

All the kinetic curves show a rapid increase in the yield after 30 minutes of the reaction. The obvious reason could be the formation of sodium carbonate as a product; which when formed in a sufficient amount speed up this reaction. Thus, sodium carbonate too possesses catalytic property and can be categorized as a catalyst for reaction (3.3.1).The strong support to this observation lies in the fact that alkali metal salts of weak acids like sodium carbonate, potassium carbonate, sodium sulphide and potassium sulphide are used to catalyze steam gasification of coal. Kellogg molten salt process involves the gasification of coal in a bath of molten sodium carbonate through which steam is passed [26]. Here, the molten salt (sodium carbonate) functions as a strong catalyst, disperses coal and transfers heat as well as eradicates the formation of tars or tar acids. The coal gasification products can be separated either by liquefaction of carbon dioxide gas or using sodium hydroxide as a carbon dioxide adsorbent.

Carbon monoxide has a high affinity for forming carbonyl compounds with the transition metals [27]. These carbonyl compounds can be readily decomposed back to the transition metals. Carbon monoxide passing over the catalysts surface may have been adsorbed and formed carbonyl compounds. These nickels based formed carbonyl compounds have increased the collision frequency of sodium hydroxide and carbon monoxide gas. As a 
result, higher $\%$ conversion of $\mathrm{NaOH}$ to $\mathrm{Na}_{2} \mathrm{CO}_{3}$ was observed in the presence of nickel or Raney nickel catalysts.

Nickel has the least corrosion rates for molten sodium hydroxide. Nickel is essentially immune to caustic stress-corrosion cracking even in molten anhydrous sodium hydroxide at high temperatures. As concentration of sodium hydroxide and temperature increase during the evaporation process or during chemical- processing, the corrosivity enhances considerably. Likewise, increasing the nickel content of nickel-based alloys produces increasing resistance to general corrosion and stress-corrosion cracking in the caustic soda. Thus, a number of nickel-base alloys can be used for handling sodium hydroxide, depending on concentration and temperature [28]. Therefore, these properties of nickel ensure the longevity and high recyclability of nickel based catalysts applied in reaction (3.3.1). 


\subsubsection{References:}

[1] S.K. Saxena, V. Drozd, A. Durygin, International Journal of Hydrogen Energy, 2008, 33, 3625-3631.

[2] S.K. Saxena, International Journal of Hydrogen Energy, 2003, 28, 49-53.

[3] B. Reichman, W. Mays, J. Strebe, M. Fetcenko, International Journal of Hydrogen Energy, 2010, 35, 4918-4924.

[4] J.A. Onwudili, P.T. Williams, International Journal of Hydrogen Energy, 2009, 34, 5645-5656.

[5] T. Kamo, K. Takaoka, J. Otomo, H. Takahashi, Fuel, 2006, 85, 1052-1059.

[6] C. Pistonesi, A. Juan, B. Irigoyen, N. Amadeo, Applied Surface Science, 2007, 253, 4427-4437.

[7] Y. Matsumura, T. Nakamori, Applied Catalysis A: Gen., 2004, 258,107-114.

[8] K. Hou, R. Hughes, R. Chemical Engineering Journal, 2001, 82, 311-328.

[9] T. Numaguchi, K. Shoji, S. Yoshida, Applied Catalysis A: Gen., 1995, 133,241-262.

[10] T. Nozaki, N. Muto, S. Kado, K. Okazaki, Catalysis Today, 2004, 89, 57-65.

[11] Beeck. Advances in Catalysis, 1950, 2, 151

[12] Trapnell. Quart. Rev., 1954, 8, 494

[13] Gregg. The surface chemistry of solids, Champan and Hall, 1961

[14] Beeck. Reviews of Modern Physics, 1945, 17, 61

[15] E. Couper, Discussions of the Faraday Society, 1950, 8, 174

[16] R. Dowden, Discussions of the Faraday Society, 1950, 8, 184

[17] E.M. Hofer, H.E. Hintermann, Transactions of the Faraday Society, 1964, 60, 14571465.

[18] C. Suryanarayan, Progress in Materials Science, 2001, 46, 1-184.

[19] C.C. Koch, Nanostructured Materials, 1997, 9, 13-22. 
[20] J. Guerrero-Paz, D. Jaramillo-Vigueras, Nanostructured Materials, 1999, 11, 11231132.

[21] U. Holzwarth, N. Gibson, Nature Nanotechnology, 2011, 6,534.

[22] L.Z. Zhou, J.T. Guo, T.D. Jiang, S.H. Wang, Journal of Materials Science Letters, 1998, 17, 137-139.

[23] G. Liang, J. Huot, R. Schulz, Journal of Alloys \& Compounds, 2001, 320,133-139

[24] H.J. Fecht, Nanostructured Materials, 1995, 6, 33-42.

[25] G.G. Lee, H. Hashimoto, R. Watanabe, Materials Transactions The Japan Institute of Metals, 1995, 36,548-554.

[26] S. Lee, Handbook of Alternative Fuel Technologies CRC Press: Taylor \& Francis, 1996.

[27] J.J. Zuckerman, D.J. Atwood, Inorganic Reactions and Methods, Formation of Bonds to Transition and Inner-Transition Metals, New York: WILEY-VCH, 1998.

[28] D.B. Craig, D.S. Anderson, Handbook of corrosion data, 2nd Edition, Ohio: ASM International, 2002. 


\subsection{CATALYTIC STUDIES OF SODIUM HYDROXIDE AND CARBON MONOXIDE REACTION}

\subsubsection{Introduction}

Carbon monoxide is a toxic gas emitted by power plants and blast furnaces with a severe impact on global warming. Generally, water-gas shift reaction uses steam to lock carbon monoxide and produces carbon dioxide and hydrogen. A vast emission of anthropogenic gas (carbon dioxide) is a major drawback of the water-gas shift reaction.

We propose to solve this problem of carbon emission using a hydroxide as a reactant with carbon monoxide gas [1]. One should note that the present scheme serves the dual purpose of carbon monoxide capture and hydrogen production.

$$
2 \mathrm{NaOH}(\mathrm{s})+\mathrm{CO}(\mathrm{g}) \rightarrow \mathrm{Na}_{2} \mathrm{CO}_{3}(\mathrm{~s})+\mathrm{H}_{2}(\mathrm{~g}) \Delta \mathrm{H}=-119 \mathrm{~kJ}\left(600^{\circ} \mathrm{C}\right)
$$

However, if sodium hydroxide is to be produced for carbonation, the method proposed here cannot be regarded as carbon-emission free because sodium hydroxide itself is produced from electrolysis of brine, which is very energy intensive process. Instead, if we use sodium hydroxide that is a byproduct from existing chlor-alkali plants, we can produce sodium carbonate and hydrogen gas using reaction (3.4.1). Sodium carbonate is a valuable byproduct and has many applications in chemical industries. Apart from the fact that the production of sodium hydroxide is an energy intensive process, there is also an imbalance between the global hydrogen demand and sodium hydroxide production; hence reaction (3.4.1) cannot be seen as a global solution for hydrogen. However, reaction (3.4.1) will be certainly helpful in mitigating the vast emission of greenhouse gases

during production of hydrogen. The purpose of present work is to study the effect of catalysis on the carbonation of the hydroxide. It is highly desirable to lower the reaction 
time or even the operating temperature of exothermic reaction (3.4.1). Thus, several catalysts are tested to accelerate reaction (3.4.1).

Nickel is a low cost, highly active and widely employed catalyst for industrial application [2-6]. Raney nickel catalysts possess high catalytic activity due to its highly porous microstructure and high surface area. It is extensively used in various industrial processes and also in organic synthesis process [7, 8]. Magnetite acts as a catalyst for water gas shift reaction $\left(\mathrm{CO}(\mathrm{g})+\mathrm{H}_{2} \mathrm{O}(\mathrm{g}) \rightarrow \mathrm{CO}_{2}(\mathrm{~g})+\mathrm{H}_{2}(\mathrm{~g}), \Delta H=-41.1 \mathrm{~kJ} / \mathrm{mol}\right)[9,10]$. Previous results [11-13] show strong effect of the catalyst's geometric factor, electronic factor and surface imperfections. Beeck [14] correlated the catalytic activity to the lattice parameter of the contact surface. The electronic factors are dependent on the extent to which $d$-band of the crystal filled up by the electrons $[15,16]$. The effect of the imperfections is due to the surface imperfections (e.g., kinks, screw dislocations) which can also behave as catalytically active sites [17]. Therefore, it is important to investigate the possible relation between the catalyst grain size and the reaction rate. In this work, different sized catalysts were prepared by mechanical milling.

Mechanical milling is one of the common methods for milling powder materials to obtain uniform distribution of composition [18]. It is quite often employed due to its simplicity, low cost, and ability to form a large number of different materials [19]. During milling, powder particles experience intensive deformation which leads to various crystal defects such as lattice strains, dislocations, vacancies and morphological changes $[18,20]$. Here, we have studied the changes in catalysts powder morphology, average particle size and crystallite size with milling time. We also examined the relation between kinetics of reaction (3.4.1) and morphological and structural changes in the catalysts. 


\subsubsection{Experimental Section}

\subsubsection{Catalyst Preparation}

The catalysts used in this work are alumina $\left(\mathrm{Al}_{2} \mathrm{O}_{3}\right)$ mixed nickel, magnetite and Raney nickel. Nickel Powder (-100 mesh), Raney nickel (-325 mesh) and alumina were delivered by Sigma Aldrich, Acros Organics and Good Fellow respectively. The various sizes of these catalysts were obtained using planetary Retsch PM100 ball mill. The cylindrical ball milling container has internal diameter of 1.6" and internal length of 1.6". The powder to ball weight ratio was 1/54. Magnetite was ball milled for 1 and $2 \mathrm{~h}$. Al2O3 mixed nickel was prepared in 2:1 ratio by weight. Then, this mixture was ground for 1 or 2 or $4 \mathrm{~h}$. For Raney nickel, milling time was 2 and $4 \mathrm{~h}$. The same revolution speed (250 rpm) was maintained for grinding all the catalyst particles.

\subsubsection{Catalyst Characterization}

X-ray diffraction patterns for different catalysts were obtained using Bruker GADDS/D8 X-ray system with Apex Smart CCD Detector and Mo direct-drive rotating anode (50 $\mathrm{kV} ; 20 \mathrm{~mA}$ ). The surface morphology of the catalyst was studied using JEOL JSM-5910LV and JEOL JSM-6330F scanning electron microscope. Image $\mathrm{J}$ software was used to determine the average particle size of catalysts. A total of nearly 50 particles of each catalyst were taken into consideration from 3-4 SEM images.

\subsubsection{Reaction Study}

Anhydrous sodium hydroxide with a purity of $98 \%$ was supplied by Sigma Aldrich. About $0.10 \mathrm{~g}$ of sodium hydroxide was dissolved using $1 \mathrm{~mL}$ of distilled water in an alumina boat. Then, the catalyst ( 3 wt. \% of sodium hydroxide) was mixed with the solution. Nitrogen gas was allowed to flow at the rate of $50 \mathrm{~mL} / \mathrm{min}$ until the required 
temperature was achieved. After that, nitrogen flow was ceased and carbon monoxide was passed through the reaction chamber at the rate of $20 \mathrm{~mL} / \mathrm{min}$. The reaction (3.4.1) was studied at several temperatures using various sizes of the different catalysts.

\subsubsection{Results and Discussion}

\subsubsection{Characterization of Catalysts}

Catalyst crystallite size was determined using Scherrer's equation. The powder X-ray diffraction pattern for alumina mixed nickel catalysts (2:1 wt. \%) (Fig.3.4.1a) shows the presence of alumina and nickel peaks. Few initial peaks of alumina disappeared as prolonged ball milling was carried out leading to the amorphorization of alumina. No oxidation of nickel was observed throughout the ball milling time. The calculated crystallite sizes for alumina mixed nickel ball milled for 1,2 and $4 \mathrm{~h}$ are 184, 158 and $150 \AA$ respectively. X-ray diffraction pattern for magnetite catalyst ball milled for different times are shown in Fig.3.4.1b. As the crystallite sizes decreased due to prolonged ball milling, diffraction peaks shift towards the low angle direction and peak widths increase. The crystallite size of coarser magnetite (in micron) decreased to 181 and $169 \AA$ for 1 and $2 \mathrm{~h}$ ball milling time respectively. 


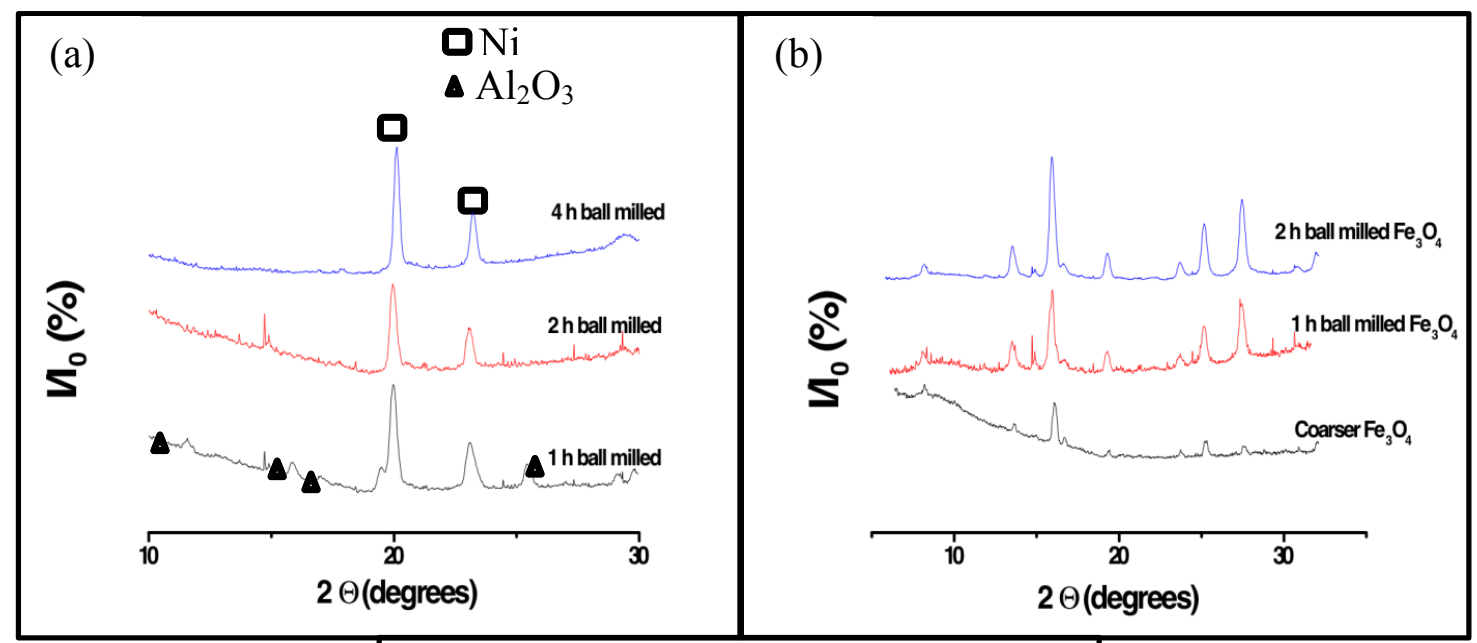

(c)

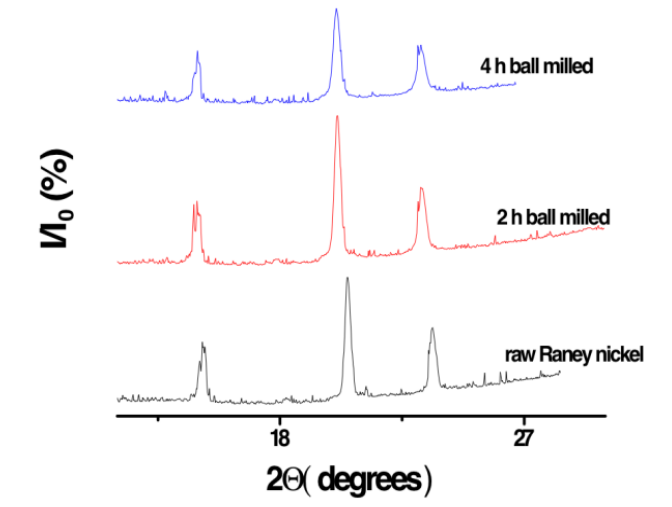

Figure 3.4.1 X-ray diffraction patterns for variously ball milled (a) alumina mixed nickel (b) magnetite (c) Raney nickel

Fig. 3.4.1c depicts the X-ray diffraction pattern for variously ball milled Raney nickel. Peak width broadening can be observed for prolonged ball milling time. The crystallite sizes for raw, 2 and 4h ball milled Raney nickel are 413, 209 and $190 \AA$ respectively. Table 3.4.1 summarizes the crystallite sizes of all the variously ball milled catalysts. 


\begin{tabular}{|c|c|c|c|}
\hline $\begin{array}{c}\text { ball milling } \\
\text { time } \\
(\text { Hours })\end{array}$ & $\begin{array}{c}\mathrm{Al}_{2} \mathrm{O}_{3} \text { mixed nickel } \\
(\AA)\end{array}$ & $\begin{array}{c}\text { Magnetite } \\
(\AA)\end{array}$ & $\begin{array}{c}\text { Raney nickel } \\
(\AA)\end{array}$ \\
\hline 0 & - & Micron size & 413 \\
\hline 1 & 184 & 181 & - \\
\hline 2 & 158 & 169 & 209 \\
\hline 4 & 150 & - & 190 \\
\hline
\end{tabular}

Table 3.4.1 Crystallite size of variously ball milled catalysts

During the prolonged milling time, the energy produced by ball milling drastically reduces the grain sizes and thus increases the lattice strain. It is a fact that the milling may cause several modifications such as vacancies [21]; atomic site interchanges [19] and dislocations [12]. Raney nickel is composed mainly of single element nickel and hence nullifies the effect of any atomic site interchanges for different ball milling time. Other modifications could be the formation of vacancies and dislocations in the unit cells of the catalysts powder particles. The developed lattice strain caused by mechanical milling is attributed to plastic deformation which is the generation and movement of dislocations $[22,23]$. According to Fecht [24], the generation and movement of dislocations could decrease grain size. High lattice strain implies to a high density of dislocation formation and which contributes to a reduction in grain size. If the grain size of catalysts particle decreases slowly that means there is a relatively less formation and movement of dislocations. Here, for both $2 \mathrm{~h}$ ball milled alumina mixed nickel and $2 \mathrm{~h}$ ball milled Raney nickel, there is a relatively higher \% reduction in crystallite sizes. This suggests 
that the mechanical milling caused a severe plastic deformation to these catalysts powder particles.

\subsubsection{Morphology and Particle Size Analysis}

Scanning electron microscope (SEM) was used to determine the surface morphology of the catalysts. Alumina mixed nickel ball milled for 2h, shown in (Fig. 3.4.2a), exhibits sponge- like morphology and consists of many small particles. The average particle sizes are $3.24,3.26$ and $2.80 \mu \mathrm{m}$ for the milling time of 1,2 and $4 \mathrm{~h}$, respectively.

Fig.3.4.2b shows the surface morphology for variously ball milled magnetite catalyst particles. Coarse magnetite has relatively larger average particle size. The average particle sizes are 4.56, 3.09 and $2.62 \mu \mathrm{m}$ for the milling time of 0,1 and $2 \mathrm{~h}$ respectively. One should note that average particle size of magnetite decreases with increase in ball milling time. 
(a)

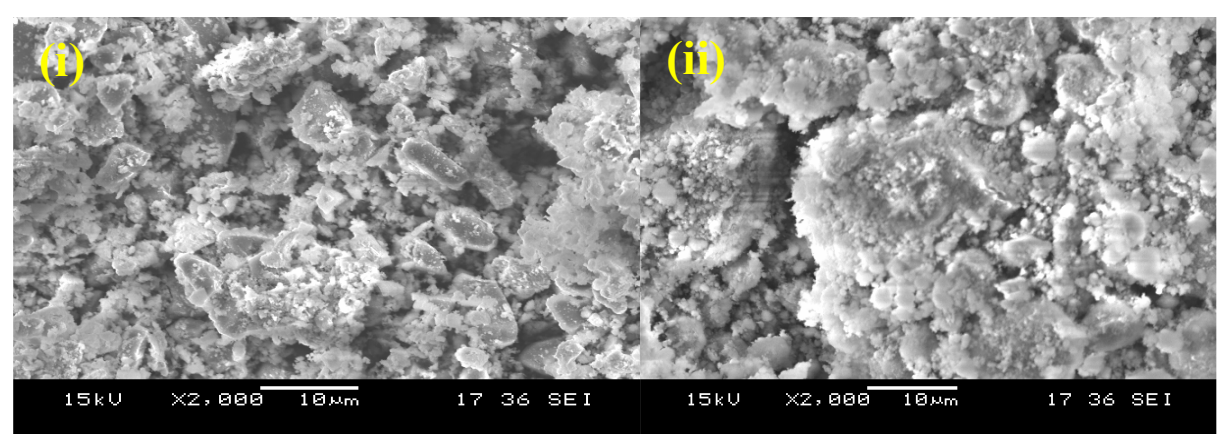

(b)

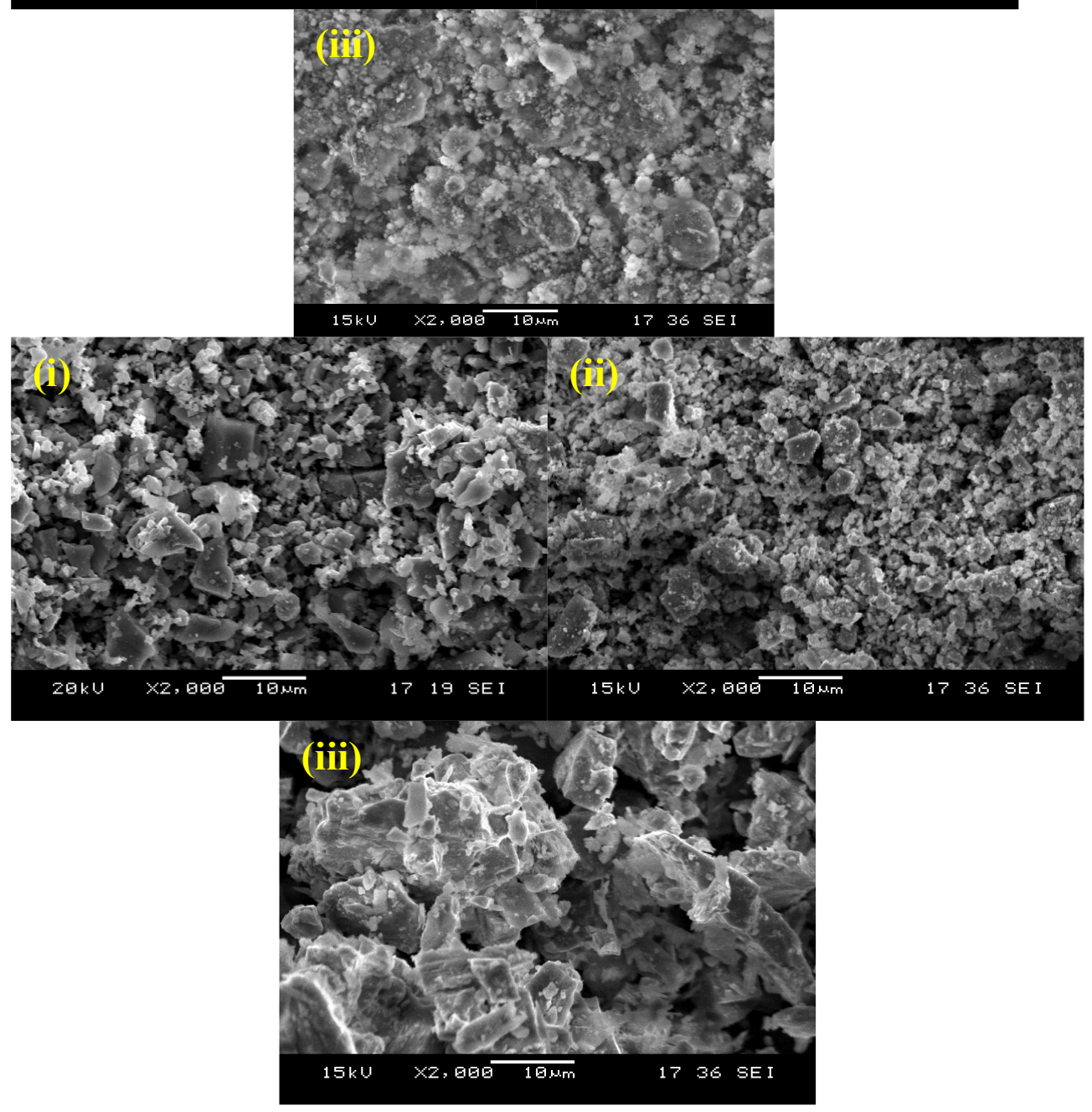

Figure 3.4.2 SEM image of (a) alumina mixed nickel ball milled for (i) 1 hour (ii) 2 hours (iii) 4 hours at (b) magnetite ball milled for (i) 1 hour (ii) 2 hours. (iii) Without ball milling at 2000x each. 


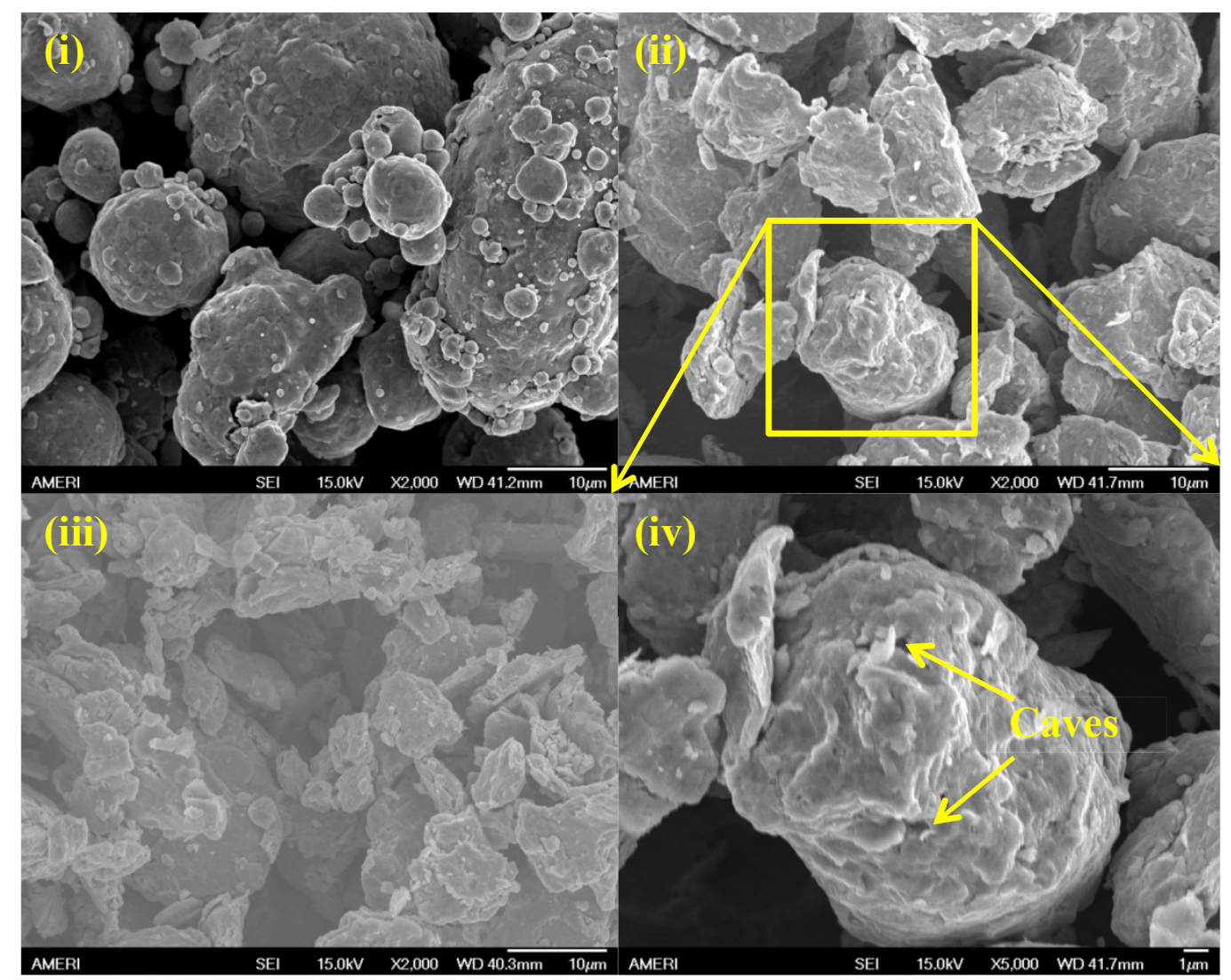

Figure 3.4.3 SEM image of Raney nickel (i) without (ii) $2 \mathrm{~h}$ (iii) $4 \mathrm{~h}$ ball milling at 2000x each and (iv) $2 \mathrm{~h}$ ball milled Raney nickel with pores (at 5000x)

Figure 3.4.3 depicts the SEM images for variously ball milled Raney nickel. A relatively high number of openings or caves are observed for $2 \mathrm{~h}$ ball milled catalyst as shown in Fig. 3.4.3iv. The globular particles of $2 \mathrm{~h}$ ball milled catalyst can be assumed to be a stacked layer of flaky disk particles (formed as an attrition product of raw Raney nickel). However, further attrition of these globular particles changed them back to platelet structure (Fig.3.4.3iii). Moreover, the sizes of Raney nickel particles varied significantly over different ball milling periods. Initially, raw Raney nickel particles are almost 
spherical in shape and have a very wide distribution of the particle sizes. The average particle size of raw, 2 and $4 \mathrm{~h}$ ball milled Raney nickel are 11.74, 15.72, and $13.72 \mu \mathrm{m}$ respectively.

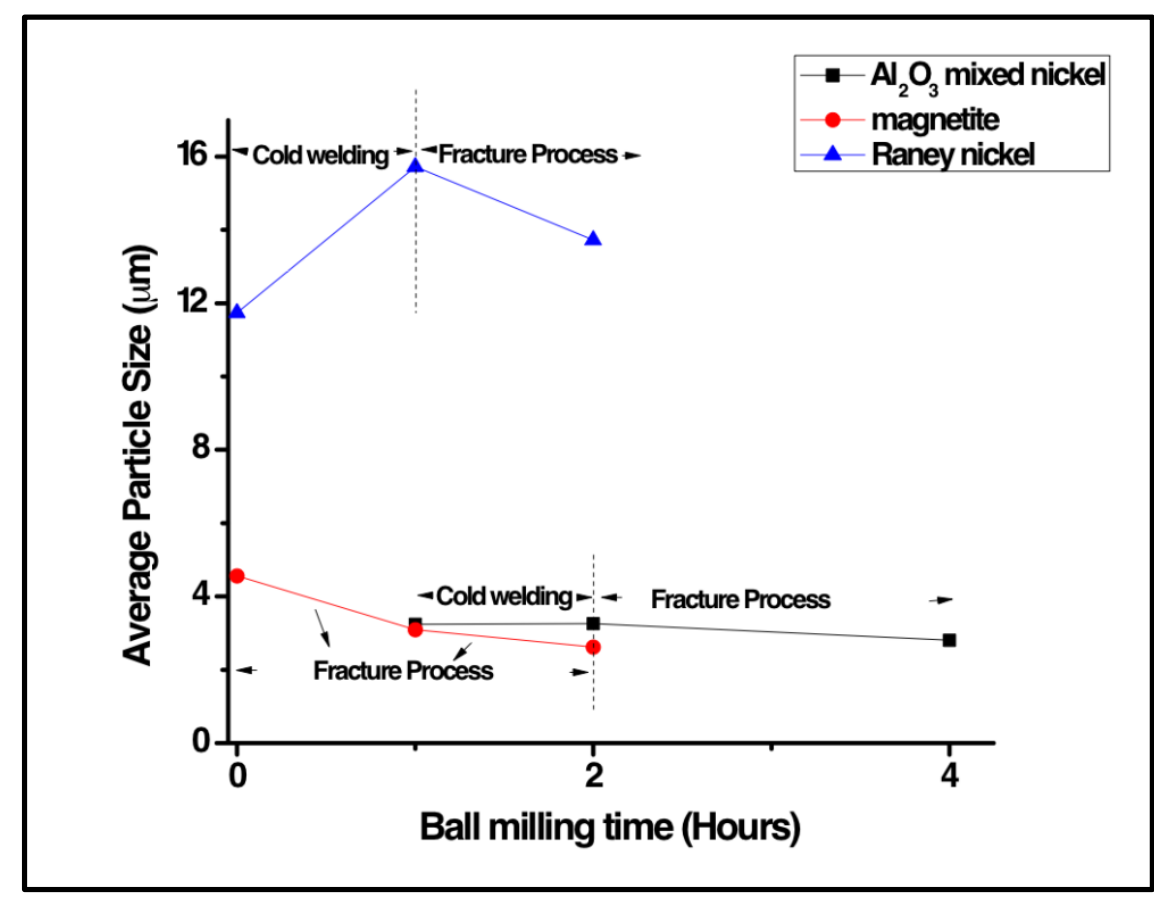

Figure 3.4.4 Change of average particle size of catalysts with milling time

It is well known that milling process is controlled by the two processes of cold welding and fracture $[25,26]$. Figure 3.4 .4 illustrates the change in average particle size with milling time for variously ball milled catalysts. It also demonstrates the dominant stages of milling process with time for different catalysts. The particle size and morphology of catalysts are determined by the competition between cold welding and fracture process. The average particle sizes of Raney nickel increases until $2 \mathrm{~h}$ milling time which is attributed to the dominant cold welding process. However, fracture process dominates only after $2 \mathrm{~h}$ and causes a decrease in the average particle size for $4 \mathrm{~h}$ milling time. Alumina mixed nickel catalyst also shows the similar trends. Alumina mixed nickel has 
almost constant particle size for first $2 \mathrm{~h}$ and then decrease in the average particle size was observed. It means that initially cold welding was dominant process and after $2 \mathrm{~h}$ milling time, it was the fracture process which prevailed. However, magnetite showed a different tendency for the milling process. The decrease in the magnetite average particle size with milling time is due to the dominant fracture process. It should be noted that for $\mathrm{Al}_{2} \mathrm{O}_{3}$ mixed nickel and Raney nickel, fracture process dominates only after $2 \mathrm{~h}$ milling time.

\subsubsection{Reaction Results}

The curves for $\%$ conversion of $\mathrm{NaOH}$ to $\mathrm{Na}_{2} \mathrm{CO}_{3}$ in the presence of variously ball milled $\mathrm{Al}_{2} \mathrm{O}_{3}$ mixed nickel, magnetite and Raney nickel catalysts at $300^{\circ} \mathrm{C}$ are shown in Figures 3.4.5, 3.4.6 and 3.4.7 respectively. A substantial increase in the $\%$ conversion of $\mathrm{NaOH}$ to $\mathrm{Na}_{2} \mathrm{CO}_{3}$ was observed due to addition of the catalyst. However, a clear distinction between the catalytic activities for these catalysts becomes discernible only after a $30 \mathrm{~min}$ run (Figures 3.4.5-3.4.7). The obvious reason could be due to the formation of product $\mathrm{Na}_{2} \mathrm{CO}_{3}$, which once formed shows catalytic activity for the reaction [27].

A $2 \mathrm{~h}$ ball milled alumina mixed nickel catalyst was catalytically most effective compared to other alumina mixed catalysts. The purpose to add alumina with nickel was to avoid the chance of agglomeration. In our previous work [28], we observed that nickel particles tend to agglomerate when ball milled in the absence of dispersant (such as alumina) [28].

In this study, we have minimized the coalescence by mixing alumina with nickel. X-ray diffraction study (Fig. 3.4.1a) confirms the amorphorization of alumina over prolonged milling time. Smaller crystallite size for alumina mixed nickel was generated as ball milling time was increased. Therefore, a better specific surface area and thus a better 
reaction yield were expected but the amorphorization of alumina particles has caused the reverse effect. Therefore, the effective surface area available for the adsorption of the gas was decreased and hence a relatively lower reaction yield was observed. Higher mechanical attrition and thermally induced deactivation could be another major cause for low catalytic activity of $4 \mathrm{~h}$ alumina mixed nickel. It can also be observed that the maximum $\%$ reduction in crystallite size was observed for $2 \mathrm{~h}$ of ball milling time for alumina mixed nickel catalysts. Therefore, an increase in the formation and movement of dislocations or vacancies as well as exchange of atomic site positions have led to the increased catalytic activity for $2 \mathrm{~h}$ ball milled alumina mixed nickel catalysts.

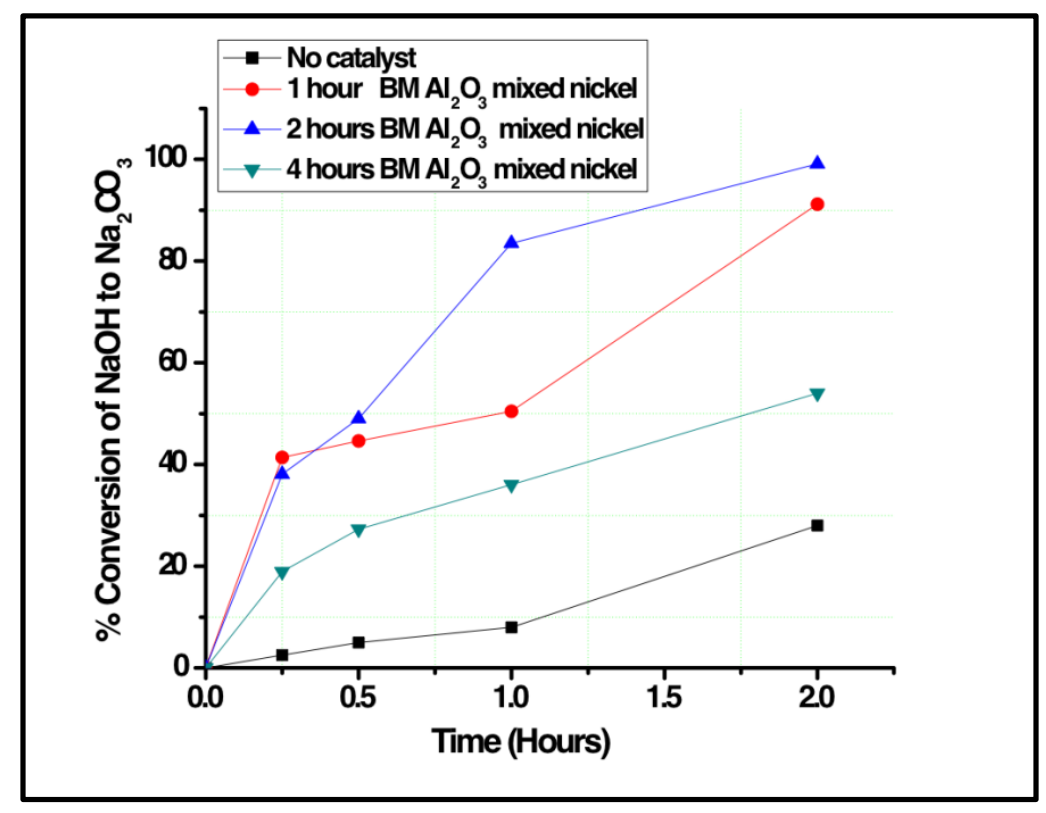

Figure 3.4.5 \% Conversion of $\mathrm{NaOH}$ to $\mathrm{Na}_{2} \mathrm{CO}_{3}$ for variously ball milled (BM) $\mathrm{Al}_{2} \mathrm{O}_{3}$ mixed nickel (2:1) (wt. \%) at $300^{\circ} \mathrm{C}$.

In the experiments using magnetite as a catalyst, the reaction yield shows a similar reaction yield for 1 and $2 \mathrm{~h}$ milling time (Figure 3.4.6). Due to the larger crystallite size, 
coarser magnetite has a low surface area to volume ratio. The poor reaction yield in the presence of coarser magnetite was in consistent with its relative larger particle size. When magnetite was milled for $1 \mathrm{~h}$, crystallite size reduced from several microns to $181 \AA$ and that causes an increase in the catalytic activity. But for $2 \mathrm{~h}$ milling time, crystallite size reduced by only $12 \AA$ compared to $1 \mathrm{~h}$ ball milled magnetite. Therefore, there is a relatively less plastic deformation for $2 \mathrm{~h}$ ball milled magnetite. Hence, $2 \mathrm{~h}$ ball milled exhibited identical catalytic activity to that of $1 \mathrm{~h}$. Thus, it can be stated that the reaction yield goes hand in hand to the particle size of magnetite. 1 and $2 \mathrm{~h}$ ball milled magnetite has comparable crystallite size and therefore their reaction yields are also similar.

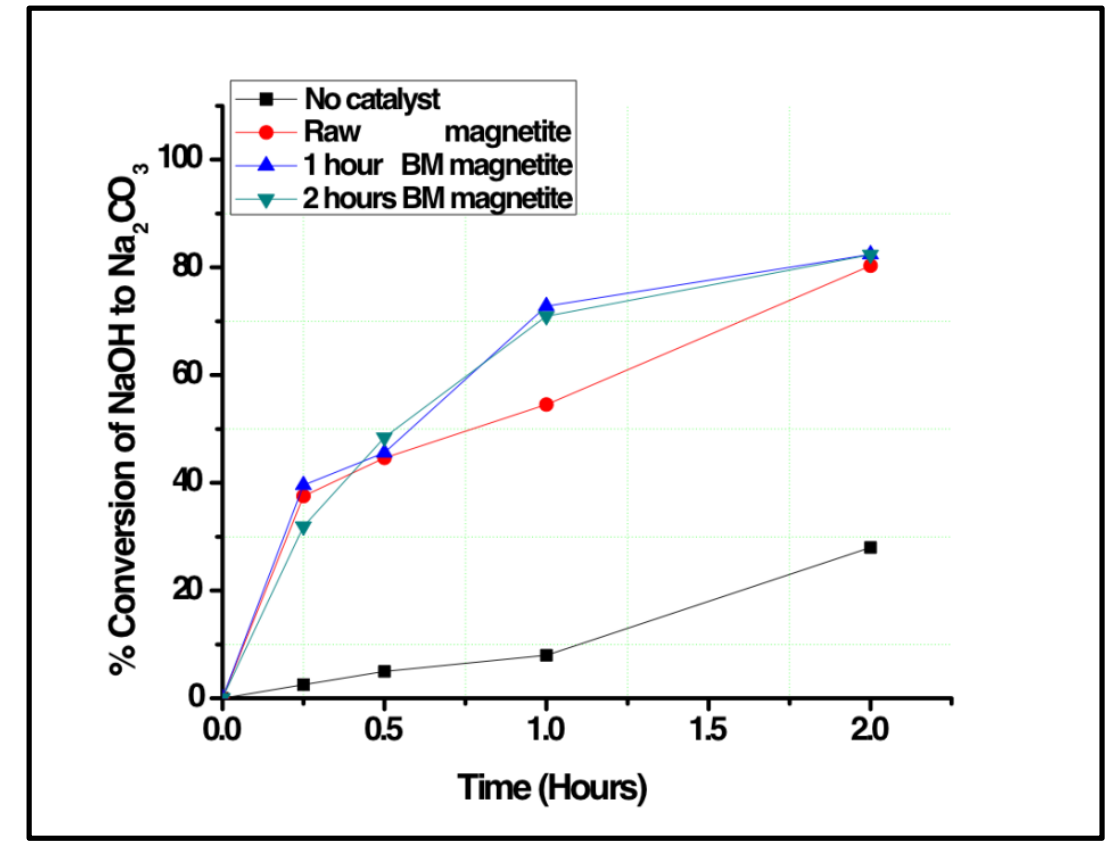

Figure 3.4.6 \% Conversion of $\mathrm{NaOH}$ to $\mathrm{Na}_{2} \mathrm{CO}_{3}$ for variously ball milled (BM) magnetite at $300^{\circ} \mathrm{C} .1$ and 2 hours ball milling time has exhibited a comparable result 


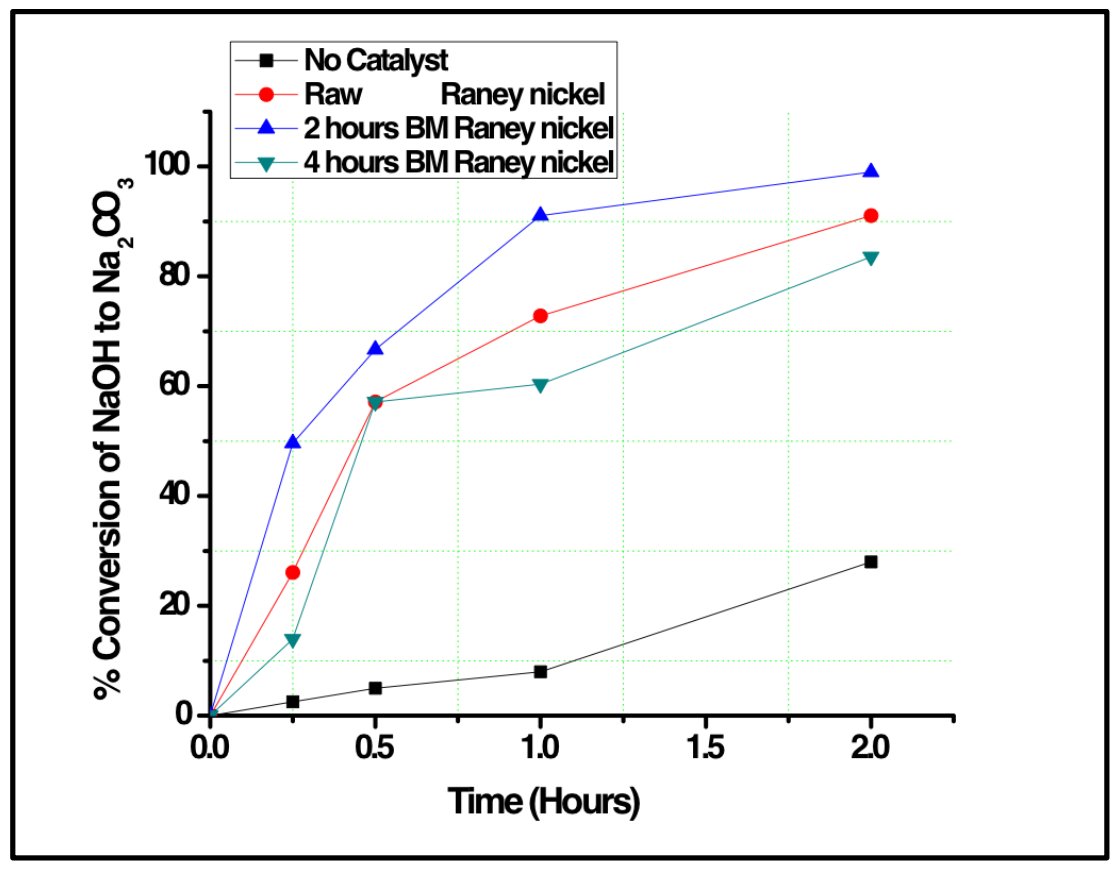

Figure 3.4.7 \% Conversion of $\mathrm{NaOH}$ to $\mathrm{Na}_{2} \mathrm{CO}_{3}$ for variously ball milled (BM) Raney nickel at $300^{\circ} \mathrm{C} .2$ hours ball milling time has exhibited the best result.

The effect for the use of Raney nickel catalyst on reaction (3.4.1) is illustrated in Figure 7. The curve shows that $2 \mathrm{~h}$ ball milled Raney nickel catalysts have the best results. $4 \mathrm{~h}$ ball milled Raney nickel catalysts have a low catalytic effect on reaction (3.4.1). The deactivation of $4 \mathrm{~h}$ ball milled Raney nickel can be due to either a high mechanical abrasion of the catalysts surface or thermally induced deactivation. The cold welding process dominates until $2 \mathrm{~h}$ of mechanical milling time for Raney nickel catalysts. As well as maximum $\%$ reduction in crystallite size was also observed for $2 \mathrm{~h}$ milling time only. Therefore, a large number of formations and movement of dislocations or vacancies have led to an increased catalytic activity for $2 \mathrm{~h}$ ball milled Raney nickel catalysts. However, there is a relatively less reduction in the crystallite size for $4 \mathrm{~h}$ milling time. Moreover, $\mathrm{X}$ - 
ray diffraction pattern for $4 \mathrm{~h}$ ball milling time clearly shows the amorphorization for the catalyst. Hence, $4 \mathrm{~h}$ milling time decreased the catalytic activity of Raney nickel.

Raw Raney nickel has a very wide distribution of particle sizes. Due to globular shape, they possess higher surface area. The globular particles are formed by the agglomeration of the disk-shaped particles by folding, enclosure, unfolding and pile-up [29]. Large number of open pores or caves formation allowed $2 \mathrm{~h}$ ball milled Raney nickel to show the highest catalytic activity compared to others. In summary, globular particles for Raney nickel has shown a better effect on reaction (3.4.1) compared to platelet like structure. 


\subsubsection{References}

1. S.K. Saxena, V. Drozd, A. Durygin, International Journal of Hydrogen Energy, 2008, $33,3625-3631$.

2. C. Pistonesi, A. Juan, B. Irigoyen, N. Amadeo, Applied Surface Science, 2007, 253, $4427-4437$.

3. Y. Matsumura, T. Nakamori, T., Applied Catalysis, 2004, 258, 107-114.

4. K. Hou, R. Hughes, Chemical Engineering Journal, 2001, 82, 311-328.

5. T. Numaguchi, K. Shoji, S. Yoshida, Applied Catalysis A, 1995, 133, 241-262.

6. T. Nozaki, N. Muto, S. Kado, K. Okazaki, Catalysis Today, 2004, 89, 57-65.

7. H. Hauptmann, W.F. Walter, Chemical Reviews, 1962, 62, 347-404.

8. E. Gerhard, K. Helmut, Prep. Solid Catalysis, 1997, 1, 30-34.

9. C.R.F. Lund, J.E. Kubsh, J.A. Dumesic, ACS Symposium Series, 1985, 279, 313.

10. D.G. Rethwisch, J. Phillips, Y. Chen, T.F. Hayden, J.A. Dumesic, Journal of Catalysis, 1985, 91, 167-180.

11. O. Beeck, Advances in Catalysis, 1950, 2, 151-195.

12. B.M.W. Trapnell, Quart. Rev., 1954, 8, 404-421.

13. S.J. Gregg, The Surface Chemistry of Solids; Reinhold Pub. Corp.: New York, NY, USA, 1969, 233.

14. O. Beeck, Reviews of Modern Physics, 1945, 17, 61-71.

15. A. Couper, D.D. Eley, Discussion of the Faraday Society, 1950, 8, 172-184.

16. D.A. Dowden, P.W. Reynolds, Discussion of the Faraday Society, 1950, 8, 184-190.

17. E.M. Hofer, H.E. Hintermann, Transactions of the Faraday Society, 1964, 60, 14571465.

18. C. Suryanarayan, Progress in Materials Science, 2001, 46, 1-184.

19. C.C. Koch, Nanostructured Materials, 1997, 9, 13-22.

20. J. Guerrero-Paz, D. Jaramillo-Vigueras, Nanostructured Materials, 1999, 11, 11231132. 
21. L.Z. Zhou, J.T. Guo, T.D. Jiang, S.H. Wang, Journal of Materials Science Letters, 1998, 17, 137-139.

22. G. Liang, J. Huot, R. Schulz, Journal of Alloys \& Compounds, 2001, 320,133-139

23. F.A. Mohamed, Acta Materialia, 2003, 51, 4107-4119.

24. H.J. Fecht, Nanostructured Materials, 1995, 6, 33-42.

25. J.B. Zhou, K.P. Rao, Journal of Alloys \& Compounds, 2004, 384, 125-130.

26. X. Zhao, Y. Ding, L. Ma, X. Shen, S. Xu, International Journal of Hydrogen Energy, 2008, 33, 6351-6356.

27. S. Lee, Alternative Fuels; Taylors\& Francis: Washington, DC, USA, 1996,127.

28. S. Kumar, S. Saxena, V. Drozd, International Journal of Energy Research, 2012, 36, $1133-1138$.

29. G.G. Lee, H. Hashimoto, R. Watanabe, Material Transactions The Japan Institute of Metals, 1995, 36, 548-554. 


\section{HYDROGEN STORAGE USING METAL HYDRIDES}

\subsection{LITERATURE REVIEW}

At ambient condition, $1 \mathrm{~kg}$ of hydrogen occupies $11 \mathrm{~m}^{3}$ of space. Therefore, to use hydrogen for vehicular applications, hydrogen needs to be either compressed as much as possible or increase the hydrogen density. Fig. 4.1.1 illustrates the phase diagram of hydrogen. Hydrogen exists as solid with a density of $70.6 \mathrm{~kg} / \mathrm{m}^{3}$ at very low temperatures $\left(\sim 11.15 \mathrm{~K}\right.$ or $\left.-262^{\circ} \mathrm{C}\right)$. However, at higher temperature $\left(\sim-273.15 \mathrm{~K}\right.$ or $\left.0^{\circ} \mathrm{C}, 1 \mathrm{bar}\right)$, hydrogen transform to a gas with low density of $0.089886 \mathrm{~kg} / \mathrm{m}^{3} .[1]$

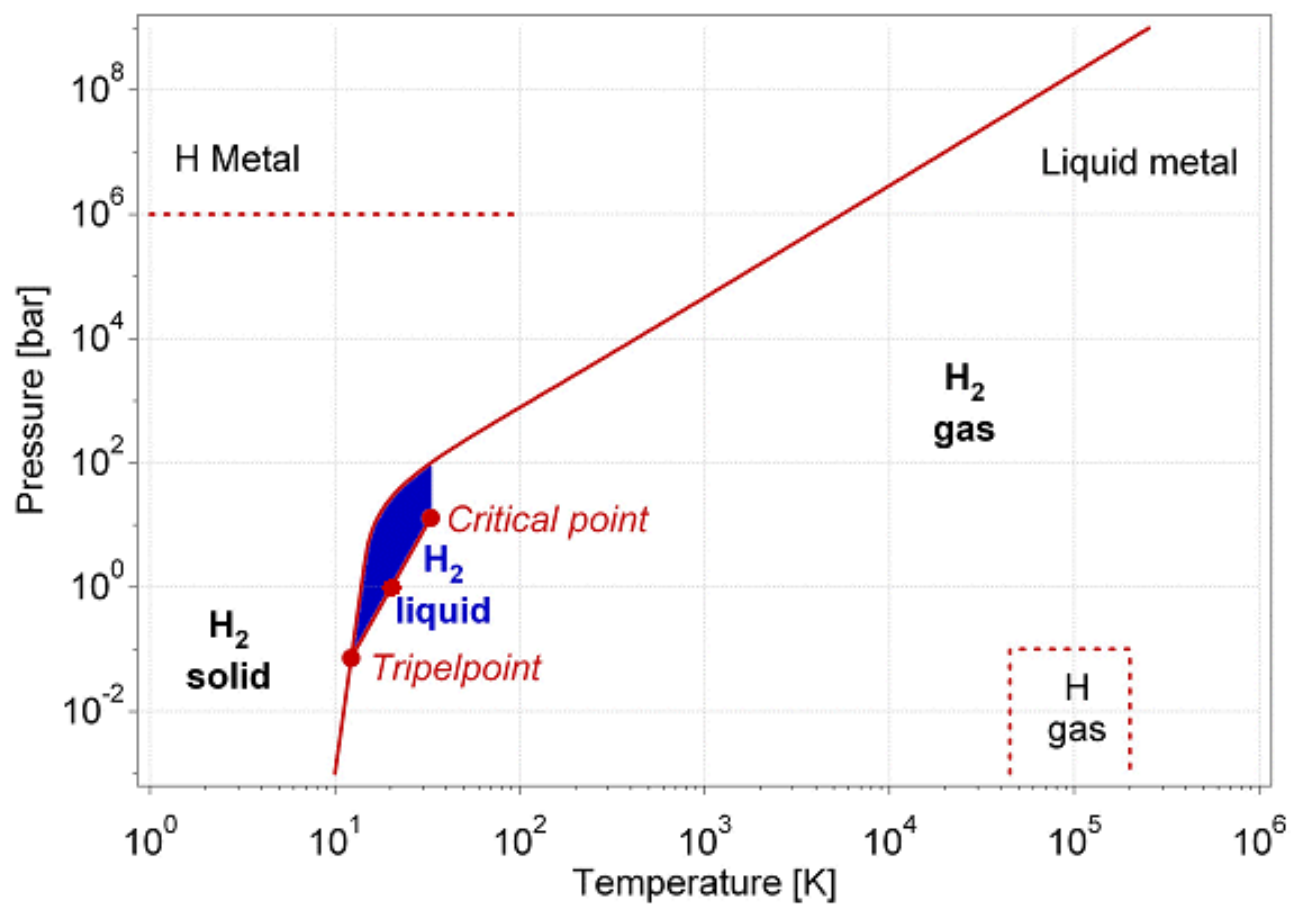

Figure 4.1.1 Primitive phase diagram of hydrogen [1]

A piston-type mechanical compressor can be used to compress hydrogen. The isothermal compression of hydrogen from 1 to 800 bars consumes $2.21 \mathrm{kWh} / \mathrm{kg}\left(\Delta G=R \cdot T \cdot \ln \left(\frac{P}{P_{0}}\right)\right)$ [2]. However, in a real practice, the compressive work for hydrogen is significantly higher. The most conventional medium to store hydrogen is to use high pressure gas 
cylinders. The materials such as austenitic stainless steel which have very high tensile strength, low density and are inert to hydrogen are selected for the manufacturing of gas cylinder [3]. There are two major concerns for high pressure gas cylinders: (1) safety issues; and (2) decrease in gravimetric density as pressure increases.

The hydrogen phase diagram illustrates that liquid hydrogen exists only between solidus line and the line from triple point at $21.2 \mathrm{~K}$ and the critical point at $32 \mathrm{~K}$. The thermodynamic calculation states that the free enthalpy change between gaseous hydrogen at $300 \mathrm{~K}$ and liquid hydrogen at $20 \mathrm{~K}$ is $11.64 \mathrm{MJ} / \mathrm{kg}$ [4]. Therefore, the required theoretical work to liquefy hydrogen from room temperature is $\mathrm{W}_{\text {th }}=$ $3.23 \mathrm{kWh} / \mathrm{kg}$. However, the technical work is approximately $15.2 \mathrm{kWh} / \mathrm{kg}$, almost half of the lower heating value of hydrogen combustion $(33.32 \mathrm{kWh} / \mathrm{kg})$ [5]. Thus, it can be easily observed that storage of hydrogen as a liquid is energetically unfavorable.

Hydrogen storage is also reported using chemical reaction with water. For instance, the binary hydride $(\mathrm{LiH})$ reacts spontaneously with water while the complex hydride $\left(\mathrm{NaBH}_{4}\right)$ reacts slowly unless catalyzed [6-9] However, for both hydrides, it is difficult to achieve the stoichiometric amount of hydrogen. A brief overview for the sodium hydroxide assisted hydrogen storage reactions can be found elsewhere [10].

This work focused on the storage of hydrogen in the form of metal hydrides. In the following sections, a review is presented for the potential solid materials for hydrogen storage. 


\subsubsection{Potential Hydrogen Storage Materials}

Figure 4.1.2 illustrates the chart for potential reversible hydrogen system considered so far [11].

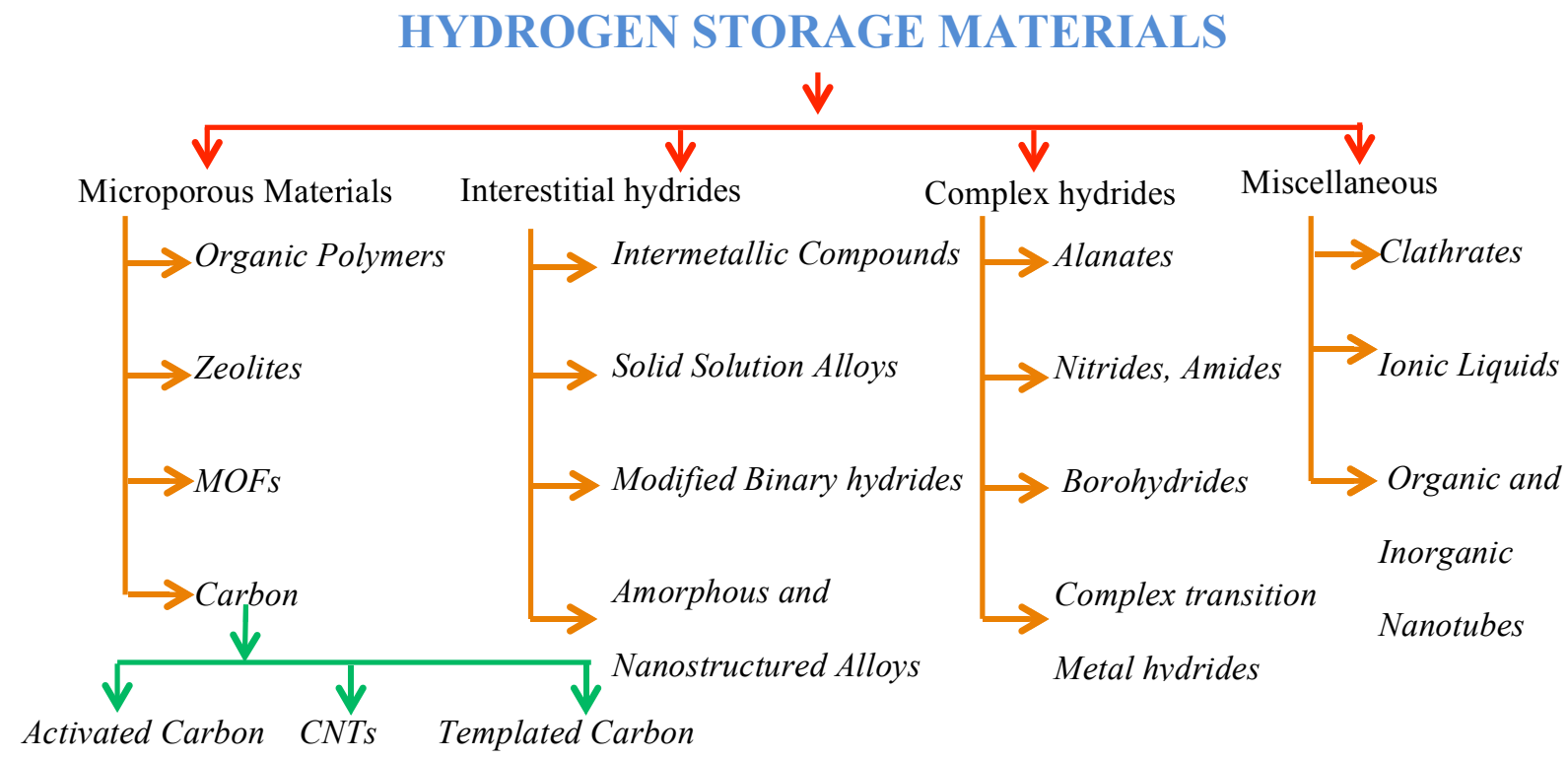

Figure 4.1.2 Chart for the potential reversible hydrogen system

Here, the attention is focused on the metal hydride and complex hydride systems because of their reversible behavior and high density. In the following section, a brief introduction of their (de-) hydrogenation of these hydride systems is presented. 


\subsubsection{Metal Hydrides}

Recently, metal-hydride has been extensively explored as a potential hydrogen storage system. The light metal such as $\mathrm{Mg}, \mathrm{Al}, \mathrm{B}, \mathrm{Na}, \mathrm{Li}$, and $\mathrm{Be}$ forms a large number of hydride compounds. These light metals are capable to store twice the number of hydrogen atoms per metal atom. However, heavier metals (such as transition metals) may also be included in the multi component system but mainly as an additive or a catalyst. Metals and alloys react with hydrogen to form metal hydrides according to Reaction 4.1.1: Direct dissociative chemisorption $\left(\mathrm{M}+x / 2 \mathrm{H}_{2} \leftrightarrow \mathrm{MH}_{x}\right)$. Where, $\mathrm{M}$ denotes a metal, a solid-solution or intermetallic compounds. Reaction (4.1.1) has a forward exothermic and reverse endothermic reaction.

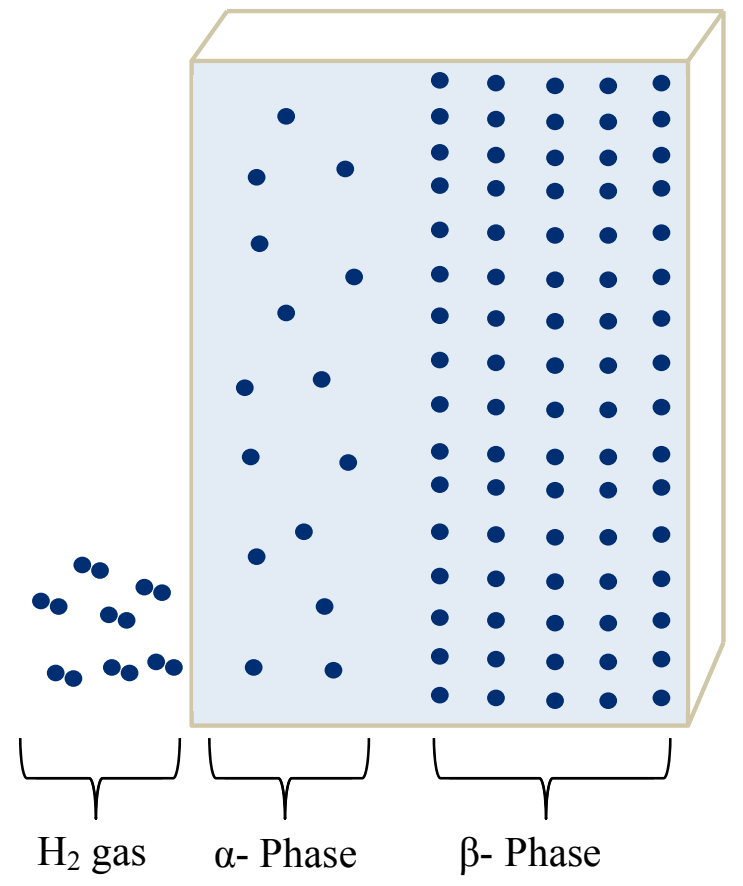

Figure 4.1.3 Schematic of hydrogen interaction with metal. The solid solution $\alpha$-phase and the hydride $\beta$-phase. 
Metal hydrides consist of metal and hydrogen atoms. Metal hydrides hold hydrogen through ionic, covalent, interstitial or complex bonds. On the criteria for extent of metalhydrogen interaction, two different kinds of metal hydrides exist: (1) $\alpha$-phase (hydrogen/metal <0.1); and (2) $\beta$-phase (hydrogen/metal >0.1) [1].

Hydrogen storage in metal hydrides is a complex process and includes several mechanistic steps. Moreover, hydrogen dissociation steps of metal hydrides depend on surface structure, morphology and purity. An optimum hydrogen-storage material is required to meet the target set by DOE (Table 1.2). A suitable hydrogen-storage material must have:

(1) High hydrogen capacity per unit mass or volume;

(2) Low dissociation temperature;

(3) Moderate dissociation pressure;

(4) Fast (de-) hydrogenation kinetics;

(5) High stability against moisture and $\mathrm{O}_{2}$;

(6) Low cost of recycling;

(7) Reversibility;

(8) Minimum heat loss during the exothermic hydride formation;

(9) Minimum heat loss during charging and discharging of hydrogen; and High safety

In the following subsections, practical storage properties such as the reversible storage capacity, gravimetric storage capacity and volumetric storage capacity are discussed in brief. 


\subsubsection{Reversible Storage Capacity}

The reversible storage capacity is defined as the quantity of hydrogen sorbed and desorbed between the lower and upper operating pressures of a hydrogen storage system. The most important criteria for any metal hydrides are their operation as a reversible system within required pressure and temperature condition. The thermodynamics of the materials plays a vital role in such situation. Zuttel explained the thermodynamic aspect of hydride formation using pressure-composition isotherm [1]. The study mentions that the stability of hydride can be presented in the form of Van't Hoff plots:

$$
\ln \left(P^{0} / P_{e q}^{0}\right)=\frac{\Delta H}{R} \cdot \frac{1}{T}-\frac{\Delta S}{R}
$$

All the notations have their usual meaning.

The shape of pressure-composition isotherm determines the pressure range over which the majority of the reversible uptake will occur. Moreover, rate of hydrogen uptake and release can also affect the amount of reversible amount of hydrogen stored. As it is possible that some of the stored hydrogen will not be released in a practical timeframe due to kinetic limitations, which could also prevent full hydrogenation upon recharging.

\subsubsection{Gravimetric Storage Capacity}

The gravimetric storage capacity is described as the amount of hydrogen stored per unit mass of material. Formula (4.1.2) illustrates the way to calculate the gravimetric storage capacity: 


$$
G_{w t \%}=\left(\frac{(H / M) M_{H}}{M_{M}+\left({ }^{H} / M\right) M_{H}} \times 100\right) \%
$$

Where, $\mathrm{H} / \mathrm{M}=$ hydrogen-to-metal atom ratio; $\mathrm{M}_{\mathrm{H}}=$ molar mass of hydrogen; $\mathrm{M}_{\mathrm{M}}=$ molar mass of the metal.

\subsubsection{Volumetric storage capacity}

The volumetric storage capacity is the amount of hydrogen per unit volume of the material. In principle, every absorbed hydrogen atom diffuses through the bulk of the material and contained within the boundaries of the crystal lattice. It should be noted that there is always a lattice expansion due to the hydrogen absorption and must be accounted for in the calculation of the volumetric storage capacity.

\subsubsection{Complex hydrides}

In complex hydrides, atomic hydrogen is often bonded ionically or covalent into the bulk of the storage material. The hydrogen in the complex hydrides is generally positioned in the corners of tetrahedron with light elements $(\mathrm{B}, \mathrm{Al}, \mathrm{Mg}$ and $\mathrm{Li})$ in the center. The complex hydrides consist of alkali or alkaline earth metals and $\left[\mathrm{AlH}_{4}\right]^{-},\left[\mathrm{BH}_{4}\right]^{-},\left[\mathrm{NH}_{2}\right]^{-}$ anionic hydrides. These complex hydrides are stable in nature and decompose only at elevated temperature. Table 4.1.1 is the summary for the complex hydrides. 


\begin{tabular}{|c|c|c|c|c|c|c|}
\hline Hydride & $\begin{array}{c}\mathrm{Wt} \\
(\mathrm{g} / \mathrm{mol})\end{array}$ & $\begin{array}{c}\mathrm{H} \\
(\mathrm{wt} \%)\end{array}$ & $\begin{array}{c}\mathrm{H} \\
\left(\mathrm{kg} / \mathrm{m}^{3}\right)\end{array}$ & Decomposition Reaction & $\begin{array}{l}\mathrm{T}_{\mathrm{d}} \\
\left({ }^{0} \mathrm{C}\right)\end{array}$ & Ref \\
\hline $\mathrm{LiAlH}_{4}$ & 37.95 & 10.55 & 74.02 & $\begin{array}{c}3 \mathrm{LiAlH}_{4} \rightarrow \mathrm{Li}_{3} \mathrm{AlH}{ }_{6}+2 \mathrm{Al}+3 \mathrm{H}_{2} \\
\mathrm{Li}_{3} \mathrm{AlH}_{6} \rightarrow 3 \mathrm{LiH}+\mathrm{Al}+3 / 2 \mathrm{H}_{2} \\
3 \mathrm{LiH} \rightarrow 3 \mathrm{Li}+3 / 2 \mathrm{H}_{2}\end{array}$ & $\begin{array}{l}112 \\
127 \\
720\end{array}$ & {$[12]$} \\
\hline $\mathrm{NaAlH}_{4}$ & 53.97 & 7.41 & 97.41 & $\begin{array}{l}3 \mathrm{NaAlH}_{4} \rightarrow \mathrm{Na}_{3} \mathrm{AlH}_{6}+2 \mathrm{Al}+3 \mathrm{H} \\
2 \\
\mathrm{Na}_{3} \mathrm{AlH}_{6} \rightarrow 3 \mathrm{NaH}+\mathrm{Al}+3 / 2 \mathrm{H}_{2} \\
\quad 3 \mathrm{NaH} \rightarrow 3 \mathrm{Na}+3 / 2 \mathrm{H}_{2}\end{array}$ & $\begin{array}{l}220 \\
250 \\
425\end{array}$ & $\begin{array}{c}{[13-} \\
14]\end{array}$ \\
\hline $\mathrm{KAlH}_{4}$ & 70.08 & 5.71 & 70.31 & $\begin{array}{c}3 \mathrm{KAlH}_{4} \rightarrow \mathrm{K}_{3} \mathrm{AlH}{ }_{6}+2 \mathrm{Al}+3 \mathrm{H}_{2} \\
\mathrm{~K}_{3} \mathrm{AlH}_{6} \rightarrow 3 \mathrm{KH}+\mathrm{Al}+3 / 2 \mathrm{H}_{2} \\
3 \mathrm{KH} \rightarrow 3 \mathrm{~K}+3 / 2 \mathrm{H}_{2}\end{array}$ & $\begin{array}{l}300 \\
340 \\
417 \\
\end{array}$ & {$[15]$} \\
\hline $\mathrm{RbAlH}_{4}$ & 116.45 & 3.44 & 124.4 & & & \\
\hline $\mathrm{CsAlH}_{4}$ & 163.08 & 2.44 & 108.9 & & & \\
\hline $\mathrm{Be}\left(\mathrm{AlH}_{4}\right)_{2}$ & 71.04 & 11.35 & -- & & & \\
\hline $\operatorname{Mg}\left(\mathrm{AlH}_{4}\right)_{2}$ & 86.3 & 9.27 & 98.15 & $\begin{array}{c}\text { a. } \mathrm{Mg}\left(\mathrm{AlH}_{4}\right)_{2} \rightarrow \mathrm{MgH}_{2}+2 \mathrm{Al}+ \\
3 \mathrm{H}_{2} \\
\mathrm{MgH}_{2} \rightarrow \mathrm{Mg}+\mathrm{H}_{2} \\
2 \mathrm{Al}+\mathrm{Mg} \rightarrow 1 / 2 \mathrm{Al}_{3} \mathrm{Mg}_{2}+1 / 2 \mathrm{Al} \\
\left.\text { b. } \mathrm{Mg}(\mathrm{AlH})_{4}\right)_{2} \rightarrow \mathrm{MgAlH}_{5}+\mathrm{Al}+ \\
1.5 \mathrm{H}_{2} \\
\mathrm{MgAlH}_{5}+\mathrm{Al} \rightarrow \mathrm{MgH}_{2}+2 \mathrm{Al}+ \\
1.5 \mathrm{H}_{2} \\
\end{array}$ & $\begin{array}{l}110-200 \\
240-380 \\
400 \\
120-155 \\
210-255\end{array}$ & $\begin{array}{l}{[16-} \\
17]\end{array}$ \\
\hline $\mathrm{Ca}\left(\mathrm{AlH}_{4}\right)_{2}$ & 102.04 & 7.84 & 96.97 & $\begin{array}{c}\mathrm{Ca}\left(\mathrm{AlH}_{4}\right)_{2} \rightarrow \mathrm{CaAlH}_{5}+\mathrm{Al}+ \\
3 / 2 \mathrm{H}_{2} \\
\mathrm{CaAlH}_{5} \rightarrow \mathrm{CaH}_{2}+\mathrm{Al}+3 / 2 \mathrm{H}_{2} \\
\mathrm{CaH}_{2} \rightarrow \mathrm{Ca}+\mathrm{H}_{2} \\
\end{array}$ & $\begin{array}{c}200 \\
260-550 \\
600-700\end{array}$ & {$[18]$} \\
\hline $\mathrm{Sr}\left(\mathrm{AlH}_{4}\right)_{2}$ & 149.65 & 5.39 & -- & & & \\
\hline $\mathrm{Ba}\left(\mathrm{AlH}_{4}\right)_{2}$ & 199.36 & 4.04 & -- & & & \\
\hline $\mathrm{LiBH}_{4}$ & 21.75 & 18.39 & 124 & $\mathrm{LiBH}_{4} \rightarrow \mathrm{LiH}+\mathrm{B}+3 / 2 \mathrm{H}_{2}$ & 400 & {$[19]$} \\
\hline $\mathrm{NaBH}_{4}$ & 37.81 & 10.58 & 118 & $\mathrm{NaBH}_{4} \rightarrow \mathrm{NaH}+\mathrm{B}+3 / 2 \mathrm{H}_{2}$ & 565 & {$[20]$} \\
\hline $\mathrm{KBH}_{4}$ & 53.90 & 7.42 & 85.57 & & 500 & {$[21]$} \\
\hline $\mathrm{RbBH}_{4}$ & 100.28 & 3.99 & 77.2 & & 600 & {$[21]$} \\
\hline $\mathrm{CsBH}_{4}$ & 147.72 & 2.71 & 65.66 & & 660 & {$[21]$} \\
\hline $\mathrm{Be}\left(\mathrm{BH}_{4}\right)_{2}$ & 38.69 & 20.84 & 126.9 & $\mathrm{Be}\left(\mathrm{BH}_{4}\right)_{2} \rightarrow \mathrm{Be}+2 \mathrm{~B}+4 \mathrm{H}_{2}$ & & {$[22]$} \\
\hline $\operatorname{Mg}\left(\mathrm{BH}_{4}\right)_{2}$ & 53.93 & 14.84 & 117.2 & $\begin{array}{c}\mathrm{Mg}\left(\mathrm{BH}_{4}\right)_{2} \rightarrow \mathrm{MgH}_{2}+2 \mathrm{~B}+3 \mathrm{H}_{2} \\
\mathrm{MgH}_{2} \rightarrow \mathrm{Mg}+\mathrm{H}_{2}\end{array}$ & $\begin{array}{l}290 \\
317 \\
\end{array}$ & $\begin{array}{c}{[23-} \\
24]\end{array}$ \\
\hline $\mathrm{Ca}\left(\mathrm{BH}_{4}\right)_{2}$ & 69.70 & 11.48 & 124.0 & $\begin{array}{c}\mathrm{Ca}\left(\mathrm{BH}_{4}\right)_{2} \rightarrow \mathrm{CaH}_{2}+2 \mathrm{~B}+3 \mathrm{H}_{2} \\
\mathrm{CaH}_{2} \rightarrow \mathrm{Ca}+\mathrm{H}_{2} \\
\end{array}$ & $347-497$ & {$[25]$} \\
\hline $\mathrm{Sr}\left(\mathrm{BH}_{4}\right)_{2}$ & 117.24 & 6.88 & -- & & & \\
\hline $\mathrm{Ba}\left(\mathrm{BH}_{4}\right)_{2}$ & 166.95 & 4.79 & -- & & 375 & {$[21]$} \\
\hline $\begin{array}{l}\mathrm{LiNH}_{2}- \\
2 \mathrm{LiH}\end{array}$ & & 10.5 & & $\begin{array}{c}\mathrm{LiNH}_{2}+2 \mathrm{LiH} \leftrightarrow \mathrm{Li}_{2} \mathrm{NH}+ \\
\mathrm{LiH}+\mathrm{H}_{2} \leftrightarrow \mathrm{Li}_{3} \mathrm{~N}+2 \mathrm{H}_{2}\end{array}$ & $150-450$ & $\begin{array}{l}{[26-} \\
28]\end{array}$ \\
\hline
\end{tabular}




\begin{tabular}{|c|c|c|c|c|}
\hline $\begin{array}{l}\mathrm{CaNH-} \\
\mathrm{CaH}_{2}\end{array}$ & 2.1 & $\mathrm{CaNH}+\mathrm{CaH}_{2} \leftrightarrow \mathrm{Ca}_{2} \mathrm{NH}+\mathrm{H}_{2}$ & $350-650$ & [26] \\
\hline $\begin{array}{l}\mathrm{Mg}\left(\mathrm{NH}_{2}\right)_{2} \\
-2 \mathrm{LiH}\end{array}$ & 5.6 & $\begin{array}{c}\mathrm{Mg}\left(\mathrm{NH}_{2}\right)_{2}+2 \mathrm{LiH} \leftrightarrow \\
\mathrm{Li}_{2} \mathrm{Mg}(\mathrm{NH})_{2}+2 \mathrm{H}_{2}\end{array}$ & $100-250$ & $\begin{array}{ll}{[29-} \\
32]\end{array}$ \\
\hline & 6.9 & $\begin{array}{c}3 \mathrm{Mg}\left(\mathrm{NH}_{2}\right)_{2}+8 \mathrm{LiH}=4 \mathrm{Li}_{2} \mathrm{NH} \\
+\mathrm{Mg}_{3} \mathrm{~N}_{2}+8 \mathrm{H}_{2}\end{array}$ & $150-300$ & [33] \\
\hline & 9.1 & $\begin{array}{c}\mathrm{Mg}\left(\mathrm{NH}_{2}\right)_{2}+4 \mathrm{LiH}=\mathrm{Li}_{3} \mathrm{~N}+ \\
\mathrm{LiMgN}+4 \mathrm{H}_{2}\end{array}$ & $150-300$ & [34] \\
\hline $\begin{array}{l}\mathrm{LiNH}_{2}- \\
\mathrm{LiBH}_{4}\end{array}$ & 11.9 & $\begin{array}{c}2 \mathrm{LiNH}_{2}+\mathrm{LiBH}_{4} \rightarrow \\
\mathrm{Li}_{3} \mathrm{BN}_{2} \mathrm{H}_{8} \rightarrow \mathrm{Li}_{3} \mathrm{BN}_{2}+4 \mathrm{H}_{2}\end{array}$ & $150-350$ & $\begin{array}{c}{[35-} \\
36]\end{array}$ \\
\hline $\begin{array}{l}\mathrm{Mg}\left(\mathrm{NH}_{2}\right)_{2} \\
-\mathrm{MgH}_{2} \\
\end{array}$ & 7.4 & $\begin{array}{c}\mathrm{Mg}\left(\mathrm{NH}_{2}\right)_{2}+2 \mathrm{MgH}_{2} \rightarrow \\
\mathrm{Mg}_{3} \mathrm{~N}_{2}+4 \mathrm{H}_{2} \\
\end{array}$ & $20 * *$ & [37] \\
\hline $\begin{array}{l}\mathrm{LiNH}_{2}- \\
\mathrm{LiAlH}_{4}\end{array}$ & 5.0 & $\begin{array}{c}2 \mathrm{LiNH}_{2}+\mathrm{LiAlH}_{4} \rightarrow \mathrm{LiNH}_{2}+ \\
2 \mathrm{LiH}+\mathrm{AlN}+2 \mathrm{H}_{2}=\mathrm{Li}_{3} \mathrm{~A} \\
+\mathrm{N}_{2}+4 \mathrm{H}_{2} \\
\end{array}$ & $20^{* *-500}$ & [38] \\
\hline $\begin{array}{l}\mathrm{Mg}\left(\mathrm{NH}_{2}\right)_{2} \\
-\mathrm{LiAlH}_{4}\end{array}$ & 8.5 & $\begin{array}{c}3 \mathrm{Mg}\left(\mathrm{NH}_{2}\right)_{2}+3 \mathrm{LiAlH}_{4} \rightarrow \\
\mathrm{Mg}_{3} \mathrm{~N}_{2}+\mathrm{Li}_{3} \mathrm{AlN}_{2}+ \\
2 \mathrm{AlN}+12 \mathrm{H}_{2} \\
\end{array}$ & 20 **-350 & [39] \\
\hline $\begin{array}{c}\mathrm{Mg}\left(\mathrm{NH}_{2}\right)_{2} \\
-\mathrm{CaH}_{2} \\
\end{array}$ & 4.1 & $\begin{array}{l}\mathrm{Mg}\left(\mathrm{NH}_{2}\right)_{2}+\mathrm{CaH}_{2} \rightarrow \\
\mathrm{MgCa}(\mathrm{NH})_{2}+2 \mathrm{H}_{2} \\
\end{array}$ & $20 * *-500$ & [40] \\
\hline $\begin{array}{c}\mathrm{NaNH}_{2}- \\
\mathrm{LiAlH}_{4}\end{array}$ & 5.2 & $\begin{array}{c}\mathrm{NaNH}_{2}+\mathrm{LiAlH}_{4} \rightarrow \mathrm{NaH}+ \\
\mathrm{LiAl}_{0.33} \mathrm{NH}+0.67 \mathrm{Al}+2 \mathrm{H}_{2} \\
\end{array}$ & $20 * *$ & [41] \\
\hline $\begin{array}{l}\mathrm{LiNH}_{2-}^{-} \\
\mathrm{CaH}_{2}\end{array}$ & 4.5 & $\begin{array}{c}2 \mathrm{LiNH}_{2}+\mathrm{CaH}_{2}=\mathrm{Li}_{2} \mathrm{Ca}(\mathrm{NH})_{2} \\
+2 \mathrm{H}_{2}\end{array}$ & $100-330$ & [42] \\
\hline $\begin{array}{l}\mathrm{LiNH}_{2}- \\
\mathrm{Li}_{3} \mathrm{AlH}_{6}\end{array}$ & 7.5 & $\begin{array}{c}4 \mathrm{LiNH}_{2}+2 \mathrm{Li}_{3} \mathrm{AlH}_{6} \rightarrow \\
\mathrm{Li}_{3} \mathrm{AlN}_{2}+\mathrm{Al}+2 \mathrm{Li}_{2} \mathrm{NH}+ \\
3 \mathrm{LiH}+15 / 2 \mathrm{H}_{2} \\
\end{array}$ & $100-500$ & [43] \\
\hline $\begin{array}{l}\mathrm{Li}_{4} \mathrm{BN}_{3} \mathrm{H}_{10} \\
-\mathrm{MgH}_{2}\end{array}$ & 9.2 & $\begin{array}{c}2 \mathrm{Li}_{4} \mathrm{BN}_{3} \mathrm{H}_{10}+3 \mathrm{MgH}_{2} \rightarrow \\
2 \mathrm{Li}_{3} \mathrm{BN}_{2}+\mathrm{Mg}_{3} \mathrm{~N}_{2}+2 \mathrm{LiH}+ \\
12 \mathrm{H}_{2}\end{array}$ & $100-400$ & [44] \\
\hline
\end{tabular}

Table 4.1.1 Summary of the complex hydrides

\subsubsection{Summary}

As a result of extensive research during the past decade, a large number of potential hydrogen storage systems are identified. Even though, the present situation is satisfactory but still there are challenges (such as slow kinetics and unfavorable thermodynamics) 
remain and needs to be resolved. Therefore, the current demand is to perform applicationfocused research and understand in-depth mechanistic steps of the hydride system. 


\subsubsection{References}

[1] A. Zuttel, Materials Today, 2003, 6, 24-33.

[2] E.L. Houston, $A$ Liquid and Solid Storage of Hydorgen. In: Proceedings of the $5^{\text {th }}$ World Hydrogen Energy Conference, Veziroqlu, T.N., and Taylor, J.B. (eds.), Pergamon Press, Oxford, 1984, 3.

[3] L. Schlapabch, In: Hydrogen in Intermetallic Compounds II, Schlapabch, L. (ed.), Springer, Heidelberg, 1988, 219.

[4] G. Chen, S. Anghaie based on NIST databases http://www.inspi.uf.edu/data/h_prop_package.html

[5] M.V. Ardenne, Effekte der Physik, Verlag Harri Deutsch, Frankfurt am Main, 1990, 712.

[6] C. Haertling, R.J. Hanrahan Jr., R. Smith, Journal of Nuclear Materials, 2006, 349, 195-233.

[7] A.W. McClaine, R.W. Breault, C. Larsen, R. Konduri, J. Rolfe, F. Becker, G. Miskolczy, Proceedings of 2000 US DOE $\mathrm{H}_{2}$ Program Review, 2000.

[8] A. Garron, D. S'wierczyn'ski, S. Bennici, A. Auroux, International Journal of Hydrogen Energy, 2009, 34, 1185 - 1199.

[9] H.I. Schlesinger, H.C. Brown, A.E. Finholt, J.R. Gilbreath, H.R. Hoekstra, E.K. Hyde, Journal of the American Chemical Society, 1953, 75, 215-219.

[10] S. Kumar, S.K. Saxena, In Materials and processes for energy: communicating current research and technological developments, A. Mendez-Vilas (ed.), Formatex Research Center (Badajoz, Spain), 2013.

[11] D. P. Broom, Hydrogen storage materials: the characterization of their storage properties, London, Springer, 2011. DOI: 10.1007/978-0-85729-221-6_1.

[12] B.Bogdanovic, M.Schwickardi, Journal of Alloys and Compounds, 1997, 253-254, 1

[13] B.Bogdanovic, R.A.Brand, A.Marjanovic, M.Schwickardi, J.Tolle, Journal of

Alloys and Compounds, 2000, 302, 36

[14] F.Schuth, B.Bogdanovic, M.Felderhoff, Chemical Communications, 2004, 2249.

[15] H.Morioka, K.Kakizaki, S.C.Chung, A.Yamada, Journal of Alloys and 
Compounds, 2003, 353, 310

[16] M.Fichtner, O.Fuhr, O.Kircher, Journal of Alloys and Compounds, 2003, 356357,418 .

[17] A.Fossdal, H.W.Brinks, M.Fichtner, B.C.Hauback, Journal of Alloys and

Compounds, 2005, 387, 47

[18] O.M.Lovvik, Physical Review B, 2005, 71, 1144111.

[19] L. Mosegaard, B. Moller, J.E. Jorgensen, U. Bosenberg, M. Dornheim, J.C. Hanson, Y. Cerenius, G. Walker, H.J. Jakobsen, F. Besenbacher, T.R. Jensen, Journal of Alloys and Compounds, 2007, 446-447, 301.

[20] A.G. Ostroff, R.T. Sanderson, Journal of Inorganic and Nuclear Chemistry, 1957, 4, 230 .

[21] W. Grochala, P.P. Edwards, Chemical Reviews, 2004, 104, 1283.

[22] M.J. van Setten, G.A.de Wijs, G. Brocks, Physical Review B, 2008, 77, 165115.

[23] J. Voss, J.S. Hummelshoj, Z. Lodziana, T. Vegge, Journal of Physics: Condensed

Matter, 2009, 21, 012203

[24] T. Matsunaga, F. Buchter, P. Mauron, M. Bielman, Y. Nakamori, S. Orimo, N. Ohba, K. Miwa, S. Towata, A. Zuttel, Journal of Alloys and Compounds, 2008, 459, 583.

[25] J. H. Kim, S.A. Jin, J.H. Shim, Y.W. Cho, Journal of Alloys and Compounds 2008,461, L20-L22.

[26] P. Chen, Z. Xiong, J. Luo, J. Lin, K.L. Tan, Nature, 2002, 420, 302-304

[27] S. Orimo, Y. Nakamori, J. R. Eliseo, A. Zuttel, C. M. Jensen, Chemical Reviews, 2007 107, 4111-4132.

[28] T. Ichikawa, S. Isobe, N. Hanada, H. Fujii, Journal of Alloys and Compounds, 2004, $365,271-276$.

[29] Z. T. Xiong, G. Wu, J. Hu, P. Chen, Advanced Materials, 2004, 16, 1522-1525.

[30] P. Chen, Oral presentation, MRS Fall Meeting, Boston, MA, 2003.

[31] W.F. Luo, Journal of Alloys and Compounds, 2004, 381, 284-287. 
[32] J. Hu, Y. Liu, G. Wu, Z. Xiong, Y.S. Chua, P. Chen, Chemistry of Materials, 2008, 20, 4398-4402.

[33] H. Y. Leng, T. Ichikawa, S. Hino, N. Hanada, S. Isobe, H. Fujii, The Journal of Physical Chemistry B, 2004, 108, 8763

[34] Y. Nakamori, S. Orimo, Journal of Alloys and Compounds, 2004, 370, 271-275

[35] F.F. Pinkerton, G.P. Meisner, M.S. Meyer, M.P. Balogh, M.D. Kundrat, The Journal of Physical Chemistry B , 2005, 109, 6-8.

[36] M. Aoki, K. Miwa, T. Noritake, G. Kitahara, Y. Nakamori, S, Orimo, S. Towata, Applied Physics A: Material Science \& Processing, 2005, 80, 1409-1412.

[37] J. Hu, G. Wu, Y. Liu, Z. Xiong, P. Chen, K. Murata, K. Sokata, G. Wolf, The Journal of Physical Chemistry B, 2006, 110, 14688-14692.

[38] Z. Xiong, G. Wu, J. Hu, Y. Liu, P. Chen, W. Luo, J. Wang, Advanced Functional Materials, 2007, 17, 1137-1142.

[39] Y. Liu, J. Hu, G. Wu, Z. Xiong, P. Chen , The Journal of Physical Chemistry C, 2007, 111, 19161-19164.

[40] Y. Liu, T. Liu, Z. Xiong, J. Hu, G. Wu, P. Chen, A.T.S. Wee, P. Yang, K. Murata, K. Sokata, European Journal of Inorganic Chemistry, 2006, 21, 4368-4373.

[41] Z. Xiong, J. Hu, G. Wu, Y. Liu, P. Chen, Catalysis Today, 2007, 120, 287-291

[42] G. Wu , Z. Xiong, T. Liu, Y. Liu , J. Hu, P. Chen, Y. Feng, A.T.S. Wee, Inorganic Chemistry, 2007, 46, 517-521.

[43] Y. Kojima, M. Matsumoto, Y. Kawai, T. Haga, N. Ohba, K. Miwa, S. Towata, Y. Nakamori, S. Orimo, The Journal of Physical Chemistry B, 2006, 110, 9632-9636.

[44] J. Yang, A. Sudik , D. J. Siegel, D. Halliday, A. Drews, R. O. Carter III, C. Wolverton, G. J. Lewis, J. W. A. Sachtler, J. J. Low, S. A. Faheem, D. A. Lesch, V. Ozolinš, Angewandte Chemie International Edition, 2008, 47, 882-887. 


\subsection{In-Situ INVESTIGATION FOR THE DEHYDROGENATION MECHANISM OF THE LiAlH 4 -MgH $2-\mathrm{NaNH}_{2}$ TERNARY SYSTEM}

\subsubsection{INTRODUCTION}

An intensive research has been focused on $\mathrm{MgH}_{2}[1-3]$, light-element complex hydrides such as amides $\left(\mathrm{NH}_{2}^{-}\right)$[4-7], alanates $\left(\mathrm{AlH}_{4}^{-}\right)$[8-11] and borohydrides $\left(\mathrm{BH}_{4}^{-}\right)$[12-15] to meet the DOE target for hydrogen storage. The theoretical hydrogen capacity of $\mathrm{LiAlH}_{4}$ is as high as 10.5 wt. $\%$, highest among the alkali metals (M) $\mathrm{AlH}_{4}$ family. $\mathrm{LiAlH}_{4}$ dehydrogenates in following three steps:

$$
\begin{array}{r}
3 \mathrm{LiAlH}_{4} \rightarrow \mathrm{Li}_{3} \mathrm{AlH}_{6}+2 \mathrm{Al}+3 \mathrm{H}_{2} \\
\mathrm{Li}_{3} \mathrm{AlH}_{6} \rightarrow 3 \mathrm{LiH}+\mathrm{Al}+3 / 2 \mathrm{H}_{2} \\
\mathrm{LiH}+\mathrm{Al} \rightarrow \mathrm{LiAl}+1 / 2 \mathrm{H}_{2}
\end{array}
$$

The hydrogen evolution from reaction (4.2.1) is thermodynamically favored at low temperatures $\left(\Delta \mathrm{H}=-27 \mathrm{~kJ} / \mathrm{mol} \mathrm{H}_{2}\right)[16]$ but the reaction is kinetically slow in transforming $\mathrm{AlH}_{4}{ }^{-}$to $\mathrm{AlH}_{6}{ }^{3-}$ [17]. A lot of efforts have been performed to improve its hydrogen storage properties such as doping with different catalysts and combining with other metal/complex hydrides. However, the destabilization of $\mathrm{LiAlH}_{4}$ is still to be resolved. The other two reactions (4.2.2 and 4.2.3) dehydrogenates at higher temperature.

The interest for sodium amide $\left(\mathrm{NaNH}_{2}, 5.1 \mathrm{wt} . \% \mathrm{H}_{2}\right)$ is growing in the recent years. A number of possible combinations such as $\mathrm{NaNH}_{2}-\mathrm{MgH}_{2}$ [18-19], $\mathrm{NaNH}_{2}-\mathrm{NaBH}_{4}$ [20-21], $\mathrm{NaNH}_{2}-\mathrm{NaAlH}_{4}$ [22] and $\mathrm{NaNH}_{2}-\mathrm{LiAlH}_{4}$ [23-24] have been investigated. The earlier 
reports suggest a relatively faster kinetics for hydrogen desorption after the inclusion of sodium amide. On the other hand, $\mathrm{MgH}_{2}$ possesses a large gravimetric hydrogen storage density (7.6 wt. \%) and can successfully destabilize $\mathrm{LiAlH}_{4}$ and $\mathrm{NaNH}_{2}$. However, $\mathrm{MgH}_{2}$ suffers unfavorable thermodynamics $\left(\Delta \mathrm{H}=\quad-76 \mathrm{~kJ} / \mathrm{mol} \quad \mathrm{H}_{2}\right)$ and slow dehydrogenation/rehydrogenation kinetics. Table 4.2.1 illustrates the hydrogen absorption and desorption for the binary combinations of $\mathrm{LiAlH}_{4} / \mathrm{MgH}_{2} / \mathrm{NaNH}_{2}$. In the present study, the ternary hydride system of $\mathrm{LiAlH}_{4}-\mathrm{MgH}_{2}-\mathrm{NaNH}_{2}$ (1:1:1 molar mixture) was prepared and investigated, in order to improve the hydrogen storage properties via the mutual destabilization among the three hydrides. The gravimetric hydrogen storage density of the ternary system is $7.75 \mathrm{wt} . \%$ and thus exceeds the target of DOE. 


\begin{tabular}{|c|c|c|c|c|c|}
\hline System & Milling & $\begin{array}{l}\mathrm{T}_{\text {dehyd. }} \\
\left({ }^{\circ} \mathrm{C}\right)\end{array}$ & $\% \mathrm{H}_{2}$ Yield & Phases Observed & Ref. \\
\hline $\begin{array}{c}\mathrm{NaNH}_{2}: \mathrm{LiAlH}_{4} \\
(1: 1)\end{array}$ & $\begin{array}{l}30: 1(\mathrm{bpr}) \\
30 \mathrm{~min} .\end{array}$ & $>120$ & 5.1 & $\begin{array}{c}\mathrm{NaNH}_{2}, \mathrm{LiAlH}_{4} \\
\mathrm{Li}_{3} \mathrm{Na}\left(\mathrm{NH}_{2}\right)_{4}, \mathrm{LiNa}_{2} \mathrm{AlH}_{6}\end{array}$ & {$[25]$} \\
\hline $\begin{array}{c}\mathrm{NaNH}_{2}: \mathrm{LiAlH}_{4} \\
(2: 1)\end{array}$ & $30: 1(\mathrm{bpr})$ & 320 & $\begin{array}{l}3.9 \mathrm{E} \mathrm{H} \text { in } 46 \mathrm{~h} \\
\text { of ball milling }\end{array}$ & $\begin{array}{c}\mathrm{Li}_{3} \mathrm{Na}\left(\mathrm{NH}_{2}\right)_{4}, \mathrm{NaAlH}_{4} \\
{\left[\mathrm{H}_{2}, \mathrm{NaH} \text { and } \mathrm{LiAlN}_{2} \mathrm{H}_{2}\right]}\end{array}$ & [26] \\
\hline $\begin{array}{c}\mathrm{NaNH}_{2}: \mathrm{LiAlH}_{4} \\
(1: 2)\end{array}$ & $30: 1(\mathrm{bpr})$ & 220 & $\begin{array}{l}3.9 \mathrm{E} \mathrm{H} \text { in } 14 \mathrm{~h} \\
\text { of ball milling }\end{array}$ & $\begin{array}{c}\mathrm{Li}_{3} \mathrm{Na}\left(\mathrm{NH}_{2}\right)_{4}, \mathrm{LiNH}_{2} \\
\mathrm{NaAlH}_{4}\end{array}$ & {$[26]$} \\
\hline $\begin{array}{c}\mathrm{MgH}_{2}: \mathrm{LiAlH}_{4} \\
(1: 1)\end{array}$ & $30: 1(\mathrm{bpr})$ & $<400$ & - & $\mathrm{Li}_{3} \mathrm{Mg}_{7}, \mathrm{Mg}_{17} \mathrm{Al}_{12}$ & {$[27]$} \\
\hline $\begin{array}{c}\mathrm{MgH}_{2}: \mathrm{LiAlH}_{4} \\
(4: 1)\end{array}$ & $\begin{array}{c}30: 1(\mathrm{bpr}) \\
18 \mathrm{~min} .\end{array}$ & $<400$ & - & $\mathrm{Mg}_{17} \mathrm{Al}_{12}, \mathrm{Li}_{0.92} \mathrm{Mg}_{4.08}$ & {$[28]$} \\
\hline $\begin{array}{l}\mathrm{MgH}_{2}: \mathrm{LiAlH}_{4} \\
(1: 1 / 2.5: 1 / 4: 1)\end{array}$ & $45: 1(\mathrm{bpr})$ & $<500$ & 7.46 & $\begin{array}{c}\text { Rehydrogenation yields } \\
\mathrm{Al}_{2} \mathrm{Mg}_{3}, \mathrm{MgH}_{2}, \mathrm{Al}\end{array}$ & {$[29]$} \\
\hline $\begin{array}{c}\mathrm{NaNH}_{2}: \mathrm{MgH}_{2} \\
(2: 3 / 2: 1)\end{array}$ & $\begin{array}{l}20: 1(\mathrm{bpr}) \\
18 \& 15 \mathrm{~h}\end{array}$ & - & $\sim 5$ & $\mathrm{H}_{2}$ and $\mathrm{Mg}_{3} \mathrm{~N}_{2}(2: 3)$ & {$[18]$} \\
\hline $\begin{array}{c}\mathrm{NaNH}_{2}: \mathrm{MgH}_{2} \\
(1: 1)\end{array}$ & $\begin{array}{c}70: 1(\mathrm{bpr}) \\
3 \mathrm{~h}\end{array}$ & $70-335$ & $\sim 3.3$ & Large formation of $\mathrm{NaH}$ & [19] \\
\hline
\end{tabular}

Table 4.2.1 Hydrogen storage properties for the binary system composed of

$$
\mathrm{LiAlH}_{4}-\mathrm{MgH}_{2}-\mathrm{NaNH}_{2}
$$

\subsubsection{EXPERIMENTAL SECTION}

All the starting materials were in the form of powder and properly handled inside Ar filled glove box. $\mathrm{LiAlH}_{4}\left(95 \%\right.$ purity), $\mathrm{MgH}_{2}$ ( $98 \%$ purity) and $\mathrm{NaNH}_{2}$ ( $95 \%$ purity) were purchased from Sigma-Aldrich. A molar mixture of 1:1:1 of $\mathrm{LiAlH}_{4}, \mathrm{MgH}_{2}$ and $\mathrm{NaNH}_{2}$ 
were homogeneously ground using mortar and pestle and used for study. A planetary Retsch Mill PM100 was employed to mechanically grind the hydrides at a revolution speed of $300 \mathrm{rpm}$ for $0.5 \mathrm{~h}$. The ball to powder ratio was $30: 1$.

PCTPro-2000 was employed to study the dehydrogenation kinetics of the ternary system. The standard start-up procedures, namely, leak check, purge gas and volume calibration at $50^{\circ} \mathrm{C}$ was used. The de-hydrogenation experiments for multinary complex hydrides were performed in a static vacuum $(\sim 0.01-0.05$ bar). The temperature programmed desorption measurements were performed between $50-380^{\circ} \mathrm{C}$ with a heating ratio of $5^{\circ} \mathrm{C} / \mathrm{min}$. The differential scanning calorimetry was performed under argon atmosphere (30 $\mathrm{ml} / \mathrm{min}$ ) at a heating rate of 5,10 and $15^{\circ} \mathrm{C} / \mathrm{min}$ to reach $500^{\circ} \mathrm{C}$. The temperature was kept constant at $500^{\circ} \mathrm{C}$ for 10 minutes.

In-Situ x-ray diffraction and Raman spectroscopy analysis were performed using a homemade furnace. The hydride mixture was put inside the capillary under glove box and hermetically sealed. The mixture was heated to a particular temperature and kept constant for $0.5 \mathrm{~h}$.

\subsubsection{RESULTS AND DISCUSSION}

\subsubsection{Temperature-programmed decomposition}

Fig. 4.2.1 shows the temperature programmed decomposition of the $\mathrm{LiAlH}_{4}-\mathrm{MgH}_{2}$ $\mathrm{NaNH}_{2}(1: 1: 1)$ mixture during the heating from $50^{\circ} \mathrm{C}$ to $380^{\circ} \mathrm{C}$ with a heating rate of $5^{\circ} \mathrm{C}$ /min. A clear difference in desorption profile can be observed for unmilled and $0.5 \mathrm{~h}$ milled mixture. The pressure data indicates that gas release, most likely hydrogen, begins 
at $50^{\circ} \mathrm{C}$. The desorption process appears to be composed of three steps. First step is the gradual but continuous release of hydrogen. Large amount of gas evolves at approximately $150^{\circ} \mathrm{C}$ and $115^{\circ} \mathrm{C}$ for unmilled and milled mixture respectively. This step can be categorized as second-step desorption of hydrogen. The third step of hydrogen release is relatively faster than the first step. The total amount of hydrogen desorbed from the unmilled and milled mixture is 5.23 and $4.61 \mathrm{wt}$ \% respectively. This is equivalent to $5.39 \mathrm{H}$ and $4.75 \mathrm{H}$ atoms per $\mathrm{LiAlH}_{4}+\mathrm{MgH}_{2}+\mathrm{NaNH}_{2}$.

The hydrogen desorption kinetics improves and dehydriding temperature reduces for ball milled sample. It may be attributed to the reduced particle size of the mixed hydrides. However, the weight loss for milled sample is relatively lower, due to evolution of hydrogen during ball milling.

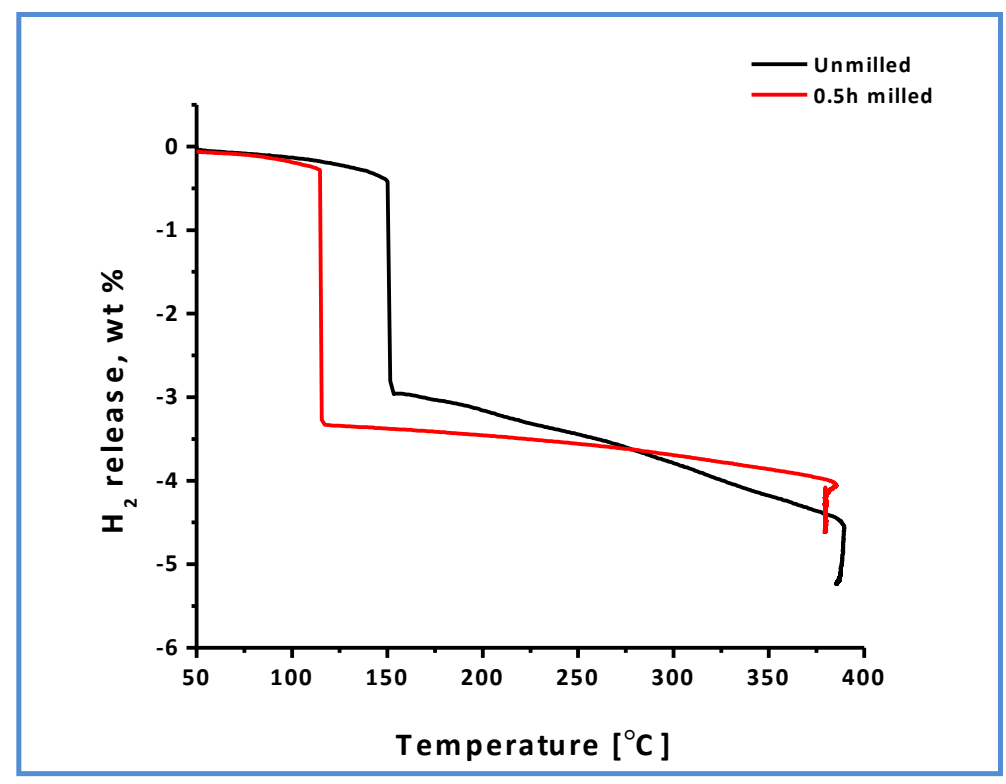

Figure 4.2.1 Temperature programmed decomposition of the $\mathrm{LiAlH}_{4}-\mathrm{MgH}_{2}-\mathrm{NaNH}_{2}$ (1:1:1) mixture 


\subsubsection{Differential Scanning Calorimetry}

DSC measurements for the binary mixture - $\mathrm{LiAlH}_{4}-\mathrm{NaNH}_{2}$ [25], $\mathrm{MgH}_{2}-\mathrm{LiAlH}_{4}$ [27, 30], $\mathrm{MgH}_{2}-\mathrm{NaNH}_{2}[18,19]$ are reported earlier. Fig. 4.2.2 presents the DSC traces of the $\mathrm{LiAlH}_{4}-\mathrm{MgH}_{2}-\mathrm{NaNH}_{2}$ mixture. The plot for the mixture shows three exothermic peaks: a strong peak around $153^{\circ} \mathrm{C}$, two peaks around $177^{\circ} \mathrm{C}$ and $197^{\circ} \mathrm{C}$ respectively. The last endothermic peak at $405^{\circ} \mathrm{C}$ is due to the decomposition of $\mathrm{MgH}_{2}$, which occurs at a temperature $32^{\circ} \mathrm{C}$ lower than that of the pure $\mathrm{MgH}_{2}$ (peak at about $437^{\circ} \mathrm{C}$ ) [31]. The overall thermodynamics is completely different from those of the starting hydrides. It is obvious that the kind of interaction occurred between mixture of amides and hydrides follows a different reaction path.

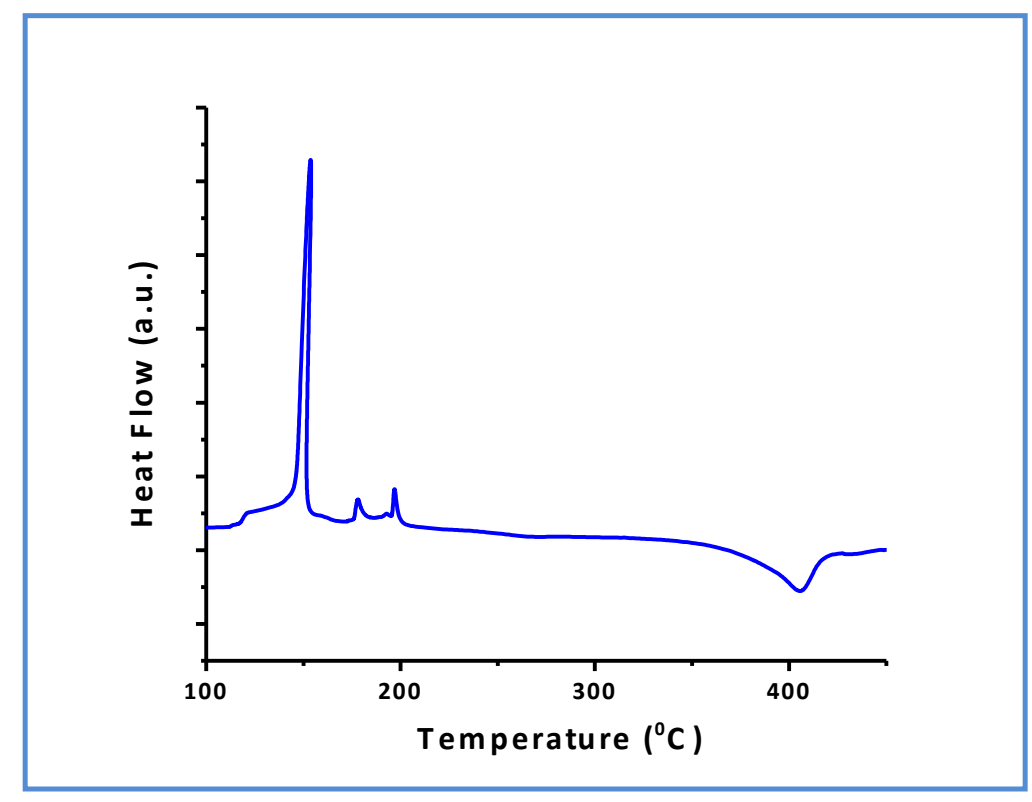

Figure 4.2.2 Differential scanning calorimetry (DSC) traces for $\mathrm{LiAlH}_{4}-\mathrm{MgH}_{2}-\mathrm{NaNH}_{2}$ samples, with a heating rate of $5^{\circ} \mathrm{C} / \mathrm{min}$. 
The Kissinger equation [32] is used to determine the activation energy required for the $\mathrm{MgH}_{2}$-related decomposition, which is given below:

$$
\ln \left(\beta / T_{P}^{2}\right)=-E_{a} /_{R T_{P}}+A
$$

Where, $\beta$ is the heating rate, $T_{\mathrm{P}}$ is the peak temperature in the DSC curve, $\mathrm{R}$ is the gas constant, and A is a linear constant. Fig. 4.2.3 illustrates the DSC traces for the mixture at a different heating rates $\left(\beta=5,10\right.$, and $15^{\circ} \mathrm{C} \min ^{-1}$, respectively). The apparent activation energy for the $\mathrm{MgH}_{2}$ - related decomposition in the $\mathrm{LiAlH}_{4}-\mathrm{MgH}_{2}-\mathrm{NaNH}_{2}$ is found to be $(173.6 \pm 6) \mathrm{kJ} / \mathrm{mol}$. The activation energy for the dehydrogenation was lowered by approximately $22 \mathrm{~kJ} / \mathrm{mol}$ compared to the bulk material $\left(\mathrm{E}_{\mathrm{a}}=195.3 \pm 10 \mathrm{~kJ} / \mathrm{mol}\right)[33]$.

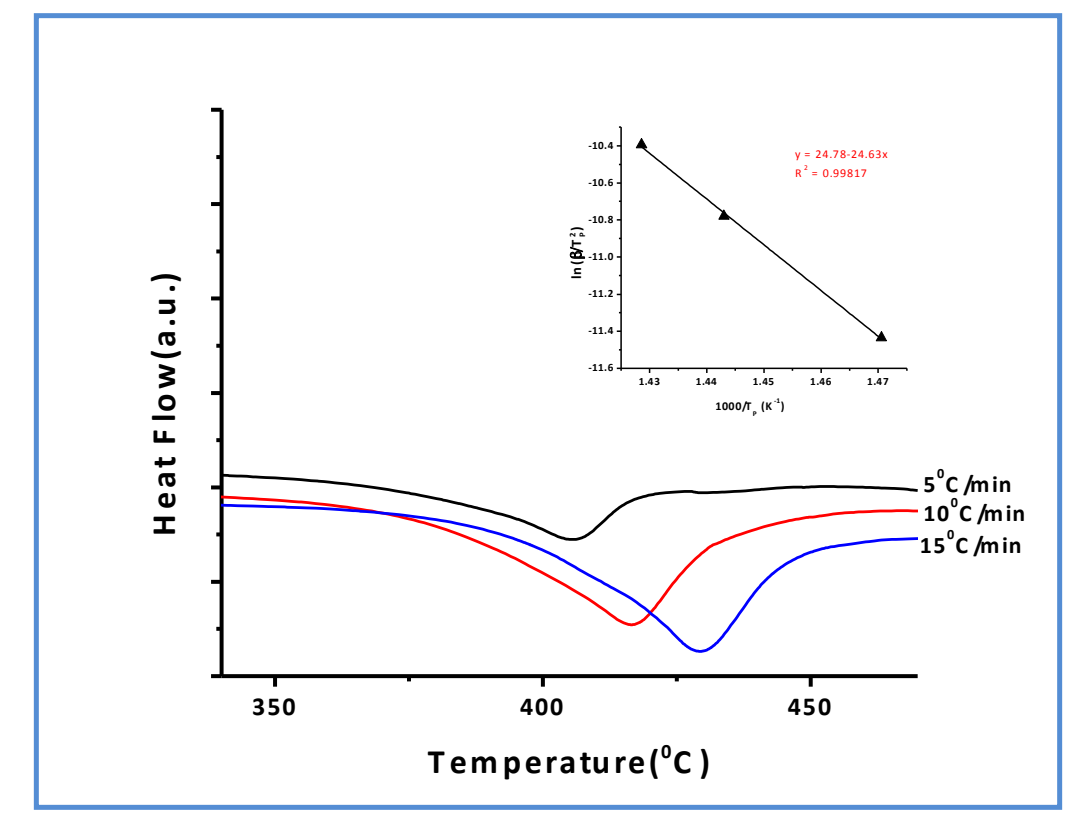

Figure 4.2.3 DSC traces of the $\mathrm{LiAlH}_{4}-\mathrm{MgH}_{2}-\mathrm{NaNH}_{2}$ at different heating rates. The inset plot is the Kissinger's analysis for the hydrogen desorption reaction of the ternary hydrides.

\subsubsection{Room Temperature Raman Spectrum}


Fig illustrates the Raman spectra for $0.5 \mathrm{~h}$ milled and unmilled $\mathrm{LiAlH}_{4}-\mathrm{MgH}_{2}-\mathrm{NaNH}_{2}$ mixture at ambient conditions. Two fundamental internal modes are observed for $\mathrm{NH}_{2}{ }^{-}$at 3210 and $3261 \mathrm{~cm}^{-1}$ in the Raman spectrum, corresponding to N-H symmetric stretching $\left(v_{1}\left(\mathrm{~A}_{1}\right)\right)$ and asymmetric stretching mode $\left(v_{3}\left(\mathrm{~B}_{2}\right)\right)$ respectively. However, no bending mode $\left(v_{2}\left(\mathrm{~A}_{1}\right)\right)$ at $1536 \mathrm{~cm}^{-1}$ was observed [34]. Moreover, the Raman spectra in the low frequency region (at 253,464 and $535 \mathrm{~cm}^{-1}$ ) correspond to the lattice modes of solid $\mathrm{NaNH}_{2}[34,35]$. However, the intensity of these peaks is especially weak and exhibits a broad FWHM after ball milling for $0.5 \mathrm{~h}$.

Three distinct peaks at 688,778 and $873 \mathrm{~cm}^{-1}$ in the spectral region, 600 to $950 \mathrm{~cm}^{-1}$, and are assigned to the bending of Al-H bonds [36-39]. Also, a shoulder peak is noticed at $816 \mathrm{~cm}^{-1}$. The high frequency spectral region $\left(1500-2000 \mathrm{~cm}^{-1}\right)$ has the Al-H symmetric peak at $1829 \mathrm{~cm}^{-1}$ and a shouldered antisymmetric peak at $1754 \mathrm{~cm}^{-1}$ ( shoulder at 1720 $\mathrm{cm}^{-1}$ ). In the Al-H bending spectral region, the intensity of the peaks are significantly reduced and becomes broad after mechanical milling. However, after milling for $0.5 \mathrm{~h}$, the shouldered antisymmetric peak at $1754 \mathrm{~cm}^{-1}$ merged with the shoulder peak at $1720 \mathrm{~cm}^{-1}$. The basic features of the Raman spectrum of $\alpha-\mathrm{MgH}_{2}$ are in agreement with the earlier reports $[40,41]$. The corresponding weak but broad peaks are observed at $\sim 945$ and $\sim 1270 \mathrm{~cm}^{-1}$. However, no discernible change is observed for $\mathrm{MgH}_{2}$ Raman peaks after milling for $0.5 \mathrm{~h}$.

In comparison with the unmilled mixture, the milled sample exhibits markedly reduction in the intensity of the peaks, and particularly, several weak peaks in the Raman active modes are found to disappear after mechanical milling. 


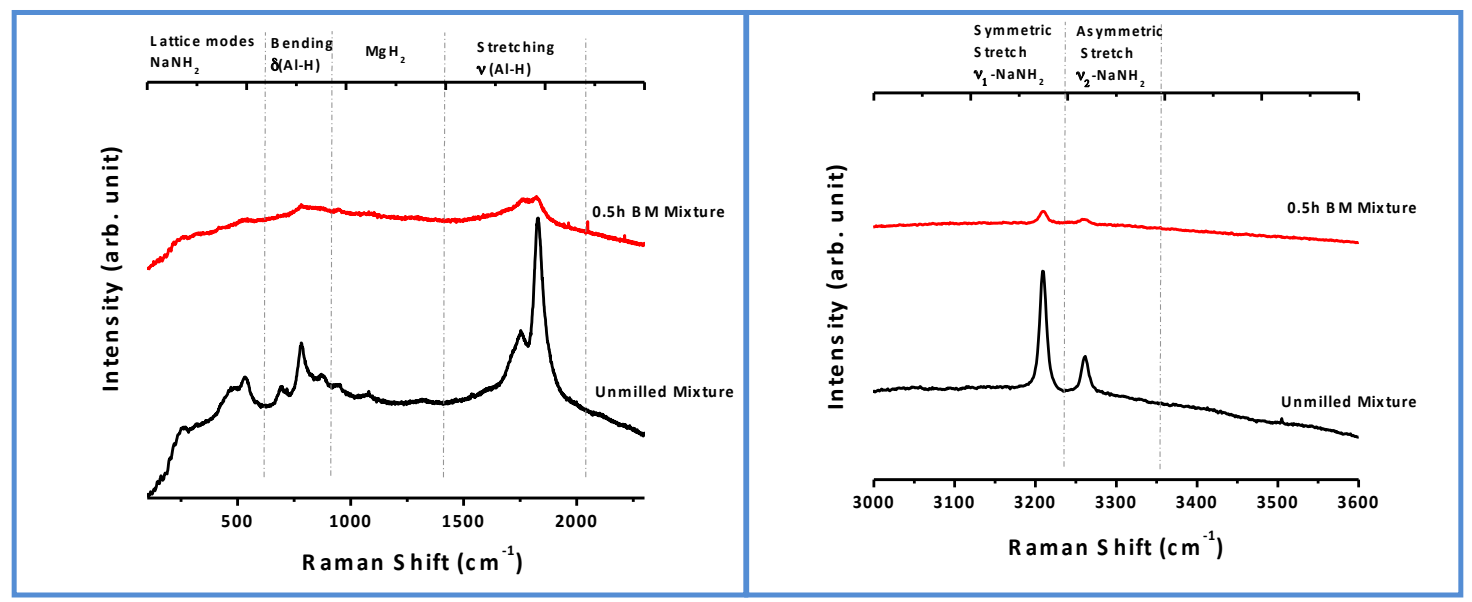

Figure 4.2.4 Room Temperature Raman Spectra for unmillled and 0.5h mechanically milled $\mathrm{LiAlH}_{4}-\mathrm{MgH}_{2}-\mathrm{NaNH}_{2}$ mixture.

\subsubsection{Temperature dependent in-situ Raman Spectrum}

In-situ Raman spectra of milled and unmilled hydride mixture, in both the low and high frequency ranges, are plotted as a function of temperature in Figs. 4.2.5-4.2.6. As illustrated, the in-situ study is performed up to $300^{\circ} \mathrm{C}$. At $50^{\circ} \mathrm{C}, \mathrm{MgH}_{2}$ peaks become more intense compared to that at ambient condition (see Fig. 4.2.5). However, the intensity of the Raman peaks corresponding to the bending and stretching modes of Al-H bonds and stretching modes of $\mathrm{NaNH}_{2}$ decreases sharply. This clearly indicates the hydrogen desorption. At $100^{\circ} \mathrm{C}, \mathrm{N}-\mathrm{H}$ symmetric stretching mode $\left(v_{1}\left(\mathrm{~A}_{1}\right)\right)$ becomes less intense and asymmetric stretching mode $\left(v_{3}\left(\mathrm{~B}_{2}\right)\right)$ completely vanish (Fig. 4.2.5). 


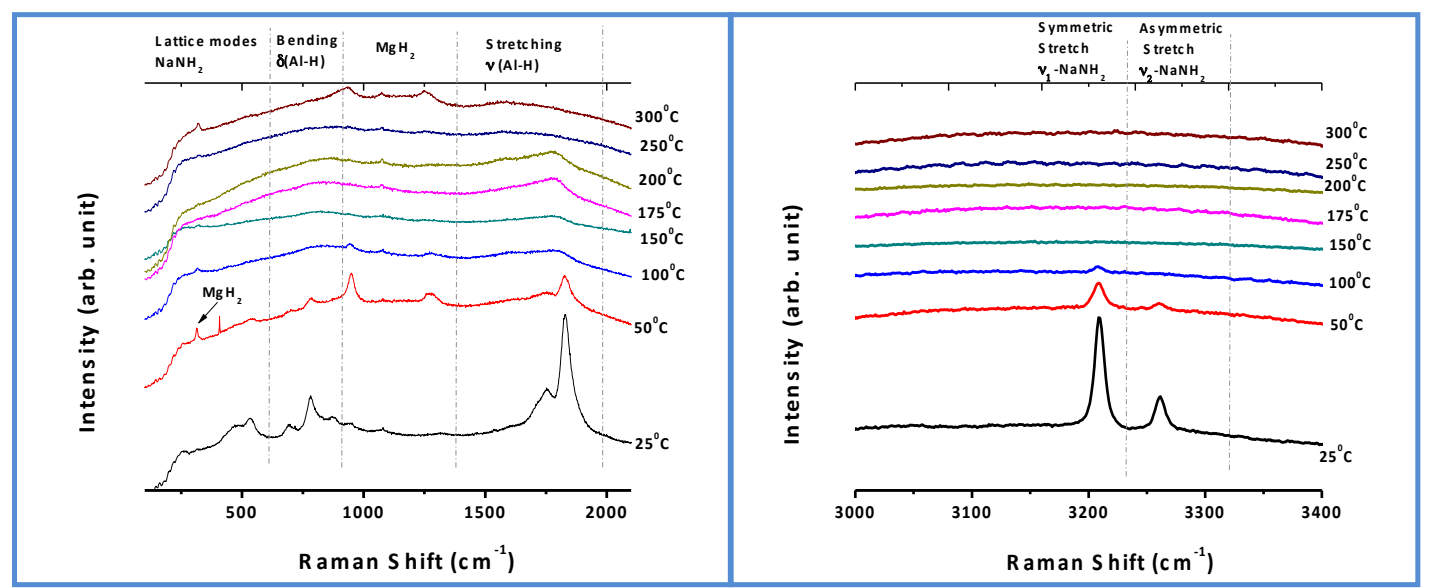

Figure 4.2.5 Temperature dependent Raman Spectra for unmilled $\mathrm{LiAlH}_{4}-\mathrm{MgH}_{2}-\mathrm{NaNH}_{2}$

In the temperature range, $100-200^{\circ} \mathrm{C}$, the stretching modes of $\mathrm{Al}-\mathrm{H}$ bonds becomes less intense and broad. Moreover, there is also a tendency for downshifting of the spectral lines of $v(\mathrm{Al}-\mathrm{H})$ towards lower frequency in the same temperature region $\left(100-200^{\circ} \mathrm{C}\right)$. But in the temperature range, $175-200^{\circ} \mathrm{C}$, the peak at $\sim 1780 \mathrm{~cm}^{-1}$ becomes more intense. This trend indicates that the Al-H bonded phase has more developed crystallinity and/ or present in greater amounts in the Raman scattering volume than at $100-175^{\circ} \mathrm{C}$. At a much higher temperature $\left(\geq 250^{\circ} \mathrm{C}\right)$, stretching modes $(v(\mathrm{Al}-\mathrm{H}))$ completely disappears. $\mathrm{MgH}_{2}$ peak becomes more intense at $300^{\circ} \mathrm{C}$ and can be attributed to the remaining undesorbed stable $\mathrm{MgH}_{2}$. 


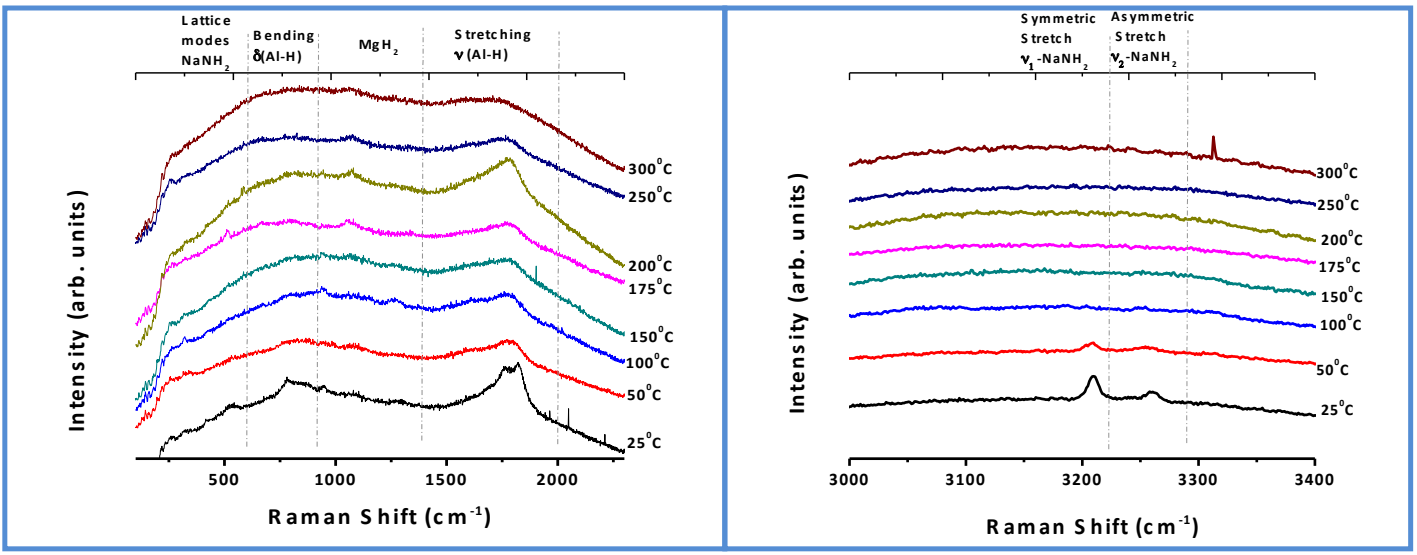

Figure 4.2.6 Temperature dependent Raman Spectra for mechanically milled

$$
\mathrm{LiAlH}_{4}-\mathrm{MgH}_{2}-\mathrm{NaNH}_{2} \text { mixture }
$$

In-situ Raman spectra of the milled mixture as a function of temperature are shown in Fig. 4.2.6. The mechanically milled sample illustrates the same behavior of the Raman spectrum on the thermal treatment as that for the unmilled mixture. However, the initial peaks of the milled sample are less intense and have broader FWHM, which indicates desorption of hydrogen during ball milling. The Raman spectrum strongly evidences the release of hydrogen during milling, which is in congruence with the temperature programmed desorption analysis of the mixture.

\subsubsection{Room Temperature X-ray diffraction analysis}

Figure 4.2.7 shows the x-ray diffraction patterns for unmilled and milled sample of ternary hydrides. Clearly, $\mathrm{LiAlH}_{4}, \mathrm{MgH}_{2}$ and $\mathrm{NaNH}_{2}$ phases react with each other during mechanical milling. The phase identification of the milled sample suggests that following reactions could take place during $0.5 \mathrm{~h}$ of milling time:

$$
\begin{aligned}
& \mathrm{LiAlH}_{4} \rightarrow 1 / 3 \mathrm{Li}_{3} \mathrm{AlH}_{6}+2 / 3 \mathrm{Al}+\mathrm{H}_{2} \\
& \mathrm{MgH}_{2}+2 \mathrm{NaNH}_{2} \rightarrow \mathrm{Mg}\left(\mathrm{NH}_{2}\right)_{2}+2 \mathrm{NaH}
\end{aligned}
$$




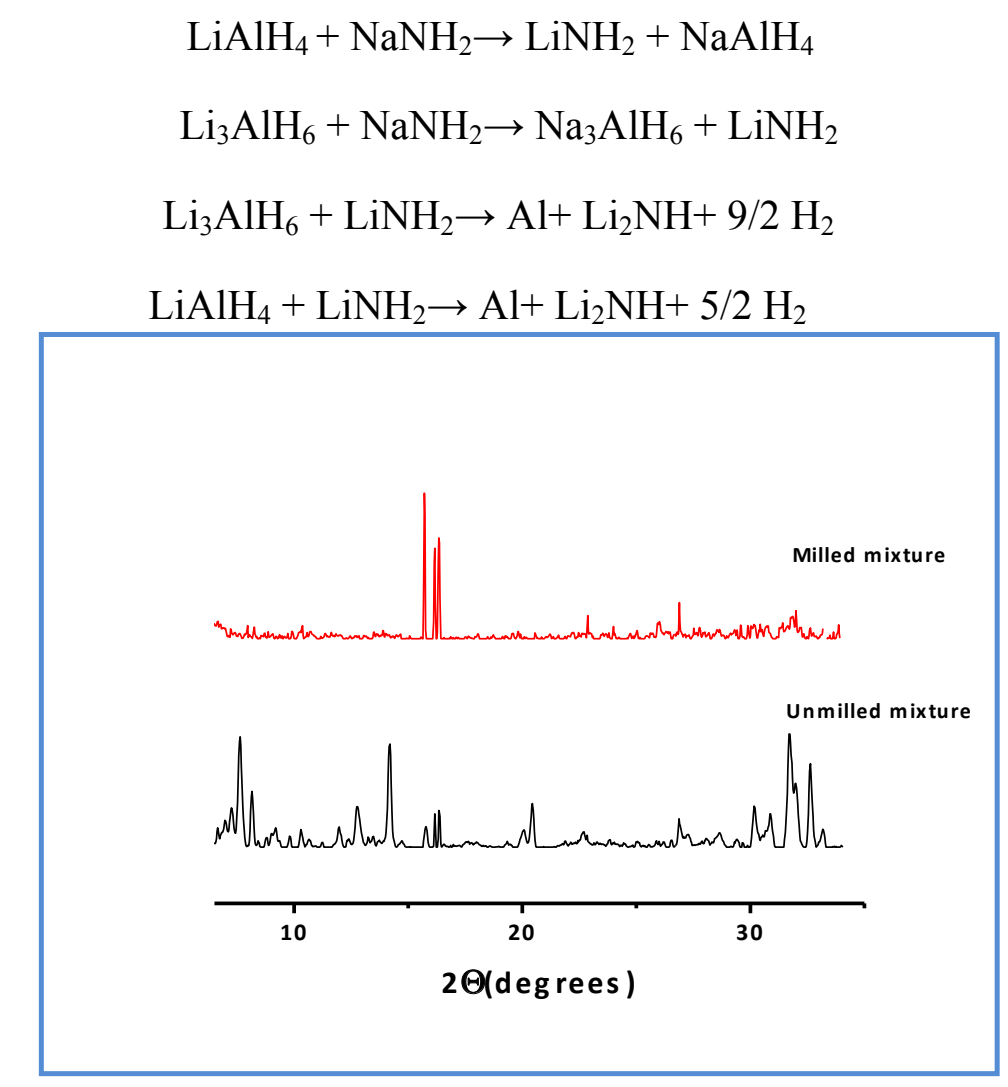

Figure 4.2.7 X-ray diffraction pattern for milled and unmilled $\mathrm{LiAlH}_{4}-\mathrm{MgH}_{2}-\mathrm{NaNH}_{2}$ mixture

The partial decomposition of $\mathrm{LiAlH}_{4}$ generates $\mathrm{Li}_{3} \mathrm{AlH}_{6}$ and $\mathrm{Al}$. Moreover, $\mathrm{LiAlH}_{4}$ reacts with $\mathrm{NaNH}_{2}$ via a metathesis reaction to form $\mathrm{LiNH}_{2}$ and $\mathrm{NaAlH}_{4}$. Further, $\mathrm{Li}_{2} \mathrm{NH}$ is formed due to reactions between: (1) $\mathrm{LiNH}_{2}+\mathrm{Li}_{3} \mathrm{AlH}_{6}$ and (2) $\mathrm{LiNH}_{2}+\mathrm{LiAlH}_{4}$. One more Li-Na exchange (metathesis reaction) is observed between $\mathrm{Li}_{3} \mathrm{AlH}_{6}$ and $\mathrm{NaNH}_{2} . \mathrm{MgH}_{2}$ and $\mathrm{NaNH}_{2}$ partially reacts to form $\mathrm{Mg}\left(\mathrm{NH}_{2}\right)_{2}$.

\subsubsection{Temperature dependent in-situ X-ray diffraction analysis}

In order to explore the hydrogen desorption mechanism, the in-situ X-ray diffraction measurement were performed for the ternary hydride mixture. The mixture was heated 
till $250^{\circ} \mathrm{C}$. At each temperature, the mixture was held for $0.5 \mathrm{~h}$ [shown in Fig. 4.2.8]. On the basis of the phase identification, the mechanism of hydrogen desorption is predicted. As can be seen from Fig. 4.2.8, the hydrogen desorption starts at $50^{\circ} \mathrm{C}$ and is in congruence with the observation from the Raman Spectroscopy.

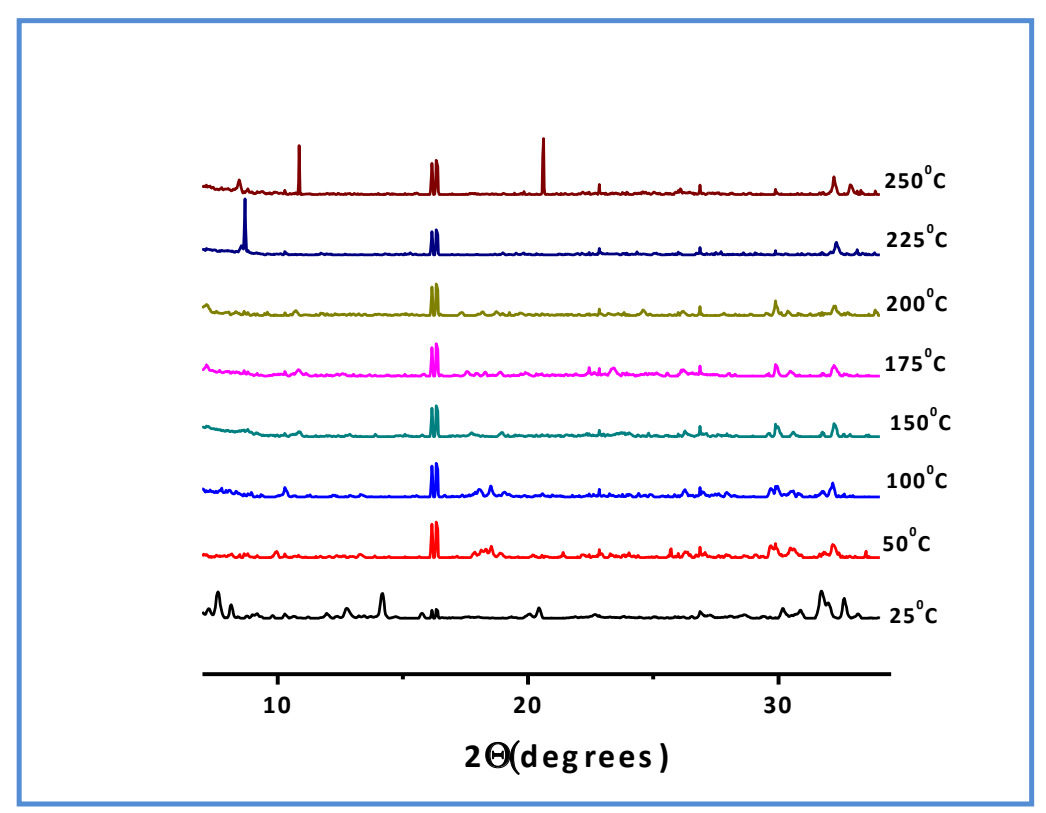

Figure 4.2.8 Temperature dependent X-ray diffraction pattern for unmilled

\section{$\mathrm{LiAlH}_{4}-\mathrm{MgH}_{2}-\mathrm{NaNH}_{2}$ mixture}

Table 4.2.2 illustrates the phases present at different temperatures for the ternary mixture. The presence of $\mathrm{Li}_{3} \mathrm{AlH}_{6}$ at $50^{\circ} \mathrm{C}$ strongly evidences the faster desorption of $\mathrm{LiAlH}_{4}$ compared to the other two hydrides, $\mathrm{MgH}_{2}$ and $\mathrm{NaNH}_{2}$. The x-ray diffraction peaks of $\mathrm{Al}$ overlap with those of $\mathrm{LiH}$ and some of the $\mathrm{Li}_{3} \mathrm{AlH}_{6}$ peaks and thus the presence or absence of $\mathrm{Al}$ cannot be conclusively demonstrated using x-ray diffraction. Further, heating of the mixture, leads to decrease of the amount of $\mathrm{Li}_{3} \mathrm{AlH}_{6} . \mathrm{Li}_{3} \mathrm{AlH}_{6}$ decomposes to release more hydrogen and $\mathrm{LiH}$ at high temperature. However, $\mathrm{MgH}_{2}$ is a stable 
hydride and requires high temperature to completely decompose. Here, even at temperature as high as $250^{\circ} \mathrm{C}$, the peaks of $\mathrm{MgH}_{2}$ is observed. However, the decrease in the intensity of $\mathrm{x}$-ray peaks of $\mathrm{MgH}_{2}$ suggests its gradual decomposition.

\begin{tabular}{|c|c|c|c|c|c|c|c|c|}
\hline Phases & $25^{\circ} \mathrm{C}$ & $50^{\circ} \mathrm{C}$ & $100^{\circ} \mathrm{C}$ & $150^{\circ} \mathrm{C}$ & $175^{\circ} \mathrm{C}$ & $200^{\circ} \mathrm{C}$ & $225^{\circ} \mathrm{C}$ & $250^{\circ} \mathrm{C}$ \\
\hline$\overline{\mathrm{MgH}_{2}}$ & $\bar{Y}$ & $\bar{Y}$ & $\bar{Y}$ & $\bar{Y}$ & $\bar{Y}$ & $\bar{Y}$ & $\bar{Y}$ & $\bar{Y}$ \\
\hline$\overline{\mathrm{LiAlH}}_{4}$ & $\bar{Y}$ & $\bar{Y}$ & $\bar{Y}$ & $\bar{Y}$ & & & & \\
\hline $\mathrm{NaNH}_{2}$ & $\bar{Y}$ & $\bar{Y}$ & $\bar{Y}$ & $\bar{Y}$ & $\bar{Y}$ & $\bar{Y}$ & $\bar{Y}$ & \\
\hline$\overline{\mathrm{Li}_{3} \mathrm{AlH}_{6}}$ & & $\bar{Y}$ & $\bar{Y}$ & $\bar{Y}$ & $\bar{Y}$ & $\bar{Y}$ & $\bar{Y}$ & $\bar{Y}$ \\
\hline $\mathrm{Na}_{3} \mathrm{AlH}_{6}$ & & & & & $\bar{Y}$ & $\bar{Y}$ & $\bar{Y}$ & $\bar{Y}$ \\
\hline$\overline{\mathrm{LiH}}$ & & & & $\overline{\mathrm{Y}}$ & $\bar{Y}$ & $\bar{Y}$ & $\bar{Y}$ & \\
\hline$\overline{\mathrm{Al}}$ & & & $\bar{Y}$ & $\bar{Y}$ & $\bar{Y}$ & $\bar{Y}$ & $\bar{Y}$ & \\
\hline $\mathrm{Mg}\left(\mathrm{NH}_{2}\right)_{2}$ & & & & $\bar{Y}$ & $\bar{Y}$ & $\bar{Y}$ & $\bar{Y}$ & \\
\hline $\mathrm{Mg}_{3} \mathrm{~N}_{2}$ & & & & & $\bar{Y}$ & $\bar{Y}$ & $\bar{Y}$ & $\bar{Y}$ \\
\hline $\mathrm{NaMgH}_{3}$ & & & & $\mathrm{Y}$ & $\mathrm{Y}$ & $\mathrm{Y}$ & $\mathrm{Y}$ & \\
\hline$\overline{\mathrm{NaH}}$ & & & & $\bar{X}$ & $\bar{Y}$ & $\bar{Y}$ & $\bar{Y}$ & $\bar{Y}$ \\
\hline$\overline{\mathrm{AlMg}}$ & & & & & $\bar{Y}$ & $\bar{Y}$ & & \\
\hline$\overline{\mathrm{Al}_{2} \mathrm{Mg}}$ & & & & & $\bar{Y}$ & $\bar{Y}$ & $\bar{Y}$ & $\bar{Y}$ \\
\hline $\mathrm{Al}_{12} \mathrm{Mg}_{17}$ & & & & & & & $\bar{Y}$ & $\bar{Y}$ \\
\hline AlN & & & & & $\bar{Y}$ & $\bar{Y}$ & $\bar{Y}$ & $\mathrm{Y}$ \\
\hline $\mathrm{LiNH}_{2}$ & & & & $\mathrm{Y}$ & $\mathrm{Y}$ & $\mathrm{Y}$ & $\mathrm{Y}$ & $\bar{Y}$ \\
\hline$\overline{\mathrm{Li}_{2} \mathrm{NH}}$ & & & & & $\bar{Y}$ & $\bar{Y}$ & $\bar{Y}$ & $\bar{Y}$ \\
\hline $\mathrm{Li}_{3} \mathrm{AlN}_{2}$ & & & & & & $\bar{Y}$ & $\bar{Y}$ & $\bar{Y}$ \\
\hline $\mathrm{Al}_{2} \mathrm{Li}_{3}$ & & & & & & $\mathrm{Y}$ & $\mathrm{Y}$ & $\mathrm{Y}$ \\
\hline
\end{tabular}

Table 4.2.2 Phases present at different temperatures for $\mathrm{LiAlH}_{4}+\mathrm{MgH}_{2}+\mathrm{NaNH}_{2}$ mixture 
$\mathrm{NaNH}_{2}$ reacts with $\mathrm{MgH}_{2}$ to form $\mathrm{Mg}\left(\mathrm{NH}_{2}\right)_{2}$, which further releases hydrogen to form $\mathrm{Mg}_{3} \mathrm{~N}_{2}$ on heating. At high temperature $\left(\geq 200^{\circ} \mathrm{C}\right)$, a large number of intermetallic compounds formed such as $\mathrm{Al}_{2} \mathrm{Mg}, \mathrm{Al}_{2} \mathrm{Li}_{3}, \mathrm{Li}_{3} \mathrm{AlN}_{2}, \mathrm{AlN}$. Thus, the overall dehydrogenation mechanism for the 1:1:1 molar mixture of $\mathrm{LiAlH}_{4}, \mathrm{MgH}_{2}$ and $\mathrm{NaNH}_{2}$ can be given as follows:

At $50-100^{\circ} \mathrm{C}$,

$$
\mathrm{LiAlH}_{4} \rightarrow 1 / 3 \mathrm{Li}_{3} \mathrm{AlH}_{6}+2 / 3 \mathrm{Al}+\mathrm{H}_{2}
$$

At $150^{\circ} \mathrm{C}$,

$$
\begin{aligned}
\mathrm{MgH}_{2}+\mathrm{NaNH}_{2} & \rightarrow \mathrm{Mg}\left(\mathrm{NH}_{2}\right)_{2}+\mathrm{NaH}+\mathrm{NaMgH}_{3} \\
\mathrm{LiAlH}_{4}+\mathrm{NaNH}_{2} & \rightarrow \mathrm{LiNH}_{2}+\mathrm{NaAlH}_{4}
\end{aligned}
$$

At $175-200^{\circ} \mathrm{C}$,

$$
\begin{aligned}
& \mathrm{Li}_{3} \mathrm{AlH} \rightarrow 3 \mathrm{LiH}+\mathrm{Al}+3 / 2 \mathrm{H}_{2} \\
& \mathrm{LiAlH}_{4}+\mathrm{Mg}\left(\mathrm{NH}_{2}\right)_{2} \rightarrow 1 / 3 \mathrm{Mg}_{3} \mathrm{~N}_{2}+1 / 3 \mathrm{Li}_{3} \mathrm{AlN}_{2}+2 / 3 \mathrm{AlN}+4 \mathrm{H}_{2} \\
& 8 \mathrm{LiH}+3 \mathrm{Mg}\left(\mathrm{NH}_{2}\right)_{2} \rightarrow 4 \mathrm{Li}_{2} \mathrm{NH}+\mathrm{Mg}_{3} \mathrm{~N}_{2}+8 \mathrm{H}_{2} \\
& \mathrm{Li}_{3} \mathrm{AlH}_{6}+\mathrm{NaNH}_{2} \rightarrow \mathrm{Na}_{3} \mathrm{AlH}_{6}+\mathrm{LiNH}_{2} \\
& 17 \mathrm{MgH}+12 \mathrm{Al} \rightarrow \mathrm{Al}_{12} \mathrm{Mg}_{17}+17 \mathrm{H}_{2} \\
& 3 \mathrm{LiH}+2 \mathrm{Al} \rightarrow \mathrm{Al}_{2} \mathrm{Li}_{3}+3 / 2 \mathrm{H}_{2}
\end{aligned}
$$

At $225-250^{\circ} \mathrm{C}$, 


\subsubsection{REFERENCES}

[1] G. Liang, J. Huot, S. Boily, A. Van Neste, R. Schulz, Journal of Alloys and Compounds, 1999, 292, 247-252.

[2] A. Zaluska, L. Zaluski, J.O. Stro“m-Olsen, Journal of Alloys and Compounds, 1999, $288,217-225$.

[3] J. F. Mao, Z. Wu, T. J. Chen, B. C. Weng, N. X. Xu, T. S. Huang, Z. P. Guo, H. K. Liu, D. M. Grant, G. S. Walker, and X. B. Yu, The Journal of Physical Chemistry C, 2007, 111, 12495-12498.

[4] P. Chen, Z. Xiong, J. Luo, J. Lin, K. Tan, Nature, 2002, 420, 302-304.

[5] W. Luo, Journal of Alloys and Compounds, 2004, 381, 284-287.

[6] H.Y. Leng, T. Ichikawa, S. Hino, N. Hanada, S. Isobe, H. Fujii, The Journal of Physical Chemistry B, 2004, 108, 8763-8765.

[7] J. Yang, A. Sudik, J. S. Donald, D. Halliday, A. Drews, R.O. Carter, C. Wolverton, G.J. Lewis, J.W.A. Sachtler, J.J. Low, S.A. Faheem, D.A. Lesch, V.Ozolins, Angewandte Chemie International Edition, 2008, 47, 882-887.

[8] B. Bogdanovic', M. Schwickardi, Journal of Alloys and Compounds, 1997, 253- 254, $1-9$.

[9] D.L. Sun, S. Srinivasan, T. Kiyobayashi, N. Kuriyama, C.M. Jensen, Journal of Physical Chemistry B, 2003, 107, 10176-10179.

[10] J. Chen, N. Kuriyama, Q. Xu, H.T. Takeshita, T. Sakai, Journal of Physical Chemistry B, 2001, 105, 11214-11220.

[11] J.F. Mao, X.B. Yu, Z.P. Guo, C.K. Poh, H.K. Liu, Z. Wu, J. Ni, Journal of Physical Chemistry C, 2009, 113, 10813-10818.

[12] A. Zu"ttel, P. Wenger, S. Rentsch, P. Sudan, Ph. Mauron, Ch. Emmenegger, Journal of Power Sources, 2003, 118, 1-7.

[13] M. Aoki, K. Miwa, T. Noritake, G. Kitahara, Y. Nakamori, S. Orimo, S. Towata, Applied Physics A: Materials Science \& Processing, 2005, 80, 1409-1412.

[14] P. Mauron, F. Buchter, O. Friedrichs, A. Remhof, M. Bielmann, N.Z. Christoph, A. Zu"ttel, Journal of Physical Chemistry B, 2008, 112, 906-910.

[15] A. Zu"ttel, S. Rentsch, P. Fischer, P. Wenger, P. Sudan, Ph. Mauron, Ch. Emmenegger, Journal of Alloys and Compounds, 2003, 356-357, 515-520. 
[16] J.W. Jang, J.H. Shim, Y.W. Cho, B.J. Lee, Journal of Alloys and Compounds, 2006, 420, 286-290.

[17] X.L. Zheng, Z.T. Xiong, S. Qin, Y.S. Chua, H. Chen, P. Chen, International Journal of Hydrogen Energy, 2008, 33, 3346-3350.

[18] N.K. Singh, T. Kobayashi, O. Dolotko, J.W. Wiench, M. Pruski, V.K. Pecharsky, Journal of Alloys and Compounds, 2012, 513, 324-327.

[19] D.A. Sheppard, M. Paskevicius, C.E. Buckley, The Journal of Physical Chemistry C, 2011, 115, 8407-8413.

[20] P.A. Chater, P.A. Anderson, J.W. Prendergast, A. Walton, V.S.J. Mann, D. Book, W.I.F. David, S.R. Johnson, P.P. Edwards, Journal of Alloys and Compounds, 2007, 446$447,350-354$.

[21] M. Somer, S. Acar, C. Koz, I. Kokal, P. Hohn, R. Cardoso-Gil, U. Aydemir, L. Akselrud, Journal of Alloys and Compounds, 2010, 491, 98-105.

[22] O. Dolotko, H. Zhang, O. Ugurlu, J.W. Wiench, M. Pruski, L. Scott Chumbley, V. Pecharsky, Acta Materialia, 2007, 55, 3121-3130.

[23] Z.T. Xiong, J. J. Hu, G.T. Wu, Y.F. Liu, P. Chen, Catalysis Today, 2007, 120, 287291.

[24] Y.S. Chua, G. Wu, Z. Xiong, P. Chen, Journal of Solid State Chemistry, 2010, 183, 2040-2044.

[25] Z.T. Xiong, J.J. Hu, G.T. Wu, Y.F. Liu, P. Chen, Catalysis Today, 2007, 120, 287291.

[26] Y.S. Chua, G. Wu, Z. Xiong, P. Chen, Journal of Solid State Chemistry, 2010, 183, 2040-2044.

[27] J. Mao, Z. Guo, X. Yu, M. Ismail, H. Liu, International Journal of Hydrogen Energy, 2011, 36, 5369-5374.

[28] M. Ismail, Y. Zhao, X. B. Yu and S. X. Dou, RSC Advances, 2011, 1, 408-414.

[29] R. Chen, X. Wang, L. Xu, L. Chen, S. Li, C. Chen, Materials Chemistry and Physics, 2010, 124, 83-87.

[30] Y. Zhang, Q.F. Tian, S.S. Liu, L.X. Sun, Journal of Power Sources, 2008, 185, 1514-1518.

[31] B. Zhao, F. Fang, D. Sun, Q. Zhang, S. Wei, F. Cao, H. Sun, L. Ouyang, M. Zhu, Journal of Solid Chemistry, 2012, 192, 210-214. 
[32] H. E. Kissinger, Journal of Research of the National Bureau of Standards, 1956, 57, 217.

[33] Z.Z. Karger, J. Hu, A. Roth, D. Wang, C. Kübel, W. Lohstroh, M. Fichtner, Chemical Communications, 2010, 46, 8353-8355.

[34] A. Liu, Y. Song, The Journal of Physical Chemistry B, 2011, 115, 7-13.

[35] P.T. Cunningham, V.A. Maroni, The Journal of Chemical Physics, 1972, 57, 14151418.

[36] A.V. Talyzin, B. Sundquist, Physical Review B, 2004, 70, 180101-3.

[37] J.C. Bureau, B. Bonnetot, P. Claudy, H. Eddaoudi, Materials Research Bulletin, 1985, 20, 1147-1155.

[38] L. D’Or, J. Fuger, Bulletin de la Société Royale des Sciences de Liège, 1956, 25, 14

[39] A.E. Shirk, D.F. Shriver, Journal of the American Chemical Society, 1973, 95, 59045912.

[40] H.G. Schimmel, M.R. Johnson, G.J. Kearley, A.J. Ramirez-Cuesta, J. Huot, F.M. Mulder, Materials Science \& Engineering B, 2004, 108, 38-41.

[41] M.A. Kuzovnikov, V.S. Efimchenko, E.V. Filatov, A.A. Maksimov, I.I. Tartakovskii, A.J. Ramirez-Cuesta, Solid State Communications, 2013,154, 77-80. 


\section{CARBON DIOXIDE CAPTURE USING METAL OXIDES}

\subsection{LITERATURE REVIEW}

The problem of carbon dioxide emission from various fossil fuel burning plants (such as power, steel, cement, gasifiers) has become an important issue that may tremendously affect our future survival. Carbon dioxide, one of the greenhouse gases, contributes to the global warming effect once release into the atmosphere [1-2]. Therefore, it is essential to capture carbon dioxide from the industrial flue gas stream, one of the leading contributors of the anthropogenic gases [3]. The development of Carbon Capture and Sequestration (CCS) technologies can be seen as a viable solution to mitigate the vast carbon emission. The separation of a pure carbon dioxide stream, combined with a well-managed geological storage site, is being considered as a mitigation option for climate change. The CCS technologies could be applied using available technologies as many of the components in these systems are already in use. However, it is widely accepted that there is a large scope for cost reduction and energy efficiency improvements in carbon dioxide capture systems.

Currently, various carbon dioxide capture technologies exist including physical absorption [4-5], chemical absorption [6-7], adsorption [8] and membranes [9]. However, they are still far from being considered as a technologically viable solution. The obvious bottlenecks are the huge amount of flue gas which needs to be treated as well as low mass transfer rate during the processes. Among all the proposed techniques, chemical absorption using aqueous alkanolamine solutions is the most conventional way for carbon dioxide capture. But these amine based solutions suffer severe drawbacks such as high 
energy consumption in regeneration process, high corrosive rate of equipment, essential pretreatment steps, large absorber volume and high sorbent cost. Because of these limitations of the chemical absorption techniques- an alternative way for post, oxy or precombustion carbon dioxide capture at fossil fuel burning power plants, mainly a solid adsorption/absorption method can be proposed.

A schematic diagram on Fig. 5.1.1 is depicted to demonstrate the concept of cyclic carbon dioxide capture process by metal oxides. The metal oxides (MO), such as $\mathrm{CaO}$ and $\mathrm{MgO}$, combine with carbon dioxide to form thermodynamically stable carbonates. Metal carbonates, when heated, liberate pure stream of carbon dioxide gas and regenerates the oxides. The combined use of exothermic carbonation reaction and endothermic regeneration reaction form a cyclic process. Eventually, the generated pure carbon dioxide gas can either be sequestered underground or used for enhanced oil recovery [10]. In general, any metal oxides which can qualify for carbon dioxide capture application must be abundant in earth's crust, react with carbon dioxide at low temperature, require low regeneration energy, should have suitable reaction kinetics and must form a carbonate that is stable in the environment at ambient conditions. Porous oxides, namely alkali and alkaline-earth metals have been reported as promising candidates for carbon dioxide capture. These metal oxides possess properties such as long durability, good mechanical strength, wide availability, low cost since they are present as natural minerals and high carbon dioxide absorption capacity at moderate working temperatures [11-14]. In this study, we review the carbon dioxide capture capacity of these different potential oxides. 

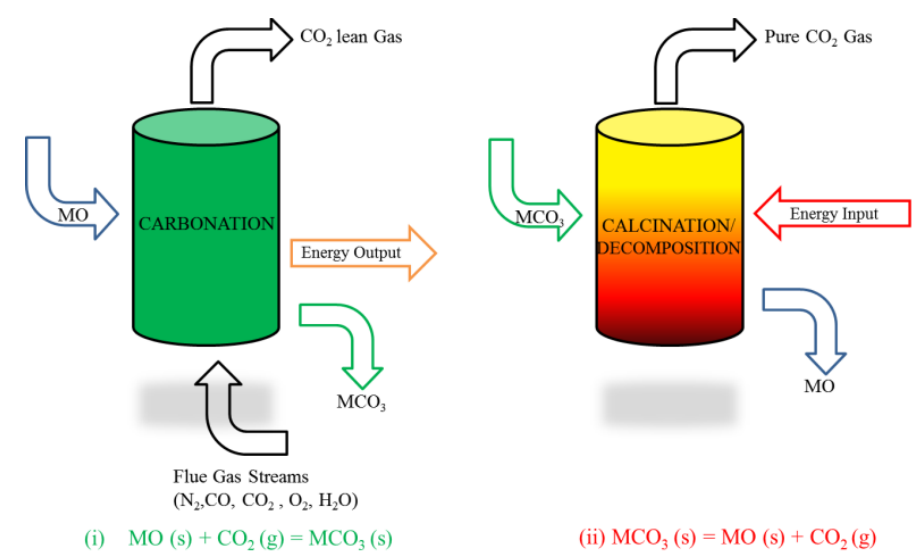

(ii) $\mathrm{MCO}_{3}(\mathrm{~s})=\mathrm{MO}(\mathrm{s})+\mathrm{CO}_{2}(\mathrm{~g})$

Figure 5.1.1 A Cyclic $\mathrm{CO}_{2}$ capture process for metal oxides (MO) and metal carbonates

$\left(\mathrm{MCO}_{3}\right)$

\subsubsection{Selection criteria for metal oxides}

Recently, researchers proposed a theoretical screening methodology to identify the most promising carbon dioxide sorbent candidates from the vast array of possible solid materials [15-17]. The methodology uses both the thermodynamic database searching with first principles density functional theory and phonon lattice dynamics calculations. The thermodynamic properties of solid materials are used for computing the thermodynamic reaction equilibrium properties of carbon dioxide absorption/desorption cycle based on the chemical potential and heat of reaction analysis. The selection is based on the pre- and post-combustion technologies and conditions in power-plants. This includes only those solid materials that may be suitable as carbon dioxide sorbent candidates and further be considered for experimental validation, if they meet the following criteria: lead to lowering in energy cost for the capture and regeneration process and could operate at desired conditions of carbon dioxide pressure and temperature. Fig. 5.1.2 illustrates the thermodynamic properties and $\mathrm{CO}_{2}$ wt. \% absorbed 
by different metal oxides. However, the thermodynamic properties and $\mathrm{CO}_{2}$ wt. \% absorbed by any sorbent could not be the only factors to select them for experimental studies. Various other important parameters such as availability or cost, regeneration temperature, kinetics, reversibility and durability must also be carefully considered before selecting any metal oxides for a large scale application.

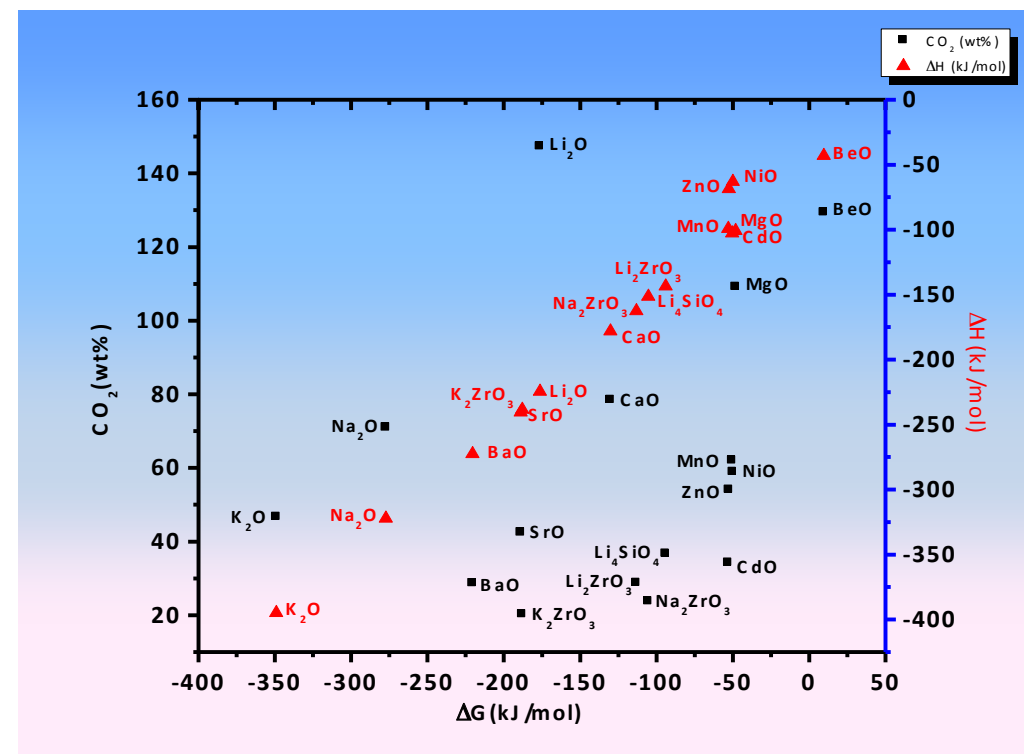

Figure 5.1.2 Thermodynamic properties and $\mathrm{CO}_{2} \mathrm{wt}$ \% for metal oxides

$$
\mathrm{MO}(\mathrm{s})+\mathrm{CO}_{2}(\mathrm{~g})=\mathrm{MCO}_{3}(\mathrm{~s}) \text { at } 300 \mathrm{~K}
$$

Based on the above figure it can deduced that $\mathrm{BeO}$ has a favorable thermodynamics, but this system is not a viable candidate for carbon dioxide capture because of the health issues related to beryllium powder or dust. It should be noted that a high exothermic forward reaction $\left(\mathrm{MO}(\mathrm{s})+\mathrm{CO}_{2}(\mathrm{~g})=\mathrm{MCO}_{3}(\mathrm{~s})\right)$ generally requires a large regeneration temperature for the oxide $\left(\mathrm{MCO}_{3}(\mathrm{~s})=\mathrm{MO}(\mathrm{s})+\mathrm{CO}_{2}(\mathrm{~g})\right)$. Also, a low $\mathrm{CO}_{2}$ wt. \% ( 4050) will require a large amount of the solid materials to deal with a huge volume of flue 
gas stream at any fossil fuel burning plants. Thus, a high regeneration temperature and low $\mathrm{CO}_{2}$ wt. \% can cause a vast energy or carbon emission penalty. Moreover, such oxides can eventually increase the electricity cost by a significant factor and thus may not be suitable for carbon dioxide capture at any plants.

The turnover temperature represents the value above which sorbents cannot absorb carbon dioxide and the release of carbon dioxide begins. The flue gas conditions are different for pre- and post- combustion carbon dioxide capture at power plants. Under pre-combustion conditions, after water-gas shift reaction, the gas stream mainly contains $\mathrm{CO}_{2}, \mathrm{H}_{2} \mathrm{O}$, and $\mathrm{H}_{2}$. The partial carbon dioxide pressure in this case is around 20-25 bar and the temperature is about $300-350^{\circ} \mathrm{C}$. But for post-combustion conditions, the flue gas stream mainly contains $\mathrm{CO}_{2}$ and $\mathrm{N}_{2}$. In this case, the partial pressure of $\mathrm{CO}_{2}$ is around $0.1-0.2$ bar, while the temperature range can vary around $27-77^{\circ} \mathrm{C}$. The goal set up by the US Department of Energy is to capture at least $90 \% \mathrm{CO}_{2}$ with an increase in the electricity cost of no more than $10 \%$ and $35 \%$ for pre- and post- combustion technologies respectively [18]. In order to minimize the energy consumption, the ideal sorbents should work in the above indicated pressure and temperature ranges to separate carbon dioxide from hydrogen. A list of turnover temperatures for different oxides can be found elsewhere [15-17].

Based on the above discussed limitations, exclusively few oxides seem to be promising and thus chosen to study for the experimental validation. The two alkaline-earth metal oxides (such as $\mathrm{CaO}$ and $\mathrm{MgO}$ ) draw the tremendous attention because of accessibility and favourable thermodynamics. Recently, Lithium, Sodium and Potassium based 
silicates or zirconates also gained interest due to their high carbon dioxide absorption capacity. Moreover, FeO can also be seen as a promising material for carbon dioxide capture at both power and non-power sectors (Iron and steel industry). In the following sections, we review the experimental studies for the most promising carbon dioxide sorbent candidates.

\subsubsection{Metal oxides}

\subsubsection{Alkali metal based oxides}

\section{(a) Lithium zirconate $\left(\mathrm{Li}_{2} \mathrm{ZrO}_{3}\right)$}

The reaction between Lithium carbonate $\left(\mathrm{Li}_{2} \mathrm{CO}_{3}\right)$ and Zirconium dioxide $\left(\mathrm{ZrO}_{2}\right)$ is well known to synthesize Lithium zirconate $\left(\mathrm{Li}_{2} \mathrm{ZrO}_{3}\right)$. However, the reverse reaction was not considered for carbon dioxide capture until 1998 [19].

$$
\mathrm{Li}_{2} \mathrm{CO}_{3}(\mathrm{~s})+\mathrm{ZrO}_{2}(\mathrm{~s}) \leftrightarrow \mathrm{Li}_{2} \mathrm{ZrO}_{3}(\mathrm{~s})+\mathrm{CO}_{2}(\mathrm{~g})
$$

The separation of carbon dioxide with aid of $\mathrm{Li}_{2} \mathrm{ZrO}_{3}$ works in a temperature range of $450-700^{\circ} \mathrm{C}$. The main advantage of this new material with respect to calcium-based absorbents is its unique thermal stability that allows achieving many absorption/regeneration cycles (over 20) without loss of capacity. Previous reports suggest that only 11-13 wt. \% change after absorption of carbon dioxide using $\mathrm{Li}_{2} \mathrm{ZrO}_{3}$ at $500-700^{\circ} \mathrm{C}$ in more than an hour is possible. Thus, it is evident that $\mathrm{Li}_{2} \mathrm{ZrO}_{3}$ has extremely slow absorption kinetics and hence, recently the addition of dopants was proposed as a solution. 
$\mathrm{K}_{2} \mathrm{CO}_{3}$ was used as a dopant of $\mathrm{Li}_{2} \mathrm{ZrO}_{3}$ causing an important increase of the absorption kinetics. $\mathrm{Li}_{2} \mathrm{CO}_{3}$ and $\mathrm{K}_{2} \mathrm{CO}_{3}$ form a eutectic mixture already at $500^{\circ} \mathrm{C}$, which presumably increases the carbon dioxide diffusion towards the inner unreacted particles during the absorption process [20]. In the case of the pure $\mathrm{Li}_{2} \mathrm{ZrO}_{3}$ (without $\mathrm{K}_{2} \mathrm{CO}_{3}$ additive), formation of an impervious shell of $\mathrm{Li}_{2} \mathrm{CO}_{3}$ on the surface leads to residual unreactive $\mathrm{Li}_{2} \mathrm{ZrO}_{3}$ core. This observation suggests that the diffusion resistance of carbon dioxide through the solid $\mathrm{Li}_{2} \mathrm{CO}_{3}$ surface layer is the rate-limiting step. In contrast, the potassium and lithium carbonate-containing $\mathrm{Li}_{2} \mathrm{ZrO}_{3}$ sample reacts with gaseous $\mathrm{CO}_{2}$ at $500^{\circ} \mathrm{C}$ to form a molten liquid outer layer and a solid interior $\mathrm{ZrO}_{2}$ core. Consequently, carbon dioxide diffuses through the molten carbonate layer at a much faster rate. Therefore, the difference in carbon dioxide sorption rate can be partially attributed to the molten carbonate layer.

$\mathrm{Y}_{2} \mathrm{O}_{3}$ was also considered as a dopant of $\mathrm{Li}_{2} \mathrm{ZrO}_{3}$ under the principle that $\mathrm{Y}_{2} \mathrm{O}_{3}$ would improve the $\mathrm{O}^{-2}$ ionic diffusion in the $\mathrm{ZrO}_{2}$ layer that is formed during the absorption. However, the addition of $\mathrm{Y}_{2} \mathrm{O}_{3}$ did not contribute to increase the absorption kinetics of the material, on the opposite; it did slow the kinetics [21]. In other findings, solid solutions of lithium and potassium meta zirconates $\left(\mathrm{Li}_{2-\mathrm{x}} \mathrm{K}_{\mathrm{x}} \mathrm{ZrO}_{3}\right)$ gave about five times faster kinetics compared to undoped $\mathrm{Li}_{2} \mathrm{ZrO}_{3}$ [22]. In the same line, solid solutions of lithium and sodium zirconates were also explored [23]. It was concluded that the higher the $\mathrm{Na}$ content in the samples the faster the absorption kinetics being produced. While, regeneration results were exactly opposed to the absorption, as higher the Li content in the mixture the faster the regeneration kinetics was produced. 


\section{(b) Lithium Orthosilicate $\left(\mathrm{Li}_{4} \mathrm{SiO}_{4}\right)$}

Lithium silicate-based $\left(\mathrm{Li}_{4} \mathrm{SiO}_{4}\right)$ sorbent material emerged as a promising candidate for high temperature carbon dioxide removal in the recent times [24-25]. In a study, Wang et al reported an interesting way to synthesize $\mathrm{Li}_{4} \mathrm{SiO}_{4}$ using rice husk, which were calcined at $800^{\circ} \mathrm{C}$ in the presence of $\mathrm{Li}_{2} \mathrm{CO}_{3}$ [26]. This material is ideally suited for carbon dioxide removal from synthesis gas (syngas) derived from gasification of carbonaceous fuels (coal, coke, natural gas, biomass, etc.) and hence is considered as a pre-combustion carbon dioxide sorbent.

$$
\mathrm{Li}_{4} \mathrm{SiO}_{4}(\mathrm{~s})+\mathrm{CO}_{2}(\mathrm{~g}) \leftrightarrow \mathrm{Li}_{2} \mathrm{SiO}_{3}(\mathrm{~s})+\mathrm{Li}_{2} \mathrm{CO}_{3}(\mathrm{~s})
$$

$\mathrm{Li}_{4} \mathrm{SiO}_{4}$ has shown the ability to remove more than $90 \%$ of the carbon dioxide from simulated syngas in both fixed-bed and fluidized bed process configuration. The lithium silicate-based sorbent is highly effective at temperatures of $250-550^{\circ} \mathrm{C}$, pressures of $0-20$ atm, carbon dioxide concentrations of $2-20 \%$, and in the presence of contaminants such as hydrogen sulfide. Yamachui et al reported a carbonation yield of $87.2 \%$ under 100 $\mathrm{cm}^{3} /$ min flow rate of pure carbon dioxide [27]. The water vapor plays a major role in increasing the carbon dioxide absorption rates of $\mathrm{Li}_{4} \mathrm{SiO}_{4}$. About 22-26 wt. \% (capacities of $\sim 5-6 \mathrm{mmol} / \mathrm{g}$ ) were obtained using a gas stream containing about $15 \% \mathrm{CO}_{2}$ and $10 \%$ $\mathrm{H}_{2} \mathrm{O}$ in $\mathrm{N}_{2}$ at $550^{\circ} \mathrm{C}[28]$.

Moreover, the sorbent has shown excellent regenerability and attrition resistance in thermal cycling tests. Recent analysis has shown that the lithium silicate-based sorbent has the capability not only to separate carbon dioxide from syngas, but also to promote the water gas- shift reaction [29]. It is reported that dopant such as $\mathrm{Al}, \mathrm{Fe}, \mathrm{Na}, \mathrm{K}$ and $\mathrm{Cs}$ 
increases the carbon dioxide uptake of lithium orthosilicate [30-31]. On the basis of a study on the particle size effects on $\mathrm{Li}_{4} \mathrm{SiO}_{4}$, the reactivity of $\mathrm{Li}_{4} \mathrm{SiO}_{4}$ was modeled as a reaction of carbon dioxide at the solid surface followed by the rate limiting diffusion of lithium [32]. Although, $\mathrm{Li}_{4} \mathrm{SiO}_{4}$-based absorbent demonstrates high capacity, calculations based on the most optimistic assumptions revealed that the scale of a fixed bed temperature swing process would be impractical for post-combustion at a $500 \mathrm{MW}$ coalfired power plant [28].

\subsubsection{Alkali earth metal oxides}

\section{(a) Magnesium oxide (MgO)}

$\mathrm{MgO}$ combines with carbon dioxide to form $\mathrm{MgCO}_{3} \cdot \mathrm{MgCO}_{3}$ is thermodynamically stable at ambient conditions. A simple calculation shows that to capture 1 ton of $\mathrm{CO}_{2}$, about 0.92 ton of $\mathrm{MgO}$ is required (assuming $100 \%$ conversion). Thus, it is certain that to capture carbon dioxide using $\mathrm{MgO}$ at any power plant site, a large quantity of $\mathrm{MgO}$ will be needed. Moreover, the kinetics and recycling efficiency of $\mathrm{MgO}-\mathrm{CO}_{2}$ reaction are also the major issues to use $\mathrm{MgO}$ as a sorbent for practical applications. $\mathrm{MgO}$ is an attractive candidate for both pre- and post-combustion capture technologies due to its low regenerating temperatures: $\mathrm{T}_{2}=287^{\circ} \mathrm{C}$ (post-combustion) and $\mathrm{T}_{1}=447^{\circ} \mathrm{C}$ (pre-combustion) [33]. One should note that $\mathrm{MgO}$ when recycled between naturally occurring magnesite or dolomite can cause relatively lesser energy or carbon emission penalty [34].

Many researchers studied the heterogeneous reaction between magnesium species and $\mathrm{CO}_{2}$ in the presence or absence of $\mathrm{H}_{2} \mathrm{O}$ [35-49]. Although, a majority of research was not directly aimed at carbon capture but still the results are valuable additions to the mineral 
carbonation research. Most of the experiments are restricted to low temperature and ambient or low pressure conditions. Hence, the reported sorption capacities of carbon dioxide on $\mathrm{MgO}$ are not very high. In contrast, recent work of Highfield et al reports a conversion of about $70-80 \% \mathrm{MgO}$ to $\mathrm{MgCO}_{3}$ in about $2 \mathrm{~h}$ with steam pressure between 5$10 \%$ of the total pressure $20-40$ bar and temperature around $300-350^{\circ} \mathrm{C}$.

One of the key factors in gas-solid reaction is the presence of water. There have been several observations when water catalyzed the reaction [50-51]. $\mathrm{MgO}-\mathrm{CO}_{2}$ reaction has been studied to some extent. The role of water vapor in increasing the activity of $\mathrm{MgO}$ is now well-established. The direct relation of porosity, surface area and particle size with the carbonation yield has been examined. However, several factors such as carbonation kinetics, sorbent reversibility and durability are still not completely resolved and thus needs to be investigated.

\section{(b) Calcium oxide (CaO)}

In 1995, Silaban and Harrison proposed the method which involves the separation of carbon dioxide at high temperatures $\left(>600^{\circ} \mathrm{C}\right)$ using the reversible reaction of $\mathrm{CaO}$ [52]

$$
\mathrm{CaO}(\mathrm{s})+\mathrm{CO}_{2}(\mathrm{~g}) \leftrightarrow \mathrm{CaCO}_{3}(\mathrm{~g})
$$

The low price (because of naturally occurring mineral, limestone) and favorable thermodynamics of $\mathrm{CaO}$ has attracted a lot of interest in the past one decade and thus the $\mathrm{CaO}-\mathrm{CO}_{2}$ system has been extensively studied. A great advantage of calcium based sorbents is that the absorption of carbon dioxide can occur at temperatures above $600^{\circ} \mathrm{C}$ (possibility of heat recovery) [53].The efficiency of the carbon dioxide capture depends on many parameters such as diffusion resistance, which depends on the size of sorbent 
particles, volume and the pore structure, as well as surface size and reaction kinetics [54]. These parameters influence carbonation, but many of them also effect calcination. A detailed list of recent methods used to enhance the carbon dioxide uptake by $\mathrm{CaO}$ based sorbents can be found elsewhere [55].

Bulk $\mathrm{CaO}$, as a $\mathrm{CO}_{2}$-sorbent, has three severe limitations: (i) Kinetics of the carbonation reaction, despite being highly exothermic, become slow after the first layer of carbonate formation because the reaction is limited by the diffusion of carbon dioxide through the thin surface layer of $\mathrm{CaCO}_{3}$ formed on $\mathrm{CaO}$ [56-57]. The uptake kinetics of $\mathrm{CaO}-$ based sorbents was improved by innovative synthesis methods or precursors [58-59] (ii) Regeneration step is very energy-intensive ( $>800^{\circ} \mathrm{C}$ for $\mathrm{CaCO}_{3}$ decomposition), so excessive sintering and mechanical failure of the oxide occurs. This leads to a drastic loss in adsorption activity after a few sorption and regeneration cycles [60] (iii) To be an effective sorbent, $\mathrm{CaO}$ that is suitable for high surface area exposure, such as a powder. However, powders can be used in fluidized beds but the pressure drop associated with them is very large. Also, use of fine powders can be problematic due to entrainment in the process flow and attrition of the material [61].

The improvement in the sorbent reversibility can be seen as a major challenge for extended operation purpose. Decrease in absorption capacity is associated with sintering of the sorbent surface because of the influence of temperature, and the reduction in porosity and active surface [62-65]. Other factors that reduce the activity of sorbents are the attrition of sorbent grains during the process and chemical inactivation [66]. It should be noted that the reaction with sulfur oxide $\left(\mathrm{SO}_{2}\right)$ is competitive to the carbonation 
reaction. Sulfurization and carbonation reactions are similar because of being heterogeneous and occurring in the porous structure of the sorbent. However, sulfurization is irreversible in the temperature range $500-900^{\circ} \mathrm{C}$, occurs in small pores and covers the surface of the sorbent [67-70]. Decrease in the absorption capacity after 45 cycles was $60 \%$ for limestone, $40 \%$ for dolomite and less than $20 \%$ for huntite and can be attributed to the differences in the sorbent structure [71].The decrease in absorption capacity by $\mathrm{CaO}$ can be limited in several ways. The parameters which have impact are dopant $\left(\mathrm{NaCl}, \mathrm{Na}_{2} \mathrm{CO}_{3}, \mathrm{KCl}, \mathrm{KMnO}_{4}, \mathrm{MgCl}_{2}, \mathrm{CaCl}_{2}, \mathrm{Mg}\left(\mathrm{NO}_{3}\right)_{2}\right)$, sorbent grain size, raw material for calcium-based sorbent, thermal pretreatment of the sorbent and steam reactivation. The properties of $\mathrm{CaO}$ obtained from calcium acetate are better than the properties of $\mathrm{CaO}$ obtained from natural limestone because it has a much better conversion and greater durability [72].

\subsubsection{Transition metal oxides}

\section{(a) Iron based oxides}

Iron oxide based materials can be used for carbon dioxide capture purpose in both the power and non-power sectors. The main advantages of this sorbent are: it's readily accessiblity, has favorable thermodynamics and can be utilized for a large number of cycles.

Recently, Ohio State University has developed an iron oxide-based oxygen carrier for particles suitable for operation in the Coal- Direct Chemical Looping (CDCL) process. CDCL is an efficient power generation process. The process consists of a unique moving 
bed reactor, namely the reducer, where pulverized coal is fully converted using iron oxide.

$$
\begin{gathered}
\mathrm{Fe}_{2} \mathrm{O}_{3}(\mathrm{~s})+\mathrm{C}(\mathrm{s})=\mathrm{FeO}(\mathrm{s})+\mathrm{Fe}(\mathrm{s})+\mathrm{CO}_{2}(\mathrm{~g}) \\
2 \mathrm{FeO}(\mathrm{s})+0.5 \mathrm{O}_{2}(\mathrm{~g})=\mathrm{Fe}_{2} \mathrm{O}_{3}(\mathrm{~s})
\end{gathered}
$$

$\mathrm{Fe}_{2} \mathrm{O}_{3}$, an oxygen carrier, reduced to $\mathrm{FeO}$ and $\mathrm{Fe}$ while the exhaust gas is a stream of pure carbon dioxide that can be sequestered or used for enhanced oil recovery. The reduced $\mathrm{FeO}$ and $\mathrm{Fe}$ mixture can then oxidized to $\mathrm{Fe}_{2} \mathrm{O}_{3}$ using air in the combustor reactor, liberating heat to produce steam [73].

Another recent study presents the carbon dioxide capture technique for iron and steel industries using iron-based raw materials easily available at the iron making sites [74].

$$
\begin{aligned}
& \mathrm{Fe}_{3} \mathrm{O}_{4}(\mathrm{~s})+\mathrm{Fe}(\mathrm{s})+4 \mathrm{CO}_{2}(\mathrm{~g}) \rightarrow 4 \mathrm{FeCO}_{3}(\mathrm{~s}) \\
& \quad 3 \mathrm{FeCO}_{3}(\mathrm{~s})+0.5 \mathrm{O}_{2}(\mathrm{~g}) \rightarrow \mathrm{Fe}_{3} \mathrm{O}_{4}(\mathrm{~s})+3 \mathrm{CO}_{2}(\mathrm{~g})
\end{aligned}
$$

The global steel production is growing rapidly, from $1248 \mathrm{Mt}$ in 2006 to $1490 \mathrm{Mt}$ in 2011, an increase of about $16 \%$ in a short span of 5 years [75]. Steel production is an energy intensive process and thus consumes huge amount of fossil fuels. Each ton of steel production emits 2.2 ton of $\mathrm{CO}_{2}$ as a world average. Therefore, iron making industries is one of the biggest targets next to power plants to curb vast emission of greenhouse gases.

A mixture of magnetite and iron combines with carbon dioxide and forms siderite. The reaction generates heat and thus can be utilized to produce steam. Siderite, once formed can further decompose back to magnetite in presence of oxygen at $350^{\circ} \mathrm{C}$. Once the 
absorption capacity of magnetite degrades, it can be sent back to blast furnace for further processing. For example, the sorbents can be processed in a blast furnace for the production of iron or steel. Thus, the proposed method can advantageously reduce or even eliminate the loss of raw materials. This system and method can be more thermodynamically favorable and can save energy. The reversibility and suitable kinetics can make the system highly favorable for carbon dioxide capture at any iron and steel industries.

\section{(b) Other transition metal oxides}

It is predicted that $\mathrm{MnO}$ can be used for both post- and pre-combustion conditions. At $\mathrm{P}_{\mathrm{CO} 2}=0.1$ bar the driving force for $\mathrm{MnO}$ to convert in $\mathrm{MnCO}_{3}$ was high even at a low temperature $77^{\circ} \mathrm{C}$. The carbon dioxide could be released at about $377^{\circ} \mathrm{Cat}$ partial $\mathrm{P}_{\mathrm{CO} 2}=10$ bar. For pre-combustion, $\mathrm{MnO}$ will capture carbon dioxide at a partial pressure of about 10 bar below $327^{\circ} \mathrm{C}$ and then could be regenerated by heating above $377^{\circ} \mathrm{C}$ to produce a stream of pure carbon dioxide.

According to the thermodynamics, $\mathrm{CdO}$ can be used for both pre-and post -combustion conditions. However, the toxicity of $\mathrm{Cd}$ system would be a big hurdle in its practical applications.

$\mathrm{ZnO}$ can be used preferably for post-combustion but not for pre-combustion. As the equilibrium temperature required for carbonate formation is $77^{\circ} \mathrm{C}$ at $\mathrm{P}_{\mathrm{CO} 2}=0.1$ bar and around $167^{\circ} \mathrm{C}$ for $\mathrm{P}_{\mathrm{CO} 2}=10$ bars [16]. Therefore, it may be essential to cool post- 
combustion gases prior to carbonation for high driving force and thus make the sorbent unfit for post-combustion capture.

The NiO material could be considered for post-combustion capture, but not precombustion. Post-combustion absorption will occur below $77^{\circ} \mathrm{C}$ and could be regenerated above $187^{\circ} \mathrm{C}$. However, $\mathrm{NiO}$ availability is a matter of big concern for the practical usage.

\subsubsection{Miscellaneous}

The adsorbent material which is promising for carbon dioxide capture from postcombustion gas streams is aluminosilicate zeolite because of the selective carbon dioxide adsorption and high capacities [76]. Numerous experiments have been conducted on this material and exhibit enhanced uptake capacity compared to the pure-silica zeolites [7779]. In general, adsorption kinetics of carbon dioxide on zeolites is comparatively fast and achieved equilibrium capacity within a few minutes. However, temperature and pressure strongly governs the carbon dioxide adsorption on zeolites. As the temperature increases, the adsorption of carbon dioxide decreases but as the gas-phase partial pressure of carbon dioxide increases, carbon dioxide adsorption increases accordingly. The presence of water vapor may limit the application of zeolite sorbents by decreasing its capacity. It is therefore clear, that by optimizing different important factors, such as basicity, pore size of zeolites, electric field strength caused by the presence of exchangeable cations in their cavities may significantly influence the carbon dioxide adsorption capacities of zeolites. 


\subsubsection{Summary}

It is certain that an improved and cost efficient process for carbon dioxide capture obtained from flue gas streams from power plants burning fossil fuels is needed to mitigate the huge emission of greenhouse gases. Among several different proposed processes, metal oxides are promising options for suitable sorbent and have a great potential in the future. However, these sorbents also have limitations and challenges which must be solved before these can be employed commercially for carbon dioxide capture purpose. Based on the current scenario, following suggestions are proposed for the future research on carbon dioxide capture using metal oxides:

(a) Improvement in the potential sorbent performance, in terms of capture capacity, reversibility rate, carbonation kinetics, multi-cycle durability and sorbent reversibility;

(b) In depth analysis of performance check of potential sorbent under actual flue gas conditions;

(c) A detailed techno-economic assessment of the potential sorbents; 


\subsubsection{References}

[1] D. Aaron, C. Tsouris, Separation Science \& Technology, 2005, 40, 321-348.

[2] C.M. White, B.R. Strazisar, E.J. Granite, J.S. Hoffman, H.W. Pennline, Journal of the Air \& Waste Management Association, 2003, 53, 645-715.

[3] T.C. Merkel, H. Lin, X. Wei, R. Baker, Journal of Membrane Science, 2010, 359, $126-139$.

[4] R.J. Littel, G.F. Versteeg, W.P.M. Van Swaaij, Chemical Engineering Science, 1991, $46,3308-3313$.

[5] P. Chiesa, S.P. Consonni, Journal of Engineering for Gas Turbines and Power, 1999, 121, 295-305.

[6] S. Bishnoi, G.T. Rochelle, Chemical Engineering Science, 2000, 55, 5531-5543.

[7] G.T. Rochelle, Science, 2009, 325, 1652-1654.

[8] P.J.E. Harlick, F.H.Tezel, Microporous and Mesoporous Materials, 2004, 76, 71-77.

[9] C.E. Powell, G.G. Qiao, Journal of Membrane Science, 2006, 279, 1-49.

[10] S.M. Benson, D.R. Cole, Elements, 2008, 4, 325-331.

[11] H. Guoxin, H. Huang, Y.H. Li, International Journal of Hydrogen Energy, 2008, 33,5422-5429.

[12] R. Siriwardane, J. Poston, K. Chaudhari, A. Zinn, T. Simonyi, C. Robinson, Energy \& Fuels, 2007, 21, 1582-1591.

[13] S.C. Lee, J.C. Kim, Catalysis Surveys from Asia, 2007, 11,171-185.

[14] J.C. Abanades, E.J. Anthony, J. Wang, J.E. Oakey, Environmental Science \& Technology, 2005, 39, 2861-2866.

[15] Y. Duan, D.C. Sorescu, The Journal of Chemical Physics, 2010, 133, 074508

[16] B. Zhang, Y. Duan, K. Johnson, The Journal of Chemical Physics, 2012, 136, 064516

[17] Y. Duan, D. Luebke, H. Pennline, International Journal of Clean Coal and Energy, 2012, 1, 1-11.

[18] DOE-NETL, Cost and performance baseline for fossil energy plants, Volume 1: Bituminous Coal and Natural Gas to Electricity Final Report. August 2007 
[19] K. Nakagawa, T.J. Ohashi, Journal of the Electrochemical Society, 1998, 145, 13441346.

[20] J. Ida, R. Xiong, Y.S. Lin, Separation and Purification Technology, 2004, 36, 41-51.

[21] G. Pannocchia, M. Puccini, M. Seggiani, S. Vitolo, Industrial \& Engineering Chemistry Research, 2007, 46, 6696-6706.

[22] M. Veliz-Enriquez, G. González, H. Pfeiffer, Journal of Solid State Chemistry, 2007, $180,2485-2492$.

[23] L.O.G. Hernández, D.L. Gutiérrez, V.C. Martínez, A.L. Ortiz, Journal of New Materials for Electrochemical Systems, 2008, 11, 137-142.

[24] K. Essaki, K. Nakagawa, M. Kato, H. Uemoto, Journal of Chemical Engineering of Japan, 2004, 37,772-777.

[25] M. Kato, K. Nakagawa, K. Essaki, Y. Maezawa, S. Takeda , R. Kogo, Y. Hagiwara, International Journal of Applied Ceramic Technology, 2005, 2, 467-475.

[26] K. Wang, X. Guo, P. Zhao, F. Wang, C. Zheng, Journal of Hazardous Material, 2011, 189, 301-307.

[27] K. Yamauchi, N. Murayama, J. Shibata, Materials Transactions, 2007, 48, 2739 2742.

[28] R. Quinn, R.J. Kitzhoffer, J.R. Hufton, T.C. Golden, Industrial \& Engineering Chemistry Research, 2012, 51, 9320-9327.

[29] J.D. Figueroa, T. Fout, S. Plasynski, H. McIlvried, R.D. Srivastava, International Journal of Greenhouse Gas Control, 2008, 2, 9-20.

[30] P. V. Korake, A. G. Gaikwad, Frontiers of Chemical Science \& Engineering, 2011, $5,215-226$.

[31] C. Gauer, W. Heschel, Journal of Material Science, 2006, 41, 2405-2409

[32] R.R. Mosqueda, H. Pfeiffer, The Journal of Physical Chemistry A., 2010, 114, $4535-454$.

[33] M. Bhagiyalakshmi, J.Y. Lee, H.T. Jang, International Journal of Greenhouse Gas Control, 2010, 4, 51-56.

[34] B. Feng, H. An, E. Tan, Energy \& Fuels, 2007, 21, 426-434

[35] L. Li, X. Wen, X. Fu, F. Wang, N. Zhao, F. Xiao, W. Wei, Y. Sun, Energy \& Fuels, 2010, 24, 5773-5780. 
[36] S.C. Lee, H.J. Chae, S.J. Lee, B.Y. Choi, C.K. Yi, J.B. Lee, C.K. Ryu , J.C. Kim, Environmental Science \& Technology, 2008, 42, 2736-2741.

[37] S.M. Ward, J. Braslaw, R.L. Gealer, Thermochimica Acta, 1983, 64, 107-114.

[38] S. Choi, J.H. Drese, C.W. Jones, Chemsuschem, 2009, 2, 796-854.

[39] X. Fu, N. Zhao, J. Li, F. Xiao, W. Wei, Y. Sun, Adsorption Science \&Technology, 2009, 27, 593-601.

[40] S. Liu, X. Zhang, J. Li, N. Zhao, W. Wei, Y. Sun, Catalysis Communications, 2008, 9,1527-1532.

[41] B. Li, X. Wen, N. Zhao, X.Z. Wang, W. Wei, Y. Sun, Z.H. Ren, Z.J. Wang, Journal of Fuel Chemistry \& Technology, 2010, 38, 473-477.

[42] Z. Yong, V. Mata, A.E. Rodrigues, Industrial \& Engineering Chemistry Research, 2001, 40, 204-209.

[43] L. Li, Y. Li, X. Wen, F. Wang, N. Zhao, F. Xiao, W. Wei, Y. Sun, Energy \&Fuels, 2011, 25, 3835-3842.

[44] S.C. Lee, B.Y. Choi, T.J. Lee, C.K. Ryu, Y.S. Soo, J.C. Kim, Catalysis Today, 2006, $111,385-390$.

[45] A.M. Ruminski, K.J. Jeon, J.J. Urban, Journal of Material Chemistry, 2011, 21, $11486-11491$

[46] D. Beruto, R. Botter, A.W. Searcy, The Journal of Physical Chemistry, 1987, 91, 3578-3581

[47] W. Lu, D. Yuan, J. Sculley, D. Zhao, R. Krishna, H.C. Zhou, Journal of the American Chemical Society, 2011, 133, 18126-18129.

[48] J. Fagerlund, J. Highfield, R. Zevenhoven, RSC Advances, 2012, 2, 10380-10393

[49] J. Highfield, J. Bu, J. Fagerlund, R. Zevenhoven, ICCDU-XI, 2011

[50] D.P. Butt, S.P. Pile, Y. Park, R. Vaidya, K.S. Lackner, C.H. Wendt, K. Nomura, Report LA-UR-98-7631, 1998

[51] A. Hassanzadeh, J. Abbasian, Fuel, 2010, 89, 1287-1297.

[52] A. Silaban, D.P. Harrison, Chemical Engineering Communications, 1995, 137, 177190 
[53] C. Salvador, D. Lu, E. Anthony, J. Abanades, Chemical Engineering Journal, 2003, 96, 187-195.

[54] R. Hughes, D. Lu, E. Anthony, Y.Wu, Industrial Engineering\& Chemistry Research, 2004, 43, 5529-5539.

[55] M. K. Moranska, G. Tomaszewicz, G. Labojko, Physicochemical Problems of Mineral Processing, 2012, 48, 77-90

[56] R. Barker, Journal of Applied Chemistry \& Biotechnology, 1974, 24, 221-227.

[57] S.K. Bhatia, D.D. Perlmutter, American Institute of Chemical Engineers Journal, 1983, 29, 79-86.

[58] H. Lu, P.G. Smirniotis, F.O. Ernst, S.E. Pratsinis, Chemical Engineering Science, 2009, 64, 1936-1943.

[59] H. Lu, E.P. Reddy, P.G. Smirniotis, Industrial \& Engineering Chemistry Research, 2006, 45, 3944-3949.

[60] J.C. Abanades, D. Alvarez, Energy \& Fuels, 2003, 17, 308-315.

[61] P. Gruene, A.G. Belova, T.M. Yegulalp, R.J. Farrauto, M.J. Castaldi, Industrial \& Engineering Chemistry Research, 2011, 50, 4042-4049

[62] J. Wang, V. Manovic, Y. Wu, E. Anthony, Applied Energy, 2010, 87, 1453-1458.

[63] E. Bouquet, G. Leyssens, C. Schönnenbeck, P. Gilot, Chemical Engineering Science , 2009, 64, 2136-2146.

[64] A. Lysikov, S. Trukhan, A. Okunev, International Journal of Hydrogen Energy, 2008, 33, 3061-3066.

[65] B. Stanmore, P. Gilot, Fuel Processing Technology, 2005, 86, 1707-1743.

[66] Y. Li, C. Zhao, H. Chen, C. Liang, L. Duan, W. Zhou , Fuel, 2009, 88, 697-704.

[67] J. Adanez, L. de Diego, F. Garcia-Labiano, Fuel, 1999, 78, 583-592

[68] W. Nimmo, A. Patsias, E. Hampartsoumian, B. Gibbs, M. Fairweather, P. Williams, Fuel, 2004, 83, 1143-1150.

[69] A. Patsias, W. Nimmo, B. Gibbs, P. Williams, Fuel, 2005, 84, 1864-1873.

[70] A. Silaban, M. Narcida, D. Harrision, Chemical Engineering Communications, 1996, $146,149-162$. 
[71] A. Bandi, M. Specht, P. Sichler, N. Nicoloso, 5th International Symposium on Gas Cleaning at High Temperature, Morgantown, 2002.

[72] V. Manovic, E. Anthony, G. Grasa, J. Abanades, Energy \& Fuels, 2008, 22, 32583264.

[73] H.R. Kim, Unit Document no. osu1352996758

[74] S. Kumar, V. Drozd, A. Durygin, S. K. Saxena, U.S. Provisional Patent Application No. 61/733,297, 2012.

[75] www.worldsteel.org

[76] O.M. Yaghi, M. Keeffe, N. Ockwig, C. Hee, M. Eddaoudi, J. Kim, Nature, 2003, $423,705-714$.

[77] M. Hudson, W. Queen, J. Mason, D. Fickel, R. Lobo, C. Brown, Journal of the American Chemical Society, 2012, 134, 1970-1973.

[78] J. Pires, M.B. de Carvalho, F.R. Ribeiro, E.G. Derouane, Journal of Molecular Catalysis, 1993, 85, 295-303

[79] A.K. Samanta, A. Zhao, G.K.H. Shimizu, P. Sarkar, R. Gupta Industrial \& Engineering Chemistry Research, 2012, 51, 1438-1463 


\subsection{AN EXPERIMENTAL INVESTIGATION OF MESOPOROUS MgO AS A POTENTIAL PRE-COMBUSTION $\mathrm{CO}_{2}$ SORBENT}

\subsubsection{INTRODUCTION}

Currently, a large focus is devoted on capturing carbon dioxide from coal-fired power plant flue streams, which continues to be the major carbon dioxide contributor [1].There are three main technological approaches for carbon dioxide capture- post-, oxy- and precombustion. Post-combustion systems capture carbon dioxide from nitrogen rich flue gas stream, produced by burning fossil fuel in air. Oxy-combustion uses pure stream of oxygen, instead of air, to combust coal and thus produces carbon dioxide rich gas stream. While, pre-combustion systems are designed mainly to remove carbon dioxide from the syngas prior to its combustion for power production [2].Under pre-combustion conditions, after the Water gas-shift reactor, the gas stream mainly consists of $\mathrm{CO}_{2}, \mathrm{H}_{2} \mathrm{O}$ and $\mathrm{H}_{2}$. The partial carbon dioxide pressure for pre-combustion capture conditions is around 20-30 bar and the temperature is between 250 and $450^{\circ} \mathrm{C}$ [3].

Both the physical and chemical solvents can be used for pre-combustion carbon dioxide capture. Unlike chemical solvent, physical solvent (such as Selexol and Rectisol) selectively absorb carbon dioxide without forming any chemical bonds. Thus, the physical solvent requires relatively less regeneration energy as compared to that of chemical solvent [4]. However, these physical solvent-based processes suffer severe disadvantages which include the loss of pressure during regeneration and requirement of a low operating temperature. Due to the necessity of a lower operating temperature, the syngas needs to be cooled prior to carbon dioxide absorption. After carbon dioxide 
absorption, the remaining hydrogen gas stream requires to be reheated to the gas turbine inlet temperature. However, chemical solvents have the advantage of high mass transfer driving force into solution and increased acid gas selectivity. Also, chemical solvents can be used in processes that utilize thermal swing regeneration and generate the carbon dioxide at elevated pressure [5].But chemical solvents increase the energy and cost penalty and thus downgraded as a future carbon dioxide sorbent [6].

Currently, the focus is to develop advanced physical and chemical solvent systems that have the potential to provide significant improvements in both cost and performance as compared to the Selexol and Rectisol for pre-combustion carbon dioxide capture. The challenges are to modify regeneration conditions to recover the carbon dioxide at a higher pressure; improve selectivity to reduce hydrogen losses; and develop a solvent that has a high carbon dioxide loading at a higher temperature, which would increase Integrated Gasification Combined Cycle (IGCC) efficiency. In the same line, another vital task is to develop a new sorbent which could be highly efficient for pre-combustion capture conditions. Consequently, the US Department of Energy (DOE) performed the thermodynamic modeling activities included screening analyses for a number of different metal oxides, zirconates, silicates and titanates under various operating conditions to identify new solid sorbents for pre-combustion carbon dioxide capture. About 18 sorbents were modeled and finally seven candidates are chosen - magnesium oxide (MgO), calcium oxide $(\mathrm{CaO})$, lithium zirconate $\left(\mathrm{Li}_{2} \mathrm{ZrO}_{3}\right)$, calcium zirconate $\left(\mathrm{CaZrO}_{3}\right)$, barium zirconate $\left(\mathrm{BaZrO}_{3}\right)$, barium titanate $\left(\mathrm{BaTiO}_{3}\right)$ and barium silicate $\left(\mathrm{BaSiO}_{3}\right)$ for further investigations [7]. Among these solid sorbents, $\mathrm{MgO}$ and $\mathrm{CaO}$ are attractive because of their easy accessibility and favorable thermodynamic properties. 
The alkaline earth metal oxides (such as $\mathrm{CaO}$ and $\mathrm{MgO}$ ) combine with carbon dioxide to form thermodynamically stable carbonates. Metal carbonates, when heated, liberates pure stream of carbon dioxide gas and regenerates the oxides. Eventually, the generated pure carbon dioxide gas can either be sequestered underground or used for enhanced oil recovery [8]. $\mathrm{CaO}$ are abundant and thus relatively easily accessible than $\mathrm{MgO}$. However, $\mathrm{CaO}$ as carbon dioxide -sorbent suffers severe major drawbacks and a detailed discussion can be found elsewhere [9]. It is a fact that regeneration of oxides needs a lot of energy [10]. $\mathrm{MgO}$ and $\mathrm{Mg}(\mathrm{OH})_{2}$ are known to be better candidates than $\mathrm{CaO}$ for carbon dioxide capture applications due to their low regeneration energy requirement and low operating temperature [11]. Thus, $\mathrm{MgO}$ (periclase), although occurs only rarely as an oxide, we choose it here for our study. One should note that $\mathrm{MgO}$ when recycled between naturally occurring magnesite or dolomite can cause relatively lesser energy or carbon emission penalty [12].

The carbon dioxide absorption capacity of $\mathrm{MgO}$ was studied as a function of particle size, surface area, temperature, pressure, supports and concentration of water vapor. The carbon dioxide uptake capacity on different $\mathrm{MgO}$ sorbents at different conditions is listed in Table 5.2.1. Most of the experiments are restricted to low temperature and ambient or low pressure condition. Hence, the reported sorption capacities of carbon dioxide on $\mathrm{MgO}$ are not very high. However, the sorbents which can operate in the range of 300$350^{\circ} \mathrm{C}$ would be ideal for the use in IGCC applications. Therefore, we study the carbon dioxide capture capacity of $\mathrm{MgO}$ in the relatively high temperature and pressure condition of $300-375^{\circ} \mathrm{C}$ and $10-50$ bars respectively. 


\begin{tabular}{|c|c|c|c|c|c|c|}
\hline & Sorbent & Gas stream & $\begin{array}{l}\mathrm{T}_{\text {carbonation }} \\
\text { ( } \mathrm{C})\end{array}$ & $\begin{array}{l}\mathrm{T}_{\text {Regeneration }} \\
\text { (C) }\end{array}$ & $\begin{array}{c}\mathrm{CO}_{2} \text { capture } \\
\text { capacity } \\
\text { (mmol/g) } \\
\text { Conversion, \% }\end{array}$ & Ref. \\
\hline 1 & $\mathrm{MgO}$ & Pure $\mathrm{CO}_{2}$ & $50-1000$ & 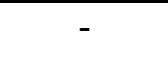 & 0.99 & [13] \\
\hline 2 & $\begin{array}{l}\mathrm{MgO} / \mathrm{Al}_{2} \mathrm{O}_{3} \\
(10 \text { wt. } \% \mathrm{MgO} \text { ) }\end{array}$ & $\begin{array}{l}\left(13 \mathrm{v} \% \mathrm{H}_{2} \mathrm{O}\right. \\
\left.13 \mathrm{v} \% \mathrm{CO}_{2}\right)\end{array}$ & 30,150 & 350 & 1.36 & [14] \\
\hline 3 & $\mathrm{MgO}$ & $\begin{array}{c}\left(11 \mathrm{v} \% \mathrm{H}_{2} \mathrm{O}\right. \\
\left.1 \mathrm{v} \% \mathrm{CO}_{2}\right)\end{array}$ & $50-100$ & $150-400$ & 1.05 & {$[15]$} \\
\hline 4 & $\mathrm{~K}_{2} \mathrm{CO}_{3} / \mathrm{MgO}$ & $\begin{array}{c}\left(11 \mathrm{v} \% \mathrm{H}_{2} \mathrm{O}\right. \\
\left.1 \mathrm{v} \% \mathrm{CO}_{2}\right)\end{array}$ & $50-100$ & $150-400$ & 2.98 & [15] \\
\hline 5 & $\mathrm{MgO}$ & $\begin{array}{c}330 / 660 \mathrm{ppm} \\
\text { in air }\end{array}$ & 0,100 & - & $0.64,0.43$ & [16-17] \\
\hline 6 & $\begin{array}{c}\mathrm{MgO} / \mathrm{MCM} \\
-41\end{array}$ & Pure $\mathrm{CO}_{2}$ & 25 & - & 1.06 & {$[18]$} \\
\hline 7 & $\begin{array}{c}\text { Mesoporous } \\
\mathrm{MgO}\end{array}$ & Pure $\mathrm{CO}_{2}$ & 25,100 & - & $1.82,2.27$ & [19] \\
\hline 8 & $\begin{array}{c}\text { Non-porous } \\
\mathrm{MgO}\end{array}$ & Pure $\mathrm{CO}_{2}$ & 25 & - & 0.45 & [19] \\
\hline 9 & $\mathrm{MgO}-\mathrm{ZrO}_{2}$ & Pure $\mathrm{CO}_{2}$ & 30,150 & - & $1.15,1.01$ & [20-21] \\
\hline 10 & $\begin{array}{c}\mathrm{MgO} \\
(31.7 \text { wt. \%)/ } \\
\mathrm{Al}_{2} \mathrm{O}_{3} \\
(22.4 \text { wt. } \%) \\
\end{array}$ & Pure $\mathrm{CO}_{2}$ & $\begin{array}{c}20,200,30 \\
0\end{array}$ & - & $0.13,0.24,0.5$ & [22] \\
\hline 11 & $\begin{array}{c}\mathrm{MgO} \\
(33.8 \text { wt. \%)/ } \\
\mathrm{Al}_{2} \mathrm{O}_{3} \\
(20.8 \text { wt. } \%)\end{array}$ & Pure $\mathrm{CO}_{2}$ & $\begin{array}{c}20,200,30 \\
0\end{array}$ & - & $0.08,0.12,0.5$ & [22] \\
\hline 12 & $\begin{array}{c}\mathrm{K}_{2} \mathrm{CO}_{3} / \mathrm{MgO} \\
/ \mathrm{Al}_{2} \mathrm{O}_{3} \\
\end{array}$ & Flue gas & 60 & 480 & 2.49 & [23] \\
\hline 13 & $\mathrm{~K}_{2} \mathrm{CO}_{3} / \mathrm{MgO}$ & $\begin{array}{c}\left(9 \mathrm{v} \% \mathrm{H}_{2} \mathrm{O},\right. \\
\left.1 \mathrm{v} \% \mathrm{CO}_{2}\right) \\
\end{array}$ & 60 & 400 & 2.7 & [24] \\
\hline 14 & $\begin{array}{c}\mathrm{MgO} \\
\text { nanocrystal }\end{array}$ & Flue gas & 60 & $60-600$ & 6.4 & [25] \\
\hline 15 & $\mathrm{MgO}$ & Pure $\mathrm{CO}_{2}$ & 350 & - & $0.089,0.091$ & {$[26]$} \\
\hline 16 & $\mathrm{MgO}$ & Pure $\mathrm{CO}_{2}$ & $300-500$ & - & $\begin{array}{c}70-80 \% \\
(\sim 200 \mathrm{~min})\end{array}$ & [27] \\
\hline 17 & $\mathrm{MgO}$ & Pure $\mathrm{CO}_{2}$ & - & - & $\begin{array}{c}100 \% \\
(\sim 120 \mathrm{~min})\end{array}$ & [28] \\
\hline
\end{tabular}

Table 5.2.1 $\mathrm{CO}_{2}$ uptake capacity of $\mathrm{MgO}$ obtained from the literature 


\subsubsection{EXPERIMENTAL PROCEDURE}

The reaction

$$
\mathrm{MgO}(\mathrm{s})+\mathrm{CO}_{2}(\mathrm{~g}) \leftrightarrow \mathrm{MgCO}_{3}(\mathrm{~s})
$$

was studied experimentally. The carbonation reaction was performed in a closed system which permits us to efficiently maintain high temperature and pressure for a long period of time. The decomposition reaction of carbonate was examined using Thermo gravimetric Analysis (TGA) technique.

About $0.2 \mathrm{~g}$ of 325 mesh sized magnesium oxide (delivered by Alfa Aesar) was put inside a closed cylindrical vessel (1.25" long and $0.35 "$ internal diameter). About $0.1 \mathrm{ml}$ of water was also introduced on the vessel walls. Chemically pure $\mathrm{CO}_{2}$ gas (Airgas) was passed into this system. Before experiments, $\mathrm{CO}_{2}$ gas was flushed three times to ensure a pure $\mathrm{CO}_{2}$ atmosphere inside the reactor. The reaction was performed for 30 minutes at a desired temperature and pressure condition. Once the reaction completed, the system was air-cooled. The product was then ground using mortar and pestle. The powder particle was again put back for another reaction at the same experimental condition. This cycle was repeated until no increment in weight of the product was observed.

Thermo gravimetric analysis (TGA) of the product was done by using TGA 2950 Thermo gravimetric analyzer. The samples (10mg) were heated under argon purge, at a heating rate of $10^{\circ} \mathrm{C} / \mathrm{min}$ to a final temperature of $800^{\circ} \mathrm{C}$. The TGA provides continuous measurements of the sample weight as a function of time and temperature. The amount of 
formation of $\mathrm{MgCO}_{3}$ was analyzed by the percent loss in weight of the sample while heating up to $800^{\circ} \mathrm{C}$ in an argon atmosphere.

The product characterization was performed using X-ray powder diffraction method. Bruker GADDS/D8 is equipped with Apex Smart CCD Detector and direct-drive rotating anode. The MacSci rotating anode (Molybdenum) operates with a $50 \mathrm{kV}$ generator and $20 \mathrm{~mA}$ current. X-ray beam size can vary from 50 to $300 \mu \mathrm{m}$. The usual collection time is $1200 \mathrm{~s}$.

An isothermal gas adsorption was employed to measure internal surface areas of the powder particles. Micromeritics Tristar II 3020 (surface area and porosimetry analyzer instrument) was used with $\mathrm{N}_{2}$ as adsorptive gas at $77 \mathrm{~K}$ (liquid nitrogen bath). The samples were first degassed under $300^{\circ} \mathrm{C}$ with a $\mathrm{N}_{2}$ gas flow for $1 \mathrm{~h}$ in order to remove the moisture and other adsorbed gases before analysis. The internal surface area was calculated using the Brunauer- Emmett-Teller (BET) method. The pore volume was also calculated from the adsorbed nitrogen after complete pore condensation $\left(\mathrm{P} / \mathrm{P}_{0}=0.9925\right)$ using the ratio of the densities of liquid and gaseous nitrogen. The pore size was calculated by using the Barrett-Joyner-Halenda (BJH) method.

\subsubsection{RESULTS AND DISCUSSION}

Fig.5.2.1 confirms the formation of $\mathrm{MgCO}_{3}$ at different temperatures and carbon dioxide pressures. $\mathrm{MgO}, \mathrm{Mg}(\mathrm{OH})_{2}, \mathrm{MgO} .2 \mathrm{MgCO}_{3}$ and $\mathrm{MgCO}_{3}$ were identified conventionally by their corresponding Joint Committee Powder Diffraction Standard (JCPDS) card number 79-0612,82-2345,31-0804 and 86-2345 respectively. 


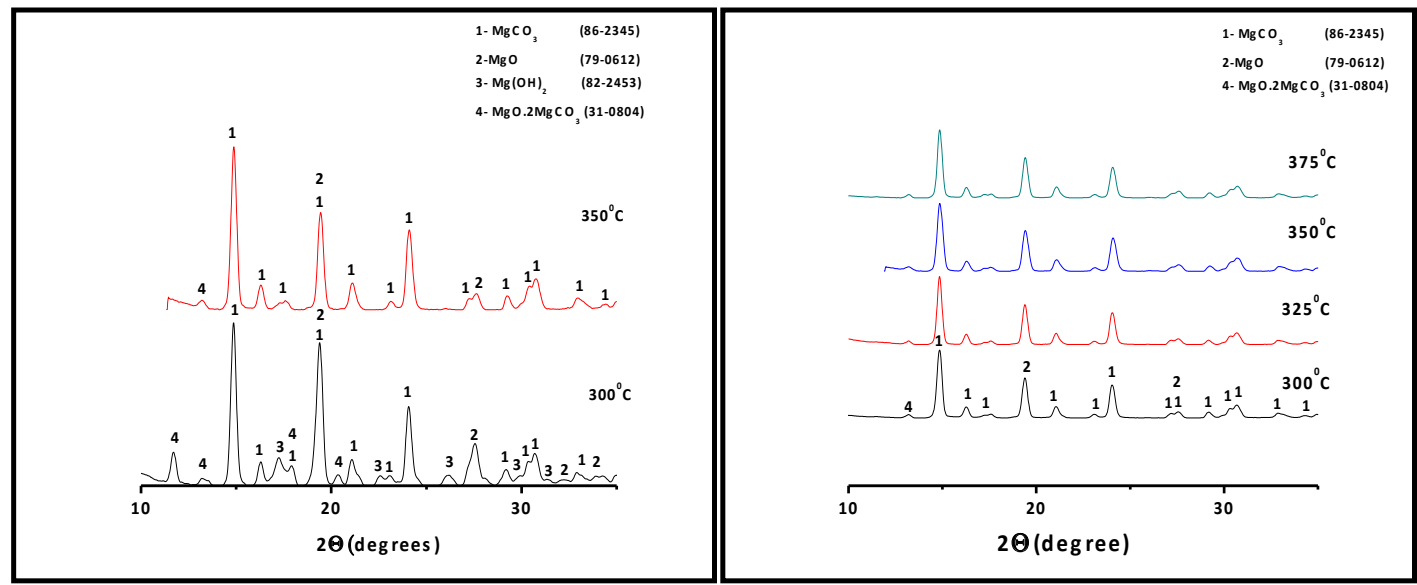

Figure 5.2.1 X-ray diffraction patterns for $\mathrm{MgCO}_{3}$ formation after reaction at various temperatures and $\mathrm{CO}_{2}$ pressure of (a) 10 bars and (b) 50 bars

One of the vital factors in gas-solid carbonation reaction is the presence of water and there have been numerous observations where water act as a catalyst [29-32]. Therefore, we have also used water $(0.1 \mathrm{ml})$ for the $\mathrm{MgO}-\mathrm{CO}_{2}$ reaction. In absence of water, no carbon dioxide was absorbed at these conditions due to the kinetic limitations. The carbon dioxide sorption capacity of $\mathrm{MgO}$ increases significantly in the presence of water vapor. Under humid condition, $\mathrm{MgO}$ rapidly locks carbon dioxide in the form of $\mathrm{MgCO}_{3}$. Recently, Fagerlund et al proposed the reaction mechanism for $\mathrm{MgO}$ carbonation in the presence of steam [27]:

$$
\begin{gathered}
\mathrm{MgO}+\mathrm{H}_{2} \mathrm{O} \leftrightarrow{\mathrm{MgO} . \mathrm{H}_{2} \mathrm{O}^{*}}_{\mathrm{MgO} . \mathrm{H}_{2} \mathrm{O}^{*}+\mathrm{CO}_{2} \leftrightarrow \mathrm{MgCO}_{3}+\mathrm{H}_{2} \mathrm{O}} \\
\mathrm{MgO}+\mathrm{CO}_{2} \leftrightarrow \mathrm{MgCO}_{3}
\end{gathered}
$$

Fig. 5.2.2 depicts the adsorption/absorption model for $\mathrm{MgO}-\mathrm{CO}_{2}-\mathrm{H}_{2} \mathrm{O}$ reaction. Based on the previous work, it could be reasonable to corroborate that water vapor surrounds $\mathrm{MgO}$ 
particles where carbon dioxide reacts to form $\mathrm{CO}_{3}{ }^{2-}$ ions and $\mathrm{H}^{+}$ions [32-34]. Free $\mathrm{Mg}^{+2}$ ions could further react with the $\mathrm{CO}_{3}{ }^{2-}$ ions to form $\mathrm{MgCO}_{3}$. However, $\mathrm{MgCO}_{3}$ forms an impervious layer around unreacted $\mathrm{MgO}$ particles and hinders the further diffusion of carbon dioxide molecules.

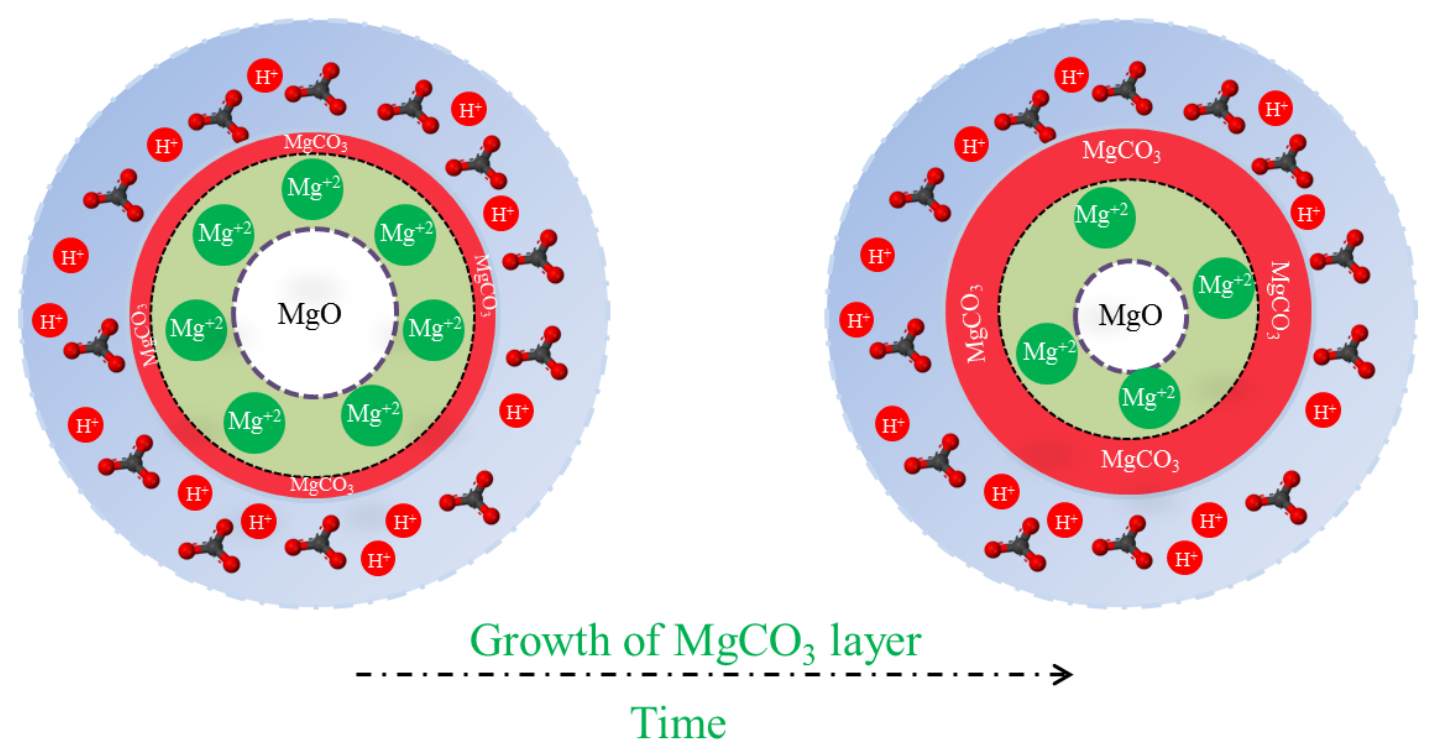

Figure 5.2.2 Adsorption/absorption model for $\mathrm{MgO}-\mathrm{CO}_{2}-\mathrm{H}_{2} \mathrm{O}$ reaction

Here, we used mortar and pestle to grind the product. Grinding helps in scrubbing off the outer nonporous layer of $\mathrm{MgCO}_{3}$. It is obvious that the use of mortar and pestle is limited to the laboratory and cannot be seen as an industrial operation. Therefore, it is recommended to have an aggregative fluidization regime for a fluidized bed reactor while scaling up $\mathrm{MgO}-\mathrm{CO}_{2}$ reaction. Also, increasing the amount of water vapor cannot lead to the complete carbonate conversion of $\mathrm{MgO}$. Thus, in addition to the amount of steam, surface properties of $\mathrm{MgO}$ (such as surface area, particle size, porosity) are also very crucial parameters for the carbonation process. 


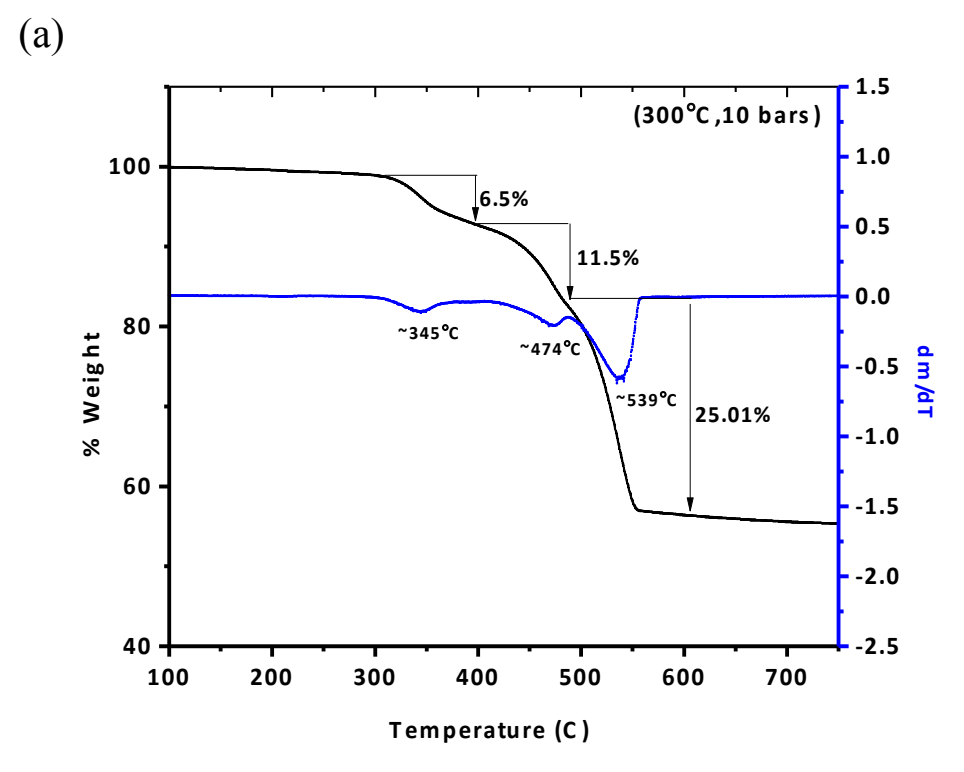

(b)

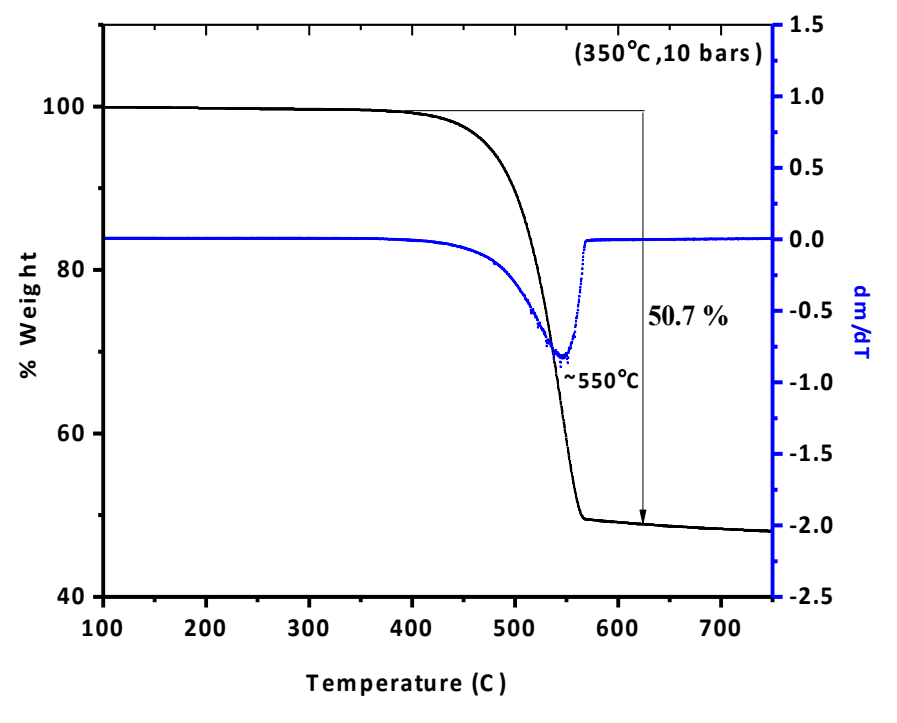

Figure 5.2.3 DTG plots for product at (a) $300^{\circ} \mathrm{C}$ and 10 bars and (b) $350^{\circ} \mathrm{C}$ and 10 bars

The thermal analysis curve does not show any significant differences in amounts of carbonate in the high pressure (50 bars) experiments. We obtained almost similar TGA plots and XRD patterns for different temperatures $300-375^{\circ} \mathrm{C}$ and 50 bars carbon dioxide pressure. However, the experiment performed at $300^{\circ} \mathrm{C}$ and 10 bars did indicate that the 
product were not simply $\mathrm{MgCO}_{3}$. The X-ray diffraction pattern in Fig. 5.2.1a confirms the presence of $\mathrm{Mg}(\mathrm{OH})_{2}$ and relatively high amount of $\mathrm{MgO}_{2} 2 \mathrm{MgCO}_{3}$ at $300^{\circ} \mathrm{C}$ and 10 bars. DTG curve (Fig. 5.2.3a) also evidences the similar situation. The two peaks around $350^{\circ} \mathrm{C}$ and $475^{\circ} \mathrm{C}$ were attributed to the losses of water of crystallization and hydroxyl water respectively. However, another peak at $550^{\circ} \mathrm{C}$ corresponds to the complete decomposition of $\mathrm{MgCO}_{3}$. But at a temperature of $350^{\circ} \mathrm{C}$ and a pressure equals 10 bars, only $\mathrm{MgCO}_{3}$ was formed. This is evidenced by both DTG analysis curve (Fig. 5.2.3b) and XRD analysis (Fig.5.2.1a).

The steps to calculate $\%$ conversion of $\mathrm{MgO}$ to $\mathrm{MgCO}_{3}$ is explained in supplementary section. A conversion of $30.54 \%$ and $96.96 \%$ for $\mathrm{MgO}$ to $\mathrm{MgCO}_{3}$ was observed at 300 and $350^{\circ} \mathrm{C}$ respectively. Here, we observed the formation of relatively high amount of magnesium oxide carbonate $\left(\mathrm{MgO} \cdot 2 \mathrm{MgCO}_{3}\right)$ at $300^{\circ} \mathrm{C}$ and 10 bars. It can be easily calculated that the carbon dioxide capture capacity of $\mathrm{MgO} .2 \mathrm{MgCO}_{3}$ is about two-third that of $\mathrm{MgCO}_{3}$. Hence, formation of $\mathrm{MgO} \cdot 2 \mathrm{MgCO}_{3}$ can significantly reduce the further uptake of carbon dioxide by $\mathrm{MgO}$ particles. However, it can be observed from X-ray patterns (Fig.5.2.1) that at higher temperature or pressure, the formation of $\mathrm{MgO} .2 \mathrm{MgCO}_{3}$ is reduced.

The calculated $\mathrm{MgO}-\mathrm{Mg}(\mathrm{OH})_{2}-\mathrm{MgCO}_{3}$ phase diagram suggest that with increase in $\mathrm{P}_{\mathrm{H} 2 \mathrm{O}}$ the transition temperature for direct conversion of $\mathrm{MgCO}_{3}$ to $\mathrm{Mg}(\mathrm{OH})_{2}$ also increases [11]. Here, with change in experimental temperature from 300 to $350^{\circ} \mathrm{C}$, partial pressure of water also increases and consequently transition temperature also increased. Therefore, the low carbonation of $\mathrm{MgO}$ in the presence of water at $300^{\circ} \mathrm{C}$ might be due to the high 
conversion of $\mathrm{MgCO}_{3}$ to $\mathrm{Mg}(\mathrm{OH})_{2}$ at a lower transition temperature. Moreover, a significant formation of $\mathrm{MgO} \cdot 2 \mathrm{MgCO}_{3}$ at $300^{\circ} \mathrm{C}$ and 10 bars also lead to a less direct conversion of $\mathrm{MgO}$ to $\mathrm{MgCO}_{3}$. Thus, it can be deduced that a low partial pressure of water can lead to a higher amount of $\mathrm{MgO} \cdot 2 \mathrm{MgCO}_{3}$ formation. Therefore, the reaction mechanism is changed to:

$$
\begin{gathered}
\mathrm{MgO}+\mathrm{CO}_{2} \leftrightarrow \mathrm{MgCO}_{3} \\
\mathrm{MgO}+2 \mathrm{MgCO}_{3} \leftrightarrow \mathrm{MgO} .2 \mathrm{MgCO}_{3}
\end{gathered}
$$

Moreover, at 50 bars of carbon dioxide pressure and a temperature of $300^{\circ} \mathrm{C}, \mathrm{MgO}$ has the highest yield of $98.54 \%$. At 50 bars and temperatures $300-375^{\circ} \mathrm{C}$, we observe a slight but continuous decrease in the absorption of $\mathrm{CO}_{2}$ with increase in temperature and thus are in agreement with other reported results [28]. It is well known that at low temperature, the physisorption process dominates but at elevated temperature carbon dioxide chemisorbs on $\mathrm{MgO}$ and thus carbon dioxide uptake capacity gradually starts decreasing. 
Carbon dioxide uptake capacity of a metal oxide is primarily dominated by the factors such as surface area, pore volume, pore functionality and pore size [26]. BET surface area measurement, pore volume and average pore sizes presented in Table 5.2.2 do indicate that carbonating with pure carbon dioxide does influence the particle structure.

\begin{tabular}{|c|c|c|c|c|}
\hline Sample & $\begin{array}{c}\text { Surface area } \\
\left(\mathrm{m}^{2} / \mathrm{g}\right)\end{array}$ & $\begin{array}{c}\text { Pore volume } \\
\left(\mathrm{cm}^{3} / \mathrm{g}\right)\end{array}$ & $\begin{array}{c}\text { Pore Size } \\
(\mathrm{nm})\end{array}$ & $\begin{array}{c}\text { SA/PV } \\
\left(10^{6} \mathrm{~m}^{-1}\right)\end{array}$ \\
\hline As received $\mathrm{MgO}$ & $95.08 \pm 1.5$ & 0.22 & 9.09 & 439.59 \\
\hline $\begin{array}{c}\text { After Reaction at } \\
\left(350^{\circ} \mathrm{C}, 10 \text { bars }\right)\end{array}$ & $4.15 \pm 0.05$ & 0.01 & 16.25 & 246.15 \\
\hline
\end{tabular}

Table 5.2.2 Surface Properties of $\mathrm{MgO}$ particles before and after carbonation reaction at $350^{\circ} \mathrm{C}, 10$ bars

As received, 325 mesh size mesoporous $\mathrm{MgO}$, have a pore size of $9.09 \mathrm{~nm}$ and a high surface area $\left(95.08 \pm 1.5 \mathrm{~m}^{2} / \mathrm{g}\right)$. The $\mathrm{N}_{2}$ adsorption- desorption isotherm curves for $\mathrm{MgO}$ follows Type IV isotherms (as per IUPAC classification); typical for mesoporous substances. Also, the hysteresis pattern is $\mathrm{H} 3$ (following IUPAC classification) indicating the presence of slit-like pores. After capture of carbon dioxide at $350^{\circ} \mathrm{C}$ and 10 bars, surface area dramatically decreased to $(4.15 \pm 0.05) \mathrm{m}^{2} / \mathrm{g}$. The ratio of surface area to pore volume is also reduced by almost half and resulting in high diffusion paths. The significant decrease in surface area attributes to the basicity of mesoporous $\mathrm{MgO}$. The mesoporous $\mathrm{MgO}$ is highly basic with well-ordered pores to hold high carbon dioxide at both lower and higher temperatures. It is well known that porous materials allow 
molecules to pass through their pore aperture for storage, separation or conversion [33]. $\mathrm{MgO}$ with a fine particle size $(<44 \mu \mathrm{m})$ has a high content of mesopores, which leads to good mass transfer properties during the absorption process. The mechanism for metal oxide reaction with carbon dioxide gas has been discussed a lot [35-37]. Carbon dioxide molecules diffuse through the pores of mesoporous $\mathrm{MgO}$ and the present large active sites hold these carbon dioxide molecules [17]. The trapped carbon dioxide molecules further react to form $\mathrm{MgCO}_{3}$.

It can be observed from Table 2 that at $350^{\circ} \mathrm{C}$ and 10 bars, $96.96 \%$ of $\mathrm{MgO}$ was converted to $\mathrm{MgCO}_{3}$ and almost all the pores have been utilized after reaction with carbon dioxide molecules. Henceforth, almost no carbon dioxide molecules could have diffused further in the pores. Noticeably, pore size increased to $16.25 \mathrm{~nm}$. Thus, it is apparent that the porosity of $\mathrm{MgO}$ particles plays a very vital role for carbon dioxide uptake.

Previously, Beruto et al has reported a very low carbon dioxide absorption capacity of $\mathrm{MgO}$ in absence of water vapor [25]. An uptake capacity of 0.089 and $0.091 \mathrm{mmol} \mathrm{CO}_{2} / \mathrm{g}$ $\mathrm{MgO}$ was observed at $350^{\circ} \mathrm{C}$ in 1.33 and 3.33 bars of carbon dioxide respectively. Thus, it was concluded that there is a high activation energy barrier to $\mathrm{MgO}$ recarbonation. On the contrary, Feng et al. [12] heated the sorbent $(\mathrm{MgO})$ until $1000^{\circ} \mathrm{C}$ in pure carbon dioxide and noted a low but almost constant (for 8 cycles) absorption capacity of 0.99 $\mathrm{mmol} \mathrm{CO}_{2} / \mathrm{g} \mathrm{MgO}$. Thus, unlike $\mathrm{CaO}$ - based sorbents, $\mathrm{MgO}$ does not show a fast decline in their carbon dioxide capture capacity over a large number of carbonation- calcination cycles. Bhagiyalakshmi et al.[18] synthesized basic mesoporous $\mathrm{MgO}$ (surface area of $250 \mathrm{~m}^{2} / \mathrm{g}$ ) using mesoporous carbon obtained from SBA-15 and obtained a maximum 
$\mathrm{CO}_{2}$ adsorption of $2.27 \mathrm{mmol} \mathrm{CO}_{2} / \mathrm{g}$ at $100^{\circ} \mathrm{C}$ and nearly $1.81 \mathrm{mmol} \mathrm{CO}_{2} / \mathrm{g}$ at $25^{\circ} \mathrm{C}$ for a feed flow rate of $30 \mathrm{ml} / \mathrm{min} \mathrm{CO}_{2}$ gas (99.9\% purity). Therefore, it is evident that even for a relatively lower surface area $\left(95 \mathrm{~m}^{2} / \mathrm{g}\right.$ compared to $\left.250 \mathrm{~m}^{2} / \mathrm{g}\right), \mathrm{MgO}$ can have a better carbon dioxide uptake at a higher temperature (here, $300-375^{\circ} \mathrm{C}$ ) and higher carbon dioxide pressure (10-50 bars). Recently, Fagerlund et al reported a very high \% conversion of $\mathrm{MgO}$ to $\mathrm{MgCO}_{3}$ under high temperature and pressure conditions [26]. However, $\mathrm{MgO}$ showed a slow conversion rate $(50 \%$ for $\sim 7 \mathrm{~h})$ for the condition $\left(\mathrm{P}_{\mathrm{CO} 2}\right.$ ( 18-19 bar), $\mathrm{P}_{\mathrm{H} 2 \mathrm{O}}(\sim 1-2$ bar $)$ and $\left.300-350^{\circ} \mathrm{C}\right)$ which can be suitable for pre-combustion capture process. The reason could be the deposition of impervious carbonate layer on the surface of $\mathrm{MgO}$ which does not allow carbon dioxide molecules to further diffuse in the pores. Therefore, continuous removal of these nonporous layers of carbonates is needed. Hence, it is recommended to have an aggregative fluidization regime for a fluidized bed reactor while scaling up $\mathrm{MgO}-\mathrm{CO}_{2}$ reaction.

In summary, we demonstrate the increase in uptake of carbon dioxide by mesoporous $\mathrm{MgO}$ at high temperature and pressure in the humid environment. We observed the significant role of temperature, pressure, water vapor and porosity of the sorbent on the improvement of the carbon dioxide absorption capacity of mesoporous $\mathrm{MgO}$. 


\subsubsection{REFERENCES}

[1] T.C. Merkel, H. Lin, X. Wei, R. Baker, Journal of Membrane Science, 2010, 359, 126-139.

[2] J. Davison, Energy, 2007, 32, 1163-1176.

[3] B. P. Burton, N. Dupin, S. G. Fries, G. Grimvall, A. Fernández Guillermet, P. Miodownik, W. A. Oats, and V. Vinograd, Z. Metallkd, 2001, 92, 514.

[4] B. Miller, D. Tillman, Combustion engineering issues for solid fuel systems, Elsevier 2008, 449-451.

[5] DOE/NETL Carbon dioxide capture and storage RD\&D roadmap, December 2010.

[6] C.H. Yu, C.H. Huang, C.S. Tan, Aerosol and Air Quality Research, 2012, 12, 745769

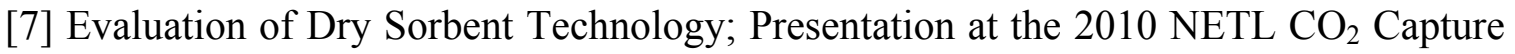
Technology Meeting, Pittsburgh, PA, September 13-17, 2010.

[8] S.M. Benson and D.R. Cole, Elements, 2008, 4, 325-331.

[9] P. Gruene, A.G. Belova, T.M. Yegulalp, R.J. Farrauto, M.J. Castaldi, Industrial \& Engineering Chemistry Research, 2011, 50, 4042-9.

[10] S. Rackley, Carbon Capture and Storage, Elsevier, Burlington, 2010.

[11] Y. Duan, D.C. Sorescu, Journal of Chemical Physics, 2010, 133, 074508-11

[12] B. Feng, H. An, E. Tan, Energy \& Fuels, 2007, 21,426-434

[13] L. Li , X. Wen, X. Fu, F. Wang, N. Zhao, F. Xiao, W. Wei, Y. Sun, Energy \& Fuels, 2010, 24, 5773-5780.

[14] S.C. Lee, H.J. Chae, S.J. Lee, B.Y. Choi, C.K. Yi , J.B. Lee, C.K. Ryu , J.C. Kim, Environmental Science \& Technology, 2008, 42, 2436-2471

[15] S.M. Ward, J. Braslaw, R. L. Gealer, Thermochimica Acta, 1983, 64, 107-114

[16] S. Choi, J.H. Drese , C.W. Jones, Chemsuschem, 2009, 2, 796-854 
[17] X. Fu , N. Zhao , J. Li , F. Xiao , W. Wei , Y. Sun, Adsorption Science \& Technology, 2009, 27, 593-601.

[18] M. Bhagiyalakshmi, J.Y. Lee, H. T. Jang, International Journal of Greenhouse Gas Control, 2010, 4, 51-56.

[19] S. Liu, X. Zhang, J. Li, N. Zhao, W. Wei,Y. Sun, Catalysis Communications, 2008, 9, 1527-1532.

[20] B. Li, X. Wen, N. Zhao, X.Z. Wang, W. Wei, Y. Sun, Z.H. Ren, Z. J. Wang, Journal of Fuel Chemistry \& Technology, 2010, 38, 473-477.

[21] Z. Yong, Vera, A.E. Rodrigues, Industrial \& Engineering Chemistry Research, 2001, 40, 204-209.

[22] L. Li, Y. Li, X. Wen, F. Wang, N. Zhao, F. Xiao, W. Wei, Y. Sun, Energy \& Fuels 2011, 25,3835-3842.

[23] S.C. Lee, B.Y. Choi, T.J. Lee, C.K. Ryu, Y.S. Soo, J.C. Kim, Catalysis Today, 2006, $111,385-390$.

[24] A.M. Ruminski, K.J. Jeon, J.J. Urban, Journal of Materials Chemistry, 2011, 21, 11486-11491.

[25] D. Beruto, R. Botter, A.W. Searcy, The Journal of Physical Chemistry, 1987, 91, 3578-3581.

[26] W. Lu, D. Yuan, J. Sculley, D. Zhao, R. Krishna, H.C. Zhou, Journal of American Chemical Society, 2011, 133,18126-9

[27] J. Fagerlund, J. Highfield, R. Zevenhoven, RSC Advances, 2012, 2, 10380-10393.

[28] J. Highfield, J. Bu, J. Fagerlund and R. Zevenhoven, ICCDU-XI, 2011

[29] D. P. Butt, S. P. Pile, Y. Park, R. Vaidya, K. S. Lackner, C. H. Wendt and K. Nomura, Report LA-UR-98-7631, 1998.

[30] A. Hassanzadeh and J. Abbasian, Fuel, 2010, 89, 1287-1297. 
[31] Y. Kato, N. Yamashita, K. Kobayashi and Y. Yoshizawa, Applied Thermal Engineering, 1996, 16, 853-862.

[32] C. Liu and S. Shih, Industrial \& Engineering Chemistry Research, 2009, 48, 8335

[33] R. Zevenhoven, S. Teir and S. Eloneva, Energy, 2008, 33, 362-370.

[34] R. Zevenhoven, S. Eloneva and S. Teir, International conference on Greenhouse Gas Technologies-8, 2006

[35] H. Deng,S. Grunder, K.E. Cordova, C. Valente, H. Furukawa, M. Hmadeh , F. Gándara, A.C. Whalley, Z. Liu , S. Asahina, H. Kazumori , M. O 'Keeffe, O. Terasaki , F.J. Stoddart, O.M. Yaghi, Science, 2012, 336, 1018-1023.

[36] S.K. Bhatia, D.D. Perlmutter, American Institute of Chemical Engineers Journal, 1983, 29, 79-86.

[37] D.P. Butt, K.S. Lackner, C.H. Wendt, S.D. Conzone, H. Kung ,Y.C. Lu, J.K. Bremser, Journal of American Ceramic Society, 1996, 79, 1892-1898. 


\subsection{INTEGRATION OF MgO FOR $\mathrm{CO}_{2}$ CAPTURE AT A 300 MWe COAL-FIRED POWER PLANT}

\subsubsection{INTRODUCTION}

Solid sorbents have the potential to reduce the energy cost as compared to the liquid solvents. Liquid solvents need large quantities of water that must be continuously heated and cooled to regenerate the solvent solution. Moreover, sorbent materials have also lower heat capacity and thus require less regeneration energy to attain a desired temperature. Despite many advantages, there are numerous challenges which hinder the efficient integration of solid sorbent based technology for $\mathrm{CO}_{2}$ capture at a power plant. Here, $\mathrm{MgO}$ is chosen for the mass and energy balance calculation for post-combustion $\mathrm{CO}_{2}$ capture.

The typical coal-fired burning plant consists of coal fired burners for coal combustion, equipped with staged heat transfer units to utilize the thermal energy in flue gas to generate steam. An assembly of superheater, boiler banks, economizer and air pre-heater constitutes a boiler. A coal-fired exhaust flue gas has a gross heating value of 11500 BTU/lb $(26.74 \mathrm{MJ} / \mathrm{kg})$ as it contains mostly $\mathrm{N}_{2}(\sim 65 \%), \mathrm{H}_{2} \mathrm{O}(\sim 18 \%), \mathrm{CO}_{2}(\sim 15 \%)$ and rest $\mathrm{O}_{2}$. Here, the calculation is performed for both the cases- (a) Post-combustion $\mathrm{CO}_{2}$ capture and (b) Pre-combustion $\mathrm{CO}_{2}$ capture process.

\subsubsection{Post-combustion process}

The retrofit of $\mathrm{MgO}$ for post-combustion $\mathrm{CO}_{2}$ capture at a coal-fired power plant is shown in Fig. 5.3.1. The flue gas after desulphurization unit is subjected to a compressor and then to the carbonation reactor. During the exothermic carbonation process, $\mathrm{MgO}$ reacts with $\mathrm{CO}_{2}$ in the presence of $\mathrm{N}_{2}$ to form $\mathrm{MgCO}_{3}$. The reacted sorbent particles are 
sent to a high temperature cyclone. Here, the gaseous mixture is sent to the combined gas and vapor power cycle. The solid mixture of product $\left(\mathrm{MgCO}_{3}\right)$ and unreacted $\mathrm{MgO}$ can then be transferred to the calcination reactor. Calcination reactor is a coal-fired unit. After the calcination, the pure stream of $\mathrm{CO}_{2}$ gas is passed through cyclone (to remove any fine solid particles) and then to a compressor. At compressor, $\mathrm{CO}_{2}$ can be liquefied and can then be transferred through pipelines to a storage site and can be injected underground. 


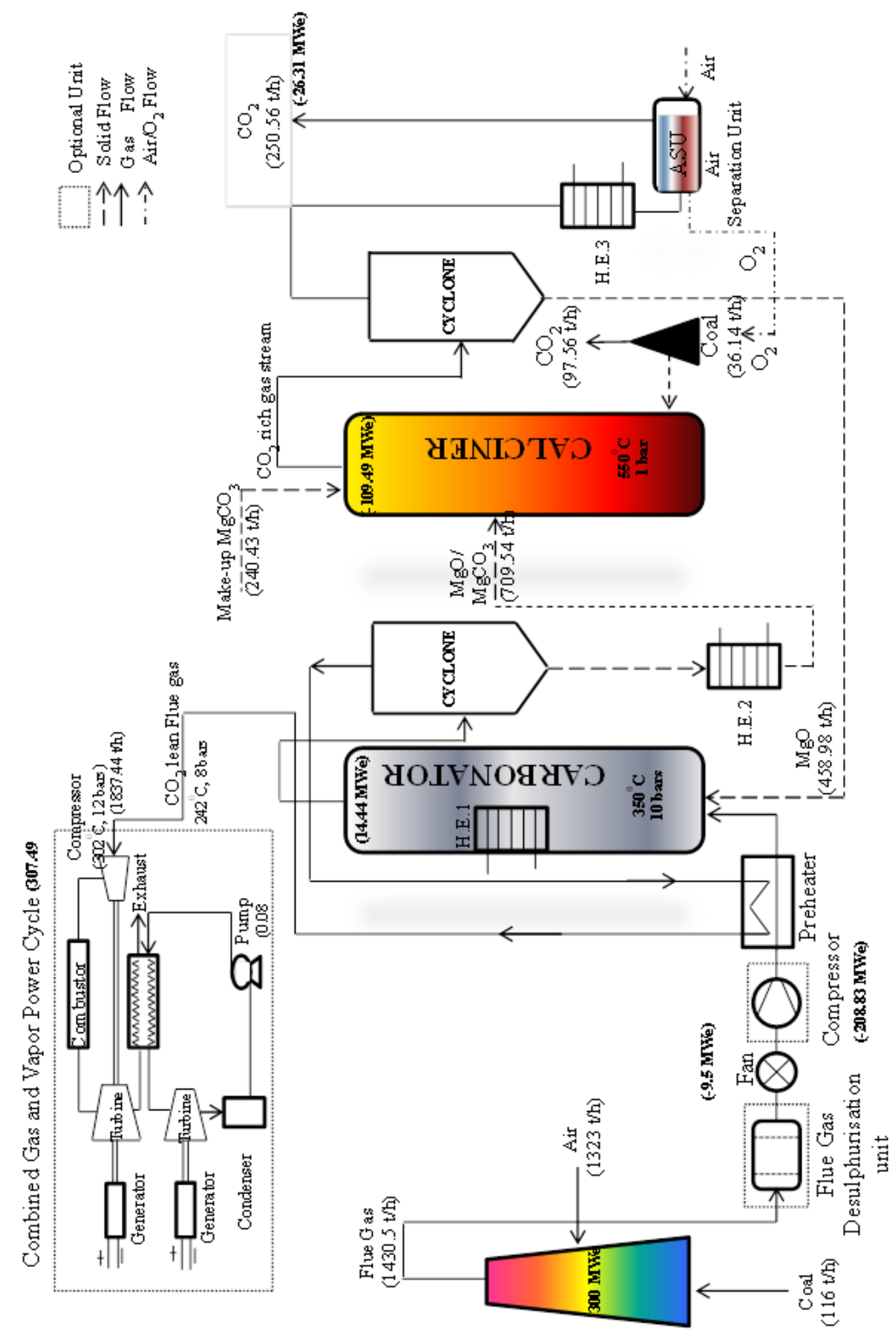




\subsubsection{Mass and Energy Analysis}

The energy calculation is carried out on a coal-fired power plant generating $300 \mathrm{MWe}$. The thermal efficiency is assumed to be $33.33 \%$. This translates to $900 \mathrm{MWt}$ energy input from coal. About 116 tons/hour of coal is required; assuming coal of calorific value $12,000 \mathrm{Btu} / \mathrm{lb}$ is to be used. While 257 tons/hour of oxygen is stoichiometrically required, a $20 \%$ excess air use can confirm complete coal combustion. This assumption translates into a total air flow of 1323 tons/hour. The flow rate of flue gas after complete combustion of coal is 1430.5 tons/hour, with $\mathrm{CO}_{2}$ flow being 313.2 tons/hour. Molar and mass flue gas composition is shown in Table 5.3.1. Flue gas desulphurization unit, flue gas compressor and combined gas and vapor power cycle are optional units. However, here, each unit is considered for calculation.

\begin{tabular}{|c|c|c|}
\hline Component & \% Mass fraction & Molar concentration \\
\hline $\mathrm{N}_{2}$ & 65 & 62.32 \\
\hline $\mathrm{CO}_{2}$ & 15 & 9.15 \\
\hline $\mathrm{H}_{2} \mathrm{O}$ & 18 & 1.67 \\
\hline $\mathrm{O}_{2}$ & 2 & 26.84 \\
\hline
\end{tabular}

Table 5.3.1 Mass and molar flue gas composition

The flue gas after desulphurization unit is first cooled to about $38^{\circ} \mathrm{C}$ and then compressed to 1.2 bars. The increase in the pressure of flue gas requires about $9.5 \mathrm{MWe}$ of electrical energy. The entire flue gas is further compressed to 10 bars of pressure, which is a very 
energy intensive process and requires 208.83 MWe. The compressed flue gas is further routed through a $\mathrm{CO}_{2}$ scrubber where the $\mathrm{CO}_{2}$ is removed by contacting the flue gas with $\mathrm{MgO}$. The experimental study indicates that $\mathrm{MgO}$ can attain an overall mass conversion of $96.96 \%$ in 3 -cycles each of $0.5 \mathrm{~h}$ at $350^{\circ} \mathrm{C}$ and 10 bars $\mathrm{CO}_{2}$ pressure. If we target to remove $80 \%$ of $\mathrm{CO}_{2}$ present in the flue gas, we require 286.89 tons/hour of $\mathrm{MgO}$. The reaction enthalpy of $\mathrm{MgO}-\mathrm{CO}_{2}$ reaction at $350^{\circ} \mathrm{C}$ and 10 bars is $\Delta \mathrm{H}=-85.62 \mathrm{~kJ} / \mathrm{mole}$. The released heat from the carbonation reactor needs to be adequately removed to maintain the high $\mathrm{CO}_{2}$ absorption capacity. Here, we consider only $20 \%$ of heat recovery from the carbonation reactor (while, the maximum efficiency $=\left(T_{2}-T_{1}\right) / T_{2}=(623-$ $300) / 623=51.84 \%)$ and this translates to a heat recovery of 11.17 MWe.

Hot and compressed $\mathrm{CO}_{2}$ lean flue gas is then subjected through the combined gas and vapor power cycle. The assumed temperature and pressure conditions are mentioned in Figure 5.3.1. The calculation shows that even if $80 \%$ of $\mathrm{CO}_{2}$ lean flue gas stream is utilized, about 307.49 MWe of electricity can be generated. $\mathrm{MgCO}_{3}$, formed as a result of carbonation reaction is sent to the calciner. Make-up $\mathrm{MgCO}_{3}$ is also injected to the calciner. Calciner uses thermal energy from the direct burning of coal. The calcination of 605.33 tons/hour of $\mathrm{MgCO}_{3}$ at $550^{\circ} \mathrm{C}$ and 1 bar $(\Delta \mathrm{H}=+164.69 \mathrm{~kJ} / \mathrm{mol})$ requires 109.49 MWe. Thus, 36.14 tons/hour of coal needs to be burnt to produce the regeneration energy (109.49 MWe). The burning of 36.14 tons/hour of coal produces 97.56 tons/hour of $\mathrm{CO}_{2}$. The total consumption of coal is increased by $(116+36.14) / 116=1.31$. Also, the overall $\mathrm{CO}_{2}$ capture reduces to only $48.8 \%$. 
$\mathrm{CO}_{2}$ rich gas stream exits the calciner and then sent to the compressor where the pure $\mathrm{CO}_{2}$ is compressed to 136 bars via multistage compressors equipped with intercooling. Several studies concur that the compression energy requirements of $\mathrm{CO}_{2}$ lie in the range of $95-135 \mathrm{kWh} /$ ton of $\mathrm{CO}_{2}$. Here, we have chosen an energy requirement of 105 $\mathrm{kWh} / \mathrm{ton}$ of $\mathrm{CO}_{2}$ as based on ASPEN simulations for multistage compression. Therefore, the compression of 250.56 tons/hour of $\mathrm{CO}_{2}$ requires $26.31 \mathrm{MWe}$. Thus, the integration of $\mathrm{MgO}$ based sorbent for $\mathrm{CO}_{2}$ capture at high temperature and high pressure reduces the electric generation capacity from $300 \mathrm{MWe}$ to $264.53 \mathrm{MWe}$.

The integration of heat recovery system in a coal-fired power plant can decrease energy penalty and also control the electricity cost. The basic heat integration technology that has been suggested in this process can be classified in three parts. At first, carbonation reaction generates much more heat than is required to maintain the carbonation temperature (H.E.1). Secondly, the hot $\mathrm{MgO} / \mathrm{MgCO}_{3}$ flow exiting the carbonator cyclone carries recyclable heat (H.E.2) and finally the $\mathrm{CO}_{2}$ rich gas stream exits as a very hot gaseous flow $\left(\sim 400-500^{\circ} \mathrm{C}\right)$ can provide additional heat (H.E.3) for steam generation.

The compression of entire flue gas is energetically unfavorable process and can put enormous parasitic burden on a coal-fired power plant. However, our experimental results suggest that compressed gases do increase the $\mathrm{CO}_{2}$ capture capacity of $\mathrm{MgO}$ and also hot and compressed $\mathrm{CO}_{2}$ lean flue gas when routed through a combined gas and vapor power cycle generates electricity. Although, the proposed integration might have high capital costs but it certainly has advantages such as high sorption capacity and relatively less parasitic load for a power plant. 
The integration of carbonation process requires electrical energy for various unit operations and regarded as a "parasitic load" for any power plant. However, a justification for the integration of any unit is needed. The calculation is based on the account of MWe produced and spent. The efficiency by which the produced energy from the carbonation reactor can be utilized will have a significant effect on the overall efficiency of the power plant. If fully utilized, this energy can alleviate the energy burden due to the compression of entire flue gas. Table 5.3.2 delineates the electrical energy produced and consumed to operate various operations. The overall electric generation capacity of plant is $264.53 \mathrm{MWe}$. Thus, this figure can be compared to that of the CCR and MEA process. 


\begin{tabular}{|c|c|c|}
\hline & $\begin{array}{c}\text { Electrical Energy } \\
\text { Produced (MWe) }\end{array}$ & $\begin{array}{c}\text { Electrical Energy Needed } \\
\text { (MWe) }\end{array}$ \\
\hline $\begin{array}{c}\text { Original Vapor } \\
\text { power cycle }\end{array}$ & 300 & 9.5 \\
\hline $\begin{array}{c}\text { Compression of flue } \\
\text { gas to 1.2 bars }\end{array}$ & & 208.83 \\
\hline $\begin{array}{c}\text { Compression of flue } \\
\text { gas to 10 bars }\end{array}$ & 11.17 & \\
\hline $\begin{array}{c}\text { Carbonation reaction } \\
\text { (20\% heat recovery) }\end{array}$ & 307.49 & \\
\hline $\begin{array}{c}\text { Combined Gas and } \\
\text { Vapor power cycle }\end{array}$ & & \\
\hline Calcination reaction & 264.53 & 26.31 \\
\hline Compression of $\mathrm{CO}_{2}$ & & \\
\hline $\begin{array}{l}\text { Overall produced } \\
\text { electrical energy }\end{array}$ & & \\
\hline
\end{tabular}

Table 5.3.2 Energy balance calculation for Post-combustion $\mathrm{CO}_{2}$ capture using $\mathrm{MgO}$ at a Coal-fired power plant

The assumption is made for the multicyclic $\mathrm{CO}_{2}$ capture using $\mathrm{MgO}$. Assuming that after 100-cycle experiment, the sorbent reactivity dropped from $44 \%$ in the 50th cycle to $40 \%$ in the 100 th cycle. If the reactivity of the sorbent falls below $20 \%$ by the $500^{\text {th }}$ cycle, then under steady state conditions, this translates to the fact that one needs to regenerate $1 / 500^{\text {th }}$ of the 286.89 tons/hour of $\mathrm{MgO}$ required for $80 \% \mathrm{CO}_{2}$ removal. Assuming a delivered price of $\$ 120 /$ ton of $\mathrm{MgO}$, we incur a make-up sorbent related annual operating cost of about $\$ 1.21$ million. 


\subsubsection{ECONOMIC ANALYSIS OF THE CARBONATION PROCESS}

The economic analysis is based on the estimated procurement cost. The total direct plant cost (TDPC) accounts for both the procurement cost as well as installation cost of equipment, piping, instrumentation and other accessories required to complete the plant construction. The total capital investment (TCI) includes charges for general facilities, contingencies, engineering, working land and miscellaneous. The calculation shows that TCI is about $57 \%$ of TDPC calculated. The total annual variable operating costs is $\$ 120.4821$ million; which corresponds to approximately $23 \%$ of TDPC. Based on the various literatures, fixed operating and maintenance cost is taken as $5 \%$ of the capital cost. The total cost is estimated by summing up the variable operating cost, fixed charges and fixed operating cost. All the equipment costs are estimated from the web service (www.matche.com). The detailed economic analysis is shown in Table 5.3.3. One should note that the capital cost of combined gas and vapor power cycle is not included in this calculation. Moreover, the equipment costs are based on 2007. However, if the natural gas combined cycle is to be considered then the $\mathrm{CO}_{2}$ capture cost exceeds to almost $\$ 191 /$ ton $\mathrm{CO}_{2}$ captured. The costs for natural gas combined cycle are: capital cost $(\$ 917 / \mathrm{kW})$, Fixed O \& M $(\$ 13.17 / \mathrm{kW})$ and Variable O \& M $(\$ 3.60 / \mathrm{kW})$. Thus, the compression of entire flue gas seems to be economically and energetically unfavorable. However, if a natural gas combined cycle can be integrated to the coal-fired burning plant, cost of carbon capture may reduce without a high increase in the electricity cost. 


\begin{tabular}{|c|c|c|}
\hline Equipment & Explanation & Cost (million \$) \\
\hline Jacketed and Agitated reactor & $\begin{array}{l}\text { Reactor Volume: } 8000 \text { gallons } \\
\text { Material: Stainless steel,304 } \\
\text { Internal Pressure: } 150 \mathrm{psi} \\
\end{array}$ & 0.4917 \\
\hline Hopper for make-up sorbent & $\begin{array}{l}\text { Bin Volume: } 1200 \mathrm{ft}^{3} \\
\text { Material: Carbon Steel } \\
\text { Pressure: Atmospheric }\end{array}$ & 0.017 \\
\hline Hopper for sorbent calcination & $\begin{array}{l}\text { Bin Volume: } 1800 \mathrm{ft}^{3} \\
\text { Material: Carbon Steel } \\
\text { Pressure: Atmospheric }\end{array}$ & 0.0201 \\
\hline Compressor & $\begin{array}{c}\text { Compressor Type: } \\
\text { Reciprocating, 1000psi } \\
\text { Compressor Power: } 3200 \mathrm{hp} \\
\text { Material: Carbon Steel }\end{array}$ & 39.47 \\
\hline $\mathrm{CO}_{2}$ Compressor Cost & & 32.7604 \\
\hline Two conveyor belts & $\begin{array}{c}\text { Type: Belt, Open, Long } \\
\text { Width/Diameter: } 40 \text { inches } \\
\text { Length: } 200 \mathrm{ft} \\
\text { Material: Carbon Steel } \\
\text { Pressure: Atmospheric }\end{array}$ & 0.3226 \\
\hline Two Cyclones & $\begin{array}{l}\text { Gas Flow: } 10000 \mathrm{ft}^{3} / \mathrm{min} \\
\text { Material: Carbon Steel } \\
\text { Pressure: Atmospheric }\end{array}$ & 0.0323 \\
\hline Fan & $\begin{array}{c}\text { Type: Axial Large } \\
\text { Diameter: } 60 \text { inches } \\
\text { Material: Stainless Steel } \\
\text { Pressure: Atmospheric }\end{array}$ & 0.0624 \\
\hline Three water heaters & $\begin{array}{c}\text { Type: Large } \\
\text { Area:100ft } \\
\text { Material: CS Shell, SS 304 Tube } \\
\text { Internal Pressure:150 psi }\end{array}$ & 0.0186 \\
\hline Sorbent Inventory & & 0.276 \\
\hline Total procurement cost: & & \$73.4711 million \\
\hline
\end{tabular}

TDPC: \$ 220.4133 million 


\begin{tabular}{|c|c|c|}
\hline General facilities & $30 \%$ & 66.124 \\
\hline Eng. Permitting and start up & $10 \%$ & 22.0411 \\
\hline contingencies & $10 \%$ & 22.0411 \\
\hline $\begin{array}{c}\text { Working capital, land and } \\
\text { miscellaneous }\end{array}$ & $7 \%$ & 15.42893 \\
\hline Total capital investment & & $\$ 346.0484$ \\
\hline
\end{tabular}

\section{Variable operating costs}

\begin{tabular}{|c|c|c|}
\hline $\begin{array}{c}\text { Variable Non-fuel operating } \\
\text { cost(\% capital) }\end{array}$ & $1 \%$ & 2.2041 \\
\hline $\begin{array}{c}\text { Calciner cost } \\
\text { (Rotary Kiln) }\end{array}$ & & 47.868 \\
\hline Make up Sorbent cost & & 1.21 \\
\hline $\begin{array}{c}\text { Total annual variable } \\
\text { operating cost }\end{array}$ & $\$ 51.2821$ million \\
\hline
\end{tabular}

Fixed operating and maintenance cost $(5 \%$ capital cost $)$

\$17.30 million

Capital charges ( $15 \%$ capital cost)

\$51.90 million

Total annual cost

$\$ 120.4821$ million

\begin{tabular}{|c|c|}
\hline $\mathrm{CO}_{2} /$ coal (tons/tons) & 2.69 \\
\hline $\begin{array}{c}\text { Total coal consumed (tons/hr) } \\
\text { (electricity generation + calcination) }\end{array}$ & 152.14 \\
\hline $\begin{array}{c}\mathrm{CO}_{2} \text { emitted (tons/hr) } \\
\text { (electricity generation + calcination) }\end{array}$ & 410.76 \\
\hline $\mathrm{CO}_{2}$ emitted(tons/year) & 3598257.6 \\
\hline Total $\mathrm{CO}_{2}$ captured (tons/hr) & 250.56 \\
\hline Total $\mathrm{CO}_{2}$ captured (tons/year) & 2194905.6 \\
\hline $\mathrm{Original} \mathrm{kgCO}_{2} / \mathrm{kWh}$ & 1.044 \\
\hline $\mathrm{kgCO}_{2} / \mathrm{kWh}$ & 0.6056 \\
\hline
\end{tabular}

Table 5.3.3 Detailed economic analysis for Post-combustion $\mathrm{CO}_{2}$ capture using $\mathrm{MgO}$ 
The parasitic energy load due to various unit operations for the proposed scheme reduces the electric generation capacity from $300 \mathrm{MWe}$ to $264.53 \mathrm{MWe}$ (Assuming the use of combined vapor and power cycle). In the literature, two different approaches are discussed to estimate $\mathrm{CO}_{2}$ capture costs. In first approach, all the costs, such as annual variable operating costs and electrical energy requirement are considered as if they are external resources. Here, the accessible electricity available for sale by the plant remains the same despite any attempt to reduce $\mathrm{CO}_{2}$ emissions. In other approach, only expenses that cannot be obtained within power plant operations are considered. In this case, all the parasitic electricity requirements are obtained from power plant operations. Hence, the final available electricity for sale is reduced. 
The levelized cost for the proposed scheme is given in Table 5.3.4 One should note that the combined gas and vapor cycle is taken into consideration.

\begin{tabular}{|c|c|}
\hline Factors & Values \\
\hline Periods (years) & 20 \\
\hline Discount Rate (\%) & 4.0 \\
\hline \multicolumn{2}{|c|}{ Renewable energy system cost and performance } \\
\hline Capital Cost $(\$ / \mathrm{kW})$ & 743 \\
\hline Capacity Factor (\%) & 16 \\
\hline Fixed O \& M Cost (\$/kW-year) & 65.4 \\
\hline Variable O \& M Cost $(\$ / k W h)$ & 0.022 \\
\hline Heat Rate (Btu/kWh) & 10107 \\
\hline Fuel Cost(\$/MMBtu) & 2.36 \\
\hline \multicolumn{2}{|c|}{ Today's Utility Electricity Cost } \\
\hline Electricity Price (cents/kWh) & 11.0 \\
\hline Cost Escalation Rate (\%) & 3 \\
\hline \multicolumn{2}{|c|}{ Results } \\
\hline $\begin{array}{l}\text { Levelized Cost of Utility Electricity } \\
\text { (cents/kWh) }\end{array}$ & 14.7 \\
\hline
\end{tabular}

Table 5.3.4 Levelized Cost for Post-combustion $\mathrm{CO}_{2}$ capture using $\mathrm{MgO}$ 
On overall basis, $\mathrm{CO}_{2}$ emission is reduced to $62.64 \mathrm{t} / \mathrm{h}$ (from $313.2 \mathrm{t} / \mathrm{h}$ ), which is about $80 \%$ reduction. The energy intensity of the proposed plant has improved from $1.044 \mathrm{kgCO}_{2} / \mathrm{kWh}$ to $0.6056 \mathrm{kgCO}_{2} / \mathrm{kWh}$. The following formula is used to estimate the cost of $\mathrm{CO}_{2}$ avoided:

Cost of $\mathrm{CO}_{2}$ avoided

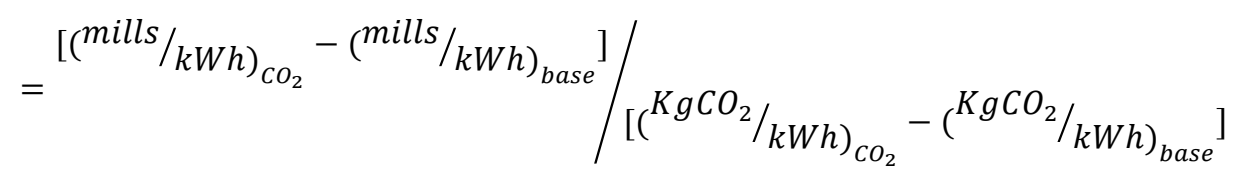

Where the subscript "base" refers to the reference plant performance and the subscript $\mathrm{CO}_{2}$ refers to the $\mathrm{CO}_{2}$ capture process integrated to coal-fired power plant operations combined with vapor and gas power cycle. The proposed process cost according to this definition is about $\mathbf{\$ 8 4 . 3 9} / \mathrm{tCO}_{2}$.

If calcination process heat can be supplied by the renewable sources and not by burning coal, the detail of $\mathrm{CO}_{2}$ capture is given in Table 5.3.5.

\begin{tabular}{|c|c|}
\hline $\mathrm{CO}_{2} /$ coal (tons/tons) & 2.69 \\
\hline $\begin{array}{c}\text { Total coal consumed (tons/hr) } \\
\text { (electricity generation) }\end{array}$ & 116 \\
\hline $\begin{array}{c}\mathrm{CO}_{2} \text { emitted (tons/hr) } \\
\text { (electricity generation }+ \text { calcination) }\end{array}$ & 313.2 \\
\hline $\mathrm{CO}_{2}$ emitted(tons/year) & 2743632 \\
\hline Total $\mathrm{CO}_{2}$ captured (tons/hr) & 250.56 \\
\hline Total $\mathrm{CO}_{2}$ captured (tons/year) & 2194905.6 \\
\hline $\mathrm{Original} \mathrm{kgCO}_{2} / \mathrm{kWh}$ & 1.044 \\
\hline $\mathrm{kgCO}_{2} / \mathrm{kWh}$ & 0.2368 \\
\hline
\end{tabular}

Table 5.3.5 Cost per carbon captured 
The energy intensity of the proposed plant scheme will improve from $1.044 \mathrm{kgCO}_{2} / \mathrm{kWh}$ to $0.2368 \mathrm{kgCO}_{2} / \mathrm{kWh}$. The corresponding $\mathrm{CO}_{2}$ capture costs then decrease to $\$ 45.83 /$ ton $\mathrm{CO}_{2}$.

As we saw in the earlier section, $\mathrm{MgO}-\mathrm{CO}_{2}$ process cannot be integrated economically to a coal-fired power plant for the post-combustion $\mathrm{CO}_{2}$ capture. Thus, the next section considers the retrofit of $\mathrm{MgO}$ for pre-combustion $\mathrm{CO}_{2}$ capture at an existing power plant.

Due to the large volumes of compressed $\mathrm{CO}_{2}$, transportation will most likely be done using pipelines rather than ground transportation. At present, petroleum companies successfully transports about 45 million ton of $\mathrm{CO}_{2}$ annually through pipeline extended by about 3700 miles for enhanced oil recovery (EOR). These pipelines are relatively thicker and expensive as it requires pressurized $\mathrm{CO}_{2}$ to be transported.

The following relation can be used to determine the distance within which storage site should be located to transport 250.56 ton/hour of compressed $\mathrm{CO}_{2}$ :

$$
\begin{gathered}
P_{1}-P_{2}=\frac{32 L f m^{2}}{\pi^{2} \rho D^{5}} \\
\text { or, } \left.D=32 L f m^{2} /\left[\left(P_{1}-P_{2}\right) \pi^{2} \rho\right]\right)^{0.2}
\end{gathered}
$$

Where, $\mathrm{P}_{1}$ and $\mathrm{P}_{2}=$ pressures at the beginning and end of the pipe respectively; $\mathrm{L}=$ length of pipe; $\mathrm{f}=$ fanning friction factor $=(1 /(4 * \log (\mathrm{D} / \mathrm{E})+2.28)) ; \mathrm{E}=$ roughness in the material $=0.000457 ; \mathrm{m}=$ mass flow rate $(\mathrm{kg} / \mathrm{s}) ; \rho=$ density $\left(\mathrm{kg} / \mathrm{m}^{3}\right) ; \mathrm{D}=\operatorname{diameter}(\mathrm{m})$.

Using formula (1), the distance can be calculated within which a safe storage site can be located to pump liquid $\mathrm{CO}_{2}$ underground. Here, the calculated distance is $183 \mathrm{~km}$. 
National Energy Technology Laboratory (NETL) suggests the cost estimation procedure for $\mathrm{CO}_{2}$ pipeline. Table 5.3.6 (a) shows the calculation. The cost incurred in $\$ /$ in $/ \mathrm{mile}$ is $86,370.97$ by using pipeline of diameter of 8.82 inches and length of 62 miles.

\section{Pipeline Capital Costs}

\begin{tabular}{|c|c|c|}
\hline Cost Type & Cost Formula & Cost \\
\hline Materials & $70,350+2.01 \times L \times\left(330.5 \times D^{2}+686.7 \times D+26,960\right)$ & $\$ 7,388,918.984$ \\
\hline Labor & $371,850+2.01 \times L \times\left(343.2 \times D^{2}+2,074 \times D+170,013\right)$ & $\$ 27,165,652.43$ \\
\hline Miscellaneous & $147,250+1.55 \times L \times(8417 \times D+7234)$ & $\$ 7,976,703.43$ \\
\hline Right of way & $51,200+1.28 \times L \times(577 \times \mathrm{D}+29,788)$ & $\$ 2,819,049.83$ \\
\hline \multicolumn{3}{|c|}{ Other Capital Costs } \\
\hline $\mathrm{CO}_{2}$ Surge Tank & & $\$ 1,244,724.00$ \\
\hline $\begin{array}{c}\text { Pipeline Control } \\
\text { System } \\
\end{array}$ & & $\$ 111,907.00$ \\
\hline \multicolumn{3}{|c|}{ Pipeline O \& M Costs } \\
\hline Fixed 0 \& M & $\$ /$ mile/year & $\$ 524,148.00$ \\
\hline
\end{tabular}

\$/in/mile

$\$ 86,370.97$

Table 5.3.6 Transportation Cost

\subsubsection{Pre-combustion process}

Pre-combustion capture process refers to mitigating $\mathrm{CO}_{2}$ from fossil fuels before they are combusted. Fossil fuels are partially combusted in steam and oxygen/air under high temperature and pressure to form synthesis or syn gas $\left(\mathrm{CO}+\mathrm{H}_{2}\right)$. $\mathrm{CO}$ can then undergo reaction with steam (water-gas shift reaction) to generate $\mathrm{CO}_{2}$ and $\mathrm{H}_{2}$-rich gas stream. 
The concentration of $\mathrm{CO}_{2}$ in the mixture may increase to $15-50 \%$. Further, the pressurized mixture of $\mathrm{CO}_{2}$ and $\mathrm{H}_{2}$ can be separated using $\mathrm{MgO}$. As mentioned earlier, $\mathrm{MgO}$ reacts with $\mathrm{CO}_{2}$ to form carbonates, which when heated liberates pure $\mathrm{CO}_{2}$. The pure $\mathrm{CO}_{2}$ can then be compressed, transported using pipeline and eventually sequestered underground. In comparison to post-combustion process, the shifted syn gas rich in $\mathrm{CO}_{2}$ and at higher pressure can be easily removed prior to hydrogen combustion. However, pre-combustion capture technology is relatively less expensive but the capital costs are higher than conventional coal-fired power plants. 


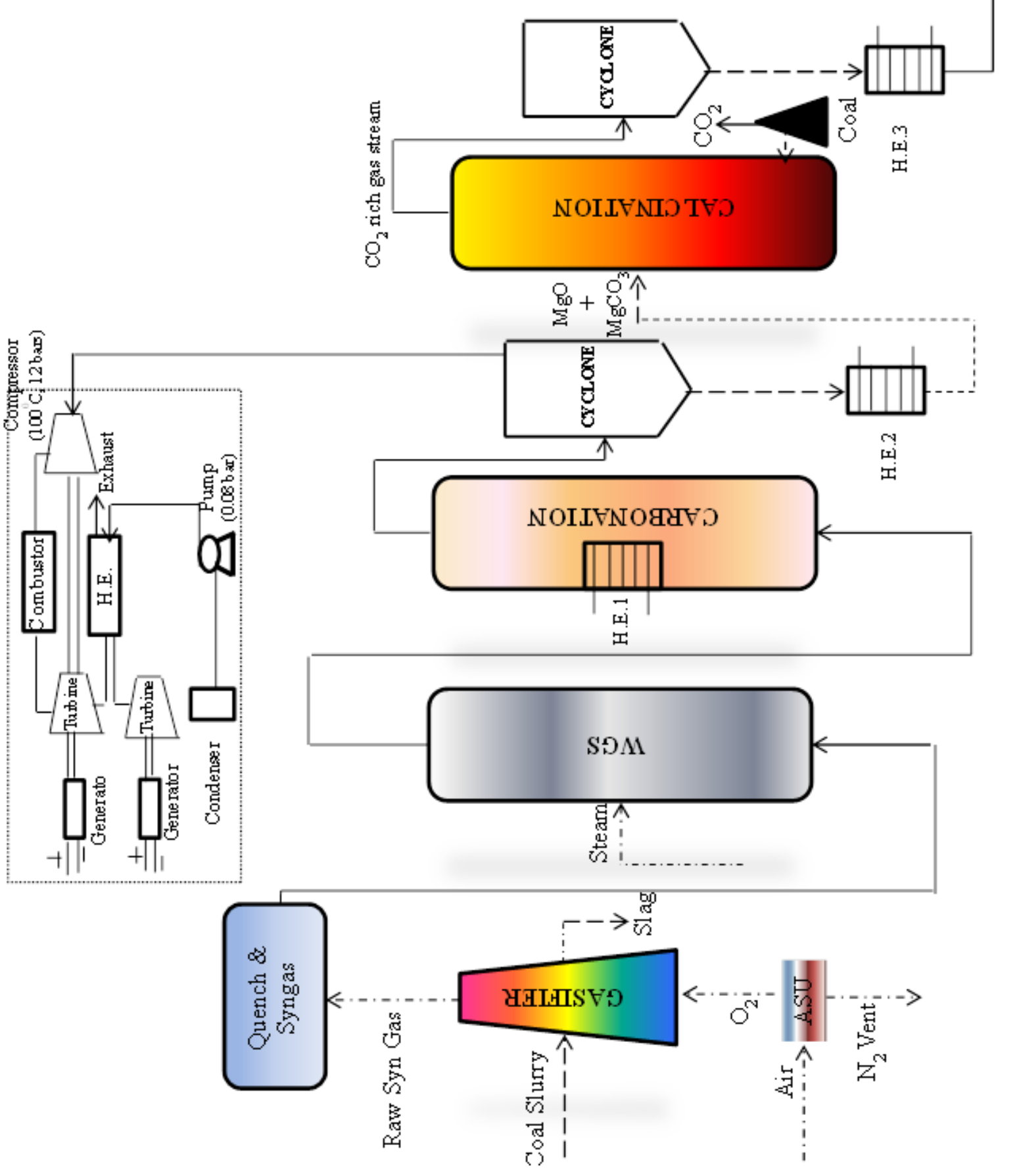




\subsubsection{Mass balance calculation}

Table 5.3.3.1 illustrates the mass flow rates of solids and gases at different stages of the process.

\begin{tabular}{|c|c|c|c|c|c|c|c|c|}
\hline $\begin{array}{c}\text { Materials } \\
\text { /Stream }\end{array}$ & In-gasifier & Out-gasifier & In-WGS & Out-WGS & In-FBR & Out-FBR & In -Calciner & Out-Calciner \\
\hline Coal & 116.00 & 0.00 & 0.00 & 0.00 & 0.00 & 0.00 & 0.00 & 0.00 \\
\hline $\mathbf{H}_{2} \mathbf{O}$ & - & - & 141.98 & 74.33 & 74.33 & 0.00 & 0.00 & 0.00 \\
\hline $\mathbf{O}_{2}$ & 154.67 & 0.00 & 0.00 & 0.00 & 0.00 & 0.00 & 0.00 & 0.00 \\
\hline $\mathbf{H}_{2}$ & 0.00 & 6.51 & 6.51 & 18.95 & 18.95 & 18.95 & 0.00 & 0.00 \\
\hline $\mathrm{CO}$ & 0.00 & 110.43 & 110.43 & 4.91 & 4.91 & 4.91 & 0.00 & 0.00 \\
\hline $\mathrm{CO}_{2}$ & 0.00 & 108.46 & 108.46 & 165.81 & 33.16 & 33.16 & 0.00 & 132.65 \\
\hline MgO & 0.00 & 0.00 & 0.00 & 0.00 & 151.89 & 30.38 & 30.38 & 151.89 \\
\hline $\mathrm{MgCO}_{3}$ & 0.00 & 0.00 & 0.00 & 0.00 & 0.00 & 254.16 & 254.16 & 0.00 \\
\hline $\begin{array}{l}\text { Total flow } \\
\operatorname{rate}(\mathrm{t} / \mathrm{h})\end{array}$ & 270.67 & 225.40 & 367.38 & 264.01 & 283.25 & 341.57 & 284.54 & 284.54 \\
\hline
\end{tabular}

Table 5.3.7 Mass balance calculation for pre-combustion $\mathrm{CO}_{2}$ capture using $\mathrm{MgO}$ at a coal-fired power plant

Assuming the same capacity of plant $(330 \mathrm{MWe})$ and thus about $116 \mathrm{t} / \mathrm{h}$ coal that is required. A $20 \%$ stocihiometrically excess of $\mathrm{O}_{2}(154.67 \mathrm{t} / \mathrm{h})$ is assumed and water should be sufficient enough to prepare coal slurry. A gasifier operates at a high temperature $\left(800-1000^{\circ} \mathrm{C}\right)$ and pressure of 55 bars. At the exit of gasifier, $\mathrm{H}_{2}, \mathrm{CO}$ and $\mathrm{CO}_{2}$ are present in $30,40,10 \%$ molar concentration and that translates to $6.51 \mathrm{t} / \mathrm{h}, 110.43 \mathrm{t} / \mathrm{h}$ and $108.46 \mathrm{t} / \mathrm{h}$ respectively. After the gasifier, synthesis gas $\left(\mathrm{CO}+\mathrm{H}_{2}\right)$ is sent to water-gas shift (WGS) reactor. The input feed of steam is twice that of syn gas. After water-gas shift reaction, the gas feed is sent for carbonation reactor in fluidized bed reactor. About $151.89 \mathrm{t} / \mathrm{h} \mathrm{MgO}$ is required for $80 \% \mathrm{CO}_{2}$ capture at the power plant. At the exit of carbonation reactor, $\mathrm{MgCO}_{3}$ is about 254.16t/h and the detailed mass of each species is given in Table 5.3.7. 


\subsubsection{Energy balance calculation}

As mentioned earlier, flue gas out of the gasifier comes out at a high pressure ( $\sim 55$ bars $)$ and high temperature $\left(\sim 800-1000^{\circ} \mathrm{C}\right)$. The raw syn gas out of the gasifier is at a slightly lower pressure of 54.51 bars and temperature of $285^{\circ} \mathrm{C}$. Conventionally, for other precombustion sorbents such as slexol, the syn gas is cooled to room temperature while the pressure is kept constant. For the purpose of using $\mathrm{MgO}$ as a sorbent, cooling of gases exiting WGS reactor will not be energetically favorable. So, here, these gases are directly sent to the carbonation reactor. Based on our experimental findings, at $300^{\circ} \mathrm{C}$ and 50 bars, we are getting about $96 \%$ conversion of $\mathrm{MgO}$ to $\mathrm{MgCO}_{3}$. Thus, for the combination of $285^{\circ} \mathrm{C}$ and 50 bars pressure, $80 \%$ conversion can be accepted. $151.89 \mathrm{t} / \mathrm{h} \mathrm{MgO}$ is required. This amount is too big and may not be practically easy to deal with such huge amount. The reaction enthalpy of $\mathrm{MgO}-\mathrm{CO}_{2}$ reaction at $300^{\circ} \mathrm{C}$ and 50 bars is $\Delta \mathrm{H}=-107$ $\mathrm{kJ} / \mathrm{mole}$. The released heat from the carbonation reactor needs to be adequately removed to maintain the high $\mathrm{CO}_{2}$ absorption capacity. Here, we consider only $10 \%$ of heat recovery from the carbonation reactor (while, the maximum efficiency $=\left(\mathrm{T}_{2}-\mathrm{T}_{1}\right) / \mathrm{T}_{2}=(-$ $300) / 623=46.23 \%$ ) and this translates to a heat recovery of $0.45 \mathrm{MWe}$.

Hot and compressed $\mathrm{H}_{2}$ can then be subjected to the combined gas and vapor power cycle. A significant amount of electricity can be generated at this point. $\mathrm{MgCO}_{3}$, formed as a result of carbonation reaction is sent to the calciner. Make-up $\mathrm{MgCO}_{3}$ is also injected to the calciner. Calciner uses thermal energy from the direct burning of coal. The calcination of 254.16 tons/hour of $\mathrm{MgCO}_{3}$ at $550^{\circ} \mathrm{C}$ and 1 bar $(\Delta \mathrm{H}=+164.69 \mathrm{~kJ} / \mathrm{mol})$ requires 11.62 MWe. Thus, 3.83 tons/hour of coal is required to regenerate $\mathrm{MgO}$. The 
burning of 3.83 tons/hour of coal produces about 10.31 tons/hour of $\mathrm{CO}_{2}$. The total consumption of coal is increased by $(116+3.83) / 116=1.033$.

As discussed earlier, $\mathrm{CO}_{2}$ exiting the calciner needs to be compressed to 136 bars. Using $105 \mathrm{kWh} /$ ton of $\mathrm{CO}_{2}$ energy required to compress $\mathrm{CO}_{2}$, compression energy for 132.65 tons/hour of $\mathrm{CO}_{2}$ requires 13.92 $\mathrm{MWe} 151.89$ tons/hour of $\mathrm{MgO}$ is regenerated in the process and thus can be recycled for the next capture cycle. Thus, the total parasitic load for pre-combustion capture using $\mathrm{MgO}$ is $25.54 \mathrm{MWe}$. One should note that electricity generated by the hydrogen used in the combined gas and vapor power cycle is not included for the energy calculation. 


\subsection{MITIGATING $\mathrm{CO}_{2}$ EMISSIONS IN THE IRON INDUSTRY USING}

\section{MIXTURE OF MAGNETITE AND IRON}

\subsubsection{INTRODUCTION}

The global steel production is growing rapidly, from $1248 \mathrm{Mt}$ in 2006 to $1490 \mathrm{Mt}$ in 2011, an increase of about $16 \%$ in a short span of 5 years [1]. Steel production is an energy intensive process and thus consumes huge amount of fossil fuels. Each ton of steel production emits 2.2 ton of $\mathrm{CO}_{2}$ as a world average. Therefore, iron making industries can be seen as one of the biggest targets next to power plants to curb vast emission of greenhouse gases.

It is known that a significant amount of the overall carbon input to the iron and steel plant flows through the iron making process (Blast furnace and smelting reduction process). In particular, blast furnace requires around $70 \%$ of the total carbon input [2]. Blast furnace gas has a pressure of about 2-3 bar and contains $\mathrm{CO}(17-25 \%), \mathrm{N}_{2}(50-55 \%), \mathrm{O}_{2}(1-5 \%)$, $\mathrm{CO}_{2}(17-25 \%)$ [3]. The $\mathrm{CO}_{2}$ capture approaches are mainly based on chemical (Monoethanolamine (MEA), MEA/piperazine mix and sterically hindered primary amines) or physical (pressure swing adsorption and vacuum pressure swing adsorption) absorption [4-5]. Chemical absorption is appropriate for $\mathrm{CO}_{2}$ capture from gases with low- $\mathrm{CO}_{2}$ partial pressures while physical absorption requires higher $\mathrm{CO}_{2}$ partial pressures. Hence, the latter approach is suitable to separate $\mathrm{CO}_{2}$ from the process gas only after water-gas shift reaction, which is operated at 20 bars [6]. A detail explanation of the existing $\mathrm{CO}_{2}$ capture process for iron and steel sector can be found elsewhere [7-9]. 
We present here a novel add-on technology which can be employed for blast furnace gas after conversion of $\mathrm{CO}$ to $\mathrm{CO}_{2}$ (using water gas shift reaction). The combined use of following reactions for $\mathrm{CO}_{2}$ capture could be energetically and economically favorable at any iron making industries. Reaction (5.4.1) suggests that a mixture of magnetite and iron can selectively combine with $\mathrm{CO}_{2}$ from blast furnace gas and forms siderite.

Reaction 5.4.1: $\quad \mathrm{Fe}_{3} \mathrm{O}_{4}(\mathrm{~s})+\mathrm{Fe}(\mathrm{s})+4 \mathrm{CO}_{2}(\mathrm{~g})=4 \mathrm{FeCO}_{3}(\mathrm{~s}) \quad \Delta \mathrm{H}\left(200^{\circ} \mathrm{C}, 10\right.$ bars $)=-$ $288.55 \mathrm{~kJ} / \mathrm{mol}$

Siderite, once formed can further decompose back to magnetite [Reaction (5.4.2)] in presence of oxygen at $350^{\circ} \mathrm{C}$. Reaction (5.4.2) liberates pure $\mathrm{CO}_{2}$ which can either be sequestered underground or used for oil gas recovery.

Reaction 5.4.2: $3 \mathrm{FeCO}_{3}(\mathrm{~s})+1 / 2 \mathrm{O}_{2}(\mathrm{~g})=\mathrm{Fe}_{3} \mathrm{O}_{4}(\mathrm{~s})+3 \mathrm{CO}_{2}(\mathrm{~g}) \quad \Delta \mathrm{H}\left(350^{0} \mathrm{C}, 1\right.$ bar $)=+$ $87.29 \mathrm{~kJ} / \mathrm{mol}$

After regeneration, the magnetite can further be recycled back to reaction (5.4.1) and thus completes the cycle. This carbonation-calcination cycle can be repeated for several times. Once the $\mathrm{CO}_{2}$ capture capacity of magnetite degrades, it can be reused to manufacture iron. In such a way, there would not be any loss of raw materials.

Magnetite is the one of the main ingredients for manufacturing iron and hence it is readily accessible. But, at present, most of the iron and steel industries are not involved in forming iron powders at their own site. However, iron powders can be manufactured using conventional techniques such as sponge-iron or water atomizing process [10]. 
Nevertheless, any industrial waste containing iron in sufficient amount can also be used instead of pure iron powders for reaction (5.4.1).

We performed thermodynamic equilibrium calculations using the software FACTSAGE and the databases therein and conducted several experiments for verification. An equilibrium calculation shows that at high pressure of carbonation reaction, the decomposition temperature of siderite is also higher. For instance, at 10 bars $\mathrm{CO}_{2}$ pressure, siderite starts decomposing around $(200-250)^{0} \mathrm{C}$. However, at 50 bars, siderite becomes unstable only after $300^{\circ} \mathrm{C}$ [Fig. 5.4.1]. A similar result was reported by Svoboda et al. [11]. The calculation also shows no formation of siderite until $100^{\circ} \mathrm{C}$ for both 10 and
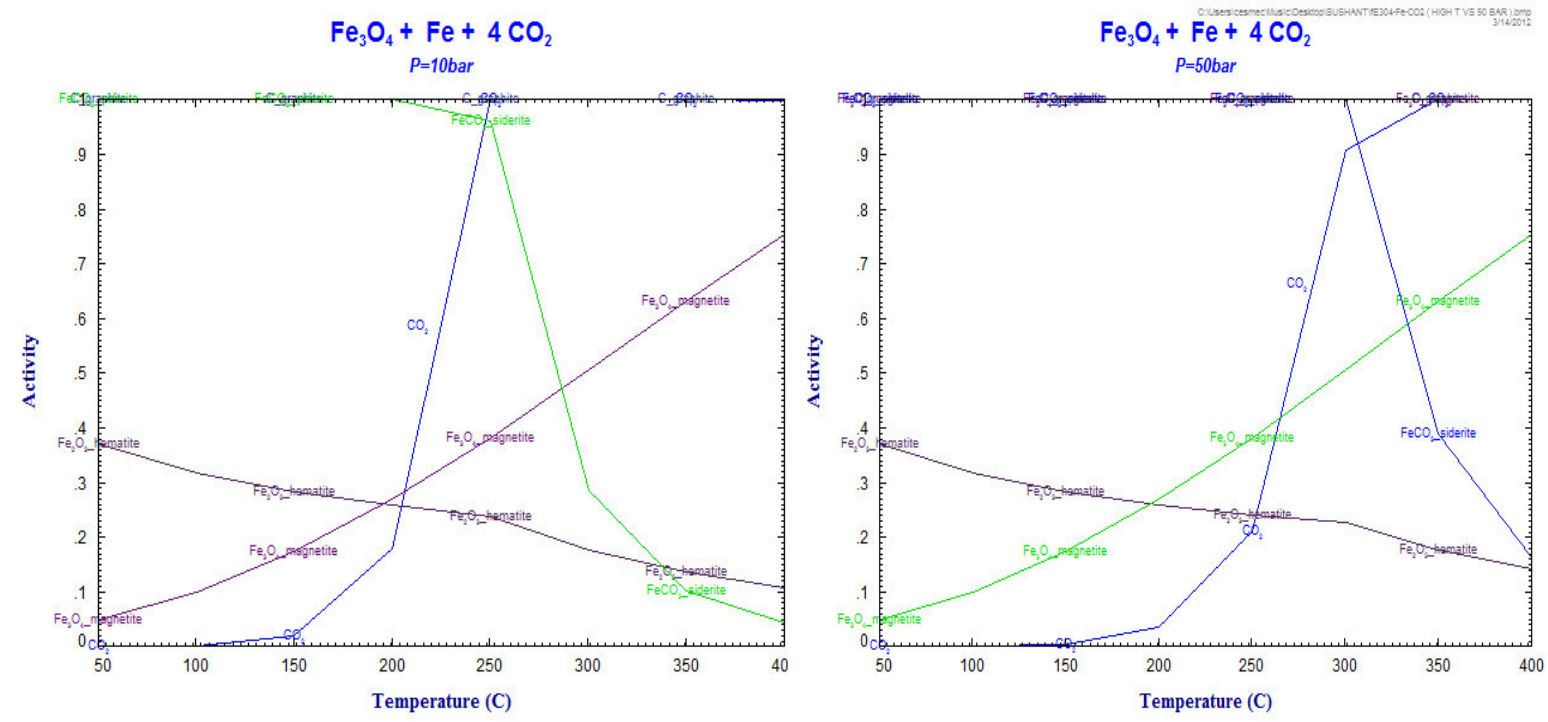

Figure 5.4.1 Equilibrium composition in the system $\mathrm{Fe}_{3} \mathrm{O}_{4}+\mathrm{Fe}+4 \mathrm{CO}_{2}$ at 10 and 50 bars pressure

Here, we performed the experiments at a relatively high pressure. High pressure $\mathrm{CO}_{2}$ capture technologies require entire process gas compression and can significantly increase the power consumption due to an additional feed gas compressor prior to the carbonation reactor [12]. However, Lampert et al. [13], who indicated that the 
compression energy penalty for add-on $\mathrm{CO}_{2}$ capture can be partially offset as the exported gas is compressed anyway before combustion in power plant.

\subsubsection{EXPERIMENTAL PROCEDURE}

The carbonation reactions were performed in a closed system while the decomposition of siderite was evaluated using thermo gravimetric analysis (TGA).

About 0.4 g mixture of $\mathrm{Fe}_{3} \mathrm{O}_{4}$ (Alfa Aesar, 98\% purity) and $\mathrm{Fe}$ (Good Fellow, 99\% purity) was ground using mortar and pestle and then put inside a closed cylindrical vessel of length 1.25 " and internal diameter of 0.35 ". About $0.10 \mathrm{~mL}$ water were added on the vessel wall to create a slight humid environment for the carbonation reaction. Chemically pure $\mathrm{CO}_{2}$ gas (Airgas) was then passed into the system. Before experiments, $\mathrm{CO}_{2}$ gas was flushed three times to ensure a pure $\mathrm{CO}_{2}$ atmosphere inside the reactor. The reaction was performed for several minutes at a desired temperature and pressure condition. Once the reaction completed, the system was air-cooled. The degree of carbonation reaction was determined by weight loss during calcination of the product.

TGA 2950 Thermo gravimetric analyzer was primarily used to identify the decomposition temperature of the product. The sample was heated under air atmosphere (flow rate $=100 \mathrm{~mL} / \mathrm{min}$.), at a heating rate of $15^{\circ} \mathrm{C} / \mathrm{min}$ to a final temperature of $800^{\circ} \mathrm{C}$. The TGA provides continuous measurements of the sample weight as a function of time and temperature. $\mathrm{FeCO}_{3}$ content in the product was analyzed by the percent loss in weight of the sample while heating up to $800^{\circ} \mathrm{C}$ in an air atmosphere. 
Powder X-ray diffraction method was used to characterize the product using Bruker GADDS/D8 X-ray diffractometer equipped with Apex Smart CCD Detector and directdrive rotating anode. The MacSci rotating anode (Molybdenum) operates with a $50 \mathrm{kV}$ generator and $20 \mathrm{~mA}$ current. X-ray beam size can vary from 50 to $300 \mu \mathrm{m}$. The usual collection time is $1200 \mathrm{~s}$.

\subsubsection{RESULTS AND DISCUSSION}

Figure 5.4.2 (i) confirm the formation of $\mathrm{FeCO}_{3}$ at $200^{\circ} \mathrm{C}$ and 10 bars of $\mathrm{CO}_{2}$ pressure. $\mathrm{Fe}_{3} \mathrm{O}_{4}$ and $\mathrm{FeCO}_{3}$ were identified by their XRD patterns (Joint Committee Powder Diffraction Standard (JCPDS) card number 89-4319 and 83-1764). A mixture of $\mathrm{Fe}_{3} \mathrm{O}_{4}$ and $\mathrm{Fe}$ locks $\mathrm{CO}_{2}$ in the form of $\mathrm{FeCO}_{3}$. Several experiments at various set of temperature, pressure and time have been performed. It is observed that the molar ratio of $\mathrm{Fe}$ and $\mathrm{Fe}_{3} \mathrm{O}_{4}$ should be at least higher than 0.75 to form $\mathrm{FeCO}_{3}$ [Fig.5.4.2 (ii)]. All the experiments have been performed in the presence of $0.1 \mathrm{~mL}$ water. However, $\mathrm{x}$-ray diffraction pattern of the product does not show any formation of iron based hydroxides. This could be attributed to the catalytic behavior of water molecules. Several other works illustrate the significant role of water in increasing the $\mathrm{CO}_{2}$ uptake capacity of metal oxides. Figure 5.4.2 (iii) shows the DTG plot for the product obtained as a result of reaction (5.4.1) performed at $200^{\circ} \mathrm{C}, 10$ bars and 3 hours under air flow rate of 100

$\mathrm{mL} / \mathrm{min}$. The peak around $100^{\circ} \mathrm{C}$ attributes to the loss of water while second peak around $350^{\circ} \mathrm{C}$ corresponds to the complete decomposition of $\mathrm{FeCO}_{3}$. 


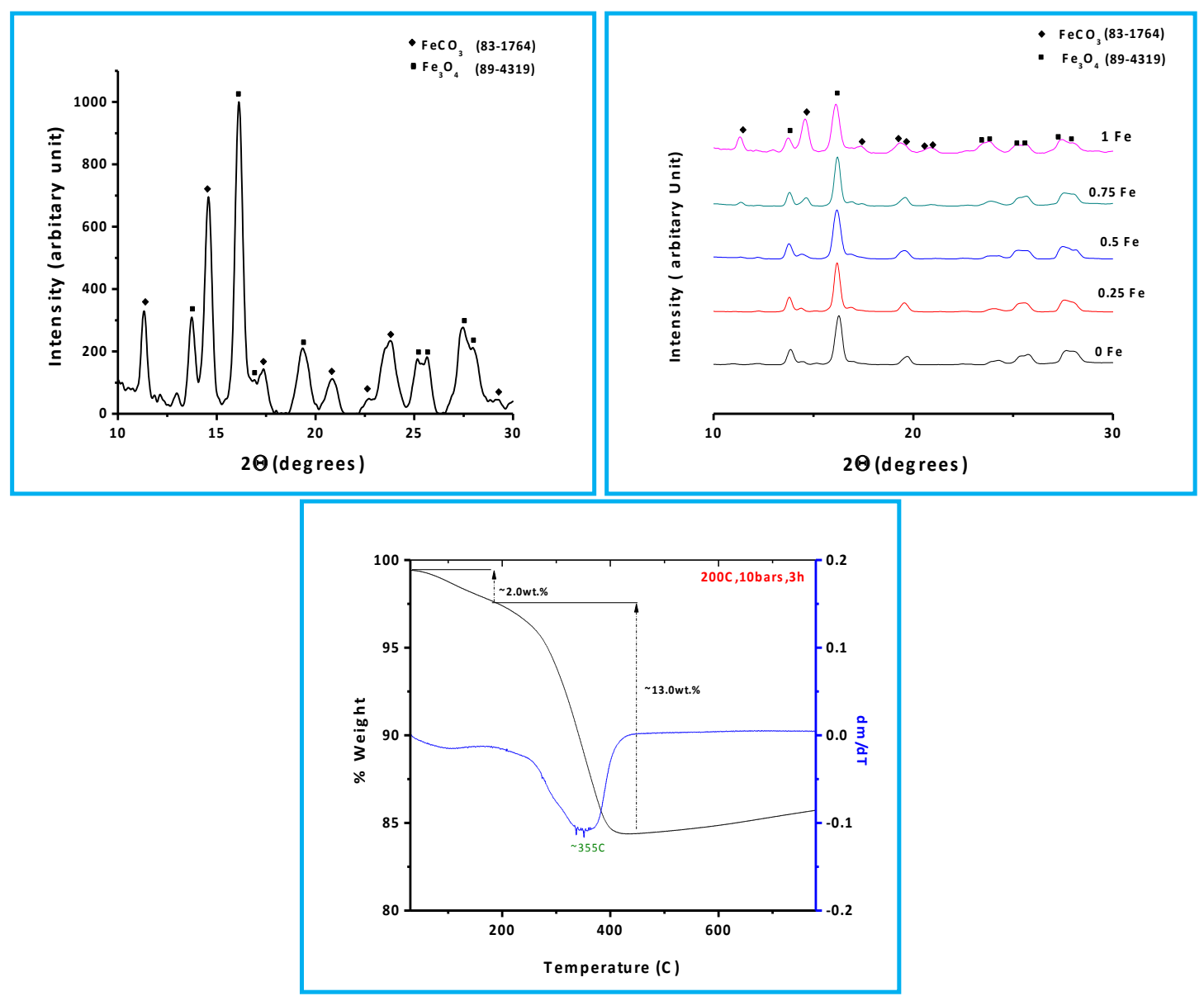

Figure 5.4.2 (i) X-ray diffraction pattern confirm the siderite formation for reaction [5.4.1] performed at $100^{\circ} \mathrm{C}, 50$ bars and $3 \mathrm{~h}$ (ii) X-ray diffraction pattern of the products for different molar composition of magnetite and iron mixture at $200^{\circ} \mathrm{C}, 10$ bars and $1 \mathrm{~h}$ (iii) DTG plot for product obtained as a result of reaction [5.4.1] performed at $200^{\circ} \mathrm{C}, 10$ bars, and $3 \mathrm{~h}$ under air flow rate of $100 \mathrm{~mL} / \mathrm{min}$. 
Table 5.4.1 illustrates the \% conversion for mixture of $\mathrm{Fe}$ and $\mathrm{Fe}_{3} \mathrm{O}_{4}$ to $\mathrm{FeCO}_{3}$ at various conditions. Based on TGA results, \% conversion for mixture of $\mathrm{Fe}$ and $\mathrm{Fe}_{3} \mathrm{O}_{4}$ to $\mathrm{FeCO}_{3}$ is calculated. At $200^{\circ} \mathrm{C}, 10$ bars and 3 hours, we observed a maximum mass conversion of $57 \%$

\begin{tabular}{|c|c|c|c|}
\hline Temperature $\left({ }^{\circ} \mathrm{C}\right)$ & Pressure(bars) & Time $(\mathrm{h})$ & \% Conversion \\
\hline 100 & 25 & 3 & 0.16 \\
\hline 100 & 50 & 1 & 0.16 \\
\hline 100 & 50 & 3 & 0.22 \\
\hline 100 & 50 & 6 & 0.43 \\
\hline 200 & 10 & 1 & 0.44 \\
\hline 200 & 10 & 3 & 0.57 \\
\hline
\end{tabular}

Table 5.4.1 Experimental result for reaction [5.4.1] at different set of temperature, pressure and time

Since the reaction between mixture of $\mathrm{Fe}$ and $\mathrm{Fe}_{3} \mathrm{O}_{4}$ is highly exothermic in nature, the observed temperature dependence suggests that the sorption of $\mathrm{CO}_{2}$ is controlled by the kinetic diffusion rather than the thermodynamic factor [14]. As the temperature is increased, more $\mathrm{CO}_{2}$ diffuses to the pores of powder mixture and the present active sites hold these $\mathrm{CO}_{2}$ molecules. Hence, these trapped $\mathrm{CO}_{2}$ molecules further react with the mixture to form $\mathrm{FeCO}_{3}$. It can be observed that the capture capacity of $\mathrm{Fe}$ and $\mathrm{Fe}_{3} \mathrm{O}_{4}$ mixture increases with increase in pressure. At $100^{\circ} \mathrm{C}$, the $\%$ mass conversion of $\mathrm{Fe}$ and $\mathrm{Fe}_{3} \mathrm{O}_{4}$ mixture increases from 0.16 to 0.22 at 25 and 50 bars of $\mathrm{CO}_{2}$ pressure. As expected, faster sorption kinetics was observed at a high pressure. One should note that as the pressure increases, the gas flux increases, and the intermolecular collisions of $\mathrm{CO}_{2}$ 
dominate and thus system is in Fickian regime. Hence, $\mathrm{CO}_{2}$ molecules intrude through each available pores of $\mathrm{Fe}$ and $\mathrm{Fe}_{3} \mathrm{O}_{4}$ powder mixture. However, at low pressure (Knudsen regime), collisions between the $\mathrm{CO}_{2}$ molecules and pore walls are dominant and the free path is limited to the geometry of void space [15]. Thus, it is apparent that at low pressure, there is relatively less $\mathrm{CO}_{2}$ capture by a mixture of $\mathrm{Fe}$ and $\mathrm{Fe}_{3} \mathrm{O}_{4}$. 


\subsubsection{REFERENCES:}

[1] www.worldsteel.org

[2] J.C.M. Farla, C.A. Hendriks, K. Blok, Climatic Change, 1995, 29, 439-61

[3] IPPC, Reference Document on best available techniques on the production of iron and steel. Integrated Pollution Prevention and control Bureau, Seville, Spain 2001

[4] F.A. Tobiesen, H.F. Svendsen, T. Mejdell, Industrial \& Engineering Chemistry Research, 2007, 46, 7811-9

[5] K. Wieder , C. Bohm , J. Wurn, The COREX and FINEX Processes - reliable, environmental friendly and economical Hot Metal Production, Kolkata, India 2005.

[6] D. Gielen, Energy Conversion and Management, 2003, 44, 1027-1037

[7] C. Xu, C.Da-qiang, Journal of Iron and Steel Research International, 2010, 17, 01-07

[8] T. Kuramochi, A. Ramirez, W. Turkenburg, A.Faaij, Progress in Energy and Combustion Science, 2012, 38, 87-112

[9] J.P. Birat, J.P. Vizioz, Y. de Lassat de Pressigny, M. Schneider, M. Jeanneau, $\mathrm{CO}_{2}$ emissions and the steel industry's available responses to the greenhouse effect, Revue de Metallurgie, Cahiers d'Informations Techniques, France 1999, 96,1203-15

[10] J.M. Capus, Metal Powders- A global survey of production, applications and markets to 2010, fourth ed., Elsevier, Oxford 2006

[11] K. Svoboda, G. Slowinski, J. Rogut, D. Baxter, Energy Conversion and Management, 2007, 48, 3063-73

[12] M.T. Ho, G.W. Allinson, D.E. Wiley, International Journal of Greenhouse Gas Control, 2010, 5, 49-60

[13] K. Lampert, A. Ziebik, W. Stanek, Energy, 2010, 35, 1188-95

[14] S.F. Wu, Industrial \& Engineering Chemistry Research, 2007, 46, 7896-9

[15] R. Feres, G.S. Yablonsky, Chemical Engineering Science, 2006, 61, 7864 - 83 


\subsection{PROCESS DESIGN FOR THE PROPOSED CARBON DIOXIDE SORBENT FOR IRON MAKING INDUSTRY}

\subsubsection{RETROFIT IN A BLAST FURNACE}

Fig.5.5.1 illustrates the idea for the integration of a mixture of magnetite and iron as a potential $\mathrm{CO}_{2}$ sorbent at any iron making industry.

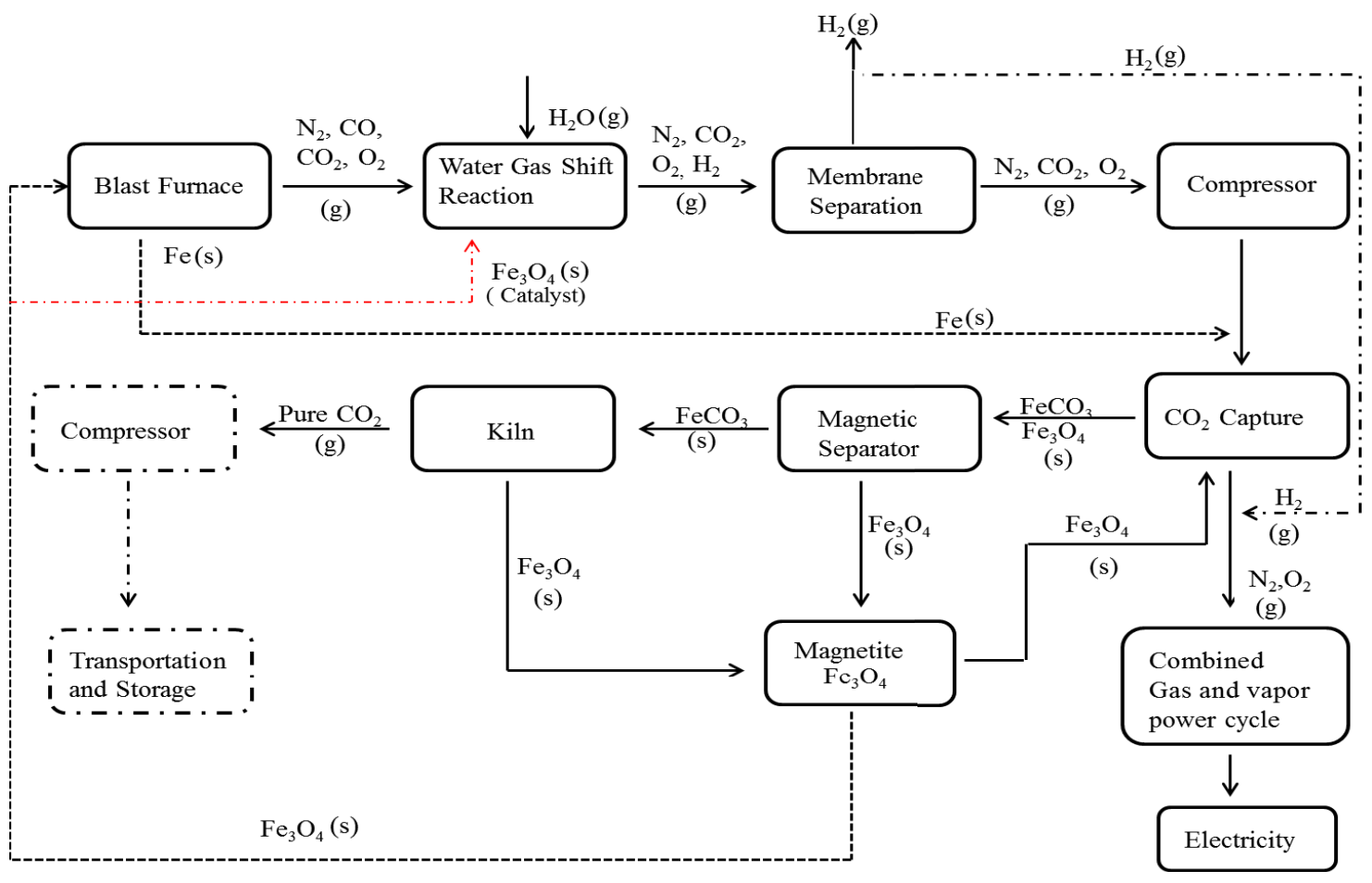

Figure 5.5.1 Flow sheet for carbonation process integrated to a blast furnace

Based on the experimental results for a mixture of iron and magnetite powder, a process design is proposed for carbon dioxide capture at iron making industries. The retrofit of the process to an existing iron making industry is shown in Fig.5.5.2. Blast furnace gas is produced when iron ore is reduced to metallic iron using coke. Since blast furnace gas contains mostly $\mathrm{N}_{2}(\sim 50 \%), \mathrm{CO}(\sim 23 \%), \mathrm{CO}_{2}(\sim 25 \%)$ and rest $\mathrm{O}_{2}$, it has a very low heating value of $93 \mathrm{BTU} / \mathrm{Cubic}$ foot $(0.037 \mathrm{~kJ} / \mathrm{l})$, compared to $\mathrm{CH}_{4}(0.364 \mathrm{~kJ} / \mathrm{l})$. The presence of a high amount of $\mathrm{CO}$ in blast furnace gas requires a water-gas shift reactor. 
Water gas shift reaction converts $\mathrm{CO}$ and stem to $\mathrm{H}_{2}$ and $\mathrm{CO}_{2}$ rich gas stream. Hydrogen gas can be separated from the mixture of $\mathrm{N}_{2}$ and $\mathrm{CO}_{2}$ using diaphragm. Further, the gas stream $\left(\mathrm{N}_{2}+\mathrm{CO}_{2}\right)$ can be compressed and heated prior to the injection into the carbonation reactor. The reaction of a mixture of iron and magnetite $(\mathrm{I}+\mathrm{M})$ with $\mathrm{CO}_{2}$ in the carbonation reactor is an exothermic reaction. The reacted sorbent particles are sent to high temperature cyclone. Further, a magnetic separator is used to separate siderite (product) and unreacted magnetite. A part of magnetite can be sent to the blast furnace or carbonation reactor for the next capture cycle. Siderite particles are subsequently decomposed to release pure carbon dioxide which can further be liquefied using carbon dioxide compressor. The magnetite obtained after calcination process can then be reinjected to either blast furnace or carbonation reactor. 


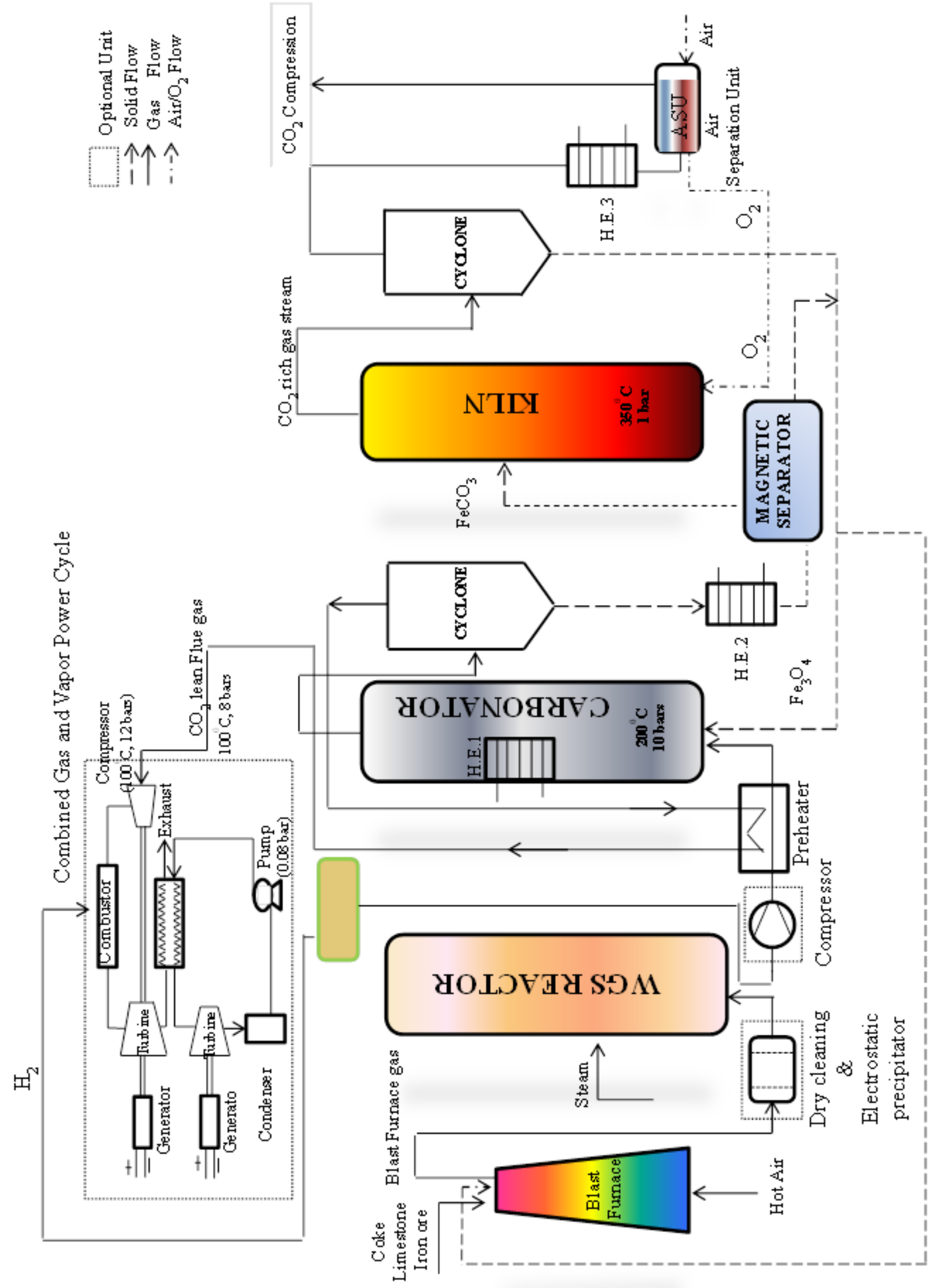


The benefit of using mixture magnetite and iron mixture is that

(i) readily accessible at any iron making industry

(ii) raw materials can be used for a large number of cycles

(iii) Once the materials adsorption capacity degrades, it can be converted back into iron

\subsubsection{MASS BALANCE CALCULATION}

A blast furnace of capacity 6000 tons/ day is considered as an example. A total of 0.4 million $\mathrm{m}^{3} / \mathrm{h}$ of blast furnace gas will be emitted. A detailed material flows is illustrated in Table 5.5.1. The respective amount of $\mathrm{N}_{2}, \mathrm{CO}, \mathrm{CO}_{2}$ and $\mathrm{O}_{2}$ out of blast furnace is $198.11 \mathrm{t} / \mathrm{h}, 91.03 \mathrm{t} / \mathrm{h}, 155.66 \mathrm{t} / \mathrm{h}$ and $9.06 \mathrm{t} / \mathrm{h}$. The assumed conditions for carbonation reaction are based on the experimental findings: $200^{\circ} \mathrm{C}, 10$ bars, $1 \mathrm{~h}$ and efficiency $=0.44$. It is also assumed that only $10 \%$ of carbonation heat is recovered from a carbonation reactor $($ Maximum efficiency $=[(473-300) / 300]=0.57)$. The calcination of siderite occurs at a temperature of $350^{\circ} \mathrm{C}$. The pure $\mathrm{CO}_{2}$ is compressed to 136 bars and transported to the storage site using pipeline.

The reaction involved in the proposed scheme is illustrated in Table 5.5.1

\begin{tabular}{|c|c|c|c|}
\hline & & Efficiency & $\begin{array}{c}\text { Enthalpy } \\
(\mathrm{kJ} / \mathrm{mol})\end{array}$ \\
\hline Reaction 1 & $\mathrm{CO}+\mathrm{H}_{2} \mathrm{O}=\mathrm{CO}_{2}+\mathrm{H}_{2}$ & 0.99 & -41.1 \\
\hline Reaction 2 & $\mathrm{Fe}_{3} \mathrm{O}_{4}+\mathrm{Fe}+4 \mathrm{CO}_{2}=4 \mathrm{FeCO}_{3}$ & 0.44 & -288.55 \\
\hline Reaction 3 & $3 \mathrm{FeCO}_{3}+1 / 2 \mathrm{O}_{2}=\mathrm{Fe}_{3} \mathrm{O}_{4}+3 \mathrm{CO}_{2}$ & 0.99 & 44.78 \\
\hline Reaction 4 & $\mathrm{Fe}_{3} \mathrm{O}_{4}+3 \mathrm{C}=3 \mathrm{Fe}+2 \mathrm{CO}+\mathrm{CO}_{2}$ & 0.9 & 52.82 \\
\hline Reaction 5 & $2 \mathrm{H}_{2}+\mathrm{O}_{2}=2 \mathrm{H}_{2} \mathrm{O}$ & 0.99 & -572 \\
\hline Heat of Vaporization & $\mathrm{H}_{2} \mathrm{O}$ & & 40.65 \\
\hline Heat Efficiency & & 2 & \\
\hline
\end{tabular}

Table 5.5.1 Reactions involved in the proposed scheme for $\mathrm{CO}_{2}$ capture at iron making industry 
Water gas shift reaction is a conventional way to generate hydrogen gas using the flow streams of CO and steam. It is generally carried out in adiabatic fixed bed reactors. One, two or even three series reactors have been suggested for water gas shift reaction. The reaction is often used in two stages. The first reactor is of high temperature $\left(350^{\circ} \mathrm{C}\right)$ and another relatively lower temperature $\left(200^{\circ} \mathrm{C}\right)$.

$$
\text { Reaction 5.5.1: } \mathrm{CO}+\mathrm{H}_{2} \mathrm{O} \rightarrow \mathrm{CO}_{2}+\mathrm{H}_{2} \quad \Delta \mathrm{H}=-41.1 \mathrm{~kJ} / \mathrm{mol}
$$

A high ratio of steam and $\mathrm{CO}$ favors $\mathrm{CO}$ conversions. However, a high amount of energy will be required for producing more steam. Therefore, trade-off exists between hydrogen production and amount of used steam. Here, we considered this ration to be 4.4:1(Steam: CO). High temperature catalyst (iron oxides) is readily available and thus can lower the operating costs at iron making industry. $9.5 \mathrm{t} / \mathrm{h}$ steam (produced via $10 \%$ heat recovery from the exothermic carbonation reaction) can be fed to the water-gas shift reactor as a complement to $248.26 \mathrm{t} / \mathrm{h}$ steam.

After water-gas shift reaction, gases $\left(\mathrm{N}_{2}, \mathrm{CO}, \mathrm{CO}_{2}, \mathrm{H}_{2}\right.$ and $\mathrm{O}_{2}$ are $198.11 \mathrm{t} / \mathrm{h}, 0.91 \mathrm{t} / \mathrm{h}$, 297.43t/h, 0.64t/h and 9.06t/h) are fed to a diaphragm, where $\mathrm{H}_{2}$ gas can be separated out. 505.5t/h of the gaseous mixture should be compressed to 10 bars prior to injection into the carbonation reactor.

$$
\text { Reaction 5.5.2: } \mathrm{Fe}_{3} \mathrm{O}_{4}+\mathrm{Fe}+4 \mathrm{CO}_{2} \rightarrow 4 \mathrm{FeCO}_{3} \quad \Delta \mathrm{H}=-288.55 \mathrm{~kJ} / \mathrm{mol}
$$

A stoichiometric amount, $\mathrm{Fe}_{3} \mathrm{O}_{4}(391.28 \mathrm{t} / \mathrm{h})$ and $\mathrm{Fe}(94.37 \mathrm{t} / \mathrm{h})$, needs to be fed into the carbonation reactor, which is assumed to be a fluidized bed reactor. After $\mathrm{CO}_{2}$ absorption, the exit gas contains $\mathrm{N}_{2}(198.11 \mathrm{t} / \mathrm{h}), \mathrm{O}_{2}(9.06 \mathrm{t} / \mathrm{h}), \mathrm{CO}(0.91 \mathrm{t} / \mathrm{h})$ and $\mathrm{CO}_{2}$ (166.56t/h). For complete $\mathrm{CO}_{2}$ absorption, about $890 \mathrm{t} / \mathrm{h} \mathrm{Fe}_{3} \mathrm{O}_{4}$ and $214.47 \mathrm{t} / \mathrm{h} \mathrm{Fe}$ is required (as efficiency $=0.44$ ). 
The mixture of magnetite and iron reacts with $\mathrm{CO}_{2}$ to form $\mathrm{FeCO}_{3} . \mathrm{FeCO}_{3}$ and unreacted mixture of $\mathrm{Fe}_{3} \mathrm{O}_{4}$ and $\mathrm{Fe}$ (219.11 and 52.85t/h respectively) can be magnetically separated.

$$
\text { Reaction 5.5.3: } 3 \mathrm{FeCO}_{3}+1 / 2 \mathrm{O}_{2} \rightarrow \mathrm{Fe}_{3} \mathrm{O}_{4}+3 \mathrm{CO}_{2} \quad \Delta \mathrm{H}=44.78 \mathrm{~kJ} / \mathrm{mol}
$$

$511.11 \mathrm{t} / \mathrm{h} \mathrm{FeCO}_{3}$ can be decomposed in the presence of oxygen to regenerate $\mathrm{Fe}_{3} \mathrm{O}_{4}$ $(337.11 \mathrm{t} / \mathrm{h})$ and release pure $\mathrm{CO}_{2}$ gas $(192.11 \mathrm{t} / \mathrm{h}) .164 .95 \mathrm{t} / \mathrm{h} \mathrm{Fe} \mathrm{O}_{4}$ can be fed back to the blast furnace for further iron making. A detailed mass balance calculation is given in Table 5.5.2.

\begin{tabular}{|c|c|c|c|c|c|c|c|c|c|c|c|c|}
\hline $\begin{array}{l}\text { Materials } \\
\text { / Stream }\end{array}$ & $\begin{array}{c}\text { Out- } \\
\text { BF } \\
\text { (1) }\end{array}$ & $\begin{array}{c}\text { Out- } \\
\text { WGS } \\
\text { (2) }\end{array}$ & $\begin{array}{c}\text { Out- } \\
\text { DPH } \\
(3)\end{array}$ & $\begin{array}{c}\text { In- } \\
\text { FBR } \\
(4)\end{array}$ & $\begin{array}{c}\text { Out- } \\
\text { FBR } \\
\text { (5) }\end{array}$ & $\begin{array}{c}\text { In- } \\
\text { FBR } \\
(6)\end{array}$ & $\begin{array}{c}\text { In- } \\
\text { WGS } \\
(7)\end{array}$ & $\begin{array}{c}\text { Out- } \\
\text { FBR } \\
\text { (8) }\end{array}$ & $\begin{array}{c}\text { In- } \\
\text { KILN } \\
(9)\end{array}$ & $\begin{array}{l}\text { Out- } \\
\text { KILN } \\
(10)\end{array}$ & $\begin{array}{c}\text { In- } \\
\text { BF } \\
(11)\end{array}$ & $\begin{array}{l}\text { Pure } \\
\mathrm{CO}_{2} \\
(12)\end{array}$ \\
\hline $\mathbf{N}_{2}$ & 198.11 & 198.11 & 0.00 & 198.11 & 198.11 & 0.00 & 0.00 & 0.00 & 0.00 & 0.00 & 0.00 & 0.00 \\
\hline $\mathrm{CO}$ & 91.13 & 0.91 & 0.00 & 0.91 & 0.91 & 0.00 & 0.00 & 0.00 & 0.00 & 0.00 & 0.00 & 0.00 \\
\hline $\mathrm{CO}_{2}$ & 155.66 & 297.43 & 0.00 & 297.43 & 166.56 & 0.00 & 0.00 & 0.00 & 0.00 & 192.19 & 0.00 & 192.19 \\
\hline $\mathrm{O}_{2}$ & 9.06 & 9.06 & 0.00 & 9.06 & 9.06 & 0.00 & 0.00 & 0.00 & 0.00 & 0.00 & 0.00 & 0.00 \\
\hline $\mathrm{H}_{2}$ & 0.00 & 0.64 & 0.64 & 0.00 & 0.00 & 0.00 & 0.00 & 0.00 & 0.00 & 0.00 & 0.00 & 0.00 \\
\hline $\mathrm{H}_{2} \mathrm{O}$ & 0.00 & 0.00 & 0.00 & 0.00 & 0.00 & 9.50 & 248.26 & 0.00 & 0.00 & 0.00 & 0.00 & 0.00 \\
\hline $\mathrm{Fe}$ & 0.00 & 0.00 & 0.00 & 0.00 & 0.00 & 0.00 & 0.00 & 52.85 & 0.00 & 0.00 & 0.00 & 0.00 \\
\hline $\mathrm{Fe}_{3} \mathrm{O}_{4}$ & 0.00 & 0.00 & 0.00 & 0.00 & 0.00 & 0.00 & 0.00 & 219.11 & 0.00 & 337.11 & 164.95 & 0.00 \\
\hline $\mathrm{FeCO}_{3}$ & 0.00 & 0.00 & 0.00 & 0.00 & 0.00 & 0.00 & 0.00 & 0.00 & 511.11 & 0.00 & 0.00 & 0.00 \\
\hline $\begin{array}{l}\text { Total } \\
(\mathrm{t} / \mathrm{h})\end{array}$ & 453.95 & 506.14 & 0.64 & 505.50 & 374.63 & 9.50 & 248.26 & 271.96 & 511.11 & 529.30 & 164.95 & 192.19 \\
\hline
\end{tabular}

$\mathrm{BF}=$ Blast Furnace, WGS $=$ Water-gas shift reactor, $\mathrm{DPH}=$ Diaphragm, FBR=Fluidized bed reactor.

Table 5.5.2 Mass balance for the proposed scheme 


\subsubsection{ENERGY BALANCE CALCULATION}

Table 5.5.3 illustrates the energy consumed and released at different stages of the proposed $\mathrm{CO}_{2}$ capture scheme. The energy values are given against the materials flow rate. Since the gases coming out of the fluidized bed reactor is compressed and hot, it is proposed that a combined gas and vapor power cycle can be used. Natural gas can be used as a feed input for the combined power cycle. For the water-gas shift reaction and carbonation reaction, $30 \%$ and $10 \%$ heat recovery is assumed respectively. If combined gas and vapor power cycle is not employed, the whole process turns out to be an energy intensive process. It can be observed that a large amount of energy is required to generate steam for water-gas shift reaction $\left(\Delta \mathrm{H}_{\text {vap. }}=40.65 \mathrm{~kJ} / \mathrm{mol}\right)$. However, a part of steam $(9.50 \mathrm{t} / \mathrm{h})$ is planned to be generated using the heat from exothermic carbonation reaction. Moreover, regeneration of iron from magnetite in the blast furnace is also taken into consideration for energy estimation.

$$
\text { Reaction 5.5.4: } \mathrm{Fe}_{3} \mathrm{O}_{4}+3 \mathrm{C} \rightarrow 3 \mathrm{Fe}+2 \mathrm{CO}+\mathrm{CO}_{2} \quad \Delta \mathrm{H}=52.82 \mathrm{~kJ} / \mathrm{mol}
$$




\begin{tabular}{|c|c|c|c|c|}
\hline & & $\begin{array}{c}\text { Flow rate } \\
(\mathrm{t} / \mathrm{h})\end{array}$ & $\begin{array}{l}\text { Energy needed } \\
\text { (GJ) }\end{array}$ & $\mathrm{kWh}$ \\
\hline & $\mathrm{H}_{2} \mathrm{O}$ & 248.2645 & 560.6639 & 155741.21 \\
\hline & Reaction 4 & 164.9467 & 37.6292 & 10452.65 \\
\hline & Reaction 3 & 511.1118 & 65.8569 & 18293.74 \\
\hline $\begin{array}{c}\text { BFG Compressed } \\
\text { to } 17 \text { bars }\end{array}$ & Compression 1 & 453.9473 & & 58201.08 \\
\hline $\begin{array}{c}\text { Compressed to } 10 \\
\text { bars }\end{array}$ & Compression 2 & 505.5003 & & 67400.04 \\
\hline $\begin{array}{c}\mathrm{CO}_{2} \text { compressed to } \\
10 \text { bars }\end{array}$ & Compression 3" & 192.1881 & & 943.64 \\
\hline $\begin{array}{c}\mathrm{CO}_{2} \text { compressed to } \\
136 \text { bars }\end{array}$ & Compression 3 & 192.1881 & & 20179.75 \\
\hline \multirow[t]{2}{*}{ Total Heat needed } & & & & 331212.12 \\
\hline & & $\begin{array}{c}\text { Flow rate } \\
(\mathrm{t} / \mathrm{h})\end{array}$ & $\begin{array}{c}\text { Energy } \\
\text { Produced } \\
\text { (GJ) }\end{array}$ & $\mathrm{kWh}$ \\
\hline $\begin{array}{l}30 \% \text { heat recovery } \\
\text { is considered }\end{array}$ & Reaction 1 & 91.13 & 40.12933535 & 11147.13 \\
\hline \multirow[t]{3}{*}{$\begin{array}{l}10 \% \text { heat recovery } \\
\text { is considered }\end{array}$} & Reaction 2 & 391.28 & 48.76265937 & 13545.29 \\
\hline & $\mathrm{H}_{2}$ & 0.6404 & 91.58 & 25438.72 \\
\hline & $\begin{array}{c}\text { (Gas + Steam }) \\
\text { Turbines }\end{array}$ & 374.6328 & & 1182801.61 \\
\hline $\begin{array}{c}\text { Total Heat } \\
\text { Produced } \\
\text { (without } \mathrm{H}_{2} \text { ) }\end{array}$ & & & & 1207494.03 \\
\hline
\end{tabular}

Table 5.5.3 Energy consumed and released at different stages of the proposed scheme 


\subsubsection{ADVANTAGES OF THE PROPOSED SCHEME}

The use of the proposed scheme for $\mathrm{CO}_{2}$ capture at any iron making industry can have one or more of the following advantageous features:

(1) Raw materials

The raw materials needed to capture $\mathrm{CO}_{2}$ gas are magnetite and iron. These materials are readily accessible at a blast furnace site. They generally do not have harmful effects unlike MEA solvents and can be easily handled. These raw materials too can be used for a large number of cycles to absorb $\mathrm{CO}_{2}$ gas. Once the materials adsorption capacity degrades, it can be converted back into iron. The raw materials can have a high adsorption capacity, for example, of about $0.7624\left(\right.$ tonCO $\left._{2} / \mathrm{tonFe}_{3} \mathrm{O}_{4}\right)$ compared to $0.4\left(\right.$ tonCO $_{2} /$ ton MEA).

(2) Hydrogen gas production

Since blast furnace has almost equal proportion of $\mathrm{CO}$ and $\mathrm{CO}_{2}$ gas, it is desirable to have a water gas shift reactor. Water gas shift reaction is a known process to produce pure hydrogen gas. Moreover, the raw material, such as magnetite, can also work as a catalyst for the water gas shift reaction. Pure hydrogen gas can be sold for $\$ 1600-1800 /$ ton.

(3) Combined gas and vapor power cycle

The gases coming out of the carbonation reactor will be mainly heated and pressurized gases. These gases can be fed in a combined gas and vapor power cycle. Thus, electricity can be produced at the same site. The design also permits to route the produced hydrogen gas into the combined gas and vapor power cycle and thus can lead to an enhanced efficiency for the turbines. 
(4) Exothermic carbonation reaction

The carbonation reaction is exothermic in nature. The produced heat can be utilized to generate steam in various embodiments. The generated steam can be passed into the water gas shift reactor to make hydrogen gas. This will partly supply the amount of steam needed to run the water gas shift reaction. Thus, it can save energy.

(5) Less Transportation cost

Since raw materials for this proposed scheme are readily accessible at a blast furnace site, it is possible to eliminate the need for extra transportation to deliver raw materials, which can ultimately reduce prices. Conventional technologies need raw materials to be transported at the site, which not only increase the cost but also emit significant amount of $\mathrm{CO}_{2}$ gas during the transportation process.

(6) No external energy supply needed

The decomposition reaction requires energy. The energy requirement can be fulfilled by either using non-fossil energy sources (nuclear, hydro, solar or wind) or electricity produced by using combined gas and vapor power cycles. Thus, unlike other conventional technologies, the methods of the disclosure can reduce or even eliminate the need to purchase any electricity or source of electricity.

(7) No chemical pretreatment steps or no chemical waste The proposed reaction uses solids (magnetite and iron) as an adsorbent for $\mathrm{CO}_{2}$ gas. They do not require any chemical pretreatment process (unlike MEA) and can be used as mined. After, several cycles of carbonation and calcination process, the raw materials can be again fed back in the blast furnace to get fresh iron. Thus, the method can reduce or 
eliminate the loss of raw materials. Moreover, unlike other chemical scrubbing technologies, the proposed method will not produce any chemical wastes. 


\subsection{THE EFFECT OF ELEVATED PRESSURE, TEMPERATURE AND PARTICLES MORPHOLOGY ON THE CARBON DIOXIDE CAPTURE USING ZINC OXIDE}

\subsubsection{INTRODUCTION}

Several oxides have been extensively studied such as calcium oxide $(\mathrm{CaO})$ or magnesium oxide (MgO) [1-6], lithium metal oxides $\left(\mathrm{Li}_{2} \mathrm{ZrO}_{3}, \mathrm{Li}_{4} \mathrm{SO}_{4}\right)$ [7-9], hydrotalcites [10-17]. However, other oxides may also prove to be a good alternative such as, zinc oxide $(\mathrm{ZnO})$ that requires low regeneration energy and can have competitive $\mathrm{CO}_{2}$ capture capacity $[18,19]$. Nevertheless, $\mathrm{ZnO}$ as a material to capture $\mathrm{CO}_{2}$ has been sparsely studied probably due to its rare occurrence in nature.

\subsubsection{Industrial production methods of $\mathrm{ZnO}$}

Due to the porous structured networks and high internal surface area, porous $\mathrm{ZnO}$ nano/microstructures, have shown promising properties viable for potential applications in gas sensing, lithium-ion battery, selective adsorption, photoluminescence, photovoltaic, and photocatalytic properties [20]. This can be evidenced by a considerable increase in the number of scientific publications and patents addressing significant and interesting role of this material. At present, annual production of $\mathrm{ZnO}$ is about one and a half million tons [21] and mainly produced using pyrometallurgical methods (the indirect process [22], the direct process $[23,24]$, or spray pyrolysis $[25,26])$ or by hydrometallurgical methods [27]. Even though, it may be possible that the same amount of $\mathrm{ZnO}$ can be repeatedly used for several times as $\mathrm{CO}_{2}$ sorbent, the annual production of $\mathrm{ZnO}$ is not sufficient enough to capture global $\mathrm{CO}_{2}$ emission. However, it is expected that 
production of $\mathrm{ZnO}$ may increase in coming years. Thus, it is worth to investigate the role of $\mathrm{ZnO}$ as a $\mathrm{CO}_{2}$ capture material.

\subsubsection{2 $\mathrm{ZnO}-\mathrm{CO}_{2}$ reaction}

Few researcher groups studied the heterogeneous reaction between $\mathrm{ZnO}$ and $\mathrm{CO}_{2}$ in the presence or absence of $\mathrm{H}_{2} \mathrm{O}$ under mild conditions. Previous experiments were performed under mild conditions, mainly room temperature and $\mathrm{P}_{\mathrm{CO} 2}$ varied from 0.01 atmospheres to 1 atmosphere (atm) [28-30]. Basic zinc carbonate, with chemical formula $\mathrm{Zn}_{3} \mathrm{CO}_{3}$ $(\mathrm{OH})_{4} \cdot 2 \mathrm{H}_{2} \mathrm{O}$ was reported as a predominant phase at these conditions. However, a strong evidence to support $\mathrm{ZnO}$ as an alternate $\mathrm{CO}_{2}$ capture material is inhibited by the lack of experimental data in the range of elevated temperature $\left(\mathrm{T} \geq 25^{\circ} \mathrm{C}\right)$ and pressure $(>1$ bar). Moreover, the correlation between $\mathrm{ZnO}$ particle size and $\mathrm{CO}_{2}$ capture capacity is still unexplored.

Thus, here, several issues are investigated related to the carbonation process of $\mathrm{ZnO}$ powders. The carbonation reaction is examined at different set of pressure, temperature and time. The particle size of oxides plays a significant role for $\mathrm{CO}_{2}$ capture capacity [3134]. Thus, the effect of particle size, surface area and pore volume on $\mathrm{CO}_{2}$ capture capacity of $\mathrm{ZnO}$ is also examined.

\subsubsection{EXPERIMENTAL PROCEDURE}

\subsubsection{Reaction Study}

Both the formation and decomposition reaction of carbonate was studied experimentally. The carbonation reactions were performed in a closed system while the decomposition of carbonates was evaluated using Thermo gravimetric analysis (TGA). 
About $0.5 \mathrm{~g}$ of $\mathrm{ZnO}$ (delivered by Fluka) was put inside a sealed cylindrical vessel with $0.10 \mathrm{~mL}$ water sprinkled on the wall of vessel to create a slight humid environment for the reaction. Chemically pure carbon dioxide gas (delivered by Airgas) was passed into the system. Before experiments, $\mathrm{CO}_{2}$ gas was flushed three times to ensure a pure $\mathrm{CO}_{2}$ atmosphere inside the reactor. The reaction was performed for several minutes at a desired temperature and pressure condition. Once the reaction completed, the system was air-cooled. After that, the product was weighed. The gain in weight of carbonated samples indicates about the reaction of $\mathrm{CO}_{2}$ with $\mathrm{ZnO}$.

TGA 2950 Thermo gravimetric analyzer (delivered by TA instruments) was primarily used to identify the decomposition temperature of the product. The sample was heated under an inert atmosphere (argon flow rate $=100 \mathrm{ml} / \mathrm{min}$.), at a heating rate of $15^{\circ} \mathrm{C} / \mathrm{min}$ to a final temperature of $700^{\circ} \mathrm{C}$. The TGA provides continuous measurements of the sample weight as a function of time and temperature. The regeneration temperature of $\mathrm{ZnCO}_{3}$ was analyzed by heating the product sample to $700^{\circ} \mathrm{C}$ in an argon atmosphere.

\subsubsection{Mechanical milling}

The effect of $\mathrm{ZnO}$ particle sizes on reaction yield has been studied. A planetary Retsch PM100 ball milling machine was used to produce different particle sizes of $\mathrm{ZnO}$. The cylindrical ball milling container has an internal diameter and length of 1.6" each. The powder to ball weight ratio was $2 / 27$. $\mathrm{ZnO}$ powder particles were milled at a revolution speed of $300 \mathrm{rpm}$ for 1 and $2 \mathrm{~h}$. 


\subsubsection{Particles characterization}

X-ray powder diffraction method was used to characterize the product. Bruker GADDS/D8 is equipped with Apex Smart CCD Detector and direct-drive rotating anode. The MacSci rotating anode (Molybdenum) operates with a $50 \mathrm{kV}$ generator and $20 \mathrm{~mA}$ current. X-ray beam size can vary from 50 to $300 \mu \mathrm{m}$. The usual collection time is 1200 S.

The FTIR analyses were performed on powder sample using the IR spectrophotometer (Perkin Elmer Spectrum ${ }^{\mathrm{TM}}$ 100). Samples were measured using attenuated total reflection (ATR) on a single bounce diamond/ZnSe ATR crystal. The spectra were collected in the mid-IR range of 4000-600 $\mathrm{cm}^{-1}(2.5-25 \mu \mathrm{m})$.

An isothermal gas adsorption was used to quantify internal surface areas of the powder particles. Micromeritics Tristar II 3020 (surface area and porosimetry analyzer instrument) was used with $\mathrm{N}_{2}$ as adsorptive gas at $77 \mathrm{~K}$ (liquid nitrogen bath). The samples were first degassed under $200^{\circ} \mathrm{C}$ with a $\mathrm{N}_{2}$ gas flow for $2 \mathrm{~h}$ in order to remove the moisture and other adsorbed gases before analysis. The internal surface area was calculated using the Brunauer- Emmett-Teller (BET) method. The pore volume was also calculated from the adsorbed nitrogen after complete pore condensation $\left(\mathrm{P} / \mathrm{P}_{0}=0.9925\right)$ using the ratio of the densities of liquid and gaseous nitrogen. The pore size was calculated by using the Barrett-Joyner-Halenda (BJH) method.

Scanning electron microscope (SEM, JEOL JSM-6330F) was used to study the morphology of powder particles. Energy Dispersive Spectrometer (EDS) was also employed to provide chemical analysis of the powder particle. 


\subsubsection{Thermodynamics and Structural Properties}

\subsubsection{Thermodynamics of $\mathrm{ZnO}-\mathrm{CO}_{2}$}

The calculation of thermodynamic equilibrium temperature for $\mathrm{ZnO}$ carbonation process at different $\mathrm{P}_{\mathrm{CO} 2}$ is performed using the software FACTSAGE and the databases therein. Figure 4.6.1 illustrates the equilibrium temperature for $\mathrm{ZnO}-\mathrm{CO}_{2}$ reaction at different $\mathrm{P}_{\mathrm{CO} 2}$ (0.1-100 bars) in both the presence and absence of water. $\mathrm{ZnCO}_{3}$ decomposes back to $\mathrm{ZnO}$ above these equilibrium temperatures. It can be observed that the stability of $\mathrm{ZnCO}_{3}$ increases with $\mathrm{P}_{\mathrm{CO} 2}$. However, in the presence of water vapor, $\mathrm{ZnCO}_{3}$ decomposes back to $\mathrm{ZnO}$ at a relatively low temperature.

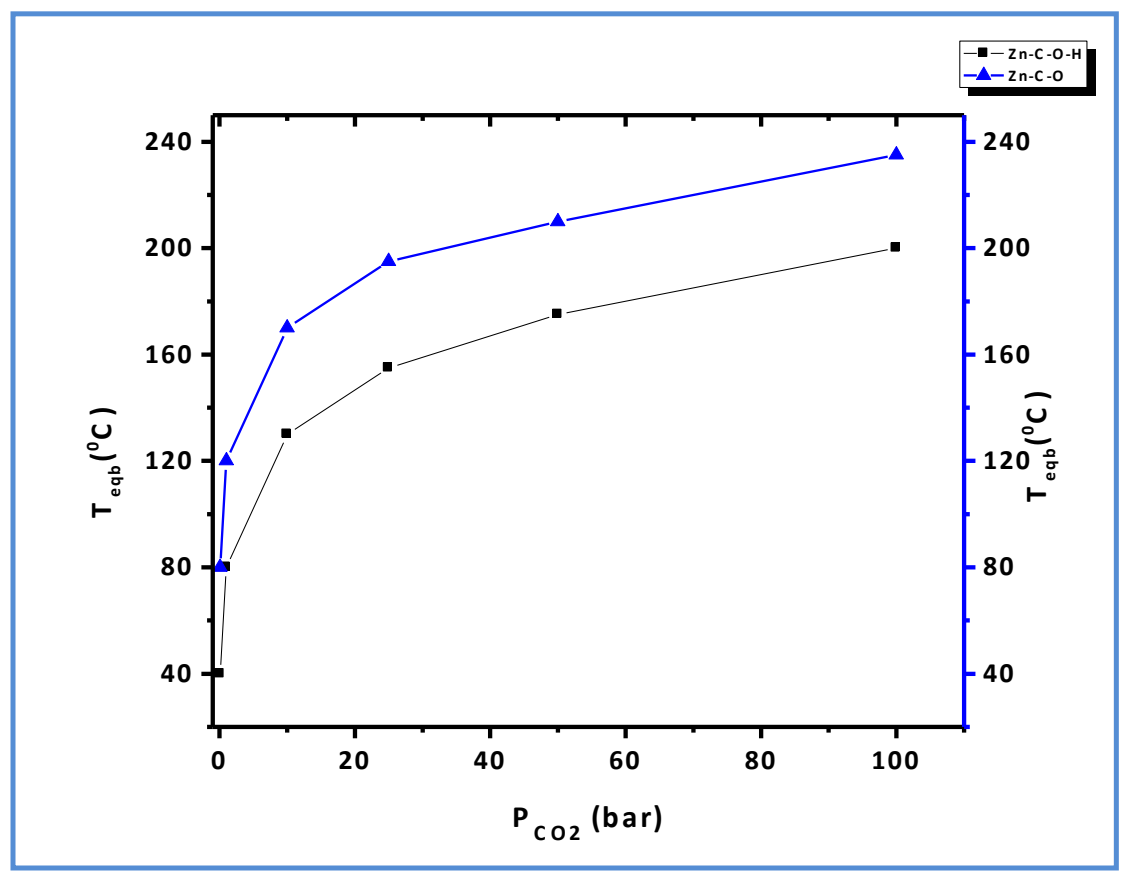

Figure 5.6.1 Equilibrium temperature for $\mathrm{ZnO}+\mathrm{CO}_{2} \rightarrow \mathrm{ZnCO}_{3}$ reaction at different $\mathrm{P}_{\mathrm{CO} 2}$ (0.1-100 bars) in the presence and absence of water 
The main components of post-combustion flue gas stream are $\mathrm{CO}_{2}, \mathrm{O}_{2}, \mathrm{H}_{2} \mathrm{O}$ and $\mathrm{N}_{2}$ and the partial pressure of $\mathrm{CO}_{2}$ is around $0.1-0.2$ bar, while the temperature varies from 27$77^{\circ} \mathrm{C}$. In Figure 5.6.1, at $\mathrm{P}_{\mathrm{CO} 2}=0.1$ bar, $\mathrm{ZnCO}_{3}$ becomes unstable and regenerates $\mathrm{ZnO}$ at 80 and $40^{\circ} \mathrm{C}$ in the absence and presence of water respectively. Hence, a hot flue gas stream $\left(\sim 40^{\circ} \mathrm{C}\right)$ may decompose $\mathrm{ZnCO}_{3}$ at $\mathrm{P}_{\mathrm{CO} 2}=0.1$ bar and can regenerate $\mathrm{ZnO}$. Thus, it can be easily deduced that cooling down the post-combustion gases prior to the carbonation process will be essential for high carbonation yield and thus may make $\mathrm{ZnO}$ unfit for post-combustion capture [35].

\subsubsection{Morphology and structural analysis}

Figure 5.6.2(i-iii) illustrates the SEM images of variously ball milled $\mathrm{ZnO}$ particles. Commercial $\mathrm{ZnO}$ particles are in tubular form and sizes are evenly distributed. The mechanical milling of $\mathrm{ZnO}$ changes the particle morphology from tubular to cubical. Interestingly, Figure 5.6.2(iv) shows the morphology of product after reaction at $75^{\circ} \mathrm{C}$ and 10 bars and the product looks similar to elongated leaf platelets. The dimension of these leaf platelets-like structures is about 0.074 micron wide and 0.35 micron long. The EDS analysis suggests that the leaf platelet is composed of $\mathrm{C}, \mathrm{O}$ and $\mathrm{Zn}$. Mechanical milling also changes the color of $\mathrm{ZnO}$ particles from white to deep yellow and it may be attributed to the thermochromic property of $\mathrm{ZnO}$ [36]. 


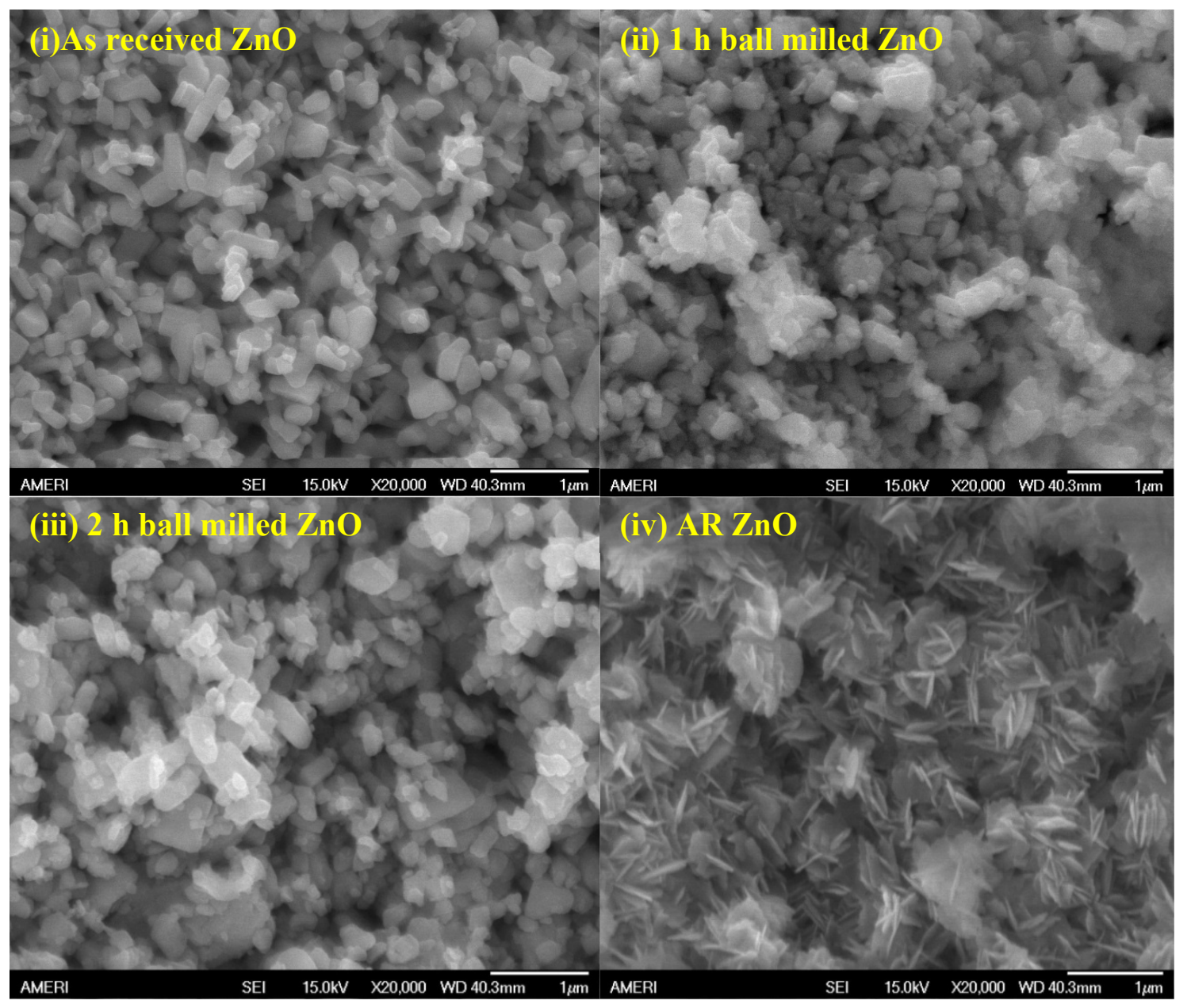

Figure 5.6.2 SEM image of (i) as received $\mathrm{ZnO}$ (ii) $1 \mathrm{~h}$ ball milled (iii) $2 \mathrm{~h}$ ball milled and (iv) $\mathrm{AR}$ (after reaction) $\mathrm{ZnO}$ at a magnification of $\mathrm{x} 20,000$ each 
$\mathrm{CO}_{2}$-uptake capacity of a metal oxide is primarily dominated by the factors, such as surface area, pore volume, pore functionality and pore size [37]. The morphology properties of milled and unmilled $\mathrm{ZnO}$ particles are given in Table 5.6.1. The $\mathrm{N}_{2}$ adsorption- desorption isotherm curves for variously milled $\mathrm{ZnO}$ obey Type IV isotherms (as per IUPAC classification); typical for mesoporous substances. Also, the hysteresis pattern is $\mathrm{H} 3$ (following IUPAC classification) indicating the presence of slit-like pores [38].

\begin{tabular}{|c|c|c|c|c|}
\hline $\mathrm{ZnO}$ & $\begin{array}{c}\text { Surface area } \\
\left(\mathrm{m}^{2} / \mathrm{g}\right)\end{array}$ & $\begin{array}{c}\text { Avg. Pore width } \\
(\AA)\end{array}$ & $\begin{array}{c}\text { Pore volume } \\
\left(\mathrm{cm}^{3} / \mathrm{g}\right)\end{array}$ & $\begin{array}{c}\text { Particle Size } \\
(\mu \mathrm{m})\end{array}$ \\
\hline As received & $5.56 \pm 0.06$ & 114.4 & 0.016 & $0.42 \pm 0.21$ \\
\hline 1 h ball milled & $7.50 \pm 0.04$ & 137.6 & 0.029 & $0.34 \pm 0.15$ \\
\hline 2 h ball milled & $7.23 \pm 0.04$ & 133.8 & 0.027 & $0.40 \pm 0.28$ \\
\hline
\end{tabular}

Table 5.6.1 Effect of ball milling on sorbent $(\mathrm{ZnO})$ properties

Mesoporous materials are defined to have pores with diameter between 2-50 $\mathrm{nm}$ and generally have high surface area. Here, pore size of commercially available $\mathrm{ZnO}$ resembles to that of mesoporous materials but has significantly low surface area $(5.56 \pm$ $0.06 \mathrm{~m}^{2} / \mathrm{g}$ ). Such a low surface area of mesoporous $\mathrm{ZnO}$ can be attributed to the high density of $\mathrm{ZnO}$ powders and also suggests that the material has no significant open porosity. However, mechanical milling slightly increased the surface area of $\mathrm{ZnO}$ particles.

The surface area of $1 \mathrm{~h}$ ball-milled $\mathrm{ZnO}$ particles is greater than that of $2 \mathrm{~h}$ milled sample followed by the as received $\mathrm{ZnO}$ particles [Table 5.6.1]. Here, the cubical $\mathrm{ZnO}$ particles 
obtained after $1 \mathrm{~h}$ of milling tend to agglomerate when further milled for $2 \mathrm{~h}$. All other structural properties such as average pore width, pore volume and average particle size of $\mathrm{ZnO}$ follow the same order (As received $<2 \mathrm{~h}$ ball milled $\mathrm{ZnO}<1 \mathrm{~h}$ ball milled $\mathrm{ZnO}$ ). $1 \mathrm{~h}$ being the smallest and therefore has the highest surface area $\left(7.50 \pm 0.04 \mathrm{~m}^{2} / \mathrm{g}\right)$. However, fine particles of $2 \mathrm{~h}$ ball milled $\mathrm{ZnO}$ tend to agglomerate and, as a result, surface area reduces to $(7.23 \pm 0.04) \mathrm{m}^{2} / \mathrm{g}$. Thus, it may be concluded that the fracture process dominates the initial ball-milling time (1h) and later, cold welding process taking place $[39,40]$.

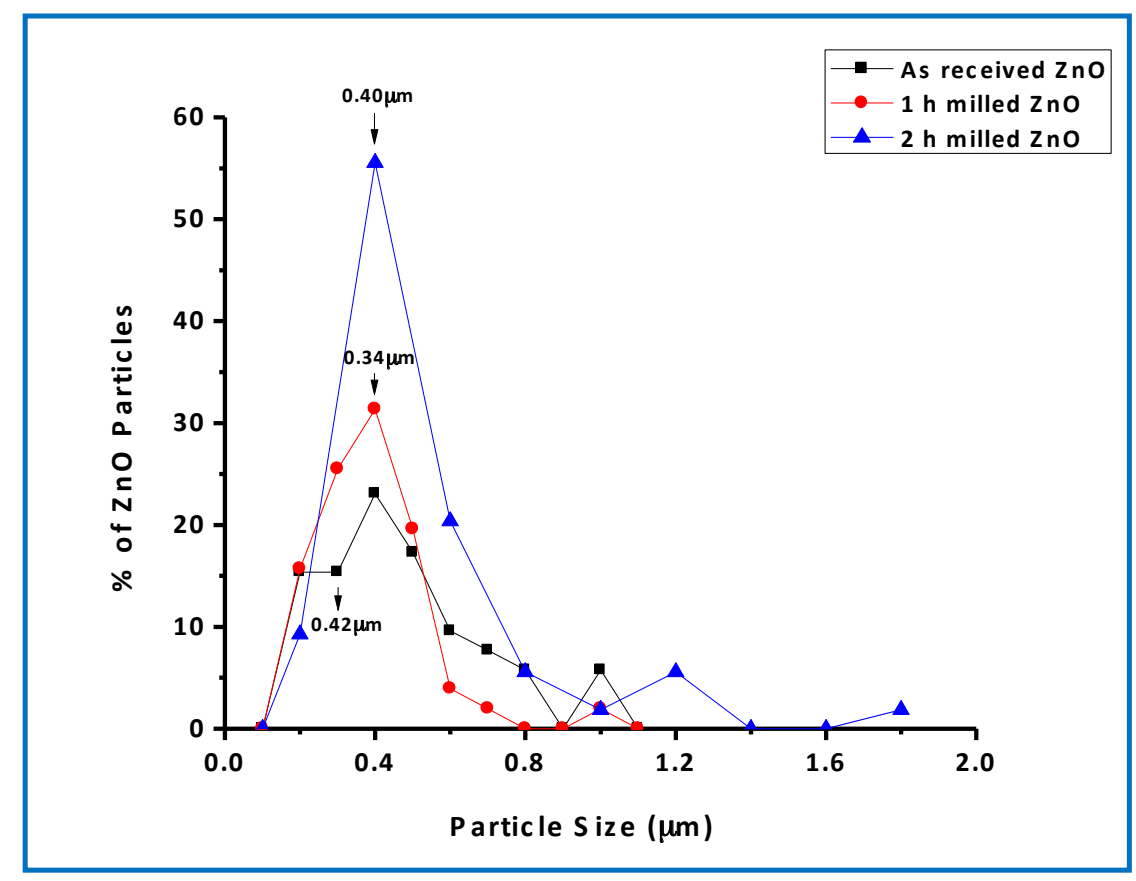

Figure 5.6.3 Particle size distribution plots for variously milled $\mathrm{ZnO}$

Fig.5.6.3 illustrates the particle size distribution of variously milled $\mathrm{ZnO}$ particles. Image $\mathrm{J}$ software was used to determine the average particle sizes of variously ball milled $\mathrm{ZnO}$ particles. A total of nearly $50 \mathrm{ZnO}$ particles were selected from 3 different SEM images to ensure a correct estimation of the average particle sizes. Commercially available $\mathrm{ZnO}$ 
has a broad particle size distribution whereas the particles of $\mathrm{ZnO}$ ball-milled for $1 \mathrm{~h}$ and $2 \mathrm{~h}$ have a narrow size distribution and most of the particles of the latter two lie in the vicinity of $0.40 \mu \mathrm{m}$.

\subsubsection{Reaction Results}

\subsubsection{Carbonation yield}

The kinetic study of the $\mathrm{ZnO}$ carbonation process is a crucial factor in the evaluation of the material for potential applications in $\mathrm{CO}_{2}$ capture. As mentioned earlier, the carbonation yield of $\mathrm{ZnO}$ is examined here at different set of temperature, pressure and time. First series of the experiments examined the effect of pressure $\left(\mathrm{P}_{\mathrm{CO} 2}=10\right.$ bars $)$ and temperature $\left(100^{\circ} \mathrm{C}\right)$ over commercially available $\mathrm{ZnO}$ at different times $(0.5-3 \mathrm{~h})$. Further, the effect of the particle size was explored for variously milled $\mathrm{ZnO}$ at $100^{\circ} \mathrm{C}$ and $\mathrm{P}_{\mathrm{CO} 2}=10$ bars. All the $\mathrm{CO}_{2}$ uptake capacity results at different conditions are plotted in Figure 6 and discussed in the following sections.

\subsubsection{X-ray Diffraction and FT-IR analysis}

Fig. 5.6.4(i) shows the formation of zinc carbonate hydroxide hydrate $\left(\mathrm{Zn}_{4}\left(\mathrm{CO}_{3}\right)(\mathrm{OH})_{6} \cdot \mathrm{H}_{2} \mathrm{O}\right)$ as indicated by the X-ray powder diffraction data. The product was identified conventionally by their corresponding Joint Committee Powder Diffraction Standard (JCPDS) file (\#11-0287). $\mathrm{CO}_{2}$ combines with $\mathrm{ZnO}$ in the presence of water as basic zinc carbonate over a wide range of temperature and pressure. The powder obtained after thermal analysis was examined using X-ray diffraction technique and the study revealed that the regeneration of ZnO (JCPDS\# 89-1397) [Figure 5.6.4 (ii)] occurred. The regeneration of $\mathrm{ZnO}$ supports the possibility of using sorbent for a large number of capture cycles. 

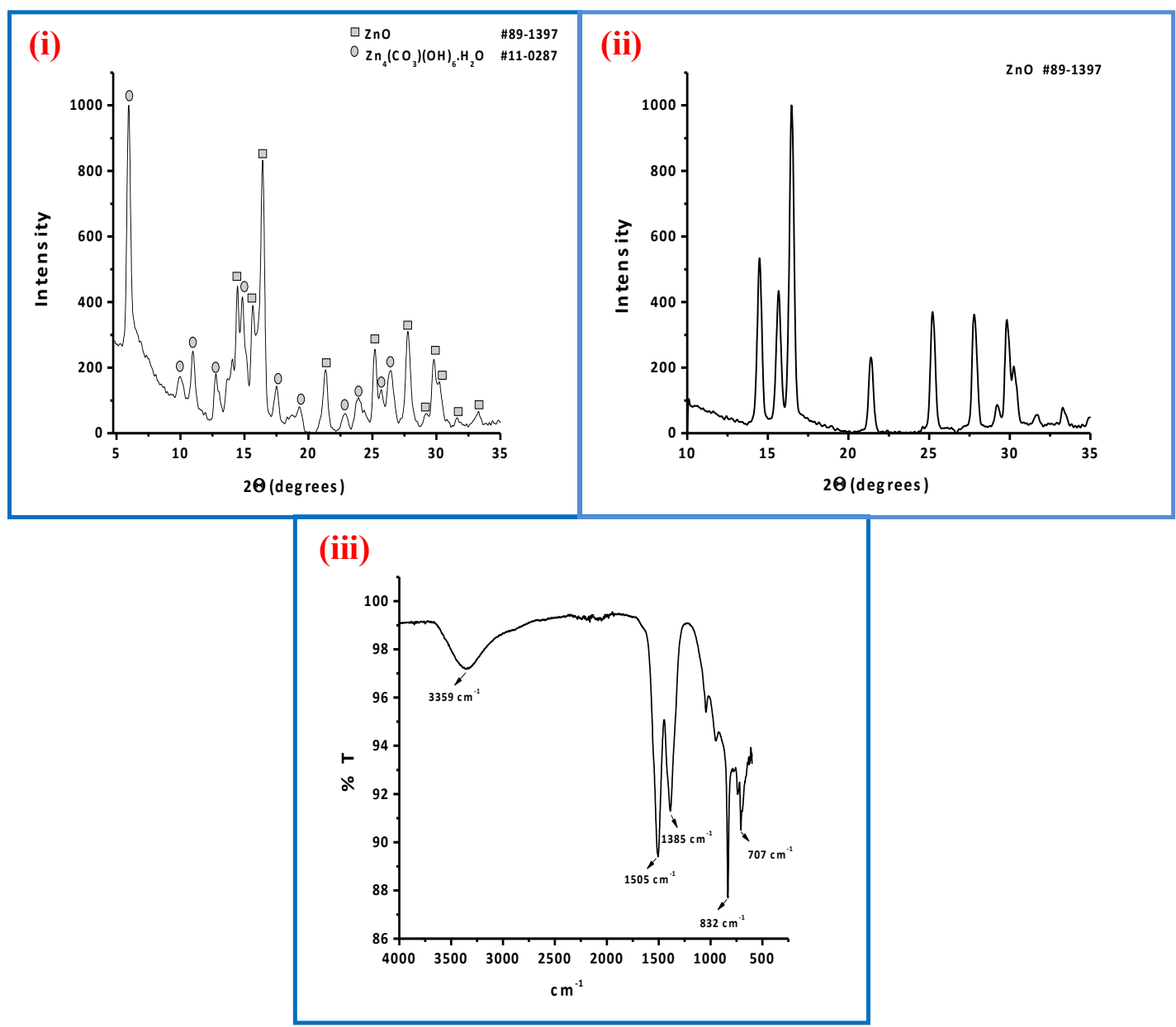

Figure 5.6.4 X-ray Diffraction patterns confirm the (i) product formation (JCPDS \# 110287) (ii) regeneration of $\mathrm{ZnO}$ (JCPDS \#89-1397) (iii) FTIR -spectra of the product in the mid IR range $\left(4000-400 \mathrm{~cm}^{-1}\right)$

The Fourier Transformed-Infrared (FT-IR) spectrum of the reaction product for experiment performed at $100^{\circ} \mathrm{C}, 10$ bars $\mathrm{CO}_{2}$ pressure and $3 \mathrm{~h}$ time is shown in Figure 5.6.4 (iii). The peaks near $707 \mathrm{~cm}^{-1}$ is due to the in-plane bending mode $(v 4)$ and is doubly degenerate for undistorted $\mathrm{CO}_{3}{ }^{2-}$ groups. The out-of-plane bending mode (v2) is observed 
around $882 \mathrm{~cm}^{-1}[41,42]$.The bicarbonate species were assigned at $1384 \mathrm{~cm}^{-1}(v 3$, O-C-O) and the stretching mode for bidentate carbonate species was found at $1606 \mathrm{~cm}^{-1}(\mathrm{v} 3$, O-CO)[43]. The peaks at $3380-3600 \mathrm{~cm}^{-1}$ indicate the presence of hydroxyl group and basic form of zinc carbonate [44].

\subsubsection{Thermal analysis}

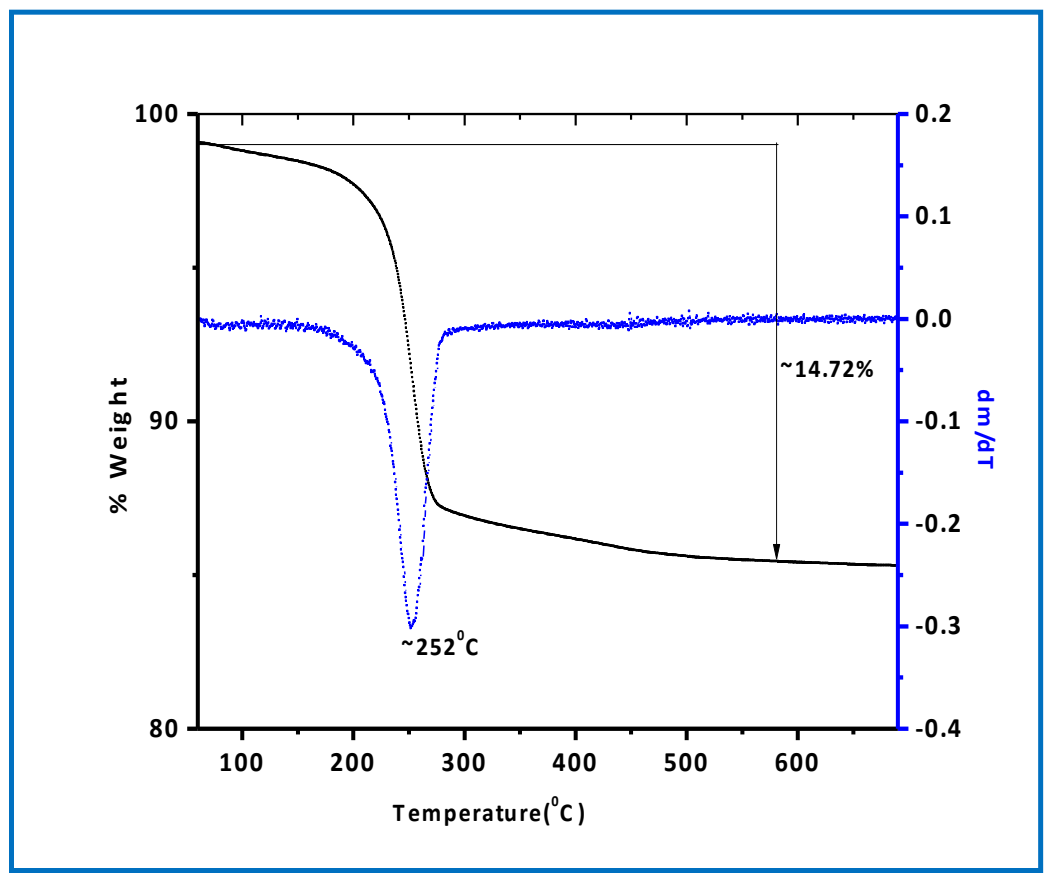

Figure 5.6.5 TG-DTG plot of thermal decomposition reaction of product; sample mass $10.0 \mathrm{mg}$, heating rate $10^{\circ} \mathrm{C} / \mathrm{min}$, and argon atmosphere

The thermodynamic calculation shows a low regeneration temperature for $\mathrm{ZnO}$. A low regeneration temperature causes low carbon emission or less energy penalty at any coalfired power plants. Here, the regeneration temperature of $\mathrm{ZnO}$ is experimentally determined using the thermogravimetry analysis method.TG-DTG plot for experiment performed at 10 bars $\mathrm{CO}_{2}$ pressure, $0.5 \mathrm{~h}$ and $75^{\circ} \mathrm{C}$ is shown in Fig. 5.6.5. Only one peak 
is recorded at $\sim 250^{\circ} \mathrm{C}$ for the combined evolution of water vapor and $\mathrm{CO}_{2}$. A weight loss of $14.72 \%$ is registered that translates to $0.068 \mathrm{~g} \mathrm{CO}_{2}$ capture using one gram of as received $\mathrm{ZnO}$.

\subsubsection{Discussion}

\subsubsection{Regeneration temperature}

Jianxun et al. synthesized the same compound, zinc carbonate hydroxide hydrate (JCPDS \#11-0287), using chemical precipitation method [41]. They too observed only one endothermic peak for zinc carbonate hydroxide hydrate and suggested that the evolution of both water vapor and $\mathrm{CO}_{2}$ occurs simultaneously. It was reported that heating rate of the sample does have an effect on the decomposition temperature [41]. The decomposition temperature was observed in the range of $197-257^{\circ} \mathrm{C}$ for various heating $\operatorname{rate}\left(5-20^{\circ} \mathrm{C} / \mathrm{min}\right)$. In the same line, a decomposition temperature of $\sim 250^{\circ} \mathrm{C}$ was found when we heated our product sample at a rate of $15^{\circ} \mathrm{C} / \mathrm{min}$ under argon flow of $100 \mathrm{~mL} / \mathrm{min}$.

$$
\mathrm{Zn}_{4}\left(\mathrm{CO}_{3}\right)(\mathrm{OH})_{6} \cdot \mathrm{H}_{2} \mathrm{O}(\mathrm{s}) \rightarrow 4 \mathrm{ZnO}(\mathrm{s})+\mathrm{CO}_{2}(\mathrm{~g}) \uparrow+4 \mathrm{H}_{2} \mathrm{O}(\mathrm{g}) \uparrow
$$

Recent work of Chen et al. reports the decomposition kinetics of precipitated $\mathrm{Zn}_{4} \mathrm{CO}_{3}$ $(\mathrm{OH})_{6} \cdot \mathrm{H}_{2} \mathrm{O}$ [45]. Based on the DTA results under different heating rates $\left(4-20^{\circ} \mathrm{C} / \mathrm{min}\right)$, they too suggested a single-step decomposition process with an activation energy of $113 \mathrm{~kJ} / \mathrm{mol}$. Kanari et al. carried out experiments to study the thermal decomposition of $\mathrm{Zn}_{4}\left(\mathrm{CO}_{3}\right)(\mathrm{OH})_{6} \cdot \mathrm{H}_{2} \mathrm{O}$ up to $400^{\circ} \mathrm{C}$. They observed simultaneous de-hydroxylation and decarboxylation of $\mathrm{Zn}_{4}\left(\mathrm{CO}_{3}\right)(\mathrm{OH})_{6} \cdot \mathrm{H}_{2} \mathrm{O}$ [46]. Thus, the present study is in well-agreement with previous reports which suggests a single-step decomposition of $\mathrm{Zn}_{4}\left(\mathrm{CO}_{3}\right)(\mathrm{OH})_{6} \cdot \mathrm{H}_{2} \mathrm{O}$ to $\mathrm{ZnO}$. 


\subsubsection{Effect of Pressure}

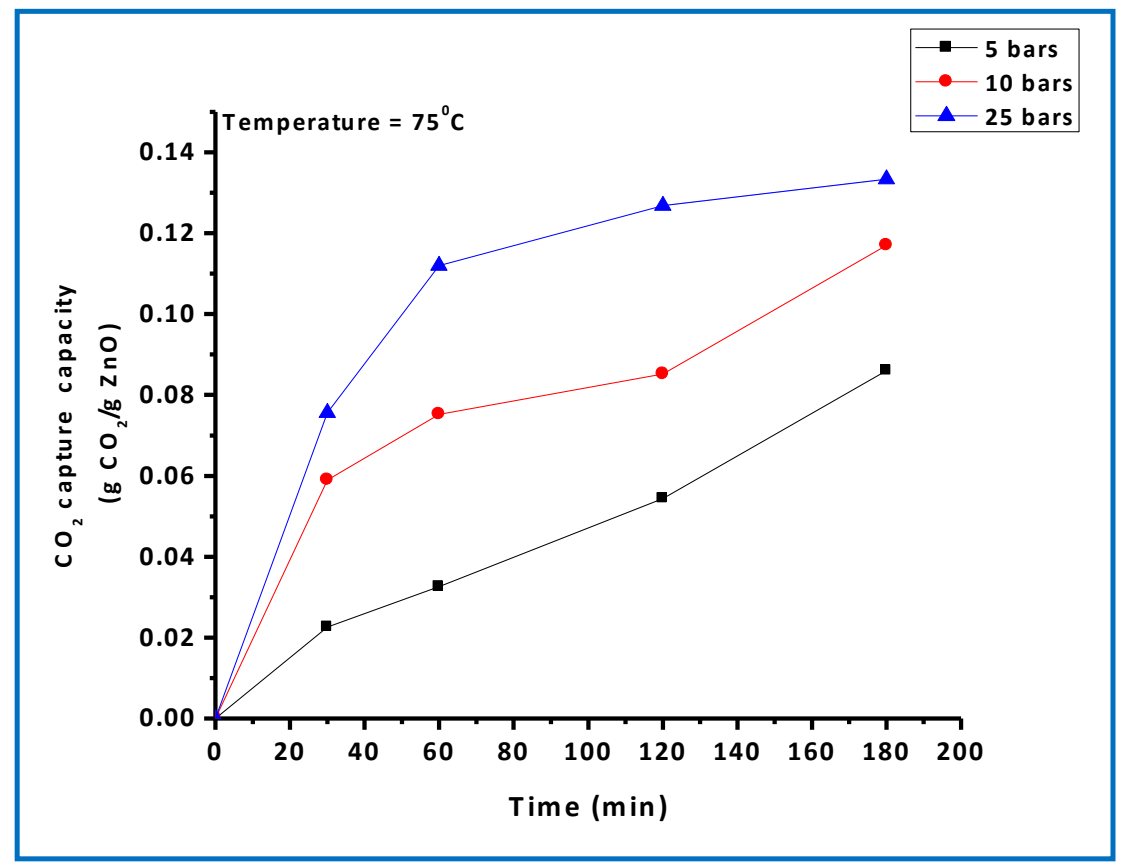

Figure 5.6.6 (i) Plot for capture capacity of $\mathrm{ZnO}$ at various pressure and time keeping constant temperature of $75^{\circ} \mathrm{C}$

It can be observed that the capture capacity increases with increase in pressure. As expected, faster sorption kinetics was observed for a high pressure condition. The noticed $\mathrm{CO}_{2}$ capture capacity for 25 bars pressure, $100^{\circ} \mathrm{C}$ and $3 \mathrm{~h}$ is $0.1334 \mathrm{~g} \mathrm{CO}_{2} / \mathrm{g} \mathrm{ZnO}$ However, when the pressure is decreased to 5 bars, $\mathrm{CO}_{2}$ capture capacity is reduced to $0.086 \mathrm{~g} \mathrm{CO}_{2} / \mathrm{g} \mathrm{ZnO}$.

A porous solid has interconnected pathways where gas molecules may collide with each other or with the pore walls. When the gas pressure is high, intermolecular collisions of $\mathrm{CO}_{2}$ dominate and hence $\mathrm{CO}_{2}$ molecules intrude through each available pores of $\mathrm{ZnO}$. However, at low pressure, collisions between the $\mathrm{CO}_{2}$ molecule and pore walls are dominant and the free path is restricted with the geometry of void space [37]. Thus, it is apparent that at low pressure, there is relatively less binding of $\mathrm{CO}_{2}$ over $\mathrm{ZnO}$ particles. 


\subsubsection{Effect of Temperature}

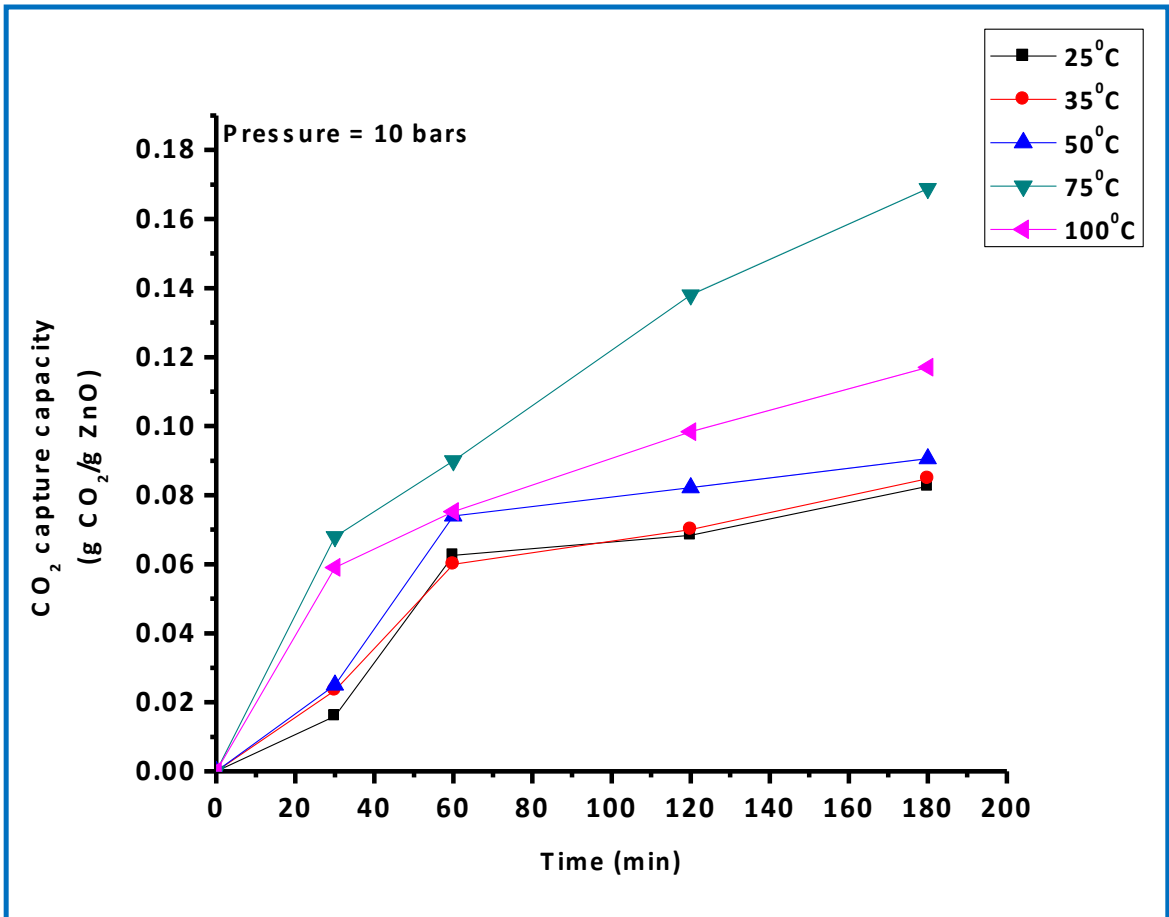

Figure 5.6.6 (ii) $\mathrm{CO}_{2}$ capture capacity variation with temperature at pressure of 10 bars The $\mathrm{CO}_{2}$ uptake increases with temperature and attain a maximum at $75^{\circ} \mathrm{C}$ for $\mathrm{P}_{\mathrm{CO} 2}=$ 10bars. The exothermic sorption of $\mathrm{CO}_{2}$ over $\mathrm{ZnO}$ is highly controlled by the kinetic diffusion rather than the thermodynamic factor. At high temperature, more $\mathrm{CO}_{2}$ diffuses to the pores and the present large active sites hold these $\mathrm{CO}_{2}$ molecules. Hence, these trapped $\mathrm{CO}_{2}$ molecules further react with $\mathrm{ZnO}$ particles to form $\mathrm{ZnCO}_{3}$. As evidenced by the experimental results, increase in temperature favors $\mathrm{CO}_{2}$ capture capacity of $\mathrm{ZnO}$. However, a decrease in conversion of $\mathrm{ZnO}$ to carbonates at $100^{\circ} \mathrm{C}$ reflects the increasing dominance of reverse reaction at a pressure of 10 bars. Thus, the experimental results validate the thermodynamic calculation using FACTSAGE software. 


\subsubsection{Effect of particle size}

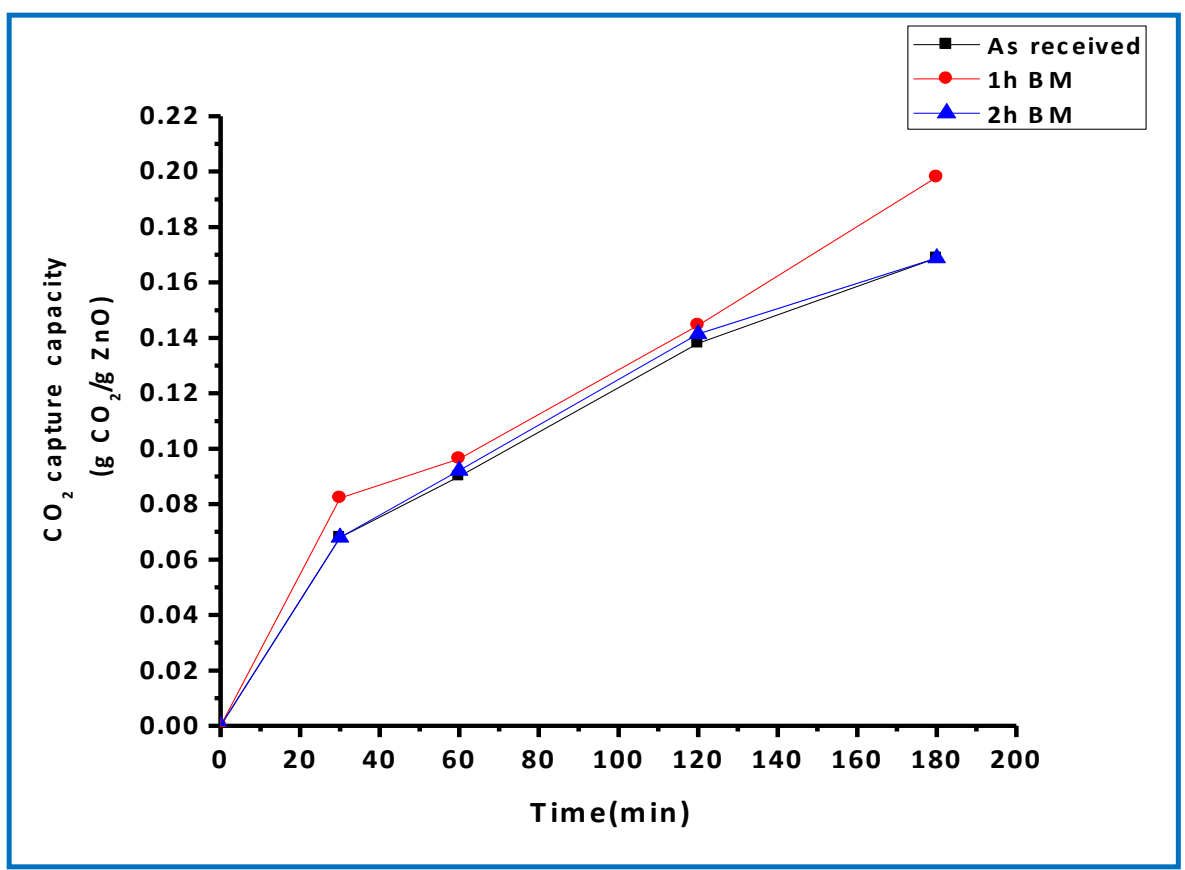

Figure 5.6.6 (iii) Effect of particle size on capture capacity of $\mathrm{ZnO}$

The effect of particle size was studied at experimental condition of $75^{\circ} \mathrm{C}$ and 10 bars $\mathrm{CO}_{2}$ pressure. The smallest average particle size for $1 \mathrm{~h}$ ball milled $\mathrm{ZnO}(0.34 \mu \mathrm{m})$ demonstrates the highest $\mathrm{CO}_{2}$ capture capacity. However, prolonged milling time (2h) has increased average particle size due to the agglomerated particles and as a result, capture capacity of $\mathrm{ZnO}$ was also decreased. $1 \mathrm{~h}$ ball milled $\mathrm{ZnO}$ exhibits highest capture capacity of $0.198 \mathrm{CO}_{2} / \mathrm{g} \mathrm{ZnO}$ for $3 \mathrm{~h}$ time. It is attributed to the relatively high surface area or pore volume compared to that of as received and $2 \mathrm{~h}$ ball milled $\mathrm{ZnO}$. During mechanical milling, intensive deformations of particle may occur which lead to various crystal defects such as lattice strains, vacancies, dislocations and morphological changes [47-50]. All these structural modifications expose more active sites of $\mathrm{ZnO}$ for $\mathrm{CO}_{2}$. Hence, the absorption capacity of $\mathrm{CO}_{2}$ over $\mathrm{ZnO}$ correlates with the surface area or pore volume of $\mathrm{ZnO}$. 


\subsubsection{Effect of moisture}

Moisture is present in the flue gas streams. The presence of moisture plays a vital role because a slight humid environment plays a promoting effect on the sorption of $\mathrm{CO}_{2}$ and thus affects the materials reactivity and capacity. Several reports evidence the significant role of steam in increasing BET surface area and porosity of the sorbent [51-55]. It should be noted that no formation of basic zinc carbonate was observed in the absence of moisture due to kinetic limitations. However, it is observed that moisture have an effect on the stability of $\mathrm{ZnCO}_{3}$ and thus control the uptake of $\mathrm{CO}_{2}$ by $\mathrm{ZnO}$. This is also because $\mathrm{H}_{2} \mathrm{O}$ tends to compete for the reaction sites with $\mathrm{CO}_{2}$ and thus causing decrease in sorption capacity.

The key variables to understand the performance of $\mathrm{ZnO}$ as a $\mathrm{CO}_{2}$ absorber such as surface area, particle size and pore volume were examined, as influenced by broad temperature and pressure range. According to the aforementioned results, zinc carbonate hydroxyl hydrate formed as a $\mathrm{ZnO}$ carbonation process product. The decomposition of carbonation product to $\mathrm{ZnO}$ occurs in a single-step with simultaneous de-hydroxylation and de-carboxylation at $\sim 250^{\circ} \mathrm{C}$. Experiments have demonstrated that $\mathrm{ZnO}$ carbonation can be effective at temperatures around $75^{\circ} \mathrm{C}$. Although $\mathrm{ZnO}$ has favorable thermodynamics, the commercial use of $\mathrm{ZnO}$ as a $\mathrm{CO}_{2}$ absorber have severe limitations such as high $\mathrm{ZnO}$ cost and slow carbonation kinetics. 


\subsubsection{REFERENCES:}

1. M.K. Aroua, W.M.A.W. Daud, C.Y. Yin, D. Adinata, Separation and Purification Technology, 2008, 62, 609-614.

2. H. Gupta, L.S. Fan, Industrial \& Engineering Chemistry Research, 2002, 41, 40354042 .

3. M.B. Jensen, L.G.M. Petterson, O. Swang, U. Olsbye, The Journal of Physical Chemistry B, 2005, 109, 16774-16781.

4. F. Teng, W. Qu, G. Wen, Z. Wang, Z. Tian, X. Yang, P. Xu, Y. Zhu, G. Xiong, Microporous Mesoporous Materials, 2008, 111, 620-626.

5. S. Teir, R. Kuusik, C.J. Fogelholm, R. Zevenhoven, International Journal of Mineral Processing, 2007, 85, 1-15.

6. T. Kojima, A. Nagamine, N. Ueno, S. Uemiya, Energy and Conservation Management , 1997, 38 Suppl., S461-S466.

7. W. D. Gunter, E. H. Perkins, T. J. McCann, Energy Conversion and Management, 1993, 34, 941-948.

8. M. Kato, K. Nakagawa, K. Essaki, Y. Maezawa, S. Takeda, R. Kogo, Y. Hagiwara, International Journal of Applied Ceramic Technology, 2005, 2, 467-475.

9. E.O. Fernández, H.K. Rusten, H.A. Jakobsen, M. Rønning, A. Holmen, D. Chen, Catalysis Today, 2005, 106, 41-46.

10. M.J. Venegas, E.F. Israel, R. Escamilla, H. Pfeiffer, Industrial \& Engineering Chemistry Research, 2007, 46, 2407-2412.

11. Y. Ding, E. Alpay, Transactions of Institute of Chemical Engineers, 2001, 79(B), 4551.

12. Y. Ding, E. Alpay, Chemical Engineering Science, 2000, 55, 3461-3474.

13. X.P. Wang, J.J. Yu, J. Cheng, Z.P. Hao, Environmental Science \& Technology, 2008, 42, 614-618.

14. M.R. Othman, Z. Helwani, W.J.N. Martunus, Fernando, Applied Organometallic Chemistry, 2009, 23, 335-346.

15. N.D. Huston, B.C. Attwood, Adsorption, 2008, 14, 781-789.

16. K.B. Lee, A. Verdooren, H.S. Caram, S. Sircar, Journal of Colloid and Interface Science, 2007, 308, 30-39. 
17. E.L.G. Oliviera, C.A. Grande, A.E. Rodrigues, Separation and Purification Technology, 2008, 62, 137-147.

18. H.T. Reijers, S.E.A.Valster-Schiermeir, P.D. Cobden, R.W. van den Brink, Industrial \& Engineering Chemistry Research, 2006, 45, 2522-2530.

19. B. Feng, H. An, E. Tan, Energy \& Fuels, 2007, 21, 426-434.

20. X. Wang, W. Liu, J. Liu, F. Wang, J. Kong, S. Qiu, C. He,L. Luan, Applied Materials \& Interfaces, 2012, 4, 817-825.

21. International Zinc Association-Zinc Oxide Information Center, [cited5/08/2011], Available from: http://www.znoxide.org/index.html

22. S. Mahmud, M.J. Abdullah, G. Putrus, J. Chong, A.K. Mohamad, Synth. React. Inorganic and Metal-Organic Chemistry, 2006, 36, 155-159.

23. S. Wetherill, U.S. Patent 0013806, 1855

24. S. Wetherill, U.S. Patent 0012418,1855

25. S. Turner, S. Tavernier, G. Huyberechts, E. Biermans, S. Bals, K. Batenburg, G. Van Tendeloo, Journal of Nanoparticle Research, 2009, 12, 615-622.

26. X. Zhao, B. Zheng, C. Li, H. Gu, Powder Technology, 1998, 100, 20-23.

27. F. Habashi, Canadian Institute of Mining Bulletin, 2001, 94, 71-76.

28. N. Ohkuma, Y. Funayama, H. Ito, N. Mizutani, M. Kato , Nihon kagaku kaishi, 1987, 802.

29. J. Galvez, R. Arana, University of Murcia Science, 1979, 38, 153

30. N. Ohkuma, Y. Funayama, H. Ito, N. Mizutani, M. Kato, Hyomen kagaku, 1988, 5, 452.

31. Y. Swada, M. Murakami, T. Nishide, Thermochimica Acta, 1996, 273, 95-102.

32. G. Qi, Y. Wang, L. Estevez, X. Duan, N. Anako, A.H.A. Park, W. Li, C.W. Jones, E.P. Giannelis, Energy \& Environmental Science, 2011, 4, 444-452.

33. F. Fang, Z.S. Li, N.S. Cai, Korean Journal of Chemical Engineering, 2009, 26, 14141421.

34. B. Zhang, Y. Duan, K. Johnson, Journal of Chemical Physics, 2012, 136, 064516.

35. E. Wiberg, A. F. Holleman, Inorganic Chemistry 2001, Elsevier 
36. W. Lu, D. Yuan, J. Sculley, D. Zhao, R. Krishna, H.C. Zhou, Journal of American Chemical Society, 2011, 133, 18126-18129.

37. J. B. Condon, Surface area and porosity determinations by physisorption: measurements and theory, 2006, Elsevier.

38. J.B. Zhou, K.P. Rao, Journal of Alloys and Compounds, 2004, 384, 125-130.

39. X. Zhao, Y. Ding, L. Ma, X. Shen, S. Xu, International Journal of Hydrogen Energy, 2008, 33, 6351-6356.

40. J. Chen, R. Zhao, H. Jiang, Transactions of Nonferrous Metals Society, 1988, 8, 149153.

41. C. Suryanarayan, Progress in Materials Science, 2001, 46, 1-184.

42. Z. Xianxi, W. Xiaojuan, Z. Guanjie, J. Jianzhuang, Chinese Journal of Inorganic Chemistry, 2002, 18, 1038-1040.

43. H. Yongning, S. Xiaoliang, M. Lidun, Chinese Journal of Applied Chemistry, 1996, $13,92-94$.

44. M. Shamsipur, S.M. Pourmortazavi, S.S. Hajimirsadeghi, M.M. Zahedi, M. RahimiNasrabadi, Ceramics International In press.

45. J. Chen, R. Zhao, H. Jiang, Y. Li, G. Bao, Transactions of Nonferrous Metals Society, 1998, 8, 149

46. N. Kanari, D. Mishra, I. Gaballah, B. Dupré, Thermochimica Acta, 2004, 410, 93-100

47. D. Stoilova, V. Koleva, V. Vassileva, Spectrochimica Acta Part A, 2002, 58, 20512059.

48. C.C. Koch, Nanostructured Materials, 1997, 9, 13-22.

49. L.Z. Zhou, J.T. Guo, T.D. Jiang, S.H. Wang, Journal of Materials Science Letters, 1998, 17,137-139.

50. G. Liang, J. Huot, R. Schulz, Journal of Alloys and Compounds, 2001, 320, 133-139.

51. S. Dobner, L. Sterns, R.A. Gralf, A.M. Squires, Industrial \& Engineering Chemistry, 1977, 16, 479-486.

52. R.W. Hughes, D. Lu, E.J. Anthony,Y. Wu, Industrial \& Engineering Chemistry Research, 2004, 43, 5529-5539. 
53. K. Laursen, W. Duo, J.R. Grace, C.J. Lim, Industrial \& Engineering Chemistry Research, 2004, 43, 5715-5520

54. A. Hassanzadeh, J. Abbasian, Fuel, 2010, 89, 1287-1297.

55. V. Manovic, E.J. Anthony, Industrial \& Engineering Chemistry Research, 2010, 49, 9105-9110. 


\subsection{HIGH PRESSURE AND HIGH TEMPERATURE STUDY FOR THE MIXTURE OF $\mathrm{MgH}_{2}$ AND Si USING MULTI ANVIL PRESS}

\subsubsection{INTRODUCTION}

Magnesium, a light metal, gained lot of attention owing to its large gravimetric density, 7.68 wt. \%. Magnesium and its alloys are potential materials for hydrogen storage. The $\mathrm{MgH}_{2}$ system is limited by poor thermodynamics $\left(\Delta \mathrm{H}_{\text {desorption }}=74.06 \mathrm{~kJ} / \mathrm{mol}, \Delta \mathrm{S}_{\text {desorption }}\right.$ $\left.=133.4 \mathrm{~kJ} / \mathrm{mol} \mathrm{H}_{2} / \mathrm{K}\right)[1]$. The high decomposition temperature $\left(>325^{\circ} \mathrm{C}\right)$, slow dehydrogenation kinetics and low diffusion rate in $\mathrm{MgH}_{2}$ have prevented pure $\mathrm{Mg}$ from being a viable storage material. Hence, it is desired to identify the best additive for destabilizing $\mathrm{MgH}_{2}$. The literature suggests that the equilibrium pressure of $\mathrm{MgH}_{2}$ at $275^{\circ} \mathrm{C}$ is about $1 \mathrm{bar}$, and the equilibrium pressure for a mixture of $\mathrm{MgH}_{2}$ and $\mathrm{Si}$ is about 100 bar at $150^{\circ} \mathrm{C}[2,3]$.

$$
\mathrm{MgH}_{2}+\mathrm{Si} \rightarrow \mathrm{Mg}_{2} \mathrm{Si}
$$

Moreover, the thermodynamics of $\mathrm{MgH}_{2} / \mathrm{Si}$ system is more improved than the pure $\mathrm{MgH}_{2}$, where thermodynamic predictions show $\Delta \mathrm{H}=36.8 \mathrm{~kJ} / \mathrm{mol} \mathrm{H}_{2}$ and $\Delta \mathrm{S}=128.1$ $\mathrm{kJ} / \mathrm{mol} \mathrm{H}_{2} / \mathrm{K}$ at $25^{\circ} \mathrm{C}$ [4]. Thus, the findings show that the mixture of $\mathrm{MgH}_{2}$ and $\mathrm{Si}$ (hydrogen capacity of $5 \mathrm{wt}$ \%) could be applicable for hydrogen storage at low temperatures. Consequently, $\mathrm{MgH}_{2} / \mathrm{Si}$ system has been investigated several times. However, some contradictory results such as Guintel et al. $\left(\mathrm{Mg}_{2} \mathrm{Si}\right.$ reaches a hydrogen absorption capacity of $2 \mathrm{wt} \%$ after $10 \mathrm{~h}$ at $300^{\circ} \mathrm{C}$ ) and Janot et al. (no significant hydrogen absorption detected for $\mathrm{Mg}_{2} \mathrm{Si}$ phases under hydrogen pressures up to 100 bars and $300^{\circ} \mathrm{C}$ ) were reported in recent times $[5,6]$. Overall, it is widely accepted that the 
$\mathrm{MgH}_{2} / \mathrm{Si}$ system is not readily reversible and the hydrogenation of the $\mathrm{Mg}_{2} \mathrm{Si}$ appears to be kinetically hindered.

\begin{tabular}{|c|c|c|c|c|c|c|c|}
\hline System & $\begin{array}{l}\text { Reaction } \\
\text { studied }\end{array}$ & $\begin{array}{c}\mathrm{T} \\
\left({ }^{\circ} \mathrm{C}\right)\end{array}$ & $\begin{array}{c}\mathrm{P} \\
\text { (bar) }\end{array}$ & $\begin{array}{l}\text { Time } \\
\text { (h) }\end{array}$ & $\begin{array}{c}\text { Crystallite } \\
\text { size } \\
(\mathrm{nm}) \\
\end{array}$ & Remarks & Ref \\
\hline $\mathrm{Mg}_{2} \mathrm{Si}$ & absorption & $\begin{array}{c}250- \\
290\end{array}$ & $\begin{array}{c}1750- \\
1800 \\
\mathrm{H}_{2}\end{array}$ & 48 & $11.9 \pm 0.1$ & $\begin{array}{l}\text { (i) } \mathrm{No}_{2} \text { absorption } \\
\text { (ii) slow kinetics for } \\
\mathrm{H}_{2} \text { desorption } \\
\text { (significant only at } \\
250^{\circ} \mathrm{C} \text { ) }\end{array}$ & {$[7]$} \\
\hline $\begin{array}{c}\mathrm{MgH}_{2} \\
+\mathrm{Si}\end{array}$ & - & 600 & $\begin{array}{c}0.5,3.8 \\
\mathrm{GPa}\end{array}$ & - & - & $\begin{array}{c}\text { (i) at } 0.5 \mathrm{Gpa}, \\
\text { formation of } \mathrm{Mg}_{2} \mathrm{Si} \\
\text { alloy } \\
\text { (ii) at } 3.8 \mathrm{Gpa}, \mathrm{MgH}_{2} \\
\text { dissociates to } \mathrm{Mg} \\
\text { and } \mathrm{H}_{2}\end{array}$ & {$[8]$} \\
\hline $\begin{array}{c}\mathrm{MgH}_{2} \\
+\mathrm{Si}\end{array}$ & desorption & $\begin{array}{c}250- \\
300\end{array}$ & - & 3 & $<50$ & $\begin{array}{c}\text { activation energy : } \\
\text { milled }(163 \mathrm{~kJ} / \mathrm{mol})< \\
\text { unmilled } \\
(213 \mathrm{~kJ} / \mathrm{mol})\end{array}$ & [9] \\
\hline $\mathrm{Mg}_{2} \mathrm{Si}$ & absorption & 300 & 95 & - & - & $\mathrm{No}_{2}$ absorption & [10] \\
\hline $\mathrm{Mg}_{2} \mathrm{Si}$ & absorption & - & 20 & 48 & - & $\mathrm{MgH}_{2}+\mathrm{Si}$ formation & {$[6]$} \\
\hline $\begin{array}{l}\mathrm{Pd} / \mathrm{Mg} \\
/ \mathrm{Mg}_{2} \mathrm{Si}\end{array}$ & absorption & $\begin{array}{c}240- \\
70\end{array}$ & 200 & $\sim 142$ & $\begin{array}{l}\text { Several } \\
\mathrm{nm} \text { films }\end{array}$ & $\begin{array}{c}\text { severe limitations of } \\
\text { kinetics for } \\
\text { hydrogenation }\end{array}$ & [11] \\
\hline
\end{tabular}

Table 6.1 Literature survey for (de-) hydrogenation of $\mathrm{MgH}_{2} / \mathrm{Si}$ System

Table 6.1 illustrates the experimental findings to date for $\mathrm{MgH}_{2} / \mathrm{Si}$ system. An interesting set of experiments have been performed on $\mathrm{Mg}$ and $\mathrm{Mg}_{2} \mathrm{Si}$ thin films. The hydrogenation was attempted in presence and absence of $\mathrm{Pd}$ catalysts under 200 bars $\mathrm{H}_{2}$ from $240^{\circ} \mathrm{C}$ to $70^{\circ} \mathrm{C}$. Kelly et al. observed that hydrogen migrated through $\mathrm{Mg}_{2} \mathrm{Si}$ and pure $\mathrm{Mg}$ embedded within the $\mathrm{Mg}_{2} \mathrm{Si}$ layer readily formed $\mathrm{MgH}_{2}$ even at $165^{\circ} \mathrm{C}$ (contrary to thermodynamics) [11]. Thus, the result shows that the hydrogen absorption into $\mathrm{Mg}_{2} \mathrm{Si}$ is 
limited by the mass transport rate of both $\mathrm{Mg}$ and $\mathrm{Si}$. The conclusion was made that the hydrogen absorption into $\mathrm{Mg}_{2} \mathrm{Si}$ system would need particles in the range of few $\mathrm{nm}$ sizes to allow for an adequate phase migration rate.

Given the kinetic and diffusion limitations with the $\mathrm{MgH}_{2} / \mathrm{Si}$ system, this work aims to study the high pressure and high temperature of the system using multi anvil apparatus. Moreover, $\mathrm{MgH}_{2} / \mathrm{Si}$ system was also ball milled under hydrogen pressure.

\subsubsection{EXPERIMENTAL SECTION}

A 3:1 molar ratio of $\mathrm{MgH}_{2}$ and $\mathrm{Si}$ was used and sealed in a brass capsule. The brass capsule was put as in 14/8 G2 assembly and compressed to the desired pressure using Multi anvil press. Once the pressure was attained, temperature was increased and set for specific duration. For the next experiment, a planetary Retsch PM 100 ball was employed to ball mill the $\mathrm{MgH}_{2} / \mathrm{Si}$ mixture under hydrogen pressure for several hours at $300 \mathrm{rpm}$.

\subsubsection{RESULTS AND DISCUSSION}

The molar mixture of $\mathrm{MgH}_{2}$ and $\mathrm{Si}$ (3:1) was compressed to 4GPa. At 4GPa, the temperature was first maintained to $500^{\circ} \mathrm{C}$ for $2 \mathrm{~h}$ and then the temperature was lowered to $150^{\circ} \mathrm{C}$ and kept constant for $12 \mathrm{~h}$. At this condition, a structural phase transition of $\mathrm{MgH}_{2}$ was observed. $\alpha-\mathrm{MgH}_{2}$ transformed to $\gamma-\mathrm{MgH}_{2}$. These two phases coexist in this temperature and pressure range [12]. X-ray diffraction pattern and Raman Spectroscopy were used to confirm the product formation (Fig. 6.1). 

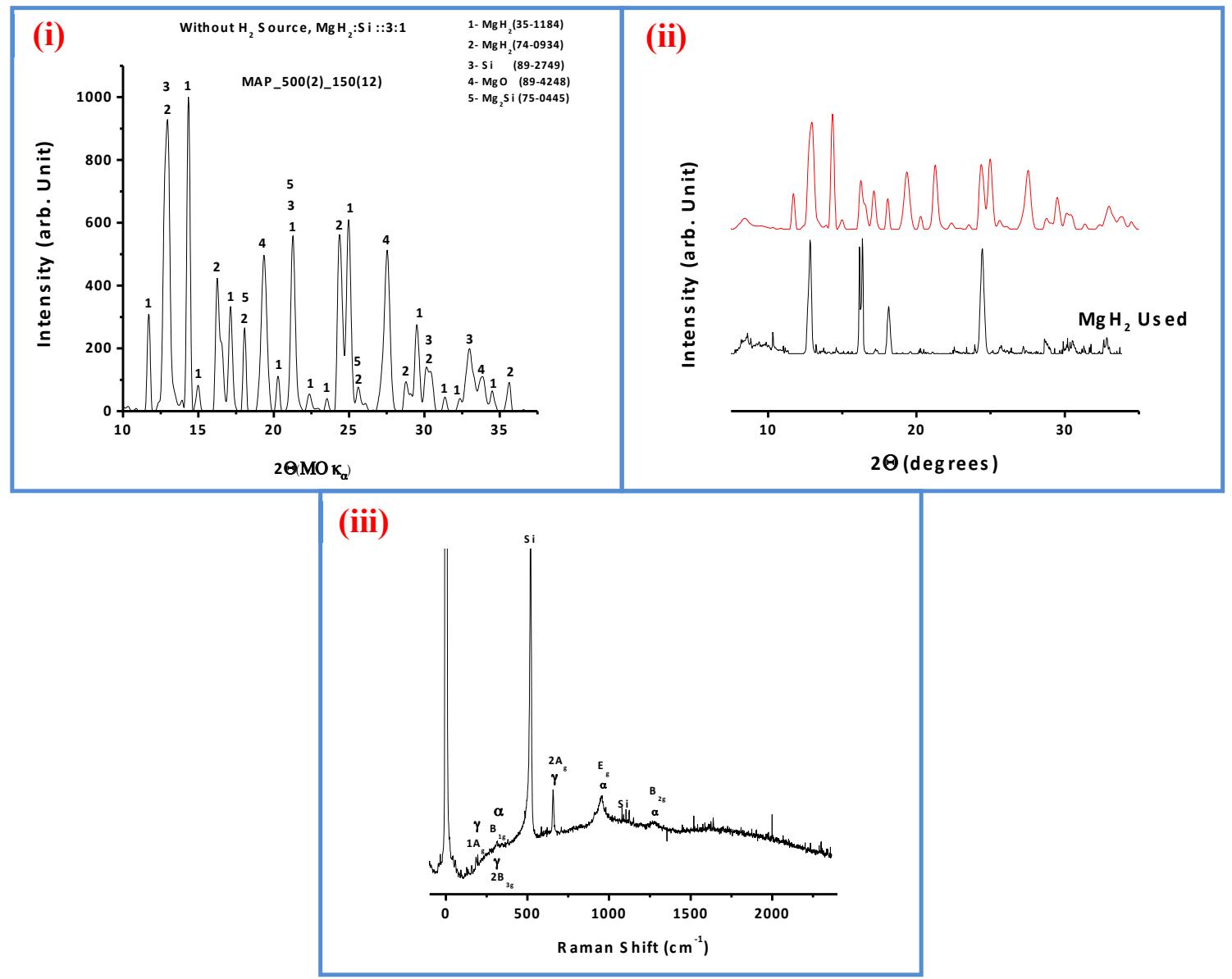

Figure 6.1 (i) X-ray diffraction of the product after compression to $4 \mathrm{GPa}$ at $500^{\circ} \mathrm{C}$ for $2 \mathrm{~h}$ and $150^{\circ} \mathrm{C}$ for $12 \mathrm{~h}$ (ii) X-ray diffraction of $\mathrm{MgH}_{2}$ used and product obtained after the experiment and (iii) Raman Spectra of the product

Figure 6.1 (i) show the X-ray diffraction of the product. It can be observed that apart from phase transformation of $\mathrm{MgH}_{2}$, a small amount of $\mathrm{MgH}_{2}$ seems to react with Si to form $\mathrm{Mg}_{2} \mathrm{Si}$. However, no distinctive peaks of $\mathrm{Mg}_{2} \mathrm{Si}$ were observed. Raman spectra of the product show the peaks characteristic for both phases. The peaks at $310 \mathrm{~cm}^{-1}, 945 \mathrm{~cm}^{-1}$ 
and $1270 \mathrm{~cm}^{-1}$ corresponds to $\alpha-\mathrm{MgH}_{2}$ [13]. The intense narrow peak at $660 \mathrm{~cm}^{-1}$ and weak peak at $313 \mathrm{~cm}^{-1}$ resembles to $\gamma-\mathrm{MgH}_{2}[12,14]$.

The next experiment was performed at a higher temperature and same pressure (4GPa). The assembly was at $900^{\circ} \mathrm{C}$ for $2 \mathrm{~h}$ and then the system was quenched instantly. At this experimental parameter, following reaction occurs:

$$
\mathrm{MgH}_{2} \rightarrow \mathrm{Mg}+\mathrm{H}_{2}
$$

Fig. 6.2 confirms the product formation. Corresponding JCPDS number of each compound is mentioned in the bracket. It can be observed that pure $\mathrm{Mg}$ was formed at this condition. The experimental findings suggest (i) the complete dissociation of $\mathrm{MgH}_{2}$ (reaction (6.2)) and (ii) less or no interaction between $\mathrm{MgH}_{2}$ and $\mathrm{Si}$ as major peaks correspond to silicon. A small amount of $\mathrm{MgO}$ was observed too. The presence of $\mathrm{MgO}$ may be because of initial impurity or exposure of the sample to air or oxygen during experiment.

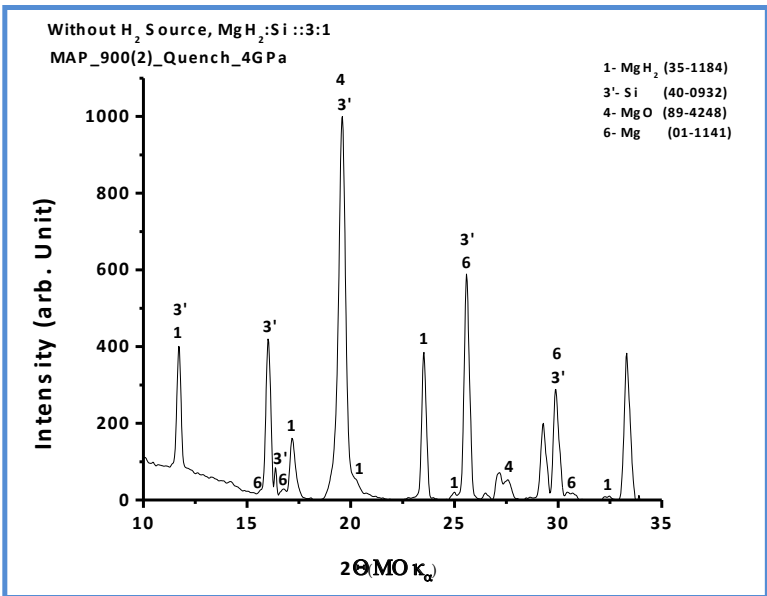

Figure 6.2 X-ray diffraction of the product after compression to $4 \mathrm{GPa}$ at $900^{\circ} \mathrm{C}$ for $2 \mathrm{~h}$ and then quenched. 
Fig. 6.3 shows the X-ray diffraction of the product obtained after ball milling of a mixture of $\mathrm{MgH}_{2}$ and $\mathrm{Si}$ under hydrogen pressure for $48 \mathrm{~h}$. The reaction suggests that the system is limited by slow kinetics and hydrogen diffusion rate as no distinct peaks were observed. At this condition, there is not any reaction occurred between $\mathrm{MgH}_{2}$ and Si.

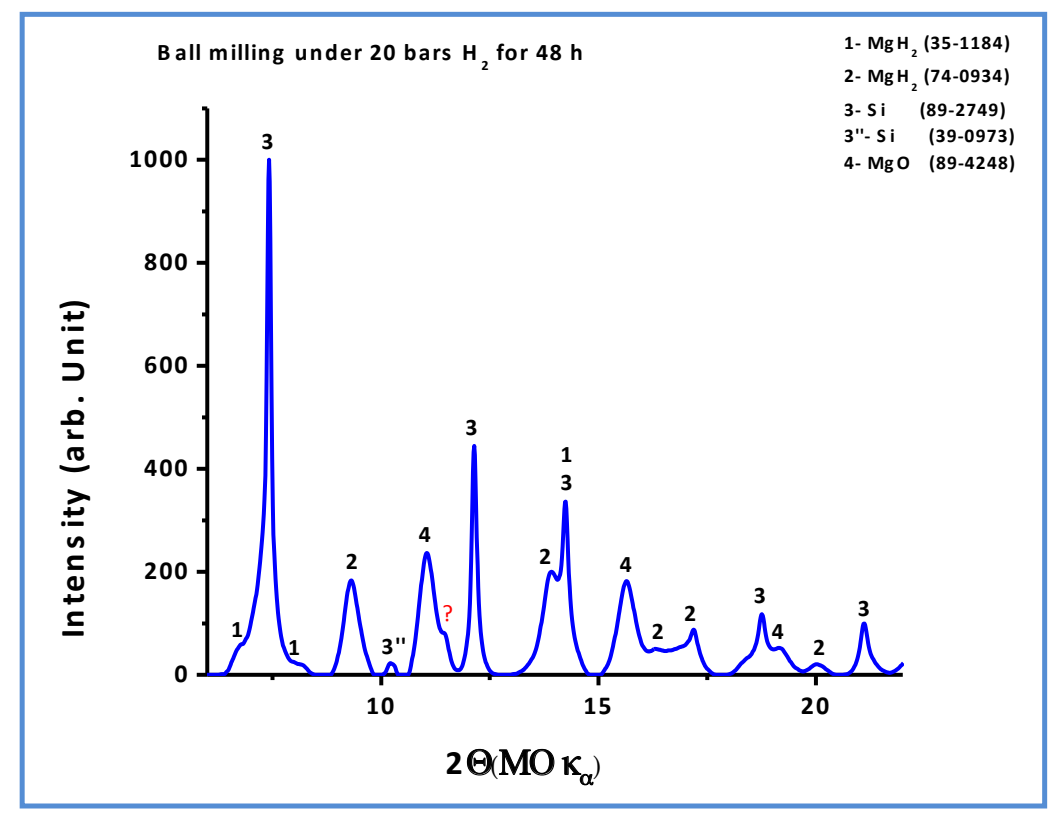

Figure 6.3 shows the X-ray diffraction of the product obtained after ball milling under $\mathrm{H}_{2}$ atmosphere.

The experiments performed here provide preliminary information and therefore it is necessary to perform extensive investigation of the system. For the future study, a lot can be suggested. However, it is certain that $\mathrm{MgH}_{2} / \mathrm{Si}$ suffers severe limitations of slow kinetics and low diffusion rate. 


\subsubsection{REFERENCES}

[1] M. Paskevicius, D.A. Sheppard, C.E. Buckley, Journal of the American Chemical Society, 2010,132, 5077-5083.

[2] J.J. Vajo, F. Mertens, C.C. Ahn, C. Robert, B. Fultz, The Journal of Physical

Chemistry B, 2004, 108, 13977

[3] T. Kelkar, S. Pal, D.G. Kanhere, Chemphyschem, 2008, 9, 928.

[4] Outukumpu, HSC Chemistry, Houston: Chemistry Software, 2006.

[5] P. Guinet, P. Perroud, J. Rebie're, Hydrogen energy system, Veziroglu- Seifritz, 1978

[6] R. Janot, F. Cuevas, M. Latroche, A. Percheron-Guegan, Intermetallics, 2006, 14, 163-169.

[7] M. Paskevicius, D.A. Sheppard, A.L. Choudhary, C.J. Webb, E. MacA. Gray, H.Y. Tian, V.K.Peterson, C.E.Buckley, International Journal of hydrogen energy, 2011, 36, 10779-10786

[8] L. George, Structural Characterization of Metal Hydrides for Energy Applications, 2010, ProQuest ETD Collection for FIU. Paper AAI3431317.

[9] J. Bystrzycki, M. Polanski, T. Plocinski, Journal of Nanoscience and Nanotechnology, 2008, 8, 1-8.

[10] M. Polanski, J. Bystrzycki, International Journal of hydrogen energy, 2009, 34, 7692-7699

[11] S.T. Kelly, S.L.V. Atta, J.J. Vajo, G.L. Olson, B.M. Clemens, Nanotechnology, 2009, 20, 204017

[12] T. Moriwaki, Y. Akahama, H. Kawamura, S. Nakano, K. Takemura, Journal of the Physical Society of Japan, 2006, 75, 074603

[13] H.G. Schimmel, M.R. Johnson, G.J. Kearley, A.J. Ramirez-Cuesta, J. Huot, F.M. Mulder, Material Science Engineering B, 2004, 108, 38-41.

[14] M.A.Kuzovnikov, V.S.Efimchenko, E.V. Filatov, A.A. Maksimov, I.I. Tartakovskii, A.J. Ramirez-Cuesta, Solid State Communications, 2013, 154, 77-80. 


\section{SUMMARY}

This dissertation presents a detailed study of various processes which could establish hydrogen as an energy carrier and also control the increasing concentration of carbon dioxide in the atmosphere due to the burning of fossil fuels. Investigations reveal substantial improvement on the mitigation of carbon dioxide during hydrogen production and carbon dioxide sorption at power and non-power sectors. Significant findings can be derived from this dissertation and are presented below. The results are sectioned in three different parts for better understanding.

\subsection{Conclusions}

(1) Clean hydrogen production methods

- Sodium hydroxide serves the dual purpose of carbon capture and hydrogen production for existing fossil-fuel based hydrogen producing methods. The inclusion of sodium hydroxide also lowers the operating temperature and thus decreases the energy penalty.

- The catalytic activity of nickel based catalysts (such as nickel, Raney nickel and alumina mixed nickel) increases with the ball milling time. However, prolonged ball milling causes the particles to coalesce and grow in size decreasing the catalytic activity. In other words, longer milling causes a decatalyzation. Moreover, globular particles have better catalytic effect than flaky disk shaped particles.

- Mechanical milling is controlled by the two processes, cold welding and fracture process. During milling, the time when fracture process 
dominates, the catalytic activity of ductile materials (such as nickel) starts decreasing. Moreover, amorphorization of the particles can also affect their catalytic effect.

- A nickel catalyzed modified steam-methane-reformation reaction takes place at much lower temperatures $\left(300-600^{\circ} \mathrm{C}\right)$ than the steam-methanereformation reaction $\left(800-1200^{\circ} \mathrm{C}\right)$. Moreover, a Raney nickel assisted modified coal-gasification reaction can lower the operating temperature from $675^{\circ} \mathrm{C}$ to $500^{\circ} \mathrm{C}$.

(2) Hydrogen Storage using multinary complex hydrides

- A 1:1:1 molar mixture of $\mathrm{LiAlH}_{4}, \mathrm{MgH}_{2}$ and $\mathrm{NaNH}_{2}$ desorbs 5.23 wt. \% of hydrogen. While, $0.5 \mathrm{~h}$ milled mixture of the ternary hydrides release 4.61 wt. \%. The hydrogen desorption kinetics improves and dehydriding temperature reduces for ball milled sample.

- The apparent activation energy for the $\mathrm{MgH}_{2}$ - related decomposition in the $\mathrm{LiAlH}_{4}-\mathrm{MgH}_{2}-\mathrm{NaNH}_{2}$ is found to be $(173.6 \pm 6) \mathrm{kJ} / \mathrm{mol}$. The activation energy for the dehydrogenation was lowered by approximately $22 \mathrm{~kJ} / \mathrm{mol}$ compared to the bulk material $\left(\mathrm{E}_{\mathrm{a}}=195.3 \pm 10 \mathrm{~kJ} / \mathrm{mol}\right)$.

- Hydrogen desorption starts at $50^{\circ} \mathrm{C}$. Intermetallic compounds such as $\mathrm{Al}_{2} \mathrm{Mg}, \mathrm{Al}_{2} \mathrm{Li}_{3}, \mathrm{Li}_{3} \mathrm{AlN}_{2}, \mathrm{AlN}$ formed at higher temperature.

- The three hydrides mutually destabilize and thus lowers the respective hydrogen desorption temperature and improves the kinetics. 
(3) Carbon dioxide capture using metal oxide

- $\mathrm{MgO}$ can be used as a potential pre-combustion carbon dioxide sorbent for a coal-fired power plant. The use of $\mathrm{MgO}$ can lead to a lesser energy penalty.

- The continuous removal of impervious layer $\left(\mathrm{MgCO}_{3}\right)$ formed around the periphery of $\mathrm{MgO}$ particles can allow higher carbon dioxide sorption. Therefore, it is recommended to use an aggregative fluidized regime for fluidized bed reactor while scaling up $\mathrm{MgO}$ - based carbonation reactor. A lower partial pressure of water vapor can form high amount of $\mathrm{MgO} .2 \mathrm{MgCO}_{3}$ that can cause a less direct conversion of $\mathrm{MgO}$ to $\mathrm{MgCO}_{3}$.

- A mixture of magnetite and iron can drastically reduce the carbon capture cost for any iron making industry. Moreover, the proposed scheme can simultaneously generate electricity. The integration can eliminate the loss of raw materials and avoid any chemical wastes for carbon capture process.

- Despite the fact that the thermodynamic favors $\mathrm{ZnO}$ as a carbon dioxide sorbent, it suffers severe limitations such as high material cost and low absorption carbon dioxide capacity.

- The carbonation and decomposition temperature are given in parenthesis for $\mathrm{MgO}\left(350^{\circ} \mathrm{C}, 550^{\circ} \mathrm{C}\right), \mathrm{ZnO}\left(75^{\circ} \mathrm{C}, 250^{\circ} \mathrm{C}\right)$ and mixture of $\mathrm{Fe}_{3} \mathrm{O}_{4} / \mathrm{Fe}$ $\left(200^{\circ} \mathrm{C}, 350^{\circ} \mathrm{C}\right)$

- Carbon dioxide uptake capacity of a metal oxide is primarily dominated by the factors such as surface area, pore volume, pore functionality and 
pore size. After carbon dioxide absorption, surface area and pore volume decreases.

(4) Destabilization of $\mathrm{MgH}_{2}$ using $\mathrm{Si}$ as an additive

- A structural phase transition of $\mathrm{MgH}_{2}(\alpha \rightarrow \gamma)$ occurs at $4 \mathrm{GPa}$ and temperature of $500^{\circ} \mathrm{C}$ (for $2 \mathrm{~h}$ ) and then lowered to $150^{\circ} \mathrm{C}$ (for $12 \mathrm{~h}$ ).

- At $4 \mathrm{GPa}$ and $900^{\circ} \mathrm{C}$ (for $2 \mathrm{~h}$ ), $\mathrm{MgH}_{2}$ decomposes to $\mathrm{Mg}$ and $\mathrm{H}_{2}$.

- Ball milling of 3:1 molar mixture of $\mathrm{MgH}_{2}$ and $\mathrm{Si}$ under $\mathrm{H}_{2}$ pressure for 48h showed no new phases.

- The interaction of $\mathrm{MgH}_{2}$ and $\mathrm{Si}$ is kinetically hindered.

\subsection{Recommendations for Future Research}

- Sodium hydroxide assisted hydrogen producing reactions need to be scaled up in the near future. Moreover, the effect for different flow rate of water vapor needs to be investigated for the modified steammethane-reformation reaction.

- It will be of a great interest to invent or modify a method in which sodium hydroxide can be produced using renewable resources such as solar, water and wind.

- Catalytic deactivation of nickel based catalysts at a higher ball milling time needs to be completely prevented. Here, dispersant (alumina) is successful in maintaining the catalytic activity but only to some extent. 
- The separation method of soda ash and sodium hydroxide that avoids energy penalty, high costs and long operation time needs to be investigated in the future.

- Rehydrogenation of the ternary hydride mixture should be tested.

- Moreover, catalysts can be explored to further improve the (de)hydrogenation of the ternary mixture.

- Metal oxide based carbon dioxide capture methods need to be performed for a larger volume of gas. The actual flue gas composition should be taken while scaling up the reaction.

- The reactions should be repeated for a large number of cycles, and also the change in surface properties of sorbents should be investigated after each cycle.

- It is recommended to develop an efficient heat recovery system for exothermic carbonation reaction.

- The interaction of $\mathrm{MgH}_{2}$ and $\mathrm{Si}$ should be investigated in the presence of hydrogen source (such as $\mathrm{NaBH}_{4}+\mathrm{Ca}(\mathrm{OH})_{2}$ ) at different set of temperature and pressure conditions.

- The reaction between $\mathrm{MgH}_{2}$ and $\mathrm{Si}$ particles in the nanometer range could also be worth to examine. 
VITA

\section{SUSHANT KUMAR}

\section{EDUCATION}

- Aug. 2009- Dec. 2013

Doctor of Philosophy (Ph.D.) in Materials Engineering, Department of Mechanical and Materials Engineering, Florida International University, Miami, GPA 3.63/4.0

- Aug. 2005-May 2009

Bachelor in Chemical Technology, Institute of Chemical Technology (erstwhile UDCT), Mumbai, India (First class)

\section{PATENT}

- $\quad$ Sushant Kumar, Vadym Drozd, Andriy Durygin and Surendra K. Saxena, Method and System for Sequestering Carbon Dioxide and Producing Hydrogen Gas, U.S. Provisional Patent Application No. 61/733,297.

\section{PUBLICATIONS}

- Surendra Saxena, Sushant Kumar and Vadym Drozd, "A Modified steammethane-reformation reaction for hydrogen production", Int $\mathrm{J}$ of Hydrogen energy, 36(2011) 4366-4369.

- $\quad$ Sushant Kumar, Surendra K. Saxena and Vadym Drozd, "A modified method for production of hydrogen from methane”, Int. J. Energy Res. 36(2012) 1133-1138.

- Sushant Kumar, Vadym Drozd and Surendra K. Saxena, "A catalytic study of the modified coal gasification process to produce clean hydrogen gas", CheM, 1(2012), 20-26.

- Sushant Kumar, Vadym Drozd and Surendra K. Saxena, "Catalytic studies of sodium hydroxide and carbon monoxide reaction", Catalysts, 2(2012), 532-543.

- Sushant Kumar, Surendra K. Saxena, Vadym Drozd and Andriy Durygin "An experimental investigation of mesoporous $\mathrm{MgO}$ as a potential pre-combustion $\mathrm{CO}_{2}$ sorbent", Under Review

- Sushant Kumar "The effect of elevated pressure, temperature and particles morphology on the carbon dioxide capture using zinc oxide", Under Review.

- Sushant Kumar, Vadym Drozd, Andriy Durygin and Surendra K. Saxena, "Mitigating $\mathrm{CO}_{2}$ emissions in the Iron Industry using mixture of magnetite and iron", Under Review.

- High pressure and temperature study on $\mathrm{MgH}_{2}$-Si system using Multi-anvil press technique, Under Preparation 
- Study of hydrogen absorption/desorption: kinetics and reversibility of multinary complex hydride system, Under Preparation

\section{BOOK CHAPTER}

- Sushant Kumar, Suredra K. Saxena, Role of sodium hydroxide for hydrogen gas production and storage, In "Materials and processes for energy: communicating current research and technological developments" Ed. A. Mendez-Vilas, Formatex Research Center (Badajoz, Spain), ISBN: 9788493984373, Page no. 452-463.

\section{CONFERENCE PAPER}

- Sushant Kumar, Integration of $\mathrm{MgO}$ Carbonation Process to Capture $\mathrm{CO}_{2}$ from a Coal-Fired Power Plant, in Materials Challenges in Alternative and Renewable Energy II: Ceramic Transactions (eds G. Wicks, J. Simon, R. Zidan, R. Brigmon, G. Fischman, S. Arepalli, A. Norris and M. McCluer), John Wiley \& Sons, Inc., Hoboken, NJ, USA, 2012. 